\author{
UNIVERSIDADE DE SÃO PAULO \\ ESCOLA DE ENGENHARIA DE SÃO CARLOS \\ DEPARTAMENTO DE ENGENHARIA DE ESTRUTURAS
}

\title{
EDIFÍCIOS COM LAJES MACIÇAS E PAREDES PORTANTES PRÉ-MOLDADAS DE CONCRETO LEVE COM PÉROLAS DE EPS
}

DIEGO DE VASCONCELOS GONÇALVES FERREIRA

(VERSÃO CORRIGIDA)

A original encontra-se disponível na Escola de Engenharia de São Carlos

São Carlos

2013 

DIEGO DE VASCONCELOS GONÇALVES FERREIRA

\section{EDIFÍCIOS COM LAJES MACIÇAS E PAREDES PORTANTES PRÉ-MOLDADAS DE CONCRETO LEVE COM PÉROLAS DE EPS}

Dissertação apresentada à Escola de Engenharia de São Carlos da Universidade de São Paulo para obtenção do título de Mestre em Engenharia Civil.

Área de concentração: Engenharia de Estruturas

Orientador: Prof. Dr. Libânio Miranda Pinheiro 
AUTORIZO A REPRODUÇÃO TOTAL OU PARCIAL DESTE TRABALHO, POR QUALQUER MEIO CONVENCIONAL OU ELETRÔNICO, PARA FINS DE ESTUDO E PESQUISA, DESDE QUE CITADA A FONTE.

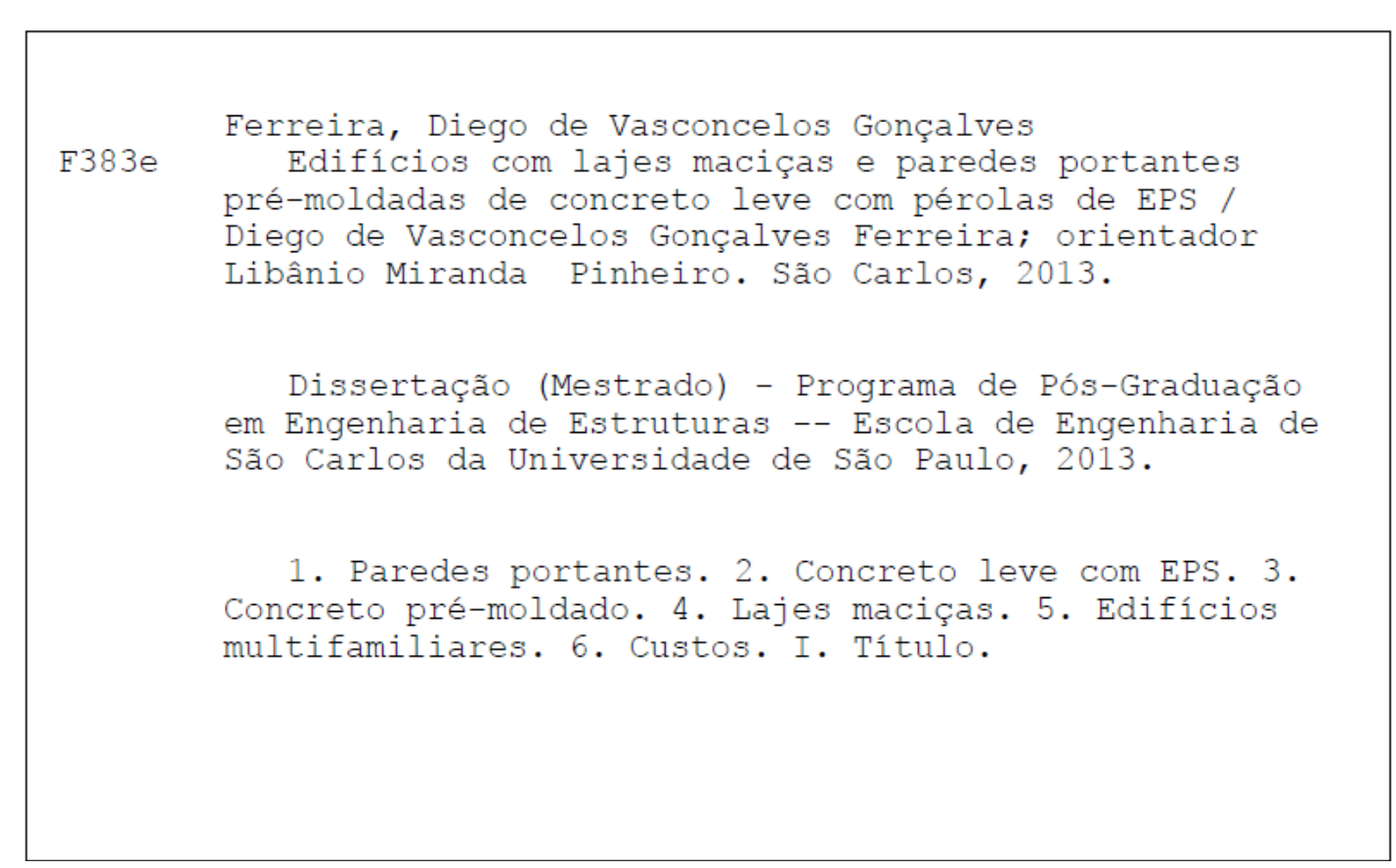




\section{FOLHA DE JULGAMENTO}

Candidato: Engenheiro DIEGO DE VASCONCELOS GONÇALVES FERREIRA.

Título da dissertação: "Edifícios com lajes maciças e paredes portantes prémoldadas de concreto leve com pérolas de EPS".

Data da defesa: $28 / 05 / 2013$

Comissão Julgadora:

Resultado:

Prof. Dr. Libânio Miranda Pinheiro (Orientador)

APROVADO

(Escola de Engenharia de São Carlos/EESC)

Prof. Associado Marcio Roberto Silva Corrêa

APROYADO

(Escola de Engenharia de São Carlos/EESC)

Prof. Dr. Marcelo de Araújo Ferreira

(Universidade Federal de São Carlos/UFSCar)

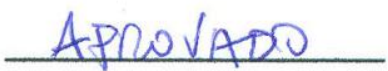

Coordenador do Programa de Pós-Graduação em Engenharia Civil (Engenharia de Estruturas):

Profa. Associada Ana Lucia Homce de Cresce El Debs

Presidente da Comissão de Pós-Graduação:

Prof. Titular Denis Vinicius Coury 



\section{AGRADECIMENTOS}

Primeiramente a Deus por ter me dado forças para conseguir alcançar meus objetivos.

Aos meus pais José Francisco e Wildes por tudo que fizeram por mim, que sempre me proporcionaram um bom estudo e deram conselhos importantes nas horas em que mais precisei. Aos meus irmãos Tiago e Iara por sempre estarem ao meu lado, nos momentos difíceis da minha vida.

À minha namorada Rafaela Faciola pela ajuda, carinho e companheirismo, durante o trabalho. Ao meu amigo Libânio, orientador deste trabalho, pela dedicação, incentivo, paciência, conselhos e ajuda para realização.

Ao meu amigo Fabrício Tomo pela ajuda para realização do trabalho e conselhos importantes para os problemas que surgiram.

Ao Prof. Márcio Corrêa pela ajuda nas etapas de consolidação do tema do trabalho.

Ao Augusto Pedreira de Freitas por fornecer as plantas arquitetônicas para elaboração da dissertação e por permitir o uso do software comercial SAP2000, nas dependências de sua empresa.

Ao Eng ${ }^{\circ}$. Milton Kerbauy pelas informações relativas aos custos dos concretos e outras ao longo do trabalho.

Aos meus colegas de trabalho e de curso pelo aprendizado adquirido ao longo dessa jornada.

A todos os familiares mais próximos por terem me apoiado nos momentos em que mais precisei.

Ao CNPQ e à CAPES por financiarem o desenvolvimento desta pesquisa. 



\section{RESUMO}

FERREIRA, D. V. G. Edifícios com lajes maciças e paredes portantes pré-moldadas de concreto leve com pérolas de EPS. Dissertação (Mestrado em Engenharia de Estruturas). Escola de Engenharia de São Carlos, Universidade de São Paulo, São Carlos.

Atualmente, muitas empresas de construção civil não acompanham o avanço tecnológico, preferindo utilizar sistemas convencionais em vez de investir em novas soluções. Além disso, há sérios problemas com mão de obra, que estão cada vez mais presentes na sociedade. Este trabalho apresenta o projeto de um edifício com elementos pré-moldados de Concreto Leve com pérolas de EPS, considerando lajes prontas maciças e paredes portantes, executadas com esse tipo de material. A princípio, foram considerados os estados limites últimos e de serviço para os elementos da estrutura, utilizando os modelos clássicos de análise estrutural. Para modelagem do edifício, foi utilizado o programa comercial SAP2000. Quanto aos procedimentos para dimensionamento das peças, foram preparadas planilhas do Excel, enquanto o detalhamento foi realizado por meio do AutoCAD. Definido o projeto estrutural, foram considerados aspectos construtivos na fábrica e na obra, levando em conta os custos de produção e de transporte, além de apresentar as vantagens que esse sistema construtivo pode proporcionar. Esses custos foram considerados para as lajes prontas maciças e para as paredes pré-moldadas. Mesmo levando em conta apenas os custos de produção e de transporte, o Concreto Leve com EPS foi comparado com o Concreto Autoadensável, o que permitiu visualizar as vantagens do primeiro, quando for considerado o custo global do empreendimento.

Palavras-chave: paredes portantes; concreto leve, concreto com EPS; concreto pré-moldado; edifícios; custos. 



\begin{abstract}
FERREIRA, D. V. G. Buildings with solid slabs and load bearing precast walls of lightweight concrete with EPS beads. Dissertation (Master's degree in Structural Engineering). Escola de Engenharia de São Carlos, Universidade de São Paulo, São Carlos, 2013.

Currently, many construction companies do not follow the technological advances, preferring to use conventional systems rather than investing in new solutions. Moreover, there are serious problems with manpower, which are increasingly present in society. This work presents the design of a building with precast elements of lightweight concrete with EPS beads, considering solid slabs ready to use and load bearing walls, made with this type of material. As a rule, the ultimate limit states and serviceability were considered for the elements of the structure, using classical models of structural analysis. For modelling the building, the commercial software SAP2000 was used. Regarding the procedures for dimensioning of the pieces, Excel spreadsheets were prepared, while the detailing was carried out by means of the AutoCAD. Defined structural design, construction aspects were considered in the factory and in the work, taking into account costs of production and transportation, besides presenting the advantages that this constructive system can provide. These costs were considered for the solid slabs ready to use and for the precast walls. Even taking into account only the cost of production and transportation, the Lightweight Concrete with EPS was compared with Self-compacting Concrete, allowing visualize the advantages of the former when considering the overall cost of the project.
\end{abstract}

Keywords: load bearing walls; lightweight concrete; EPS concrete, precast concrete; buildings; costs. 



\section{LISTA DE FIGURAS}

Figura 1.1: Edifícios do Programa de Aceleração do crescimento...........................................24

Figura 2.1: Dispositivos internos com laços ou com chapa chumbada .................................... 31

Figura 2.2: Dispositivos internos com furo e cabo de aço ou com furo e tarugo de aço........... 31

Figura 2.3: Dispositivos internos com alças fixadas posteriormente ..................................... 32

Figura 2.4: Dispositivos com laço interno ou com dispositivo para levantamento lateral....... 32

Figura 2.5: Balancins para manuseio de painéis.................................................................... 33

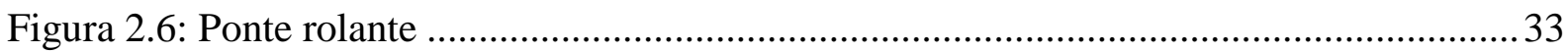

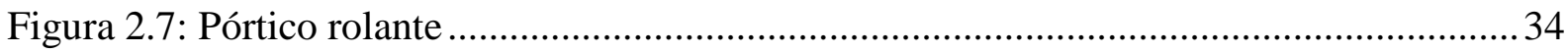

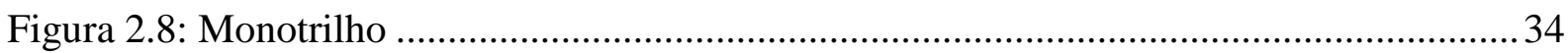

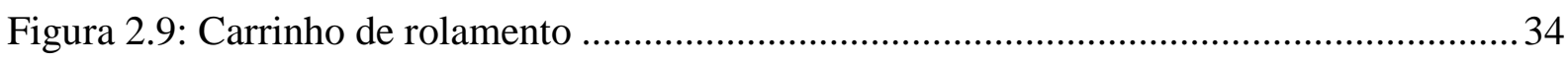

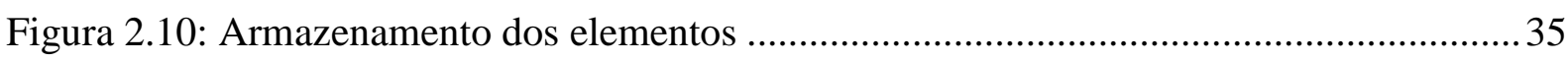

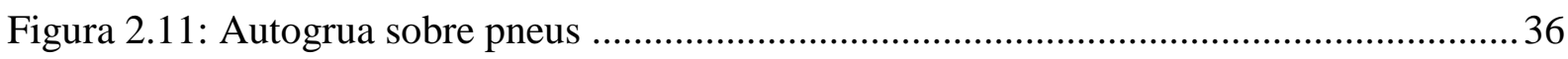

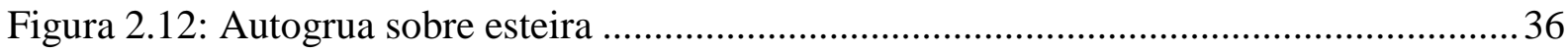

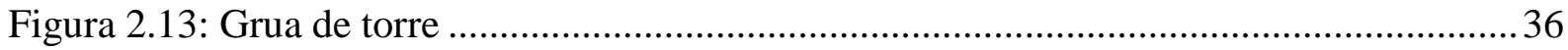

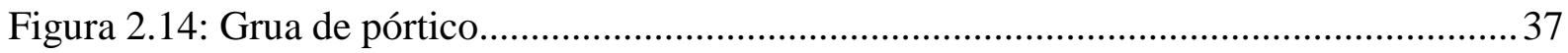

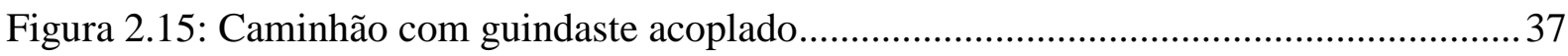

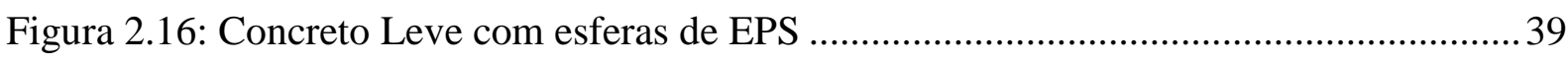

Figura 2.17: Agregados que podem ser utilizado no CLE ................................................ 40

Figura 3.1: Processo de fabricação da laje pronta maciça ....................................................... 43

Figura 3.2: Detalhes para alças de içamento ......................................................................... 44

Figura 3.3: Detalhe de ligação por costura entre lajes.......................................................... 45

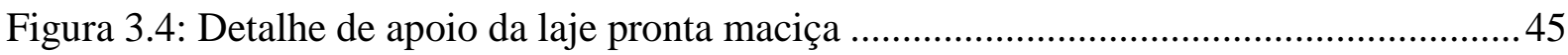

Figura 3.5: Detalhes dos materiais elétricos na laje ............................................................ 46

Figura 3.6: Desenho geral das lajes prontas maciças ............................................................. 47

Figura 3.7: Juntas em estruturas de painéis portantes ........................................................ 48

Figura 3.8: Ligação parede-laje-parede ............................................................................ 51

Figura 3.9: Espraiamento das tensões de compressão .........................................................52

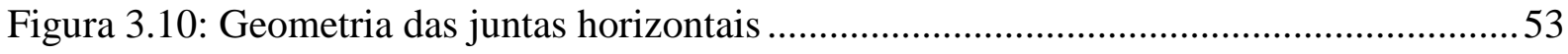

Figura 3.11: Diagrama da geometria e resistência da junta.....................................................53

Figura 3.12: Reforço no painel sobre duas lajes de piso ...................................................54 
Figura 3.13: Desmoldagem de painéis através de dois pontos na borda superior 57

Figura 3.14: Desmoldagem de painéis através de quatro pontos na borda superior 57

Figura 3.15: Desmoldagem de painéis através de quatro pontos na superfície 58

Figura 3.16: Desmoldagem de painéis através de oito pontos na superfície 59

Figura 3.17: Transporte de painel pré-moldado..... 61

Figura 3.18: Içamento através de dois pontos de rotação 62

Figura 3.19: Içamento através de três pontos de rotação 62

Figura 4.1: Deslocamento do topo de uma barra isolada..... 64

Figura 4.2: Modelo de pórtico bidimensional. 64

Figura 4.3: Representação do painel com abertura 65

Figura 4.4: Trecho rígido 66

Figura 4.5: Representação do painel isolado 67

Figura 4.6: Empenamento térmico no painel 69

Figura 4.7: Painel sem restrição lateral ao longo do comprimento 71

Figura 4.8: Painel com apenas uma restrição lateral ao longo do comprimento 71

Figura 4.9: Painel com duas restrições laterais ao longo do comprimento. 72

Figura 4.10: Edifício em Ronan Point, Londres 74

Figura 4.11: Mecanismos de colapso progressivo ............................................................ 75

Figura 4.12: Condição de equilíbrio da barra de ancoragem no regime plástico...................... 77

Figura 4.13: Modelo idealizado entre os esforços de tração e final do deslizamento............... 78

Figura 4.14: Mecanismo de rotação para os painéis em balanço devido a um dano local ...... 79

Figura 4.15: Ação de balanço em lajes pré-moldadas ............................................................ 81

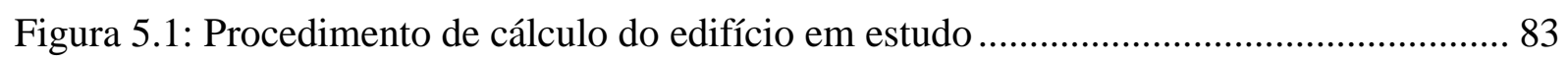

Figura 5.2: Planta baixa do pavimento térreo do edifício, unidades em centímetros ............... 85

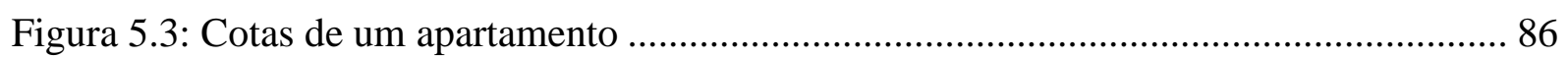

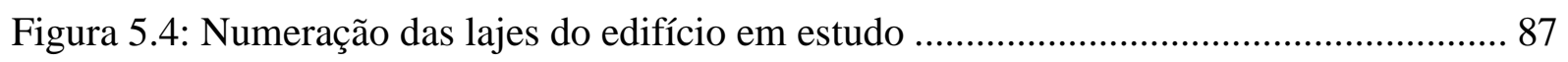

Figura 5.5: Nomenclatura adotada para os painéis pré-moldados ........................................... 88

Figura 5.6: Lajes do edifício com suas respectivas dimensões e áreas de e dimensões .......... 90

Figura 5.7: Representação das reações de apoio das lajes nos respectivos painéis ................. 93

Figura 5.8: Área de influência para determinação das forças do vento .................................. 95

Figura 5.9: Exemplo das partes sólidas e abertas no painel ................................................... 97

Figura 5.10: Modelo de pórtico plano na direção x .............................................................. 100 
Figura 5.11: Modelo de pórtico plano na direção y............................................................... 101

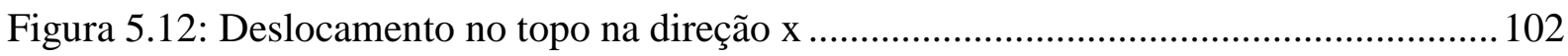

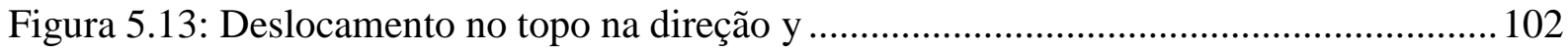

Figura 5.14: Esforços normais nos painéis, provocados pelo vento da direção x ...................103

Figura 5.15: Esforços normais nos painéis, provocados pelo vento da direção y ................... 103

Figura 5.16: Momentos fletores nos painéis, provocados pelo vento na direção x ................. 104

Figura 5.17: Momentos fletores nos painéis, provocados pelo vento na direção y ................. 104

Figura 5.18: Análise da alternativa de suporte de carga nos painéis pré-moldados ................ 108

Figura 5.19: Força resultante Q e sua localização em painel isolado..................................... 109

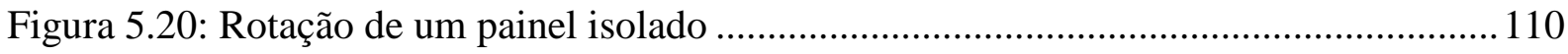

Figura 5.21: Situação de laje em balanço, com a retirada do painel de apoio........................ 111

Figura 6.1: Dimensões do painel PF11D em centímetros ...................................................113

Figura 6.2: Diagrama de esforços de compressão ...........................................................116

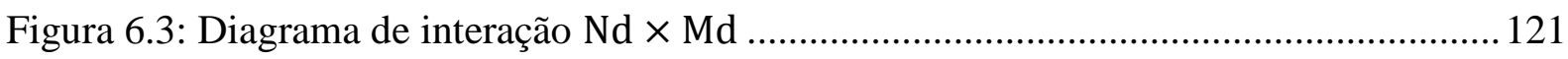

Figura 6.4: Detalhe da ligação da junta vertical com silicone............................................... 122

Figura 6.5: Detalhe da ligação horizontal por compressão ..................................................124

Figura 6.6: Posições dos dispositivos auxiliares para fase transitória.................................. 125

Figura 6.7: Espraiamento das forças à $45^{\circ}$, na fase transitória do painel ............................. 125

Figura 6.8: Momentos fletores M11 na desmoldagem, em kN.m/m................................. 127

Figura 6.9: Momentos fletores M22 na desmoldagem, em kN.m/m................................ 127

Figura 6.10: Diagrama de momento fletor do transporte do painel, em kN. cm ...................128

Figura 6.11: Momentos fletores M11 na montagem, com inclinação de 30 ${ }^{\circ}$, em kN.m/m.... 130

Figura 6.12: Momentos fletores M11 na montagem, com inclinação de $60^{\circ}$, em kN.m/m... 130

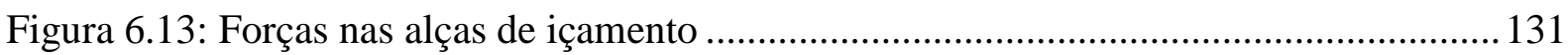

Figura 6.14: Força nas pernas da alça de içamento ............................................................ 132

Figura 6.15: Detalhamento do painel - Elevação e planta .................................................. 134

Figura 6.16: Detalhamento do painel - Armação ............................................................... 135 



\section{LISTA DE TABELAS}

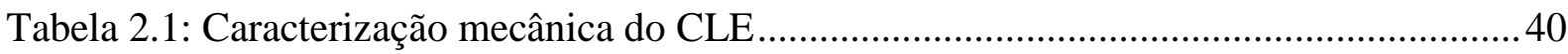

Tabela 2.2: Valores correspondentes de resistência à compressão e massa específica .............41

Tabela 3.1: Coeficientes de multiplicação para desmoldagem e ações dinâmicas...................55

Tabela 3.2: Valores das máximas cargas por eixo permitidas nas rodovias nacionais .............60

Tabela 5.1: Dimensões e quantidades de ambientes por pavimento do edifício ....................... 84

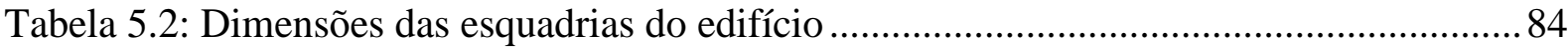

Tabela 5.3: Resumo das áreas de influência das lajes do edifício .......................................... 90

Tabela 5.4: Carregamentos das lajes do pavimento tipo ....................................................... 90

Tabela 5.5: Reações de apoio das lajes do pavimento tipo .....................................................91

Tabela 5.6: Momentos de cálculo para as lajes do pavimento tipo ........................................91

Tabela 5.7: Área de aço para as lajes do pavimento tipo ....................................................91

Tabela 5.8: Telas soldadas utilizadas nas lajes do pavimento tipo........................................92

Tabela 5.9: Verificações das lajes do pavimento tipo ........................................................... 92

Tabela 5.10: Carregamentos verticais nos painéis ................................................................. 93

Tabela 5.11: Carregamentos verticais até a fundação ............................................................. 94

Tabela 5.12: Valores utilizados para obtenção da força de arrasto .........................................96

Tabela 5.13: Forças de arrasto para direção X e Y ....................................................................96

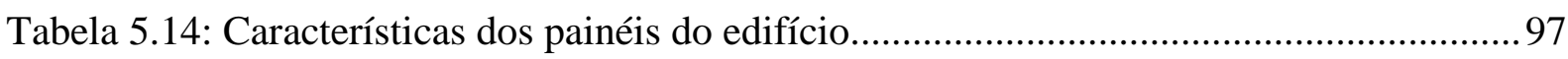

Tabela 5.15: Características geométricas dos painéis ............................................................98

Tabela 5.16: Área e Momento de inércia total das seções sólidas ...........................................98

Tabela 5.17: Características geométricas dos lintéis ..............................................................99

Tabela 5.18: Área e momento de inércia total dos lintéis ....................................................99

Tabela 5.19: Esforços normais e momentos fletores, provocados pela ação do vento........... 105

Tabela 5.20: Resumo dos dados para as respectivas bitolas ............................................... 107

Tabela 6.1: Esforços solicitantes no painel PF11D ao longo do edifício .............................. 115

Tabela 6.2: Cálculo dos esforços normais para as combinações 1 e 2 .................................116

Tabela 6.3: Resumo dos momentos fletores M11 e M22 nos dispositivos auxiliares............126

Tabela 6.4: Resumo da quantidade de aço no painel.......................................................... 136

Tabela 7.1: Tensões nas bases dos painéis pré-moldados para o CLE ( $\mathrm{v}=40 \mathrm{~m} / \mathrm{s}) \ldots \ldots \ldots \ldots . . . .138$

Tabela 7.2: Tensões nas bases dos painéis pré-moldados para o CAA $(\mathrm{v}=45 \mathrm{~m} / \mathrm{s}) \ldots \ldots \ldots \ldots 139$ 
Tabela 7.3: Tensões nas bases dos painéis pré-moldados para o CLE ( $\mathrm{v}=45 \mathrm{~m} / \mathrm{s})$ .140

Tabela AP.1: Volume de concreto dos painéis pré-moldados . .153

Tabela AP.2: Volume de concreto das lajes prontas maciças 154

Tabela AP.3: Custo de produção dos elementos para CLE e CAA. 154

Tabela AP.4: Peso dos painéis pré-moldados...... 155

Tabela AP.5: Peso das lajes prontas 155

Tabela AP.6: Custo de transporte para CLE e CAA... 155

Tabela AP.7: Relação dos custos de produção e transporte com o custo global......... 156 


\section{Sumário}

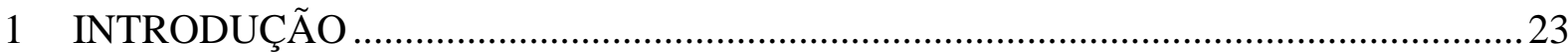

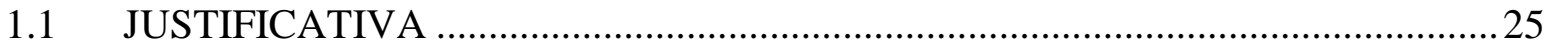

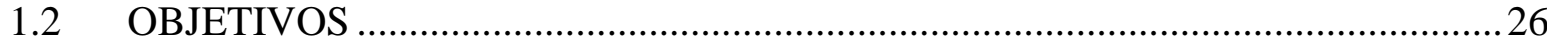

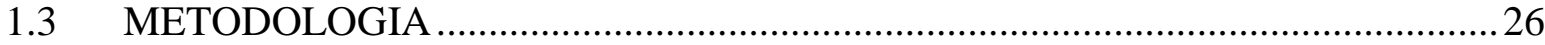

1.4 ESTRUTURA DA DISSERTAÇÃO................................................................... 27

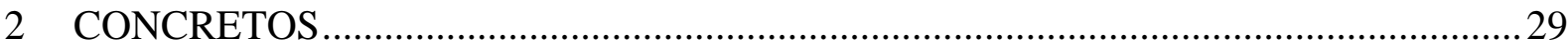

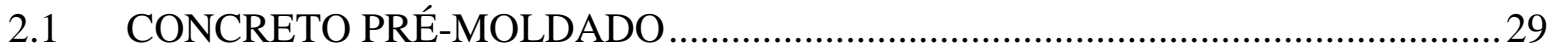

2.1.1 Processo de fabricação dos elementos pré-moldados ........................................ 30

2.1.2 Dispositivos auxiliares para manuseio ........................................................... 31

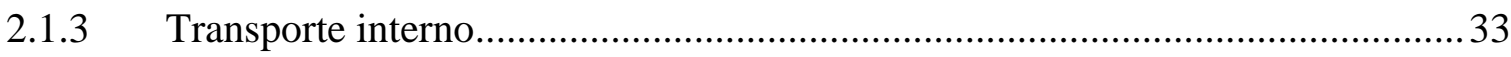

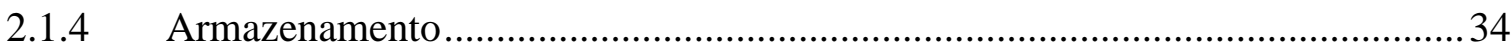

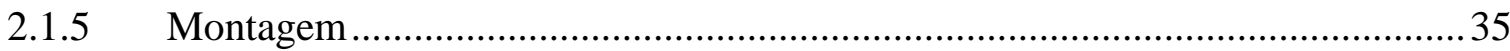

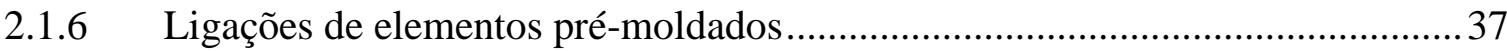

2.2 CONCRETO LEVE ESTRUTURAL COM ESFERAS DE EPS ............................38

3 SISTEMAS CONSTRUTIVOS DE PAINÉIS PRÉ-MOLDADOS ..................................43

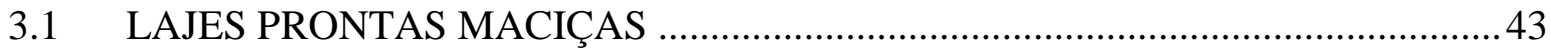

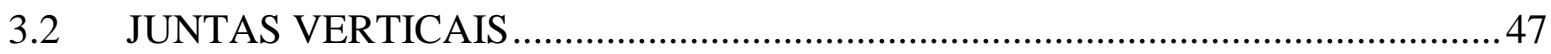

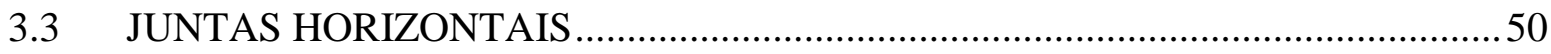

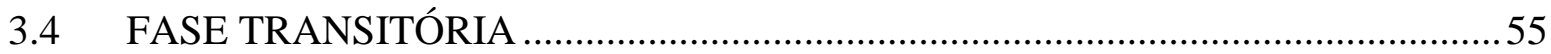

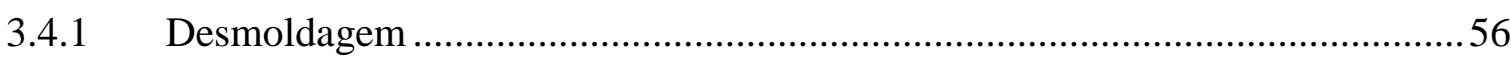

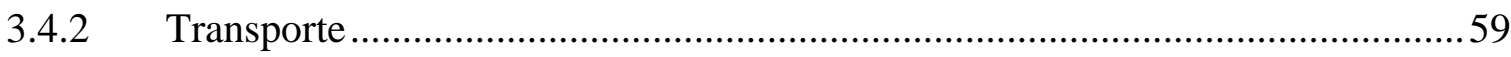

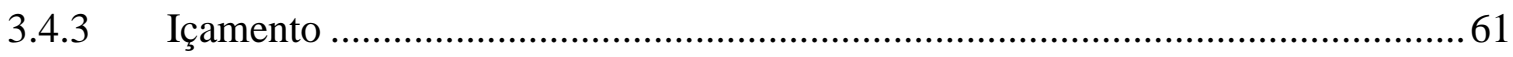

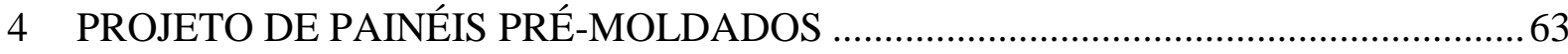

4.1 MODELO DE ASSOCIAÇÃO DE PÓRTICOS PLANOS …...................................63 


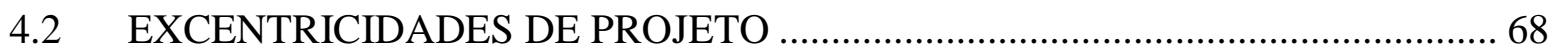

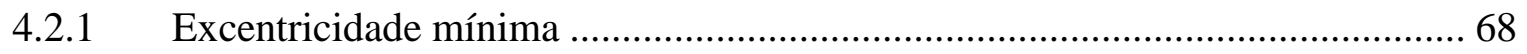

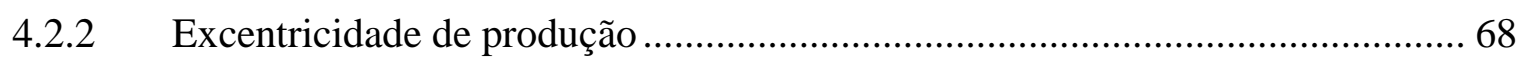

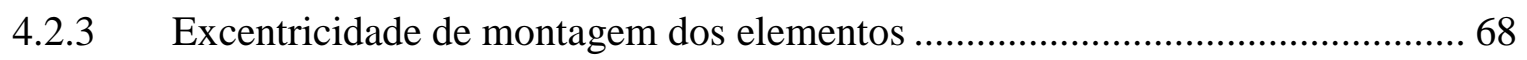

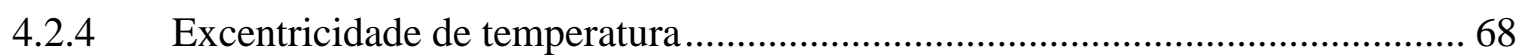

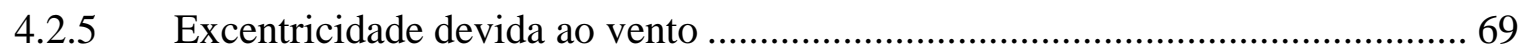

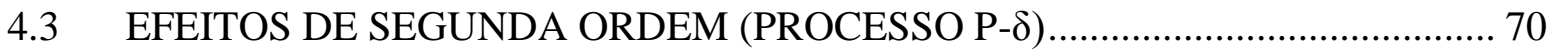

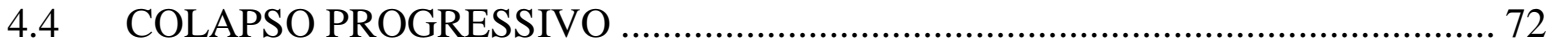

4.4.1 Determinação da energia de deformação das barras de ligação......................... 75

4.4.2 Mecanismos de rotação - Ação de balanço para painéis .................................... 78

4.4.3 Mecanismos de rotação - Ação de balanço para lajes ........................................ 80

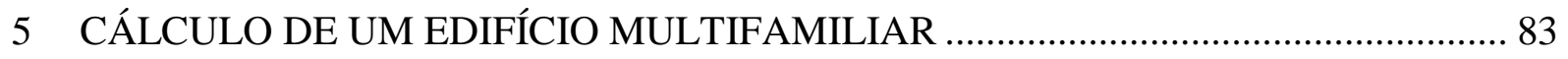

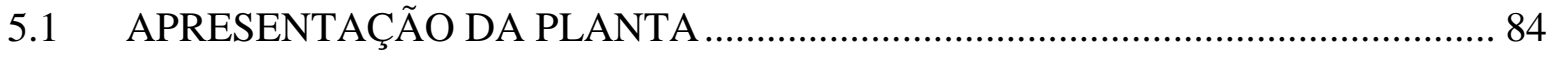

5.2 CONSIDERAÇÕES DE PROJETO .............................................................. 88

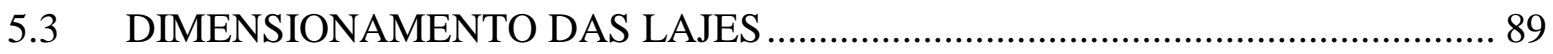

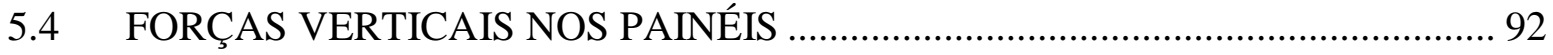

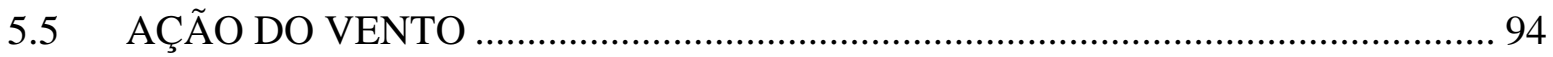

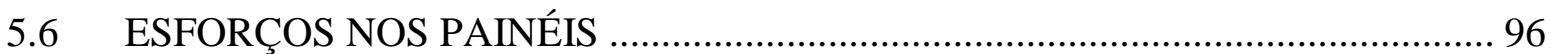

5.7 PREVENÇÃO AO COLAPSO PROGRESSIVO............................................... 105

5.7.1 Determinação da energia de deformação da barra de ligação........................... 106

5.7.2 Exemplo de um painel isolado amarrado por um ponto ................................ 107

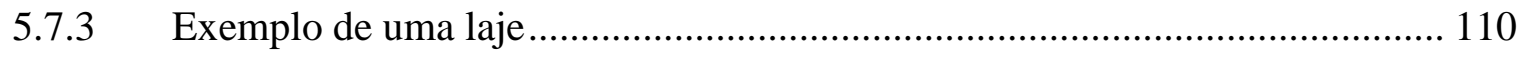

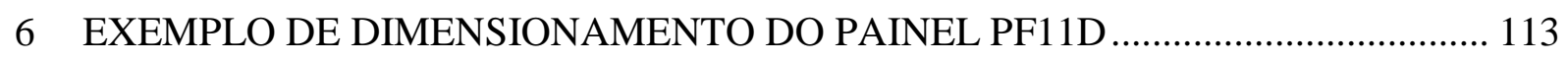

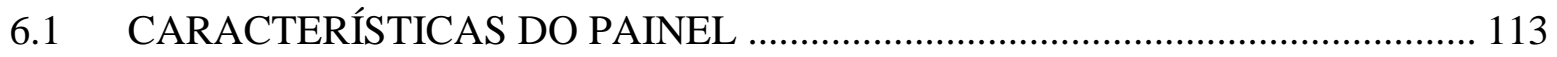

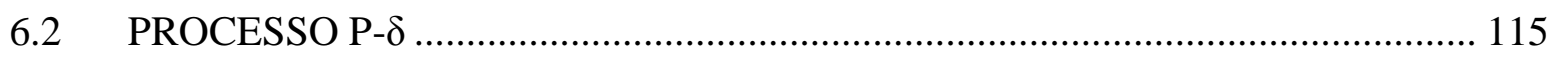

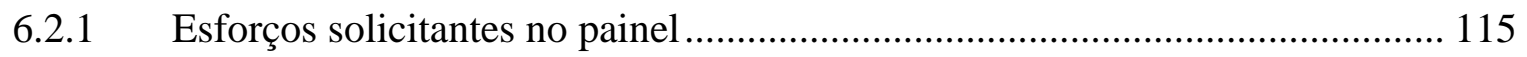




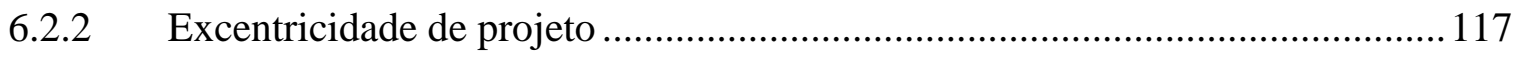

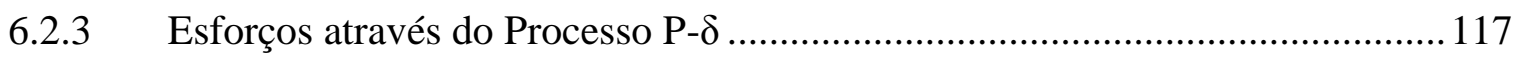

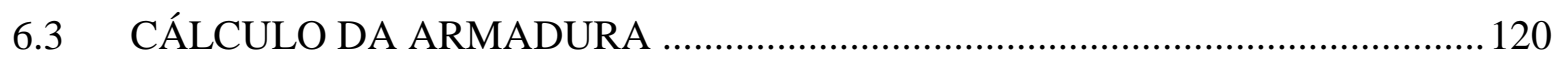

6.4 DIMENSIONAMENTO DAS JUNTAS .......................................................... 121

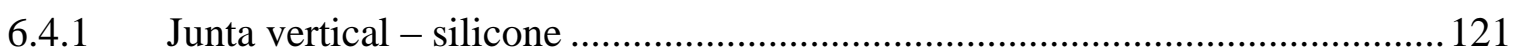

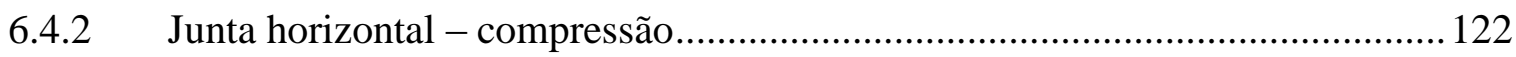

6.5 VERIFICAÇÃO DO PAINEL NA FASE TRANSITÓRIA ................................. 124

6.5.1 Fase transitória - Desmoldagem do painel................................................... 126

6.5.2 Fase transitória - Transporte do painel.......................................................... 128

6.5.3 Fase transitória - Montagem do painel ........................................................ 129

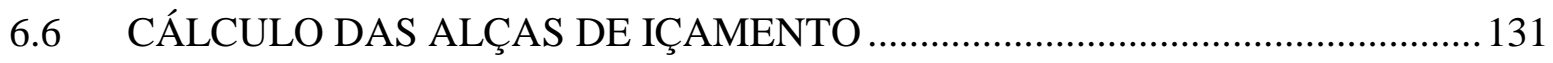

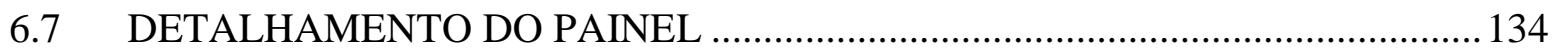

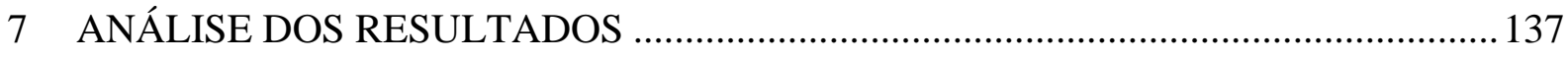

7.1 VERIFICAÇÕES PARA A AÇÃO DO VENTO .............................................. 137

7.2 DESLOCAMENTO NO TOPO DO EDIFÍCIO ................................................. 141

7.3 COLAPSO PROGRESSIVO .......................................................................... 141

7.4 VERIFICAÇÃO NA FASE TRANSITÓRIA ...................................................... 142

7.5 CUSTOS ENVOLVIDOS NA EDIFICAÇÃO …............................................. 142

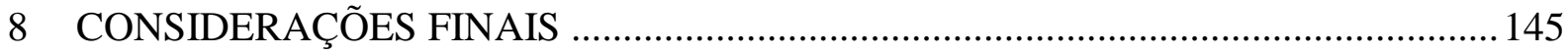

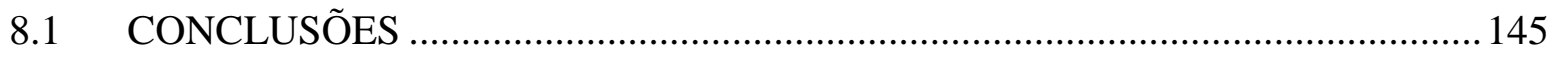

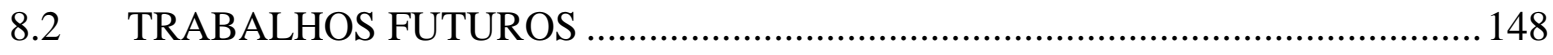

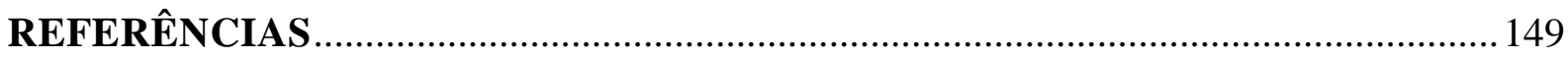

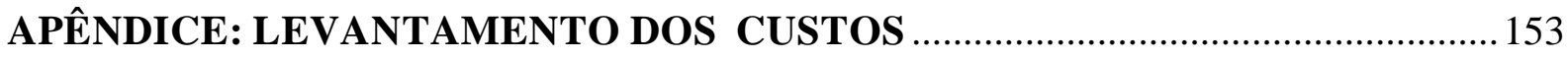





\section{INTRODUÇÃO}

Embora haja avanços recentes, a indústria da construção civil ainda está atrasada em relação aos demais ramos industriais. Os principais motivos que levam a esse atraso dizem respeito a: baixa produtividade, elevado desperdício de materiais, falta de profissionais qualificados, morosidade e baixo controle de qualidade.

Os elementos pré-moldados têm sido utilizados no segmento da construção civil a fim de melhorar o rendimento e a trabalhabilidade, tornando o canteiro de obra mais produtivo e mais limpo, evitando, assim, o desperdício de materiais.

A competitividade entre as empresas desse ramo resulta em uma busca constante por aumento da produção, com rapidez de execução e redução nos custos, almejando maior lucro. Para tal fim, justifica-se a utilização do sistema pré-moldado, visto que essa tecnologia apresenta soluções que atendem as exigências requeridas pelas empresas.

No Brasil, a Engenharia Civil encontra-se em fase de implantação do Programa de Aceleração do Crescimento (PAC) proposto pelo Governo Federal desde meados de 2007. As obras do PAC têm sido projetadas com sistemas pré-moldados, utilizando, em sua grande maioria, estruturas com lajes maciças moldadas in loco, lajes prontas maciças e pré-lajes, em edifícios como os indicados na Figura 1.1.

A vantagem principal de utilizar a pré-laje é a redução do peso da peça de concreto, que influencia diretamente na diminuição de gastos com transporte e com maquinário para içamento das peças. As lajes prontas maciças se destacam pela ausência da concretagem da capa de concreto na obra, reduzindo de forma significativa o tempo de execução. Portanto, essas variáveis, como o peso da peça e o tempo de execução, estão relacionadas diretamente aos custos envolvidos na construção.

Essas peças de concreto podem ser confeccionadas de concreto convencional ou de concreto leve, dependendo da finalidade da obra. Quando ocorre a necessidade de uma estrutura mais leve, por exemplo, nos casos de solos com baixa capacidade portante, é interessante a escolha de um concreto leve, que reduz de forma significativa a massa específica. 


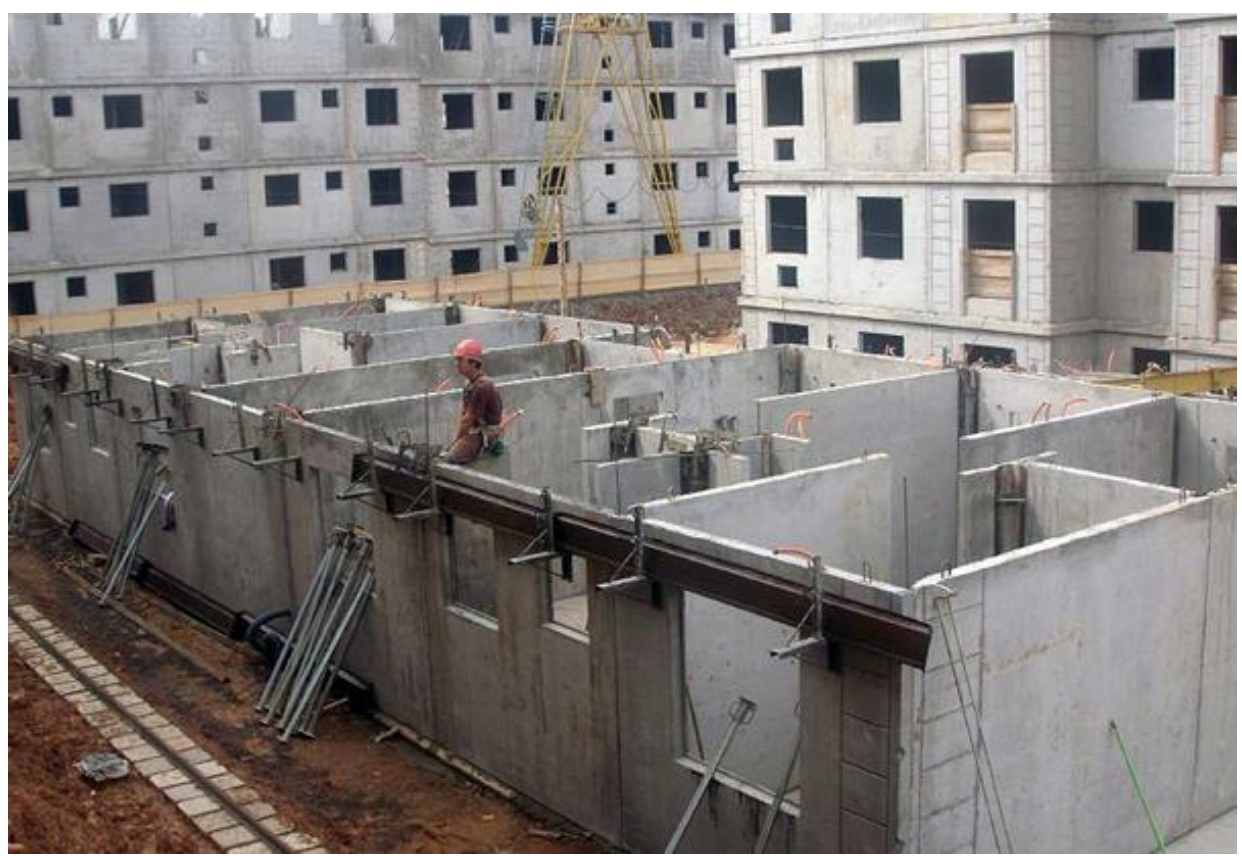

Figura 1.1: Edifícios do Programa de Aceleração do crescimento (Fonte: http://usimak.blogspot.com.br/2012_06_08_archive.html, acesso em: 07/08/2012)

Recentemente, os avanços na Engenharia Civil mostraram a inovação do Concreto Leve para o Concreto Leve com EPS (CLE), ou Concreto Ultraleve ${ }^{\circledR}$ Estrutural, que teve seu pedido de patente aprovado pelo Instituto Nacional de Propriedade Industrial (INPI), por solicitação de seu inventor, Engenheiro Civil Milton José Kerbauy. Nesse pedido de patente, considera-se Concreto Ultraleve ${ }^{\circledR}$, ou Concreflex ${ }^{\circledR}$, aquele com massa específica inferior a $1300 \mathrm{~kg} / \mathrm{m}^{3}$, sendo esta menor que as admitidas para Concreto Leve, de acordo com normas internacionais.

Os estudos realizados no Departamento de Engenharia de Estruturas da Escola de Engenharia de São Carlos da Universidade de São Paulo (EESC-USP), nesta linha de pesquisa, começaram em 2011 com um projeto de doutorado envolvendo a utilização de esferas de EPS em Concreto Ultraleve ${ }^{\circledR}$ (CATOIA, 2012). Esse trabalho teve como objetivo principal caracterizar o material e estudar sua aplicação em lajes.

Para a realização dos ensaios de caracterização do material e das lajes, o Engenheiro Kerbauy cedeu corpos de prova, bem como os modelos. Os ensaios preliminares demonstraram que é possível obter uma resistência à compressão superior a $17 \mathrm{MPa}$ e massa específica inferior a $1680 \mathrm{~kg} / \mathrm{m}^{3}$. Pode-se inferir que esses valores corroboram com as especificações da NBR NM 35 para Concreto Leve Estrutural. 
Os resultados mostraram também que podem ser utilizados concretos com resistências menores, porém ainda mais leves, com Fator de Eficiência (FE), relação entre resistência e massa específica, compatível com a aplicação estrutural desse concreto em vários tipos de elementos estruturais.

Como ainda são poucos os ensaios de caracterização do material, foi adotado neste trabalho que o CLE apresenta as mesmas características do concreto comum, para utilização das equações que são fornecidas nas normas nacionais e internacionais existentes. No futuro, as equações podem ser adaptadas, ou não, dependendo dos resultados de novos ensaios.

\subsection{JUSTIFICATIVA}

O estudo inicial sobre o Concreto Leve com EPS (CLE), ou Concreto Ultraleve ${ }^{\circledR}$, permite vislumbrar a possibilidade de sua aplicação em várias situações, como, por exemplo, na substituição de outros tipos de lajes. Essa substituição refere-se à melhoria no sistema, por conta das desvantagens apresentadas pelo concreto convencional, sendo as principais o elevado peso específico e a dificuldade de manuseio.

Outra vantagem que se destaca no CLE em relação ao concreto convencional é a redução considerável da massa específica, o que diminui o consumo de aço nos elementos sem comprometer a resistência para a finalidade em que o elemento estrutural está sendo utilizado.

Vale ressaltar que, em termos ambientais, o concreto em estudo é um material sustentável, pois pode ser obtido a partir de resíduos de EPS, que são incorporados na produção, e também é possível o uso de refugos industriais, sem comprometer as características do produto. Além disso, reduzem a emissão de poluentes para atmosfera, pela utilização de máquinas menos robustas.

O uso de EPS virgem ou de resíduos também implica em economia, por conta da maior quantidade de energia necessária para produção de outros tipos de agregados leves, como, por exemplo, a argila expandida. 
O interesse em buscar novos sistemas construtivos, aliado aos conhecimentos das características do CLE e do sistema de pré-moldados, permitiu unir essas informações para realizar este trabalho, que objetiva mostrar detalhes importantes de projeto, de execução e de implantação do sistema estrutural, assim como os custos envolvidos para viabilizar o emprego adequado dessas tecnologias.

\subsection{OBJETIVOS}

Como objetivo geral, este trabalho apresenta um estudo sobre a viabilidade da utilização do Concreto Leve com EPS (CLE), empregando o EPS como produto substitutivo dos agregados graúdos e parte dos miúdos. Será considerada a construção de um edifício residencial com lajes prontas maciças e paredes portantes, ambas pré-moldadas.

Para dimensionamento dos elementos estruturais, foi admitido que todos os critérios de cálculo apresentados nas normais nacionais e internacionais podem ser utilizados para o CLE, pela falta de mais ensaios experimentais do material.

Essa alternativa é comparada com solução estrutural empregando concreto autoadensável (CAA), para um com estrutura do mesmo tipo. O trabalho mostra, também, as vantagens e as desvantagens da utilização de cada concreto analisado.

Apresenta-se, por fim, uma estimativa dos custos envolvidos na produção dos elementos estruturais, transporte e outros fatores que influenciam no custo total de uma edificação.

\subsection{METODOLOGIA}

Para alcançar os objetivos propostos, foi realizado um levantamento de referências com relação aos elementos de lajes prontas maciças, painéis portantes pré-moldados, detalhamento dessas peças de concreto e orçamento.

Foram utilizados diversos recursos, entre os quais: acervo da Biblioteca Central da Escola de Engenharia de São Carlos, da biblioteca do Sistema Integrado de Bibliotecas - SIBI USP e acesso à rede internet, para outras pesquisas e comunicação com professores e pesquisadores do assunto e colaboração de empresas de engenharia. 
Com a fundamentação teórica bem definida, o modelo do edifício em estudo foi lançado no software comercial SAP 2000, a fim de se obterem os esforços necessários para a análise do modelo e o seu dimensionamento.

Foram elaboradas planilhas para dimensionamento dos elementos que irão compor a estrutura do edifício residencial em estudo, levando em conta as recomendações indicadas em normas nacionais e internacionais.

Para as peças que compõem a estrutura do edifício, o detalhamento foi realizado com base em recomendações de projeto e em práticas usuais do cenário da construção civil, de modo a apresentar detalhes típicos, de fácil compreensão.

Foram computados os custos envolvidos na execução do edifício, levando em conta produção e transporte, além de apresentar fatores que influenciam nos custos da obra, considerando os valores comerciais do cenário atual da Engenharia Civil.

\subsection{ESTRUTURA DA DISSERTAÇÃO}

O presente trabalho compara alguns dos custos envolvidos na construção de um edifício residencial com estrutura de painéis portantes e lajes prontas maciças, com finalidade de viabilizar o uso do concreto leve com EPS (CLE). O conteúdo de cada capítulo é resumido a seguir.

Capítulo 1 - Introdução, com os subitens: justificativa, objetivos, metodologia e estrutura da dissertação.

Capítulo 2 - Tipos de concretos que foram considerados no trabalho, como o concreto pré-moldado e concreto leve estrutural com esferas de EPS. Sobre o concreto prémoldado foram enfatizados: processo de fabricação, dispositivos auxiliares para manuseio, transporte interno, armazenamento, montagem e ligações entre os elementos.

Capítulo 3 - Principais características do sistema construtivo de painéis pré-moldados, em que foi comentado sobre as lajes prontas maciças, juntas verticais e horizontais e as respectivas fases transitórias envolvidas no processo de fabricação até a disposição final dos elementos. 
Capítulo 4 - Diretrizes para elaboração de projeto de edifícios de painéis pré-moldados, sendo utilizado o modelo de associação de pórticos planos e consideradas as excentricidades previstas em normais nacionais e internacionais para projeto de edifícios pré-moldados. Foram apresentadas, também, algumas considerações sobre efeitos de segunda ordem e sobre colapso progressivo.

Capítulo 5 - Cálculo do edifício multifamiliar adotado, em que foram consideradas algumas hipóteses de cálculo para obtenção dos esforços. Foi realizado o dimensionamento das lajes e o cálculo dos esforços provenientes das cargas e das ações do vento. Foram apresentadas também medidas de segurança para prevenção ao colapso progressivo.

Capítulo 6 - Roteiro de dimensionamento de um painel do edifício, sendo determinados os esforços que atuam no painel, provenientes dos esforços verticais, ações do vento e efeitos de segunda ordem. Em seguida foi calculada a armadura necessária para resistir aos esforços. Foi realizado também o dimensionamento das juntas verticais e horizontais, as verificações nas fases transitórias, o cálculo das alças de içamento e o detalhamento do painel.

Capítulo 7 - Análise dos resultados obtidos, fazendo uma comparação entre o CLE e o concreto comum. Foi verificado o comportamento do edifício para ação do vento e colapso progressivo, e do painel na fase transitória. Foram levantados alguns custos envolvidos no sistema construtivo adotado.

Capítulo 8 - Conclusões do trabalho, que mostraram a viabilidade da utilização do CLE em edifícios de múltiplos pavimentos, sem comprometer a estrutura da edificação.

Por fim, foram apresentadas as Referências Bibliográficas, seguidas de um Apêndice, no qual se apresentam estimativas de custos, com mais detalhes. 


\section{CONCRETOS}

O concreto é o material mais utilizado na construção civil. Conforme dados encontrados em Concreto \& Construções (2009), o consumo mundial chega a 11 bilhões de toneladas por ano, que corresponde a um consumo médio de 1,9 tonelada por habitante, mostrando sua enorme importância para a humanidade. Alguns tipos de concretos foram apresentados neste trabalho, como o concreto pré-moldado e o Concreto Leve com EPS.

\subsection{CONCRETO PRÉ-MOLDADO}

Os elementos pré-fabricados buscam atender as demandas do meio técnico através da comercialização de produtos que sejam satisfatórios, em termos de economia, eficiência, desempenho técnico e segurança. A pré-fabricação desses elementos envolve a fase de fabricação somente em indústria, podendo, mesmo assim, a indústria instalar-se no próprio local da obra, desde que atenda aos rigorosos controles de qualidade. Já o prémoldado é executado fora do local definitivo na estrutura, ou seja, produzido na obra, sem o rigor no controle de qualidade como ocorre na indústria.

A eficiência estrutural das peças pré-moldadas depende da utilização de elementos mais esbeltos, com melhores características, devido ao alto controle tecnológico durante a fase de fabricação. Além disso, deve ser garantido o uso otimizado dos materiais, com redução do desperdício de recursos.

O emprego das peças pré-fabricadas de concreto na construção civil representa um razoável progresso em termos construtivos, pois permite a racionalização e o aperfeiçoamento técnico das obras, com maior eficiência produtiva, por se tratar de um sistema que trabalha com a repetição de elementos.

De acordo com El Debs (2000), os elementos pré-moldados podem ser classificados, quanto ao peso, como "leves" e "pesados". O pré-moldado é considerado "pesado" quando o elemento confeccionado necessita de equipamentos especiais para transporte e montagem. Já o pré-fabricado "leve" é aquele que não necessita de equipamentos especiais para transporte e montagem, permitindo improvisação nos equipamentos, ou até mesmo a possibilidade de montagem manual. 


\subsubsection{Processo de fabricação dos elementos pré-moldados}

A execução dos elementos pré-fabricados pode ser dividida em três fases, que consideram as atividades preliminares, a execução e as atividades posteriores (El Debs, 2000).

O citado autor relata que as atividades preliminares envolvem a preparação dos materiais e o transporte ao local de trabalho. A fase de preparação dos materiais engloba o armazenamento das matérias-primas, o preparo (corte e dobramento), bem como a eventual montagem da armadura, dosagem e mistura do concreto. Para a fase do transporte dos materiais ao local de trabalho, a armadura é conduzida montada ou desmontada, e o concreto recém-misturado é transportado até a fôrma, de maneira mecânica ou manual.

Na prática dos elementos pré-moldados, é comum a utilização do concreto autoadensável (CAA) para sua confecção, principalmente em elementos que apresentam elevada densidade de armadura. As principais vantagens desse concreto são: não ocorre necessidade de vibradores na obra, reduzindo drasticamente o custo com mão de obra, energia elétrica e equipamentos. Porém apresenta um custo mais elevado com material, quando comparado com o concreto comum.

A fase de execução é dividida em quatro etapas: preparação da fôrma e da armadura, colocação do concreto (moldagem), cura e desmoldagem. A preparação da fôrma e da armadura consiste na limpeza das peças e na aplicação do desmoldante. Em seguida, coloca-se a armadura e as peças complementares, dando prosseguimento ao fechamento da fôrma. O concreto é lançado e, após o processo de adensamento, são realizados os acabamentos finais. O processo de cura do concreto é concluído após o período em que o elemento moldado permanece na fôrma e adquire a resistência adequada. A desmoldagem consiste na retirada do elemento da fôrma (El Debs, 2000).

Nas atividades posteriores destacam-se o transporte interno, os acabamentos finais e o armazenamento. O transporte interno é a fase em que os elementos são conduzidos do local de desmoldagem até a área de armazenamento ou a área de acabamento. Nos acabamentos finais são realizadas as inspeções e os tratamentos finais, como possíveis remendos e maquiagens. E por fim, as peças são armazenadas em local apropriado, até o envio à obra (El Debs, 2000). 


\subsubsection{Dispositivos auxiliares para manuseio}

Segundo El Debs (2000), para movimentação dos elementos pré-moldados, são necessários equipamentos e dispositivos auxiliares, exceto nos casos de elementos muito pequenos, em que essa operação é realizada de forma manual. Os dispositivos auxiliares para manuseio dos elementos são os necessários para içamento.

Esses dispositivos são divididos em internos e externos. Os dispositivos internos podem ser laços ou chapas (Figura 2.1), orifícios (Figura 2.2), peças com alças rosqueadas posteriormente (Figura 2.3) e dispositivos especiais (Figura 2.4).

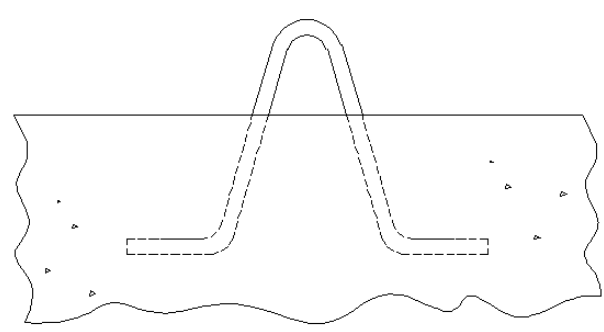

a) Com laços

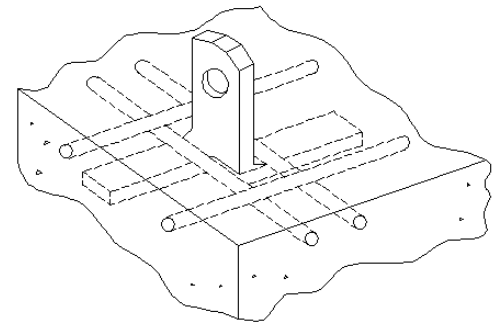

b) Com chapa

Figura 2.1: Dispositivos internos com laços ou com chapa chumbada [Adaptado: El Debs (2000)]

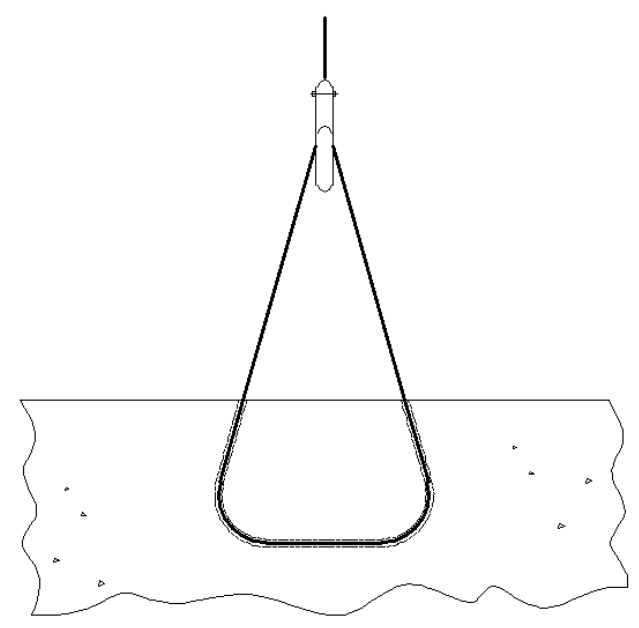

a) Com furo e cabo de aço

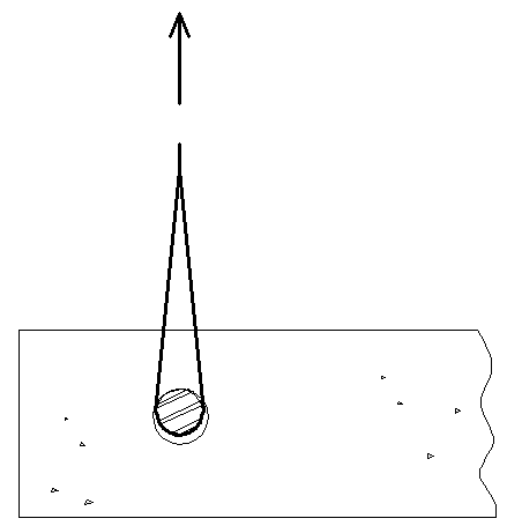

b) Com furo e tarugo de aço

Figura 2.2: Dispositivos internos com furo e cabo de aço ou com furo e tarugo de aço [Adaptado: El Debs (2000)] 

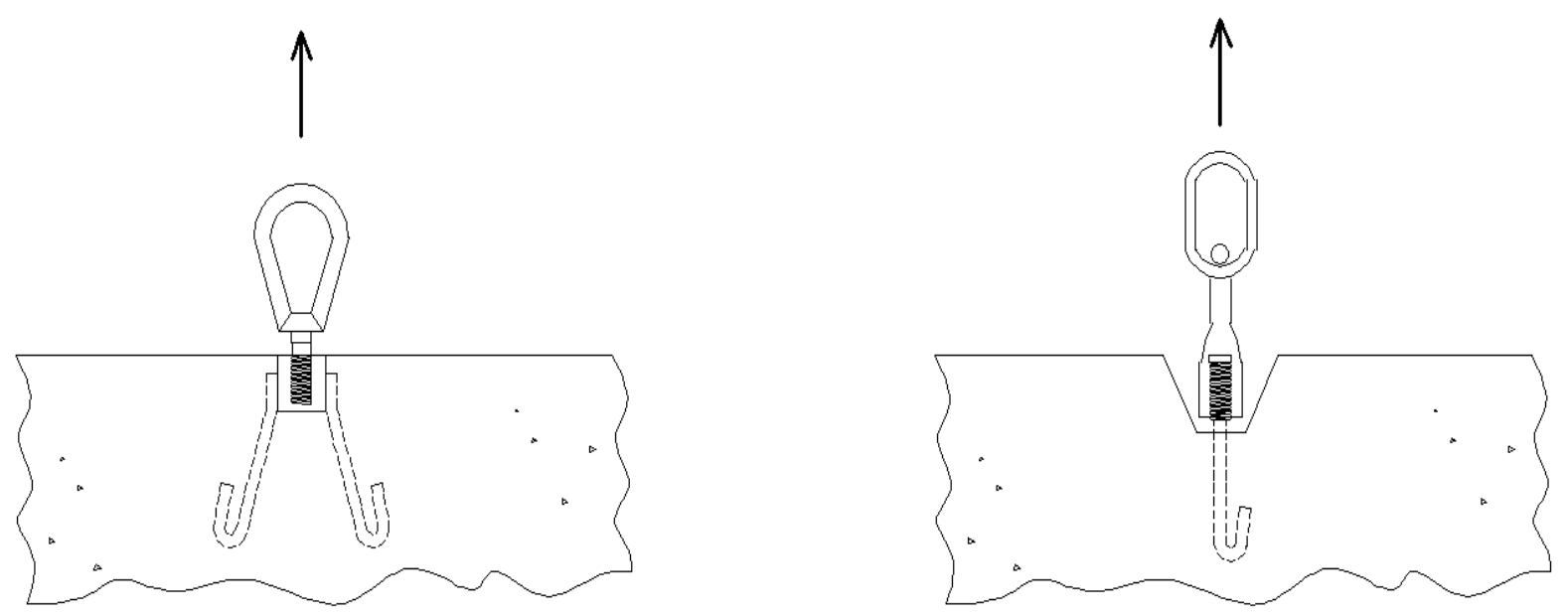

Figura 2.3: Dispositivos internos com alças fixadas posteriormente [Adaptado: El Debs (2000)]

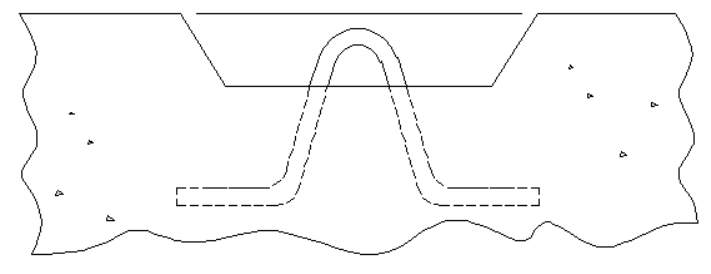

a) Com laço interno

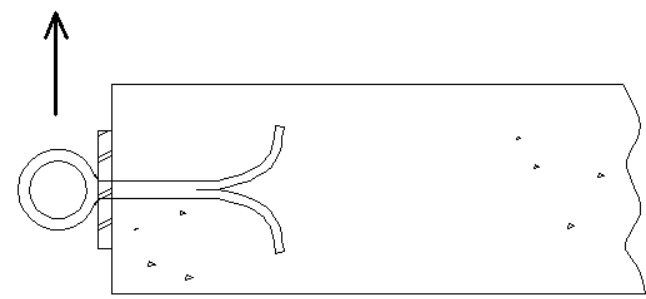

b) Com dispositivo especial para levantamento lateral

Figura 2.4: Dispositivos com laço interno ou com dispositivo especial para levantamento lateral [Adaptado: El Debs (2000)]

Os laços chumbados são os mais empregados para içamento. Posteriormente sua parte externa deve ser cortada e suas pontas protegidas contra corrosão, em geral com o uso de uma camada de concreto.

Para evitar o corte posterior, os laços chumbados podem ser dispostos em cavidades (Figura 2.4a), que posteriormente são preenchidas por concreto.

Os dispositivos externos podem ser: balancins, prensadores transversais, braços mecânicos e ventosas, sendo os balancins os mais comuns (Figura 2.5). 


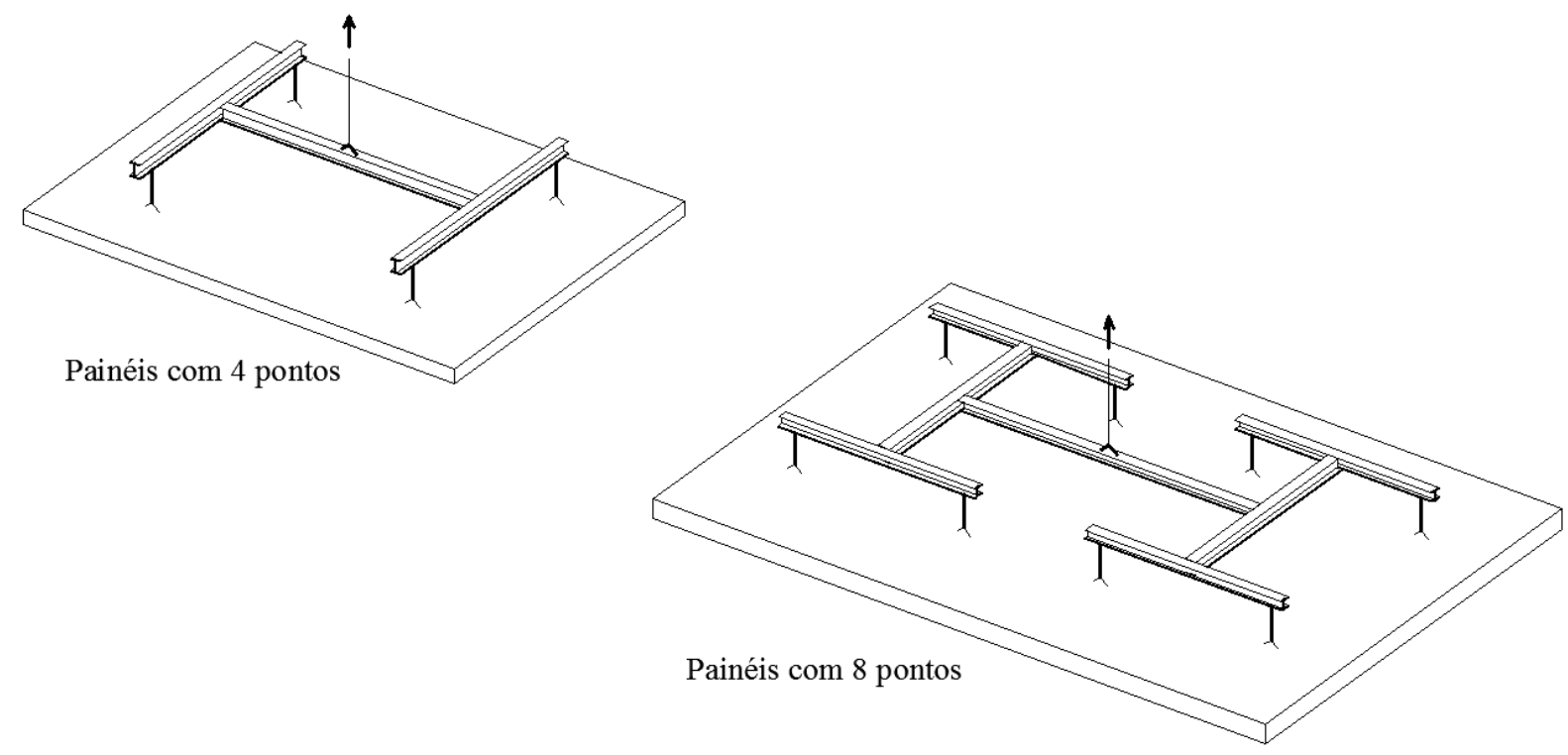

Figura 2.5: Balancins para manuseio de painéis [Adaptado: El Debs (2000)]

\subsubsection{Transporte interno}

O transporte interno na fábrica é realizado por meio de pórticos rolantes, carrinhos de rolamento, pontes rolantes, monotrilhos e outros equipamentos do gênero. As Figuras 2.6 a 2.9 apresentam exemplos de equipamentos para transporte dos elementos, da área de execução para a de armazenamento. Os mais utilizados nas fábricas são as pontes rolantes e os pórticos rolantes (El Debs, 2000).

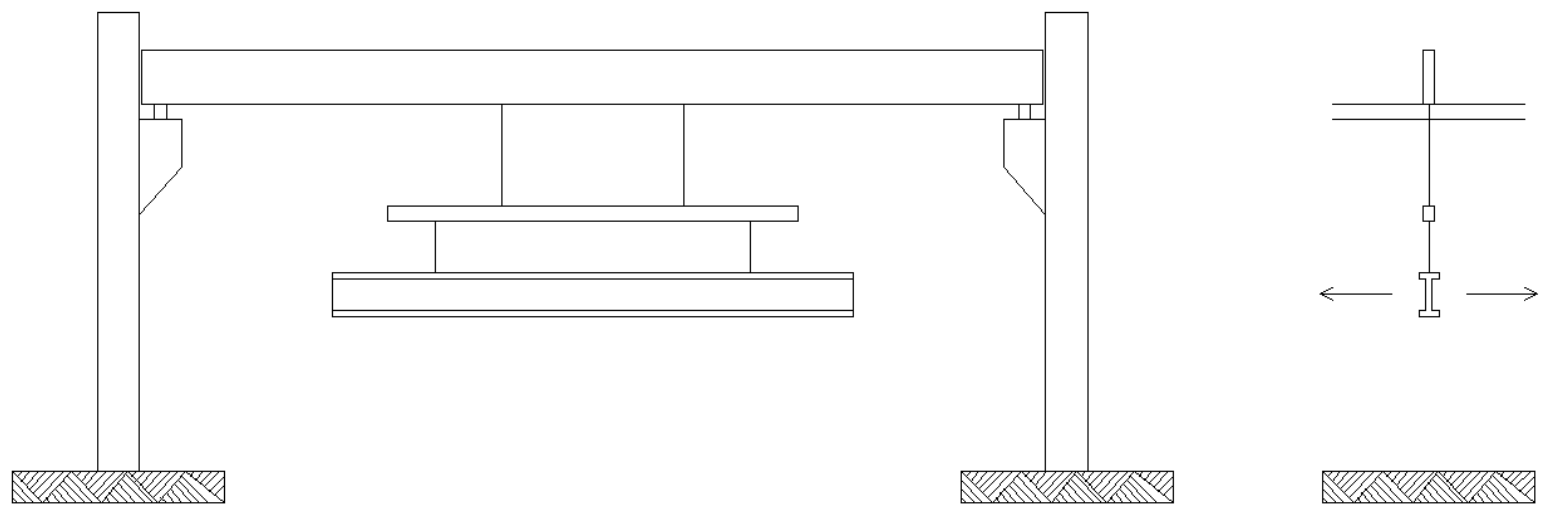

Figura 2.6: Ponte rolante [Adaptado: El Debs (2000)] 


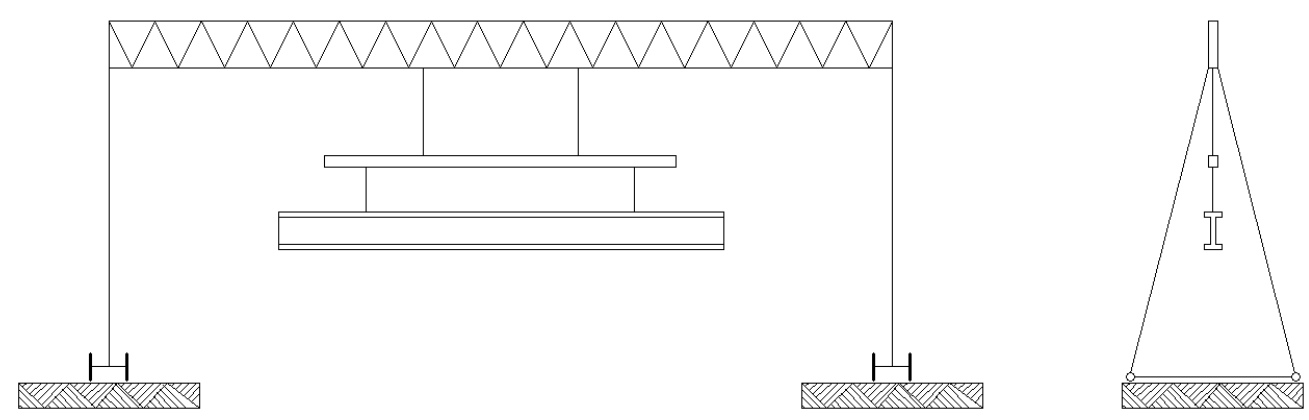

Figura 2.7: Pórtico rolante [Adaptado: El Debs (2000)]
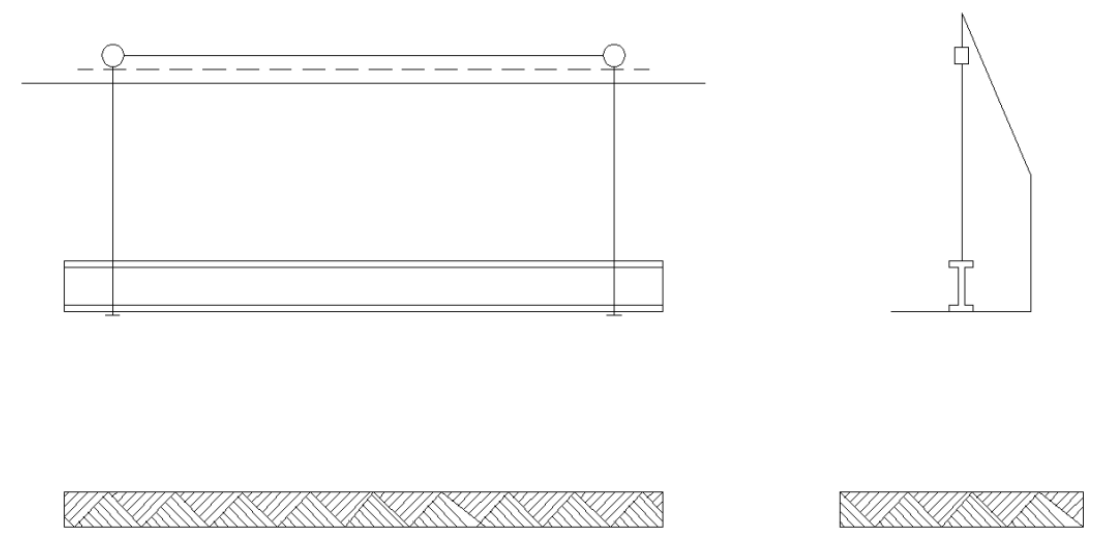

Figura 2.8: Monotrilho [Adaptado: El Debs (2000)]
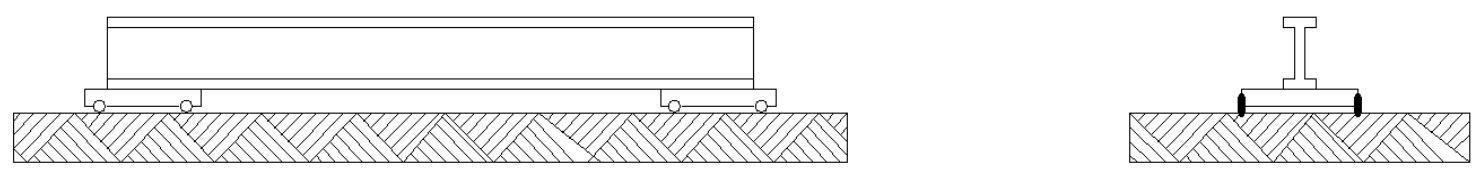

Figura 2.9: Carrinho de rolamento [Adaptado: El Debs (2000)]

\subsubsection{Armazenamento}

De acordo com El Debs (2000), o armazenamento dos elementos é realizado após a execução, quando as peças são retiradas do local de fabricação e armazenadas em área apropriada. Nessa etapa, alguns elementos podem necessitar de acabamento superficial, como retoques.

O referido autor recomenda não utilizar mais de duas linhas de apoio para armazenar os elementos pré-moldados, e colocá-los na posição correspondente à de utilização definitiva, como mostra a Figura 2.10. Essa etapa requer cuidados especiais com os seguintes aspectos: possibilidade de deformações excessivas devidas à pouca idade do concreto; e abaulamentos devidos à variação de temperatura e às retrações diferenciadas nas faces dos painéis. 

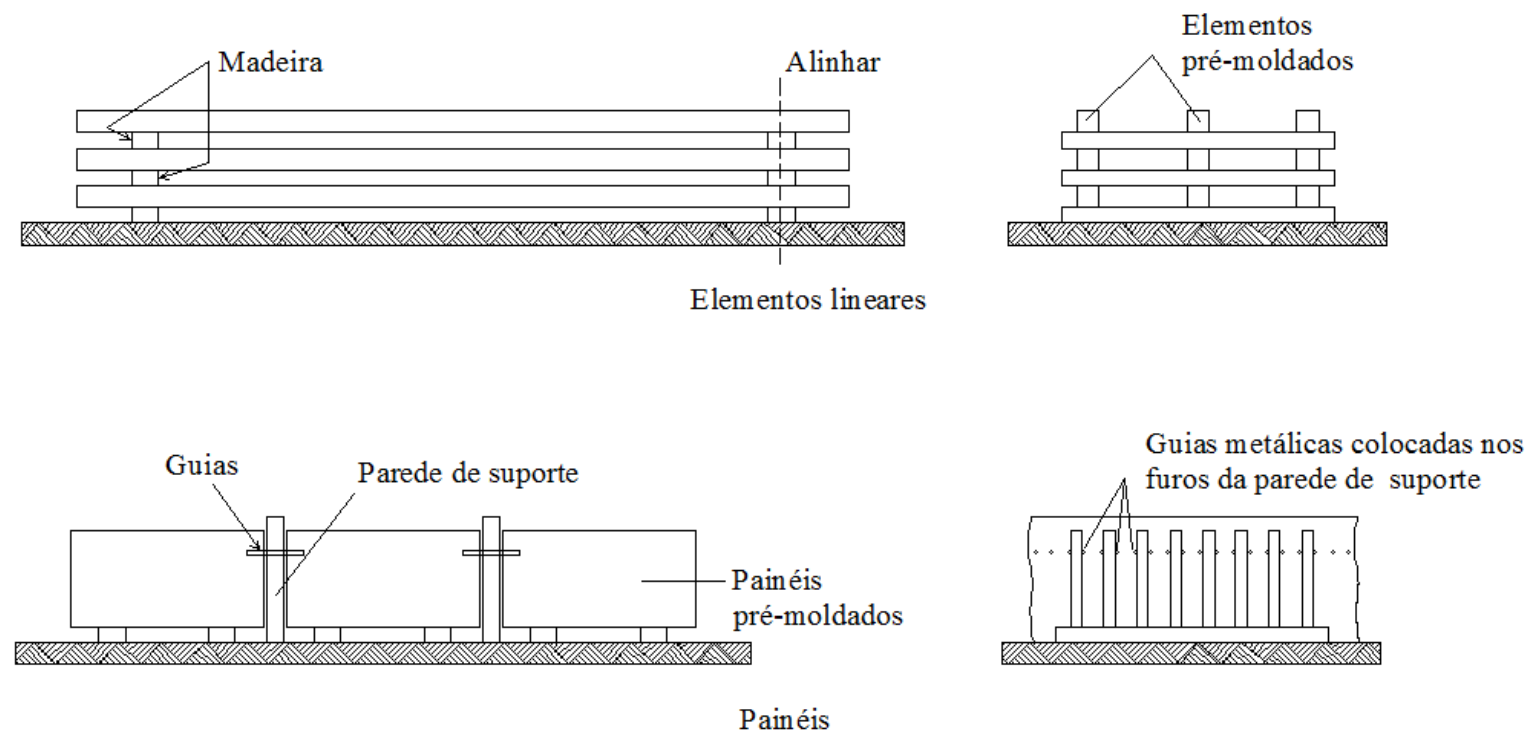

Figura 2.10: Armazenamento dos elementos [Adaptado: El Debs (2000)]

\subsubsection{Montagem}

A montagem dos elementos pré-moldados é realizada por meio de equipamentos que permitem a colocação segura da peça na posição final, de acordo com o projeto.

Os equipamentos mais utilizados na fase de montagem são as autogruas sobre pneus (Figura 2.11), as autogruas sobre esteiras (Figura 2.12), as gruas de torre (Figura 2.13), as gruas de pórtico (Figura 2.14) e os caminhões com guindastes acoplados (Figura 2.15).

Segundo El Debs (2000), os fatores que são levados em consideração para a escolha do equipamento e da respectiva capacidade são os seguintes:

a) Pesos, dimensões e raios de levantamento das peças mais pesadas e maiores;

b) Número de levantamentos a serem feitos e frequência das operações;

c) Mobilidade requerida, condições de campo e espaço disponível;

d) Necessidade de transportar os elementos levantados;

e) Necessidade de manter os elementos no ar por longos períodos;

f) Condições topográficas de acesso;

g) Disponibilidade e custo do equipamento. 


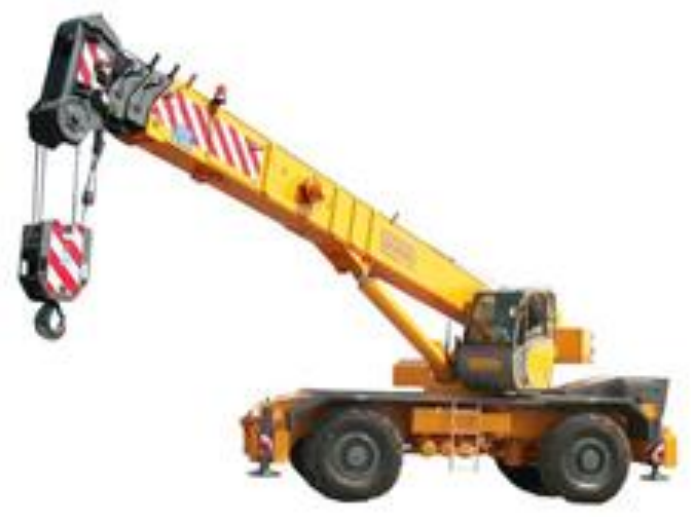

Figura 2.11: Autogrua sobre pneus (Fonte: http://www.transgruas.com/es/productos/galeria-de-fotos/fotos-gruasautopropulsadas.htm, acesso em: 13/07/2012)

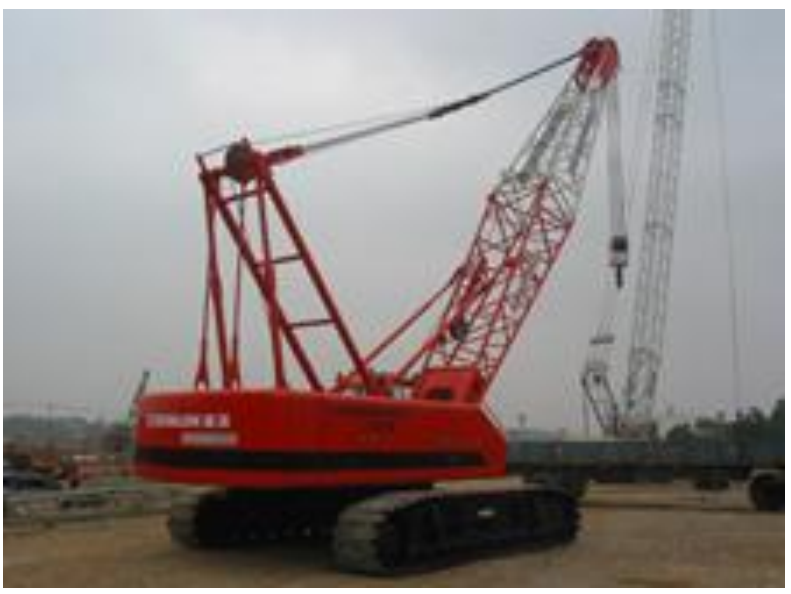

Figura 2.12: Autogrua sobre esteira (Fonte: http://portuguese.alibaba.com/product-gsimg/crawler-crane-291613880.html, acesso em: 13/07/2012)

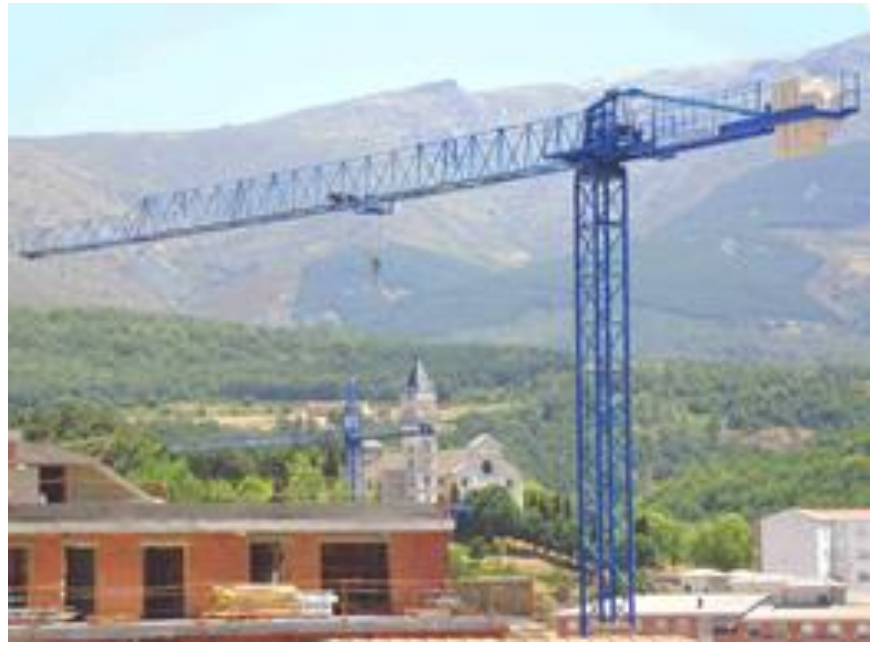

Figura 2.13: Grua de torre (Fonte: http://cranesandconstruction.wordpress.com/tag/gruatorre/, acesso em: 13/07/2012) 


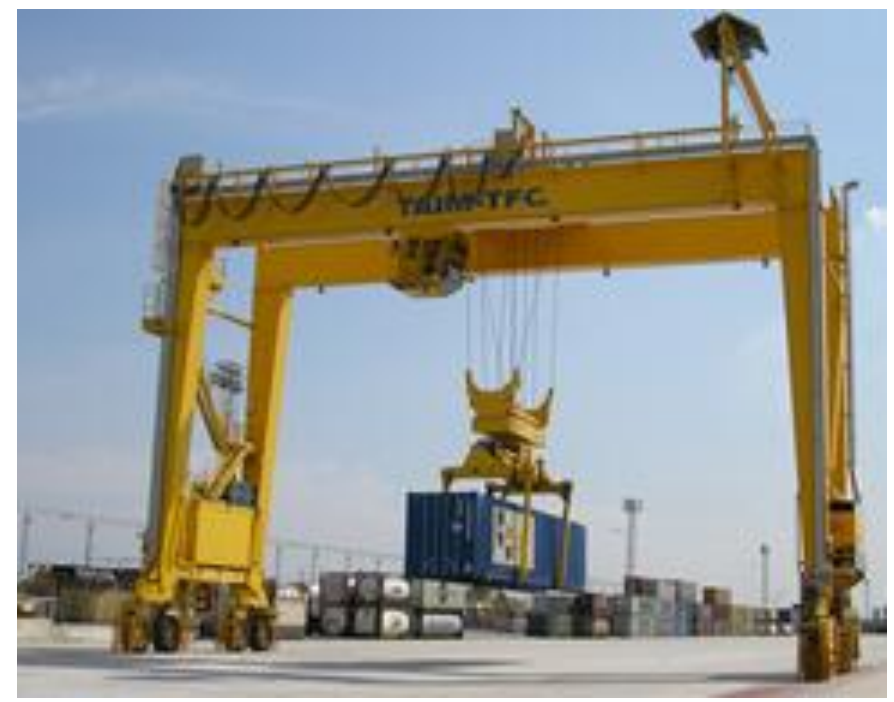

Figura 2.14: Grua de pórtico (Fonte: http://www.panoramio.com/photo/44402414, acesso em: $13 / 07 / 2012$ )

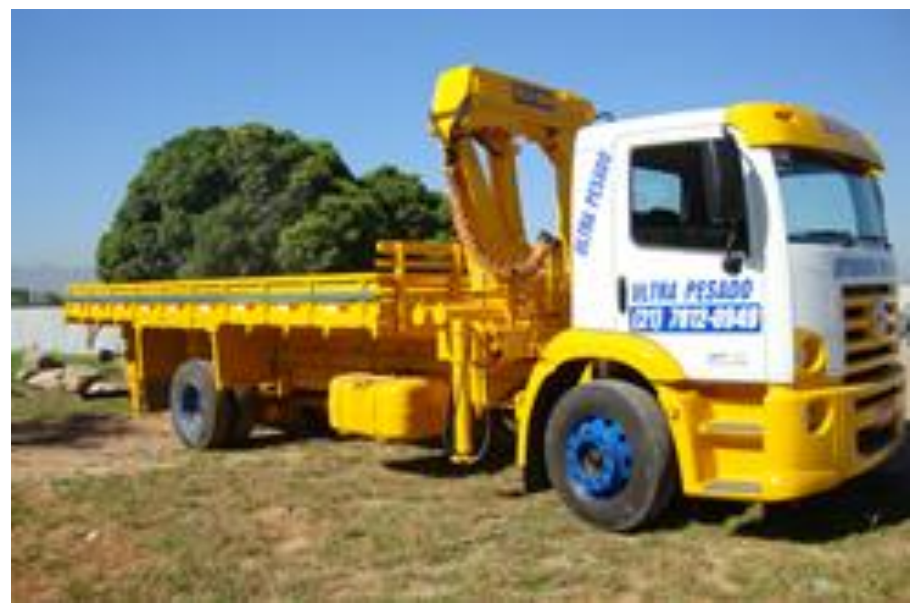

Figura 2.15: Caminhão com guindaste acoplado (Fonte: http://ultrapesado.com.br/slide-2/, acesso em: 13/07/2012)

\subsubsection{Ligações de elementos pré-moldados}

Ao longo dos últimos anos, foram realizados estudos para a evolução no conceito estrutural do material pré-fabricado, no que diz respeito às ligações das peças estruturais de concreto.

Melo (2007) comenta que a criação de uma estrutura de pré-fabricados de concreto, na fase de modelagem, deve levar em consideração as ligações entre as peças, visto que a indústria da pré-fabricação é caracterizada pela produção de elementos estruturais em usina, e a montagem final das peças é realizada somente no canteiro de obras. 
A distribuição dos esforços será melhorada quanto mais rígida for a ligação, ou seja, com ela aproximando-se da continuidade perfeita. Dessa forma, maior será a possibilidade de otimização e de economia na estrutura. Portanto, essa economia é inversamente proporcional ao grau de liberdade das ligações.

É comum, na fase de projeto, a prática equivocada de admitir uma estrutura totalmente monolítica e, durante a construção do empreendimento, almejar os inúmeros benefícios e flexibilidades que uma estrutura isostática pode proporcionar (Melo, 2007).

Esse autor relata que, para se obter economia no projeto de uma estrutura monolítica, é necessário colocar em prática todos os conceitos estruturais de elementos pré-fabricados. Se isto não for feito, o projeto torna-se mais complexo e detalhado, influenciando diretamente no aumento de tempo para realizá-lo. Esse detalhamento impõe condições na fase de execução, em especial na montagem da obra, que pode gerar sequências obrigatórias, consolidações intermediárias (que dependem da cura do concreto, por exemplo) entre outros, que aumentam a complexidade de gerenciamento do empreendimento.

Sendo o pré-fabricado sinônimo de rapidez, o aumento de complexidade (com maior consumo de tempo) torna-se antagônico à economia desejada. Por isso mesmo, a equação, em que as variáveis são tempo, conceito estrutural e economia, deve ser definida desde o início do empreendimento e mantida pelo projeto estrutural até a entrega da obra, para que os objetivos sejam efetivamente alcançados.

\subsection{CONCRETO LEVE ESTRUTURAL COM ESFERAS DE EPS}

De acordo com Rossignolo e Agnesini (2005), é comum a utilização do concreto leve para economia no custo total da obra, com redução da armadura e redução dos custos com transporte e montagem de construções pré-fabricadas. $\mathrm{O}$ baixo peso específico também pode ser adequado no caso de solos com baixa capacidade de carga.

Esse concreto possui inúmeras vantagens, nas quais se destacam o baixo peso específico, adequada retração por secagem e fluência, maior durabilidade, isolamento térmico e resistência a altas temperaturas. Como desvantagens pode-se citar a necessidade de maior cuidado com a segregação (flutuação do agregado graúdo), baixo módulo de elasticidade e custos com os agregados leves (Rossignolo e Agnesini, 2005). 
O Concreto Leve Estrutural (CLE), ou Concreto Ultraleve ${ }^{\circledR}$, tem sua patente registrada no Instituto Nacional de Propriedade Industrial (INPI) por Kerbauy (2011).

De acordo com Catoia (2012), o material é constituído de agregados granulares e inertes, como areia e Poliestireno Expandido (EPS). O EPS é responsável pela redução da massa específica do concreto e atua como agregado graúdo e como incorporador de ar, apresentando distribuição homogênea (Figura 2.16).

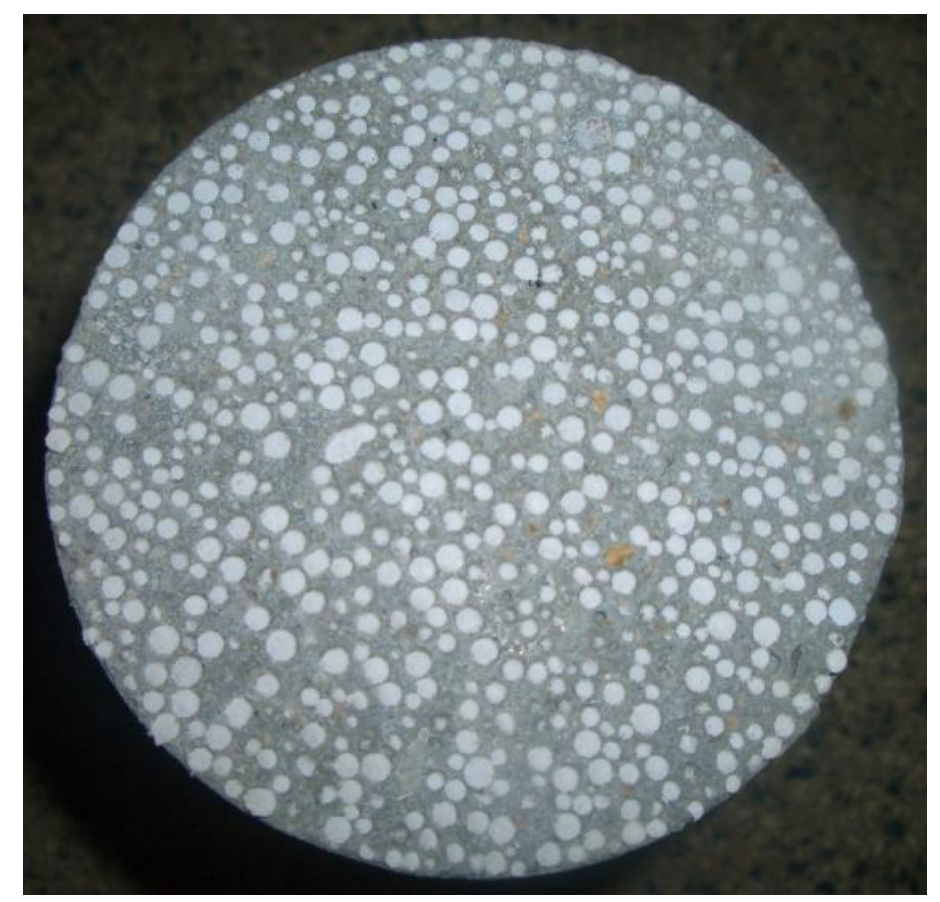

Figura 2.16: Concreto Leve com esferas de EPS [Fonte: Catoia (2012)]

Conforme Kerbauy (2011), o Concreto Ultraleve ${ }^{\circledR}$ Estrutural pode ser produzido por meio de quatro tipos principais de agregados graúdos, sem o comprometimento de suas características. Os tipos podem ser classificados em pérolas de EPS, EPS moído ou reciclado, refugo de poliuretano (PU) e EPS extrudado (EPEx), como mostra Figura 2.17.

Catoia (2012) ressalta que o CLE apresenta facilidade no lançamento, adensamento e nivelamento, devido ao menor peso dos agregados, caracterizando um concreto reodinâmico. A aplicação desse tipo de concreto proporciona um ambiente de trabalho mais agradável, pois os vibradores causam menos ruído e as fôrmas são menos desgastadas. Essas consequências são causadas geralmente pelos processos de vibração e de adensamento. 


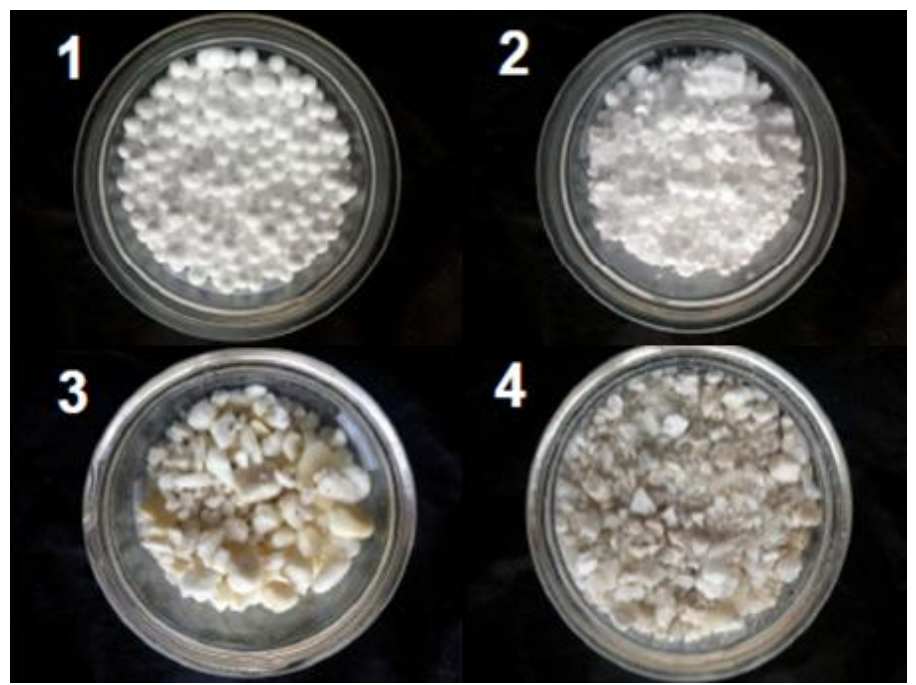

Figura 2.17: Agregados que podem ser utilizado no CLE: 1) Pérolas de EPS; 2) EPS moído ou reciclado; 3) Refugo de poliuretano (PU); 4) EPS extrudado (EPEx) [Adaptado: Kerbauy (2011)]

$\mathrm{O}$ autor realizou um estudo em três tipos de traço para o concreto, nomeados "A", "B" e “C”. Na Tabela 2.1, são apresentados os valores para peso específico, resistência à compressão e fator de eficiência (relação entre resistência à compressão e massa específica).

Tabela 2.1: Caracterização mecânica do CLE [Fonte: Catoia (2012)]

\begin{tabular}{|c|c|c|c|c|c|}
\hline \multicolumn{2}{|c|}{ Característica } & \multirow{2}{*}{ Unidade } & \multicolumn{3}{c|}{ Traço } \\
\cline { 4 - 6 } Estado Fresco & $\boldsymbol{\gamma}_{\mathbf{F}}$ & $\mathrm{kg} / \mathrm{m}^{3}$ & 1209 & 1272 & 1373 \\
\hline \multirow{4}{*}{$\mathbf{1}$ dia } & $\boldsymbol{\gamma}_{\mathbf{1}}$ & $\mathrm{kg} / \mathrm{m}^{3}$ & 1195 & 1263 & 1325 \\
\cline { 2 - 6 } & $\mathbf{f}_{\mathbf{c} \mathbf{1}}$ & $\mathrm{MPa}$ & 7,8 & 8,7 & 9,3 \\
\cline { 2 - 6 } & $\mathbf{F E}_{\mathbf{1}}$ & $\mathrm{MPa} \cdot \mathrm{dm}^{3} / \mathrm{kg}$ & 6,5 & 6,9 & 7,0 \\
\hline \multirow{4}{*}{$\mathbf{7}$ dias } & $\boldsymbol{\gamma}_{\mathbf{7}}$ & $\mathrm{kg} / \mathrm{m}^{3}$ & 1140 & 1268 & 1328 \\
\cline { 2 - 6 } & $\mathbf{f}_{\mathbf{c}}$ & $\mathrm{MPa}$ & 10,2 & 14,4 & 14,3 \\
\cline { 2 - 6 } & $\mathbf{F E}_{\mathbf{7}}$ & $\mathrm{MPa} \cdot \mathrm{dm}^{3} / \mathrm{kg}$ & 8,9 & 11,4 & 10,8 \\
\hline \multirow{4}{*}{$\mathbf{2 8}$ dias } & $\boldsymbol{\gamma}_{\mathbf{2 8}}$ & $\mathrm{kg} / \mathrm{m}^{3}$ & 1191 & 1279 & 1355 \\
\cline { 2 - 6 } & $\mathbf{f}_{\mathbf{c 2 8}}$ & $\mathrm{MPa}$ & $13,3 *$ & 15,9 & $17,2 *$ \\
\cline { 2 - 6 } & $\mathbf{F E}_{\mathbf{2 8}}$ & $\mathrm{MPa} \cdot \mathrm{dm}^{3} / \mathrm{kg}$ & 11,2 & 12,4 & 12,7 \\
\cline { 2 - 6 } & $\mathbf{E}_{\mathbf{c i}}$ & $\mathrm{GPa}$ & 8,98 & 11,36 & 12,17 \\
\cline { 2 - 6 } & $\mathbf{E}_{\mathbf{c s}}$ & $\mathrm{GPa}$ & 8,08 & 10,08 & 11,02 \\
\hline
\end{tabular}

(*) Valores estimados, por conta do pequeno número de ensaios.

* $\mathrm{E}_{\mathrm{ci}}$ é o módulo de elasticidade inicial, e $\mathrm{E}_{\mathrm{cs}}$ é o módulo de elasticidade secante. 
De acordo com Catoia (2012), para o traço "B", foram realizados dois ensaios para determinação da resistência do CLE à tração, o de compressão diametral e o de flexão. No ensaio de compressão diametral, foi obtido o valor de 1,11 MPa para resistência média à tração, enquanto que no ensaio de flexão foi obtido o valor de 1,39 MPa.

O Fator de Eficiência (FE), ou eficiência estrutural, relaciona a resistência à compressão com a massa específica. Esse parâmetro é comumente utilizado na caracterização de concretos leves, e pode ser representado pela equação (2.1):

$$
\mathrm{FE}=\frac{\mathrm{f}_{\mathrm{c}}}{\gamma}
$$

$\mathrm{f}_{\mathrm{c}}=$ resistência à compressão $(\mathrm{MPa})$;

$\gamma=$ massa específica $\left(\mathrm{kg} / \mathrm{dm}^{3}\right)$.

Catoia (2012) ressalta ainda que a comparação do Fator de Eficiência dos traços analisados permite concluir que os valores relativos a 28 dias são muito próximos ao de um concreto convencional de $30 \mathrm{MPa}$ e massa específica de $2400 \mathrm{~kg} / \mathrm{m}^{3}$, que possui uma Fator de Eficiência de $12,5 \mathrm{MPa} \cdot \mathrm{dm}^{3} / \mathrm{kg}$.

Com relação aos ensaios de retração para o CLE, os valores apresentaram-se próximos ao limite superior do intervalo entre $500 \times 10^{-6} \mathrm{~m} / \mathrm{m}$ e $1000 \times 10^{-6} \mathrm{~m} / \mathrm{m}$ de retração por secagem de concretos leves com agregados leves convencionais, apresentado por Rossignolo e Agnesini (2005).

Como o produto desenvolvido ainda é novo, não existem normas nacionais que possam ser utilizadas para validação do material. Segundo a ABNT NBR NM 35:1995, para concreto estrutural leve, devem-se atender os valores apresentados na Tabela 2.2.

Tabela 2.2: Valores correspondentes de resistência à compressão e massa específica [Adaptado: ABNT NBR NM 35:1995]

\begin{tabular}{|c|c|}
\hline $\begin{array}{c}\text { Valores mínimos de resistência à } \\
\text { compressão aos 28 dias }(\mathbf{M P a})\end{array}$ & $\begin{array}{c}\text { Valores máximos de massa } \\
\text { específica }\left(\mathbf{k g} / \mathbf{m}^{\mathbf{3}}\right)\end{array}$ \\
\hline 28 & 1840 \\
\hline 21 & 1760 \\
\hline 17 & 1680 \\
\hline
\end{tabular}


Ensaios realizados no Laboratório de Estruturas da EESC mostraram que o CLE pode atingir resistência à compressão superior a $17 \mathrm{MPa}$, com massa específica inferior a $1680 \mathrm{~kg} / \mathrm{m}^{3}$. Esses valores atendem aos limites estabelecidos pela NBR NM 35 para concreto leve estrutural.

Vários tipos de cimento disponíveis no mercado podem ser empregados no CLE, em que o consumo varia em uma faixa de $300 \mathrm{~kg} / \mathrm{m}^{3}$ a $600 \mathrm{~kg} / \mathrm{m}^{3}$, dependendo da finalidade da aplicação. De acordo com a ABNT NBR 6118:2007, os concretos estruturais devem atingir uma resistência mínima de $20 \mathrm{MPa}$, sendo possível obter essa resistência com o CLE.

Portanto, dependendo do tipo de elemento estrutural fabricado, o CLE pode apresentar diversas vantagens, pois possui cerca de $50 \%$ da massa específica do concreto convencional. Dessa forma, a estrutura torna-se muito mais leve, com reduções nos custos de armaduras, içamento, transporte e fundações, por exemplo. 


\section{SISTEMAS CONSTRUTIVOS DE PAINÉIS PRÉ-MOLDADOS}

Os sistemas construtivos de painéis pré-moldados utilizam esses elementos para exercerem função estrutural (painel portante) e de vedação, podendo empregar lajes moldadas in loco, pré-lajes e lajes prontas maciças. Estas lajes prontas apresentam vantagens, como não necessitar de cimbramento na obra, ocorrendo poucas concretagens no local.

\subsection{LAJES PRONTAS MACIÇAS}

Em projetos de lajes prontas maciças, é realizada uma compatibilização prévia das instalações hidráulicas e elétricas. Esse fato ocorre devido a esse tipo de laje não necessitar de um complemento in loco na espessura final. Dessa forma, não é necessário, também, o cimbramento, o que minimiza a utilização de fôrmas e escoras.

O processo de fabricação (Figura 3.1) envolve o controle de cura, umidade, temperatura, adições, armadura e instalações, resultando em peças com excelente acabamento. Elas chegam prontas ao canteiro de obra, necessitando, apenas, de dispositivos mecânicos para colocar a laje em sua posição de serviço, o que é feito com o auxílio de içadores.
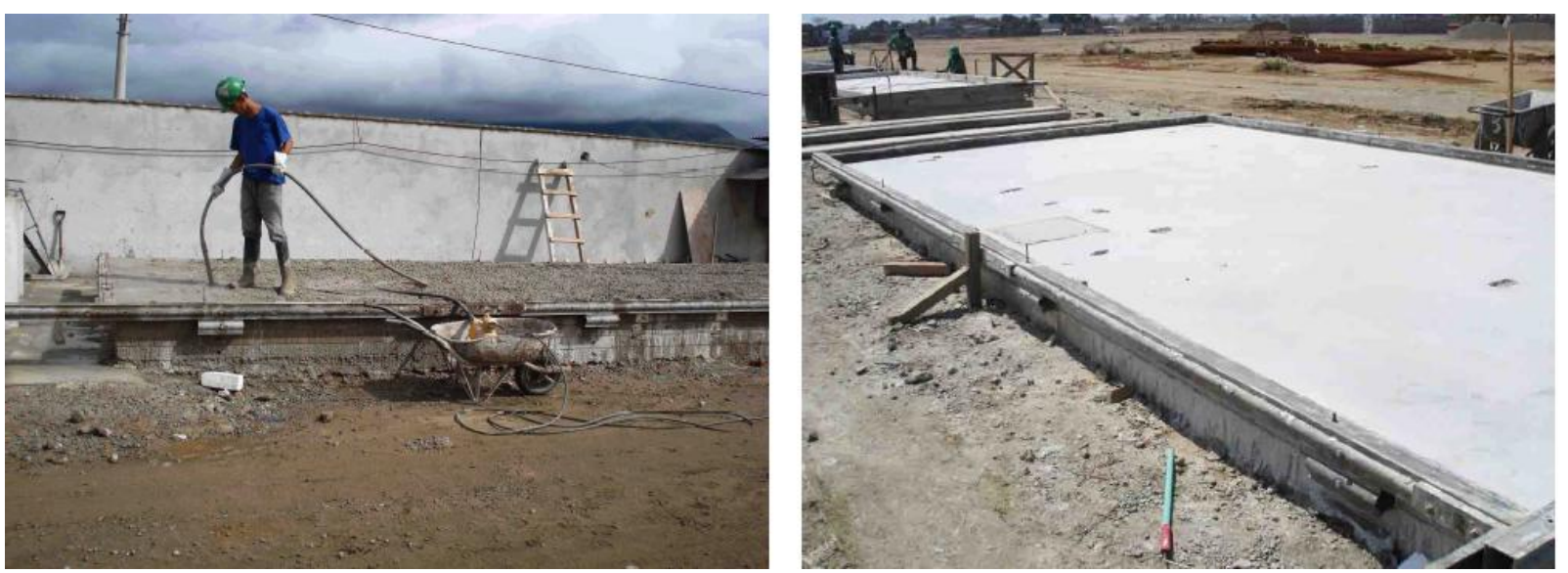

Figura 3.1: Processo de fabricação da laje pronta maciça [Fonte: Brumatti (2008)]

O dimensionamento e detalhamento da posição do gancho de içamento das lajes prontas maciças devem ser realizados com cautela, assegurando a integridade da superfície no transporte da peça (Figura 3.2). As alças mais utilizadas para içamento são as de cabo de protensão (cordoalha) e barra de aço CA-25, e devem garantir a perfeita ancoragem. 

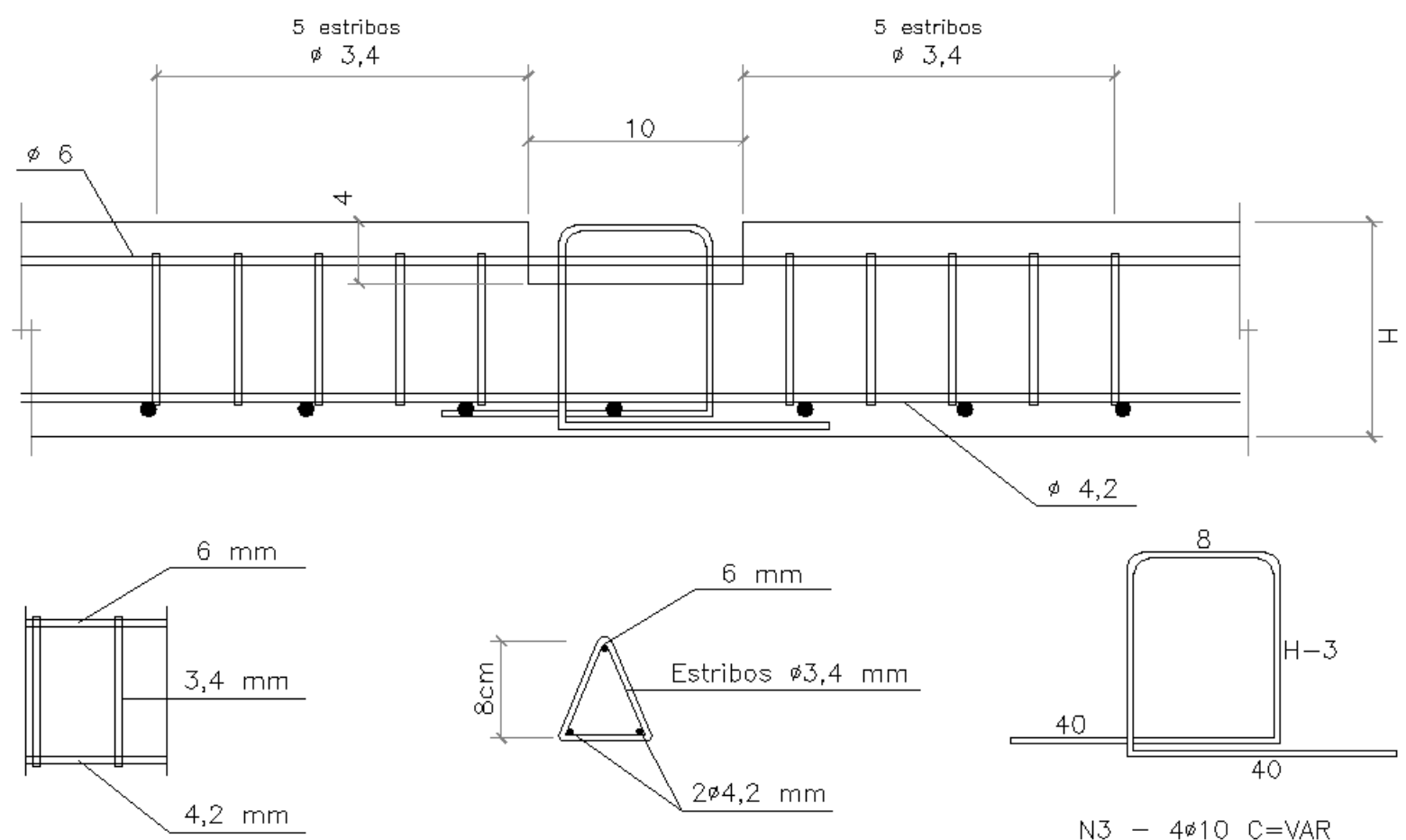

N3 - 4\$10 C $=$ VAR

POR PEÇA (CA25)

Figura 3.2: Detalhes para alças de içamento [Adaptado: Melo (2007)]

As lajes prontas maciças não são flexíveis quanto à sua execução. Como a laje já possui a sua espessura total, não é possível ocorrer na obra alguma adaptação para nivelamento dos apoios, exigindo um rigoroso controle prévio de nível, antes de colocar a peça na sua posição final de serviço.

De acordo com Melo (2007), a execução da ligação na junta longitudinal entre duas lajes é a única concretagem in loco nesse sistema construtivo (Figura 3.3), tarefa que é realizada com a ajuda de uma armadura colocada in loco, que garante a costura entre as lajes, evitando movimentações diferenciais e fissuras nas alvenarias de vedação.

Para garantir o efeito do diafragma rígido, o engenheiro estrutural deve prever a armadura necessária para garantir a continuidade entre as lajes. Esse sistema tem se mostrado bastante satisfatório nos edifícios residenciais.

Uma recomendação prescrita por Melo (2007) é de se utilizar um apoio da laje com um comprimento mínimo de $5 \mathrm{~cm}$, como mostra a (Figura 3.4). Esse comprimento mínimo acarreta em um melhor apoio da laje no painel e evita uma possível quebra ou deslizamento da laje. 

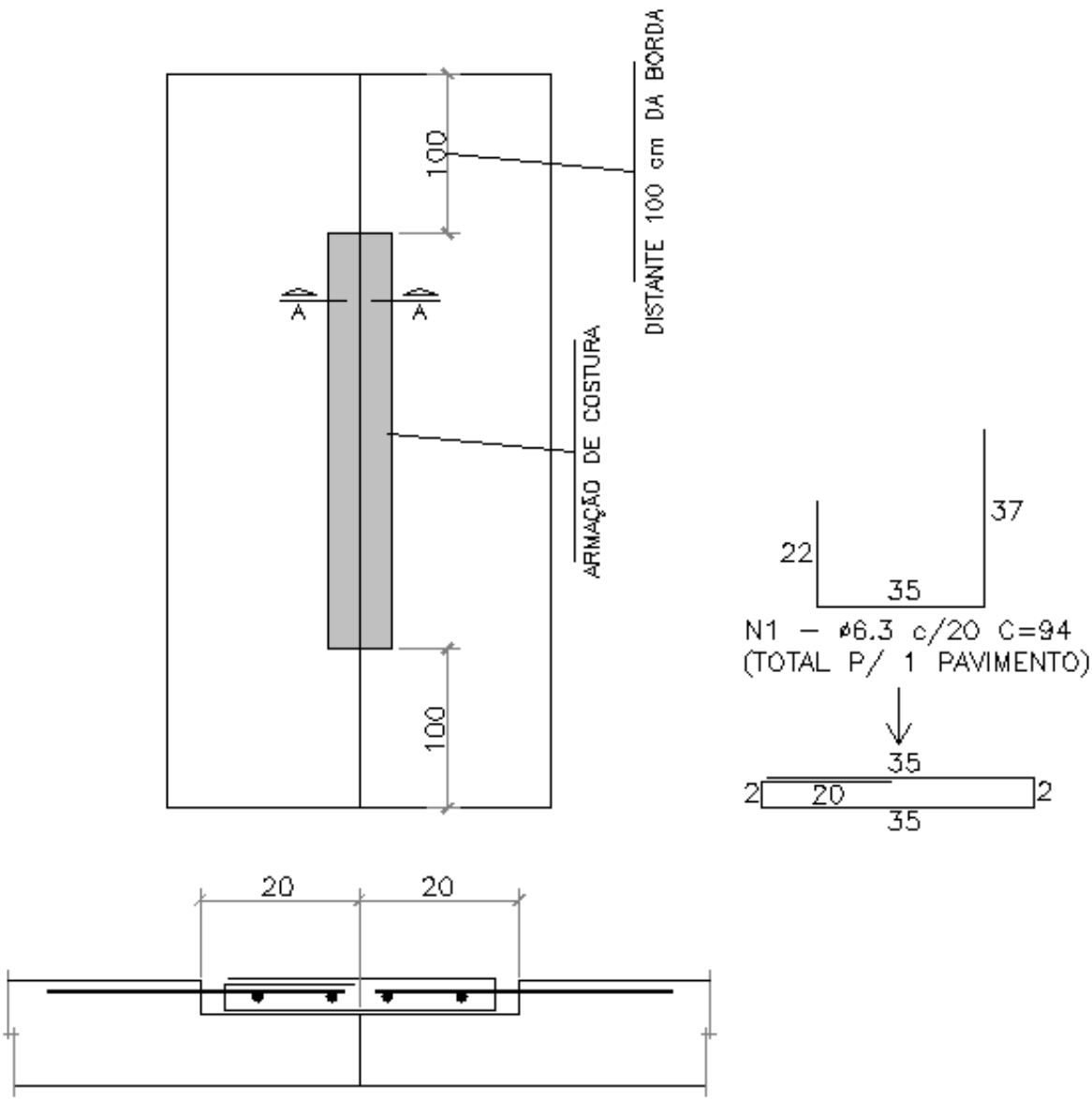

1) ENFIAR O ESTRIBO ABERTO

2) FAZER AS DUAS ULtIMAS DOBRAS

Figura 3.3: Detalhe de ligação por costura entre lajes [Adaptado: Melo (2007)]

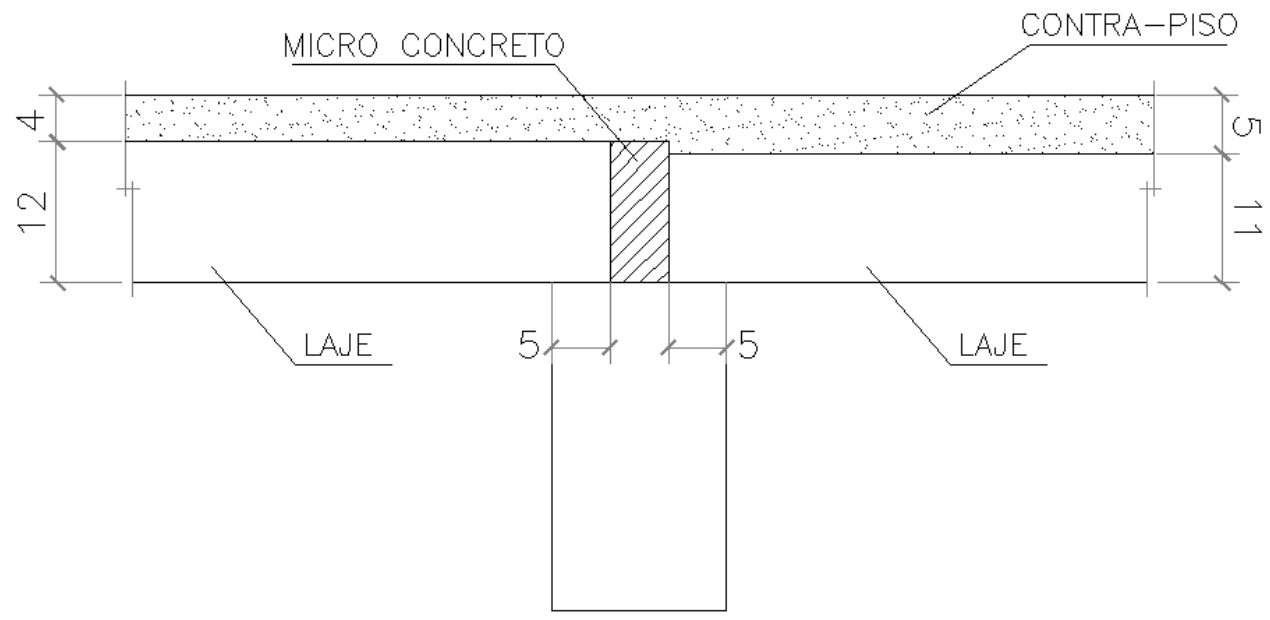

Figura 3.4: Detalhe de apoio da laje pronta maciça [Adaptado: Melo (2007)] 
As instalações elétricas e hidráulicas são embutidas nas lajes, visto que essas lajes chegam prontas à obra, sem necessidade de retrabalho. Melo (2007) recomenda que as regiões de emenda para costura das lajes devem ser utilizadas também para as emendas dos eletrodutos, o que evita detalhes adicionais na laje. Se as emendas forem posicionadas na metade da altura da laje, evitam o surgimento de fissuras na face inferior (Figura 3.5). Essas fissuras são comuns nas estruturas convencionais.
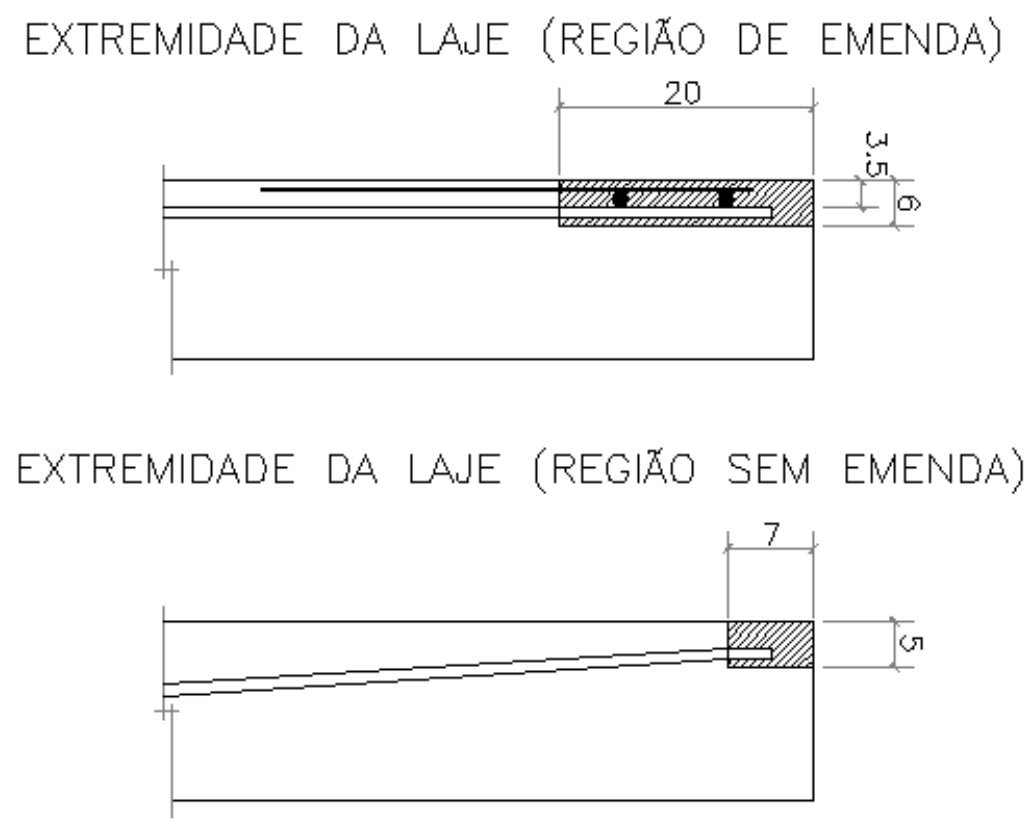

CAIXA DE LUZ E POSICIONAMENTO DE CONDUITE NA LAJE

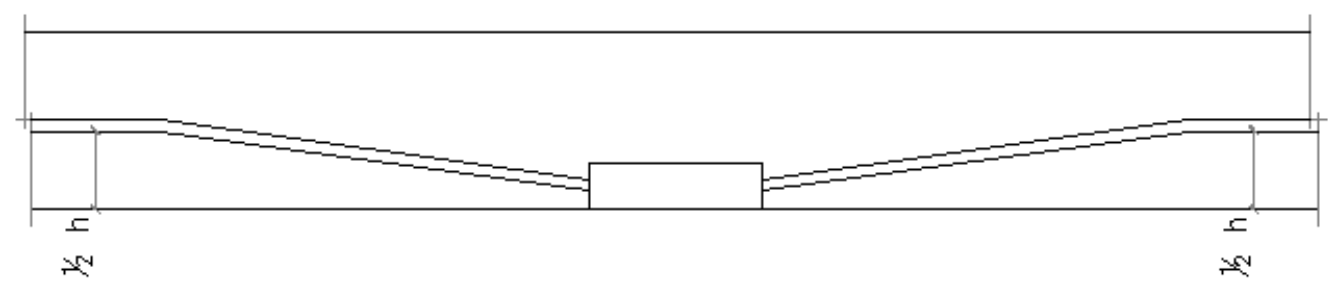

Figura 3.5: Detalhes dos materiais elétricos na laje [Adaptado: Melo (2007)]

Na Figura 3.6 apresenta-se um esquema de como se compõe o desenho das lajes prontas maciças, com os respectivos eletrodutos já posicionados, de acordo com a compatibilização prévia entre os projetos e as furações previstas para a hidráulica, já incorporadas na laje pronta maciça. A fabricação em série garante a posição correta das furações, não sendo necessários mais ajustes na obra. 


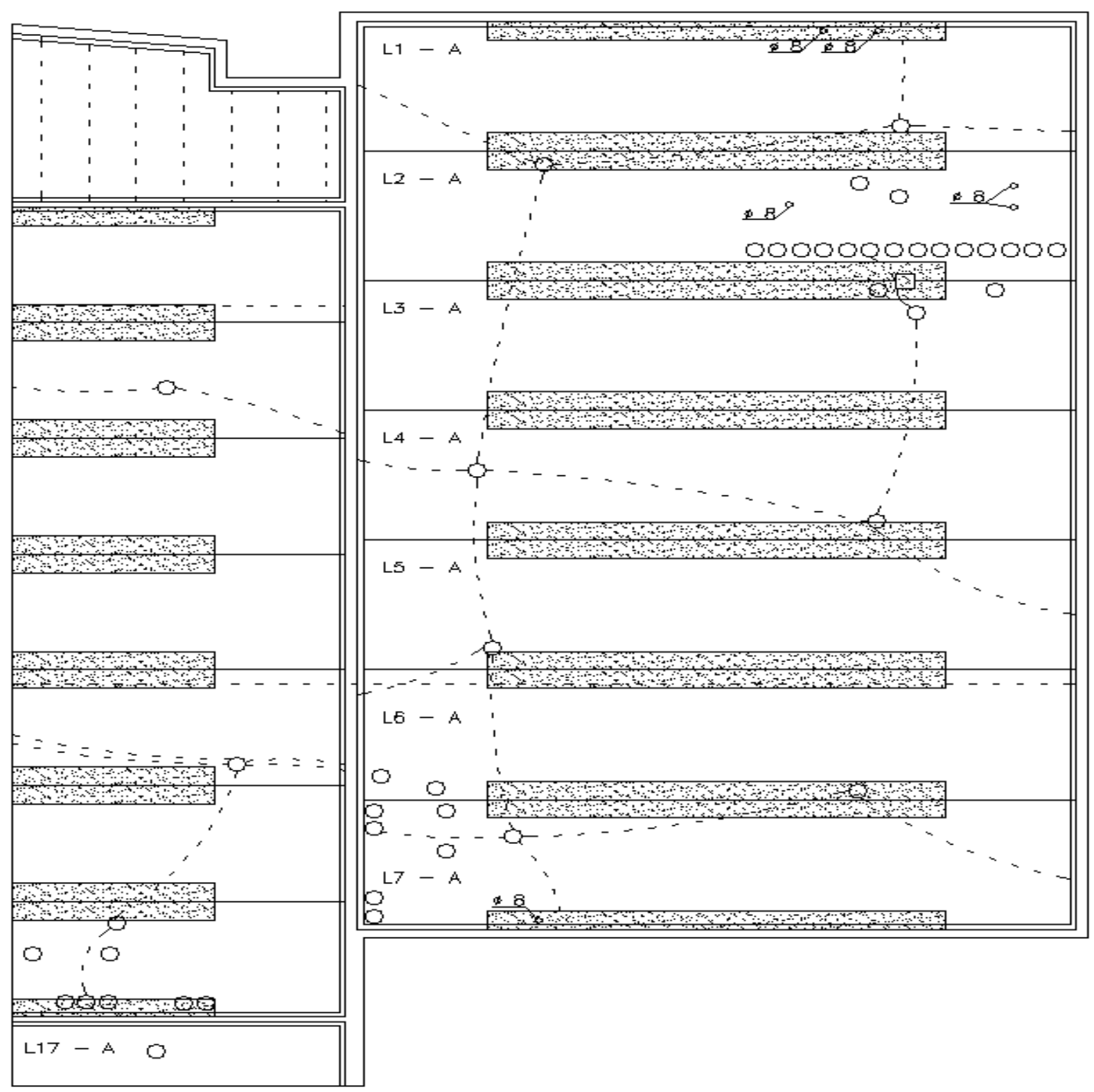

Figura 3.6: Desenho geral das lajes prontas maciças [Adaptado: Melo (2007)]

O citado autor comenta que a principal vantagem da aplicação do sistema pré-moldado em lajes maciças é a ausência de acabamento na parte inferior, o que influencia na redução dos custos envolvidos na construção.

\subsection{JUNTAS VERTICAIS}

O esforço principal nas juntas verticais é o de cisalhamento, que pode ser decorrente de uma ação horizontal no seu plano ou fora dele, o que causa flexão nos painéis (Figura 3.7 (a) e (b)), ou por diferentes valores de ações verticais entre os painéis adjacentes (Figura 3.7 (c)). 


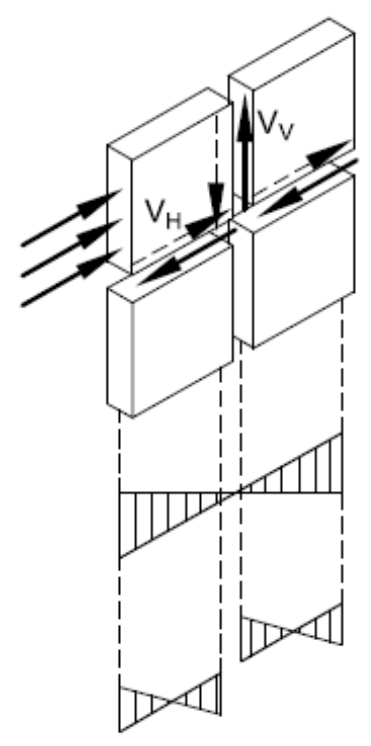

(a) Carregamento lateral no plano do painel

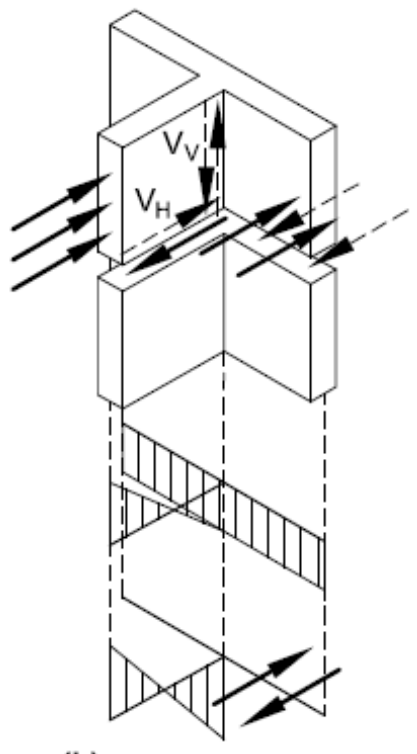

(b) Carregamento lateral fora do plano do painel

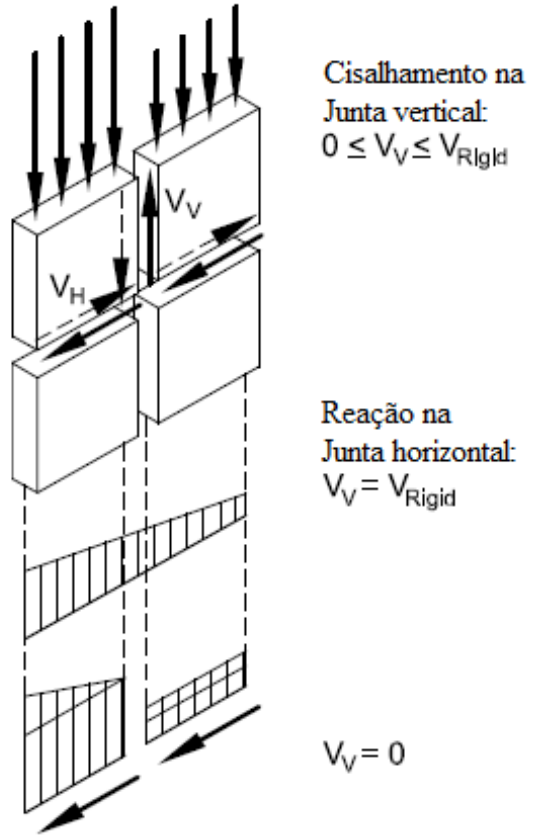

(c) Diferença de cargas gravitacionais

Figura 3.7: Juntas em estruturas de painéis portantes: a) Esforços horizontais no plano;

b) Esforços horizontais fora do plano; c) Diferença de ações verticais [Fonte: CPCI (2007)]

As juntas verticais podem ser classificadas quanto à finalidade estrutural, ou seja, com transferência de esforços ou apenas para garantir estanqueidade. De acordo com PereswietSoltan (1980), as juntas com finalidade estrutural são classificadas em juntas planas e juntas dentadas. Já para as juntas sem finalidade estrutural existem diversas classificações, dentre elas a junta de silicone.

Os selantes à base de silicone, poliuretano ou polissulfeto de baixo módulo de elasticidade são os mais recomendados para se aplicar nas juntas entre os painéis, visto que essas peças apresentam susceptibilidade a movimentações. Esses selantes são capazes de absorver os movimentos das juntas superiores a 12\% da sua largura (Klosowski, 1989).

Para o caso de juntas entre painéis que coincidem com juntas estruturais (em especial, nos casos de juntas estruturais apresentarem distância significativa entre elas), vale ressaltar que os selantes tendem a apresentar fissuras. Esse fato ocorre devido aos selantes apresentarem certa capacidade de absorção das deformações provenientes da distância entre as juntas (movimentação do painel), e não da movimentação e variação dimensional da junta (Oliveira, 2002). Por essa razão, as juntas entre os painéis, que coincidem com as juntas estruturais do edifício, são projetadas com largura maior e preenchidas com selantes de alto desempenho. 
O PCI (2007) recomenda definir as características de desempenho do selante após a definição da respectiva largura. Os elementos pré-moldados devem apresentar juntas que garantam acomodação do painel aos efeitos de dilatação térmica, assim como uma tolerância de construção e instalação adequada do selante. Essas tolerâncias devem ser rigorosamente controladas, a fim de garantir uma adequação às especificações do selante. Para os casos de juntas estreitas, com ligação mal instalada, ou uma possível falha por tração, as peças prémoldadas, nas proximidades das juntas, podem receber um carregamento inesperado, distorção, fissuras ou até mesmo fragmentação local.

A largura mínima da junta é determinada a partir do cálculo prévio das movimentações do conjunto estrutura e vedação, que possam vir a ocorrer em um determinado período, do desempenho do selante, em relação à capacidade de absorção das deformações, e também das dimensões de tolerância da montagem do painel (PCI, 2007). Nesse cálculo, pode-se considerar também o a ação de sismos e outros eventos, como apresentado na equação (3.1):

$$
J=\frac{100 A}{X}+B+C
$$

$\mathrm{J}=$ largura mínima da junta;

$\mathrm{X}=$ fator de acomodação do selante, que varia conforme o material;

$A=$ soma do montante de movimentações térmicas, de retração, de deformação

lenta e outras que ocorrem com o conjunto estrutura vedação;

$\mathrm{B}=$ tolerância de montagem do painel;

$\mathrm{C}=$ considerações de sismos ou outras eventuais ações.

Para garantir a qualidade no preenchimento das juntas e o desempenho do selante, o PCI (2007) recomenda também uma largura mínima de $19 \mathrm{~mm}$. No caso das juntas de quinas, essa largura mínima deve ser de $30 \mathrm{~mm}$, para acomodar eventuais movimentações e encurvamentos de montagem. Já para o caso das juntas de dois estágios, é sugerida largura mínima de $19 \mathrm{~mm}$, a fim de permitir a colocação do selante de $25 \mathrm{~mm}$ nas faces internas dos painéis, o que é recomendado para o isolamento deles.

A qualidade da junta pode ser avaliada a partir da relação entre a largura e a profundidade. Essa relação pode ser determinada pelo próprio fabricante do material de vedação, que seria o selante. Por outro lado, o PCI (2007) sugere algumas recomendações em relação à qualidade da junta: 
- Para juntas dimensionadas entre $19 \mathrm{~mm}$ e $25 \mathrm{~mm}$, a profundidade do selante deve ser equivalente à metade da largura. $\mathrm{O}$ material de vedação deverá apresentar forma côncava permitindo a obtenção de maior espessura nas faces dos painéis. O selante deve ter um contato mínimo de $6 \mathrm{~mm}$ com todas as superfícies de colagem, para garantir a adesão;

- Para juntas maiores que $25 \mathrm{~mm}$ de largura, a profundidade do selante deve ser limitada em $13 \mathrm{~mm}$, no máximo, sendo o valor ideal de $10 \mathrm{~mm}$. Para vedações superiores a $50 \mathrm{~mm}$, a profundidade deve ser fornecida pelo fabricante do selante.

Para a aplicação do selante nas juntas, deve-se atentar à profundidade em que o material será instalado. Dessa forma, utiliza-se um produto existente no mercado que permite delimitar essa profundidade de aplicação do selante nas juntas. Esse produto deve funcionar de maneira que não ocorra aderência com o selante.

Por outro lado, o desempenho do selante não está relacionado com a profundidade. Caso seja aplicado em excesso, as tensões sobre o selantes são amplificadas, o que acarreta em possível deslocamento prematuro das interfaces dos elementos pré-moldados. Em casos de pouco selante, não será possível acomodar as movimentações dos elementos, e assim podem ocorrer fissuras.

\subsection{JUNTAS HORIZONTAIS}

As juntas horizontais são submetidas a esforços de compressão e cisalhamento. Os esforços de compressão são provenientes de ações verticais devidas ao peso próprio da estrutura e das cargas atuantes nas lajes dos pavimentos. Os esforços de cisalhamento são devidos a vento e sismos, por exemplo.

Os esforços solicitantes das juntas submetidas à compressão podem ser obtidos por meio do Método dos Elementos Finitos (MEF) ou por relações empíricas simplificadas, resultantes do modelo de bielas e tirantes (FIB, 2008).

Em juntas horizontais submetidas à compressão, o desvio das forças de compressão originam esforços de tração que aumentam de acordo com o aumento do desvio e influenciam diretamente na resistência da junta, como mostra a Figura 3.8. 


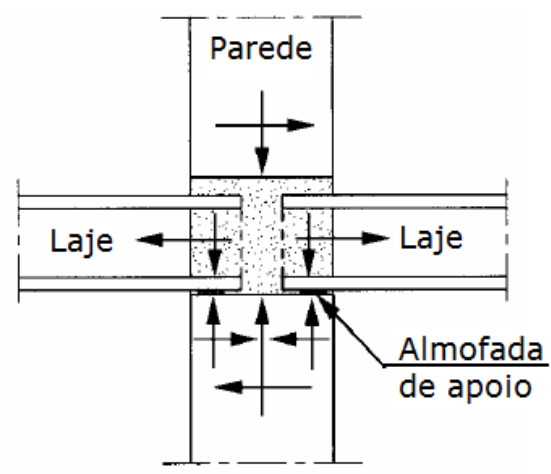

a)

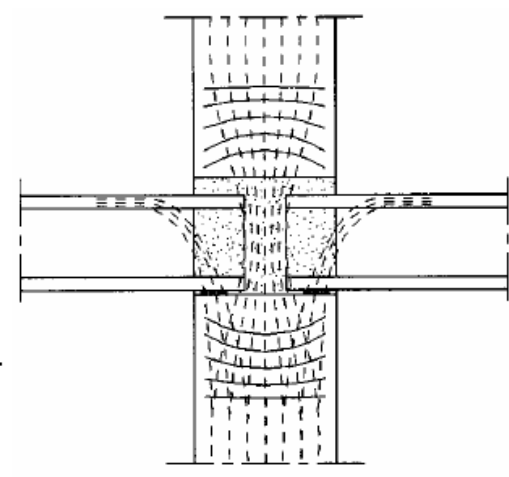

b)

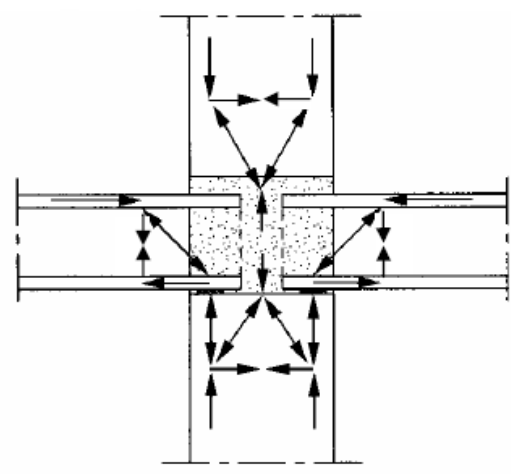

c)

Figura 3.8: Ligação parede-laje-parede: a) forças; b) análise das tensões baseada no MEF; c) modelo biela-tirante [Fonte: FIB (2008)]

A tensão de compressão do concreto $\left(\mathrm{f}_{\mathrm{cd}}{ }^{*}\right)$ deve ser limitada em quatro vezes o valor da resistência de cálculo da junta ( $\left.f_{\text {cd,junta }}\right)$, como apresentado nas equações (3.2) e (3.3) (FIB, 2008).

$$
\begin{gathered}
\mathrm{f}_{\mathrm{cd}}{ }^{*}=\mathrm{f}_{\mathrm{cd} \text {,junta }} \cdot \sqrt{\mathrm{A}_{2} / \mathrm{A}_{1}} \leq 4,0 \cdot \mathrm{f}_{\mathrm{cd} \text {,junta }} \\
\mathrm{N}_{\mathrm{Rd}}=\mathrm{f}_{\mathrm{cd}^{*}} \cdot \mathrm{A}_{1} \leq 4,0 \mathrm{f}_{\mathrm{cd} \text {,junta }} \cdot \mathrm{A}_{1}
\end{gathered}
$$

$\mathrm{N}_{\mathrm{Rd}}=$ valor de cálculo da força normal resistente de compressão;

$\mathrm{A}_{1}=$ área de apoio $\left(\mathrm{a}_{1} \cdot \mathrm{b}_{1}\right)$;

$\mathrm{A}_{2}=$ projeção da área de apoio devido ao espraiamento de tensões $\left(\mathrm{a}_{2} \cdot \mathrm{b}_{2}\right)$.

A Figura 3.9 apresenta a metodologia para determinar as dimensões nas seguintes situações: a) distante da borda de concreto; b) próximo à borda de concreto; c) próximo a outro carregamento.

Vale ressaltar que o espraiamento das tensões, apresentado na Figura 3.9, ocorre em uma proporção de 2:1 nas três situações, o que possibilita obter de forma simples o valor da área de apoio $\mathrm{A}_{2}$.

A FIB (2008) recomenda, ainda, dimensionar a junta horizontal sob esforço de compressão pelas equações (3.4) a (3.6), nas quais o valor de $\beta$ é determinado pelo diagrama apresentado na Figura 3.11. Os parâmetros utilizados para determinação do valor de $\beta$ e da resistência de cálculo da junta são apresentados na Figura 3.10. 


$$
\begin{gathered}
\mathrm{f}_{\mathrm{cd} \text {,junta }}=\beta \cdot \mathrm{f}_{\mathrm{cd} \text {,painel }} \\
\beta_{0}=\mathrm{f}_{\mathrm{cd} \text {,argam. }} / \mathrm{f}_{\mathrm{cd} \text {,painel }} \\
\beta=\mathrm{f}_{\mathrm{cd} \text {,junta }} / \mathrm{f}_{\mathrm{cd} \text {,painel }}
\end{gathered}
$$

$\mathrm{f}_{\mathrm{cd} \text {,painel }}=$ resistência de cálculo do concreto do painel à compressão;

$\mathrm{f}_{\mathrm{cd}, \text { argam. }}=$ resistência de cálculo da argamassa à compressão;

$\mathrm{t}=$ espessura da argamassa.

a)

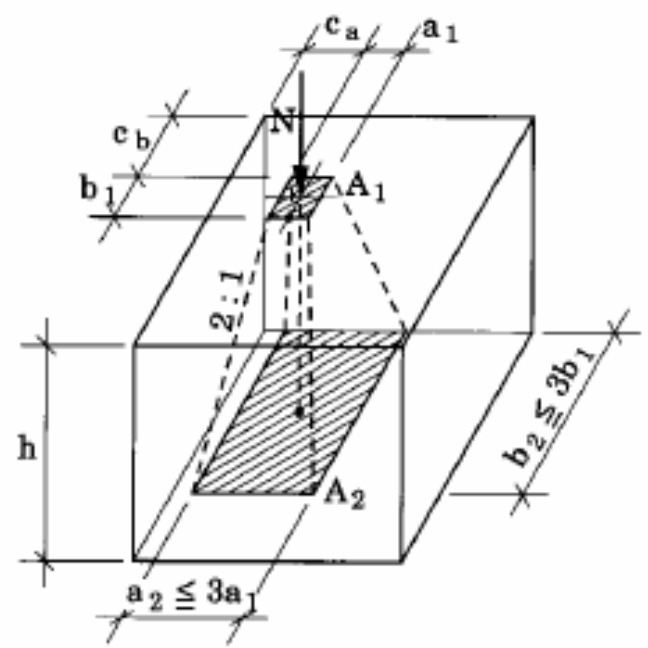

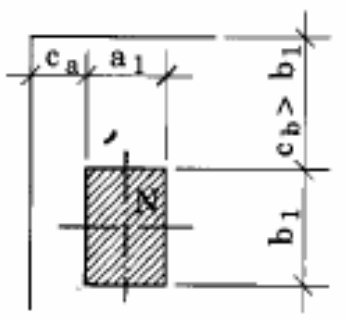

b)

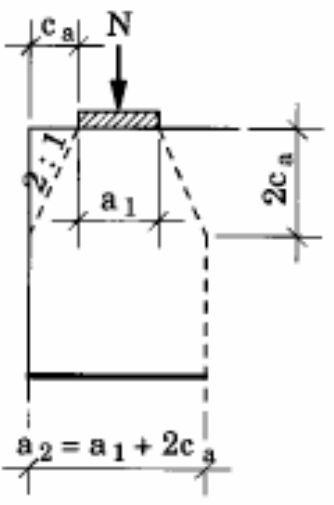

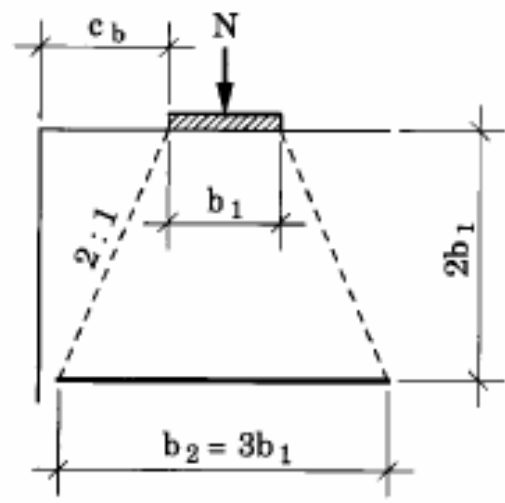

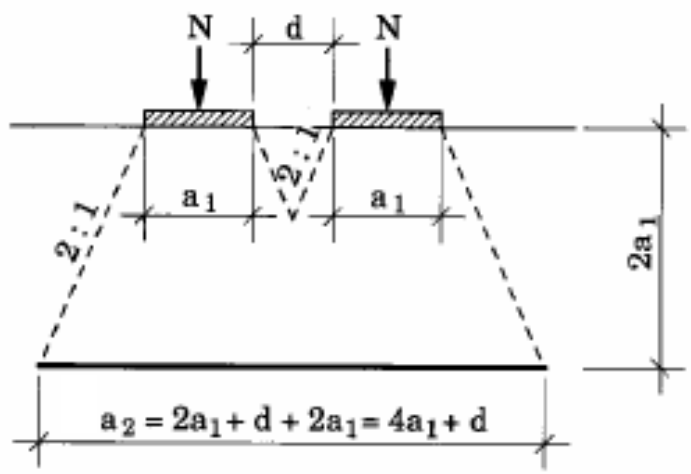

c)

Figura 3.9: Espraiamento das tensões de compressão: a) distante da borda de concreto; b) próximo à borda de concreto; c) próximo a outro carregamento [Fonte: FIB (2008)] 


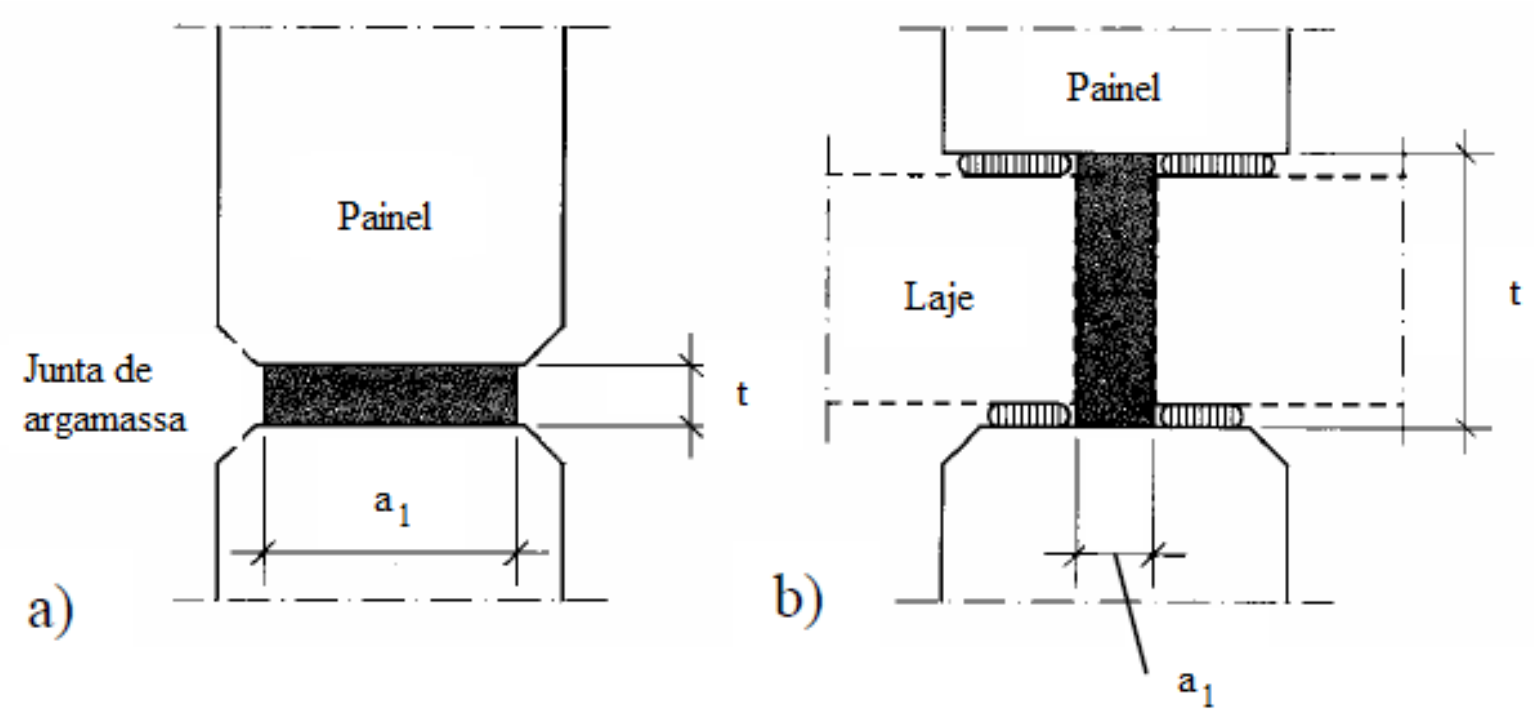

Figura 3.10: Geometria das juntas horizontais: a) Parede-parede; b) Parede-laje-parede.

[Adaptado: FIB (2008)]

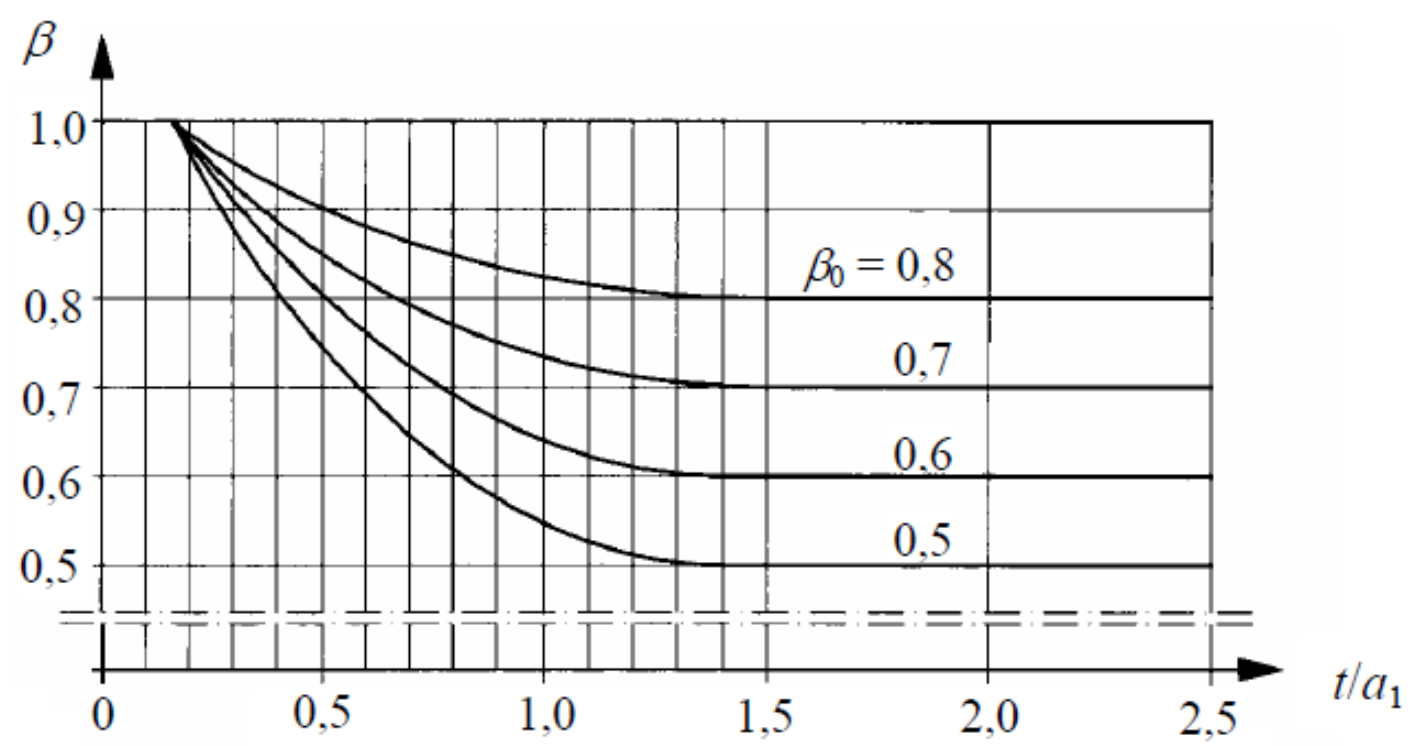

Figura 3.11: Diagrama da geometria e resistência da junta [Fonte: FIB (2008)]

O dimensionamento das armaduras para resistência das tensões de tração laterais podem ser determinados pelas equações simplificadas sugeridas no Eurocode 2. Para a verificação da armadura, o critério utilizado leva em consideração a magnitude da força de compressão $(\mathrm{N})$ e a espessura do painel (h), com base nas condições:

- $\mathrm{N} \leq 0,5 \mathrm{~h} \cdot \mathrm{f}_{\mathrm{cd}}$, não há necessidade de armaduras;

$-0,5 \mathrm{~h} \cdot \mathrm{f}_{\mathrm{cd}}<N \leq 0,6 h \cdot \mathrm{f}_{\mathrm{cd}}$, usar armadura conforme a Figura $3.12 \mathrm{com} \phi \geq 6 \mathrm{~mm} \mathrm{e}$ espaçamento (s) igual ao menor entre a espessura do painel (h) ou $200 \mathrm{~mm}$. 

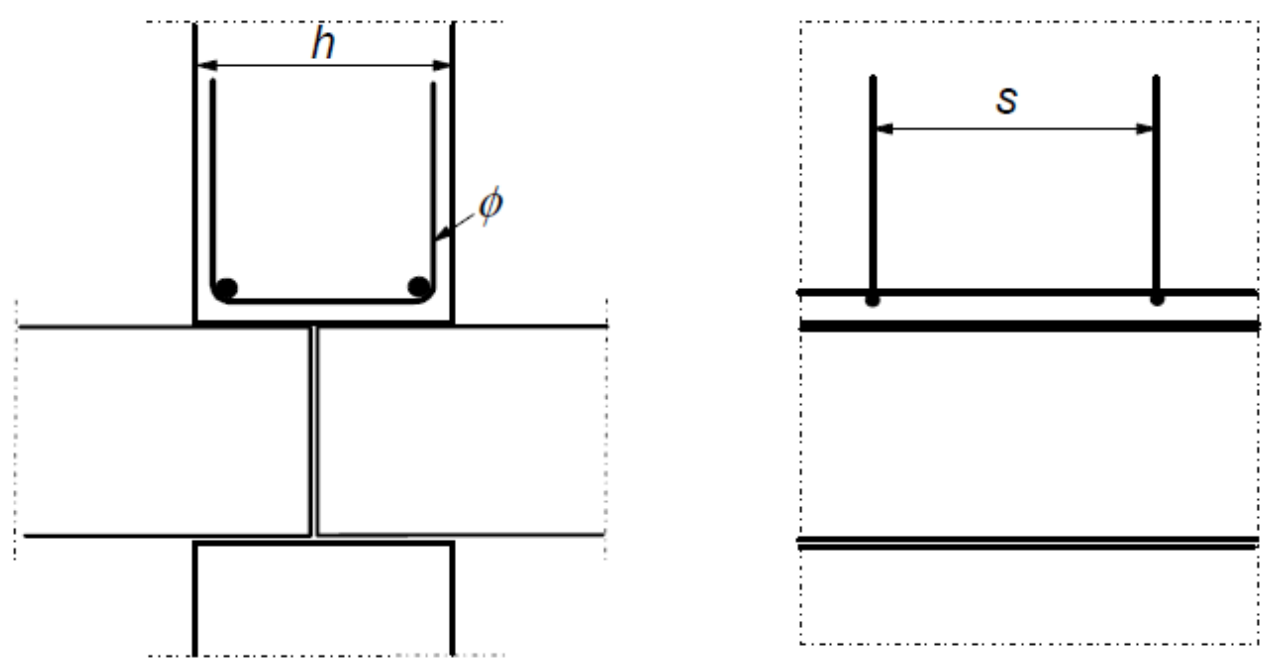

Figura 3.12: Reforço no painel sobre duas lajes de piso (Fonte: Eurocode 2)

Para esforços de compressão superiores aos limites estabelecidos no parágrafo anterior, o dimensionamento da armadura deve levar em consideração a resistência à tração, que pode ser obtida pela equação (3.7):

$$
\mathrm{T}_{\mathrm{s} 1}=0,25 \cdot \mathrm{N} \cdot\left[\left(1-\mathrm{a}_{1}\right) / \mathrm{a}_{2}\right]
$$

Os valores de $\mathrm{a}_{1}$ e $\mathrm{a}_{2}$ são determinados conforme indicado na Figura 3.9.

Nos casos em que ocorre excentricidade da força de compressão, uma parcela adicional $\left(\mathrm{T}_{\mathrm{s} 2}\right)$ é incorporada aos esforços, sendo ela dada por:

$$
\mathrm{T}_{\mathrm{s} 2}=0,015 \cdot \mathrm{N}\left[1-(2 \mathrm{e} / \mathrm{h})^{1 / 2}\right]
$$

Nesta equação, e é a excentricidade do carregamento.

Assim sendo, o esforço de tração solicitante final $\left(\mathrm{T}_{\mathrm{s}}\right)$ é determinado pela soma das parcelas $\mathrm{T}_{\mathrm{s} 1}$ e $\mathrm{T}_{\mathrm{s} 2}$ :

$$
\mathrm{T}_{\mathrm{s}}=\mathrm{T}_{\mathrm{s} 1}+\mathrm{T}_{\mathrm{s} 2}
$$

Com o valor do esforço de tração solicitante final determinado, encontra-se a armadura necessária através da equação (3.10):

$$
A_{s} \geq T_{s} / f_{y d}
$$

em que $\mathrm{f}_{\mathrm{yd}}$ é a resistência de cálculo da armadura à tração. 


\subsection{FASE TRANSITÓRIA}

A fase transitória compreende desmoldagem, içamento, transporte e montagem das peças, ou seja, situações que antecedem a disposição final.

Nessas fases, os painéis pré-moldados são submetidos a diferentes tipos de esforços que merecem uma atenção especial, sendo necessária a verificação da perfeita funcionalidade do elemento.

De acordo com as recomendações normativas do PCI (2010), para os elementos de concreto dimensionados contra fissura, que se encontram na fase transitória, o módulo de ruptura do concreto $\left(\mathrm{f}_{\mathrm{r}}\right)$ deve ser dividido por um fator de segurança igual a 1,5. Além disso, deve-se também corrigir a unidade de tensão psi (Sistema Imperial) para MPa, multiplicando-se por 0,083, como mostra e equação (3.11):

$$
\mathrm{f}_{\mathrm{r}}=\frac{0,083 \cdot 7,5 \lambda \sqrt{\mathrm{f}^{\prime}{ }_{\mathrm{c}}}}{1,5}=0,415 \cdot \lambda \sqrt{\mathrm{f}^{\prime}{ }_{\mathrm{c}}}(\mathrm{MPa})
$$

$\lambda=$ fator de redução das propriedades mecânicas do concreto;

$\mathrm{f}^{\prime}{ }_{\mathrm{c}}=$ resistência à compressão do concreto $(\mathrm{MPa})$.

Os coeficientes devidos à desmoldagem e ações dinâmicas que devem ser considerados nos painéis pré-moldados, para a fase transitória, são apresentados na Tabela 3.1.

Tabela 3.1: Coeficientes de multiplicação para desmoldagem e ações dinâmicas

[Adaptado: PCI (2010)]

\begin{tabular}{|c|c|c|}
\hline \multirow{2}{*}{ Tipo do produto } & \multicolumn{2}{|c|}{ Acabamento } \\
\cline { 2 - 3 } & $\begin{array}{c}\text { Agregado exposto com } \\
\text { retardador }\end{array}$ & $\begin{array}{c}\text { Molde liso (apenas } \\
\text { desmoldante) }\end{array}$ \\
\hline $\begin{array}{c}\text { Plano, com lateral } \\
\text { removível }\end{array}$ & 1,2 & 1,3 \\
\hline Plano & 1,3 & 1,4 \\
\hline Fôrma com inclinação & 1,4 & 1,6 \\
\hline Fôrma especial & 1,5 & 1,7 \\
\hline \multicolumn{2}{|c|}{1,2} \\
\hline Todos os produtos & Manuseio e montagem \\
\hline \multicolumn{2}{|c|}{1,5} \\
\hline Todos os produtos & Transporte \\
\hline
\end{tabular}




\subsubsection{Desmoldagem}

Os painéis pré-moldados podem ser confeccionados tanto na posição vertical, em baterias verticais, quanto na horizontal, em mesas horizontais.

A produção em baterias verticais apresenta um custo mais elevado, porém, os painéis, após confecção, já se encontram na posição vertical, ou seja, nesse tipo de produção, o painel é finalizado na posição correta, o que evita o surgimento de esforços adicionais nessa etapa transitória de desmoldagem.

Na confecção em mesa horizontal, o processo é mais econômico. No entanto, surgem esforços de sucção devidos ao processo de desmoldagem do painel.

Esses esforços devem ser corrigidos por coeficiente que levam em consideração o tipo de fôrma utilizada e o tipo de desmoldante, como mostra a Tabela 3.1.

As situações de desmoldagem para painéis pré-moldados, para confecção em mesa horizontal, são apresentadas no PCI (2007).

É possível observar desmoldagens dos seguintes tipos: dois pontos de içamento pela borda superior; quatro pontos de içamento pela borda superior; quatro pontos de içamento pela superfície; e oito pontos de içamento pela superfície.

A desmoldagem do painel por meio de dois pontos de içamento na borda superior acarreta no surgimento de esforços que dependem do posicionamento dos pontos em que a peça será içada (Figura 3.13).

O PCI (2010) determina que o esforço $\mathrm{M}_{\mathrm{y}}$ deve ser resistido pela seção com largura de a/2. Os esforços solicitantes são dados pelas equações:

$$
\begin{gathered}
M_{x}=\frac{\mathrm{qa}^{2}}{8}(\mathrm{kN} \cdot \mathrm{m} / \mathrm{m}) \\
-\mathrm{M}_{\mathrm{y}}=+\mathrm{M}_{\mathrm{y}}=0,0107 \mathrm{qab}^{2}(\mathrm{kN} . \mathrm{m})
\end{gathered}
$$

$\mathrm{q}=$ peso do painel por unidade de área $\left(\mathrm{kN} / \mathrm{m}^{2}\right)$;

$\mathrm{a}=$ altura do painel $(\mathrm{m})$;

$\mathrm{b}=$ comprimento do painel $(\mathrm{m})$. 


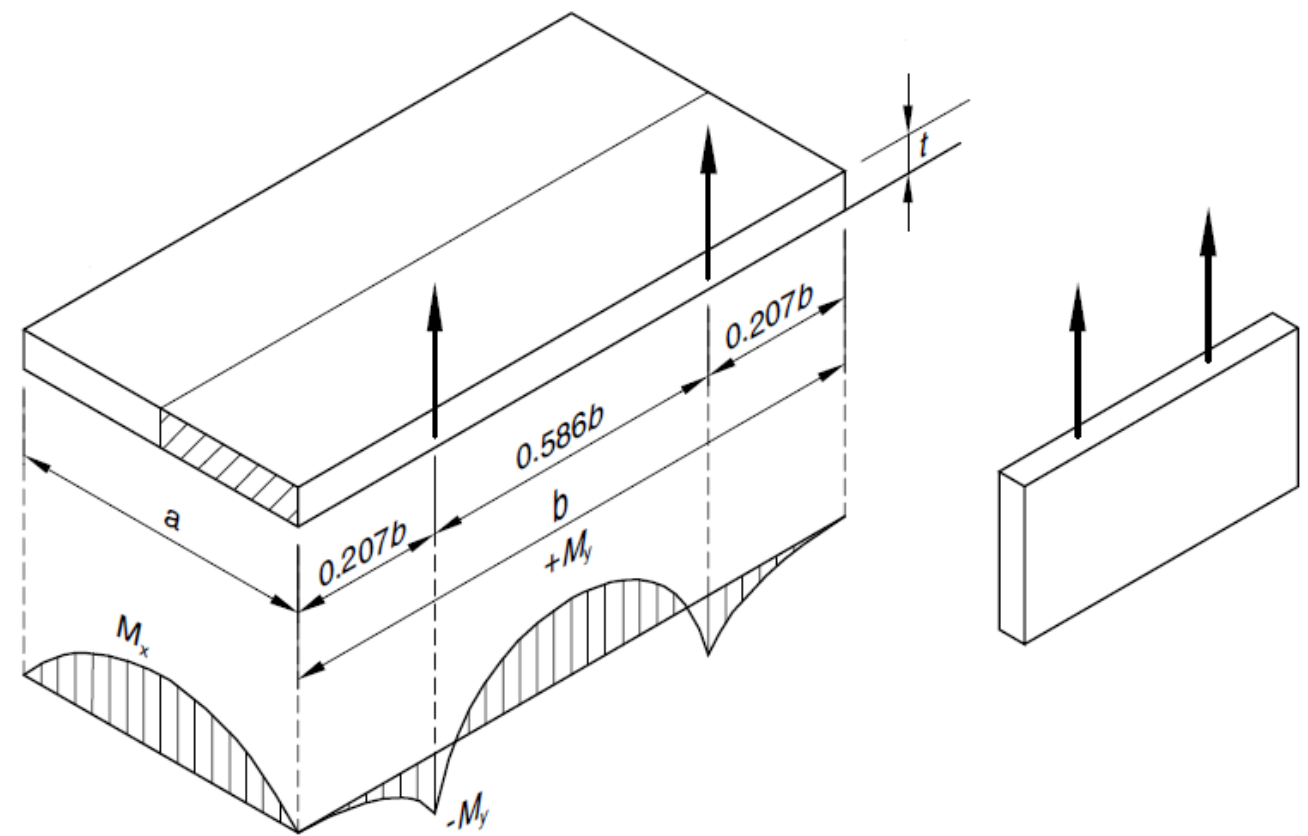

Figura 3.13: Desmoldagem de painéis através de dois pontos na borda superior e diagramas de momentos fletores [Adaptado: PCI (2010)]

$\mathrm{Na}$ desmoldagem do painel por meio de quatro pontos de içamento na borda superior surgem os esforços indicados na Figura 3.14, que dependem do posicionamento dos pontos em que a peça será içada, de modo semelhante ao mostrado na Figura 3.13.
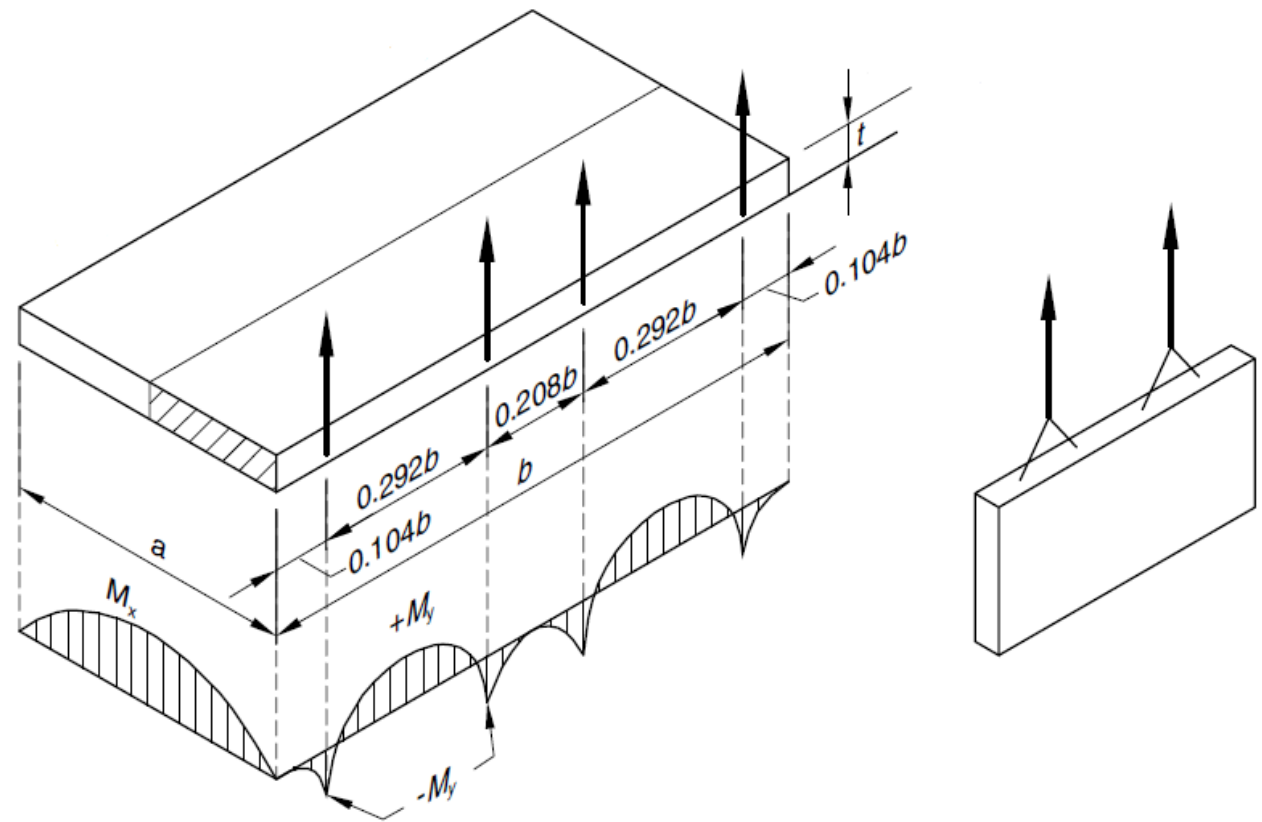

Figura 3.14: Desmoldagem de painéis através de quatro pontos na borda superior e diagramas de momentos fletores [Adaptado: PCI (2010)] 
O PCI (2010) determina que o esforço $\mathrm{M}_{\mathrm{y}}$ deve ser resistido pela seção com largura de $\mathrm{a} / 2$, assim como nos içamento de dois pontos pela borda superior. Os esforços solicitantes são apresentados através das equações que seguem:

$$
\begin{gathered}
\mathrm{M}_{\mathrm{x}}=\frac{\mathrm{qa}^{2}}{8}(\mathrm{kN} \cdot \mathrm{m} / \mathrm{m}) \\
-\mathrm{M}_{\mathrm{y}}=+\mathrm{M}_{\mathrm{y}}=0,0027 \mathrm{qab}^{2}(\mathrm{kN} . \mathrm{m})
\end{gathered}
$$

A desmoldagem do painel por meio de quatro pontos de içamento na superfície promove o surgimento de esforços que dependem do posicionamento dos pontos em que a peça será içada (Figura 3.15).
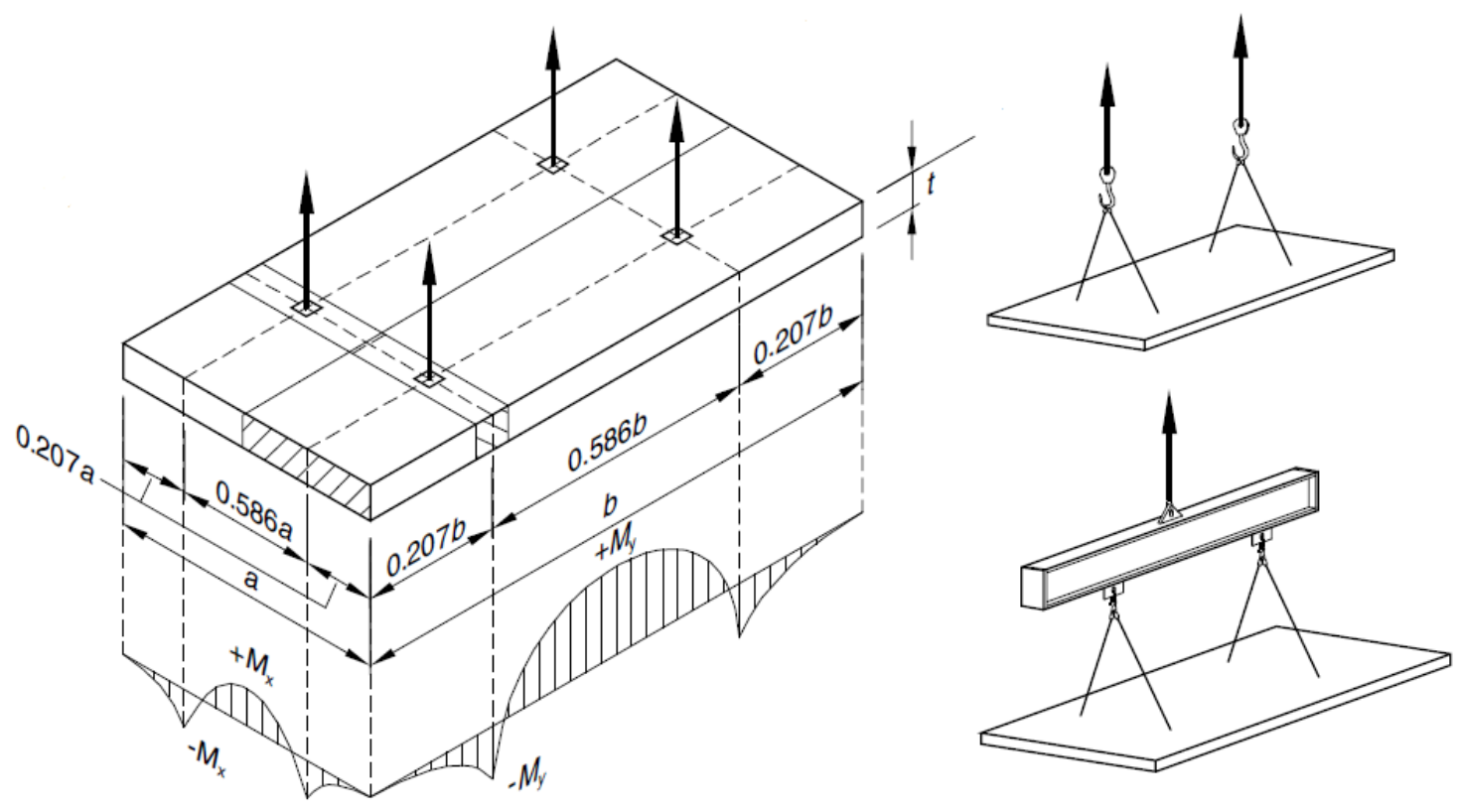

Figura 3.15: Desmoldagem de painéis através de quatro pontos na superfície e diagramas de momentos fletores [Adaptado: PCI (2010)]

O PCI (2010) determina que o esforço $M_{x}$ deve ser resistido pela seção com largura igual ao menor valor entre $15 \mathrm{t}$ e b/2, onde $t$ é a espessura do painel. Já o esforço $\mathrm{M}_{\mathrm{y}}$ deve ser resistido pela seção com largura a/2. Os esforços solicitantes são dados pelas equações:

$$
\begin{aligned}
& +\mathrm{M}_{\mathrm{x}}=-\mathrm{M}_{\mathrm{x}}=0,0107 \mathrm{qa}^{2} \mathrm{~b}(\mathrm{kN} . \mathrm{m}) \\
& +\mathrm{M}_{\mathrm{y}}=-\mathrm{M}_{\mathrm{y}}=0,0107 \mathrm{qab}{ }^{2}(\mathrm{kN} . \mathrm{m})
\end{aligned}
$$


A desmoldagem do painel em oito pontos de içamento na superfície promove o surgimento de esforços que dependem do posicionamento dos pontos em que a peça será içada (Figura 3.16).
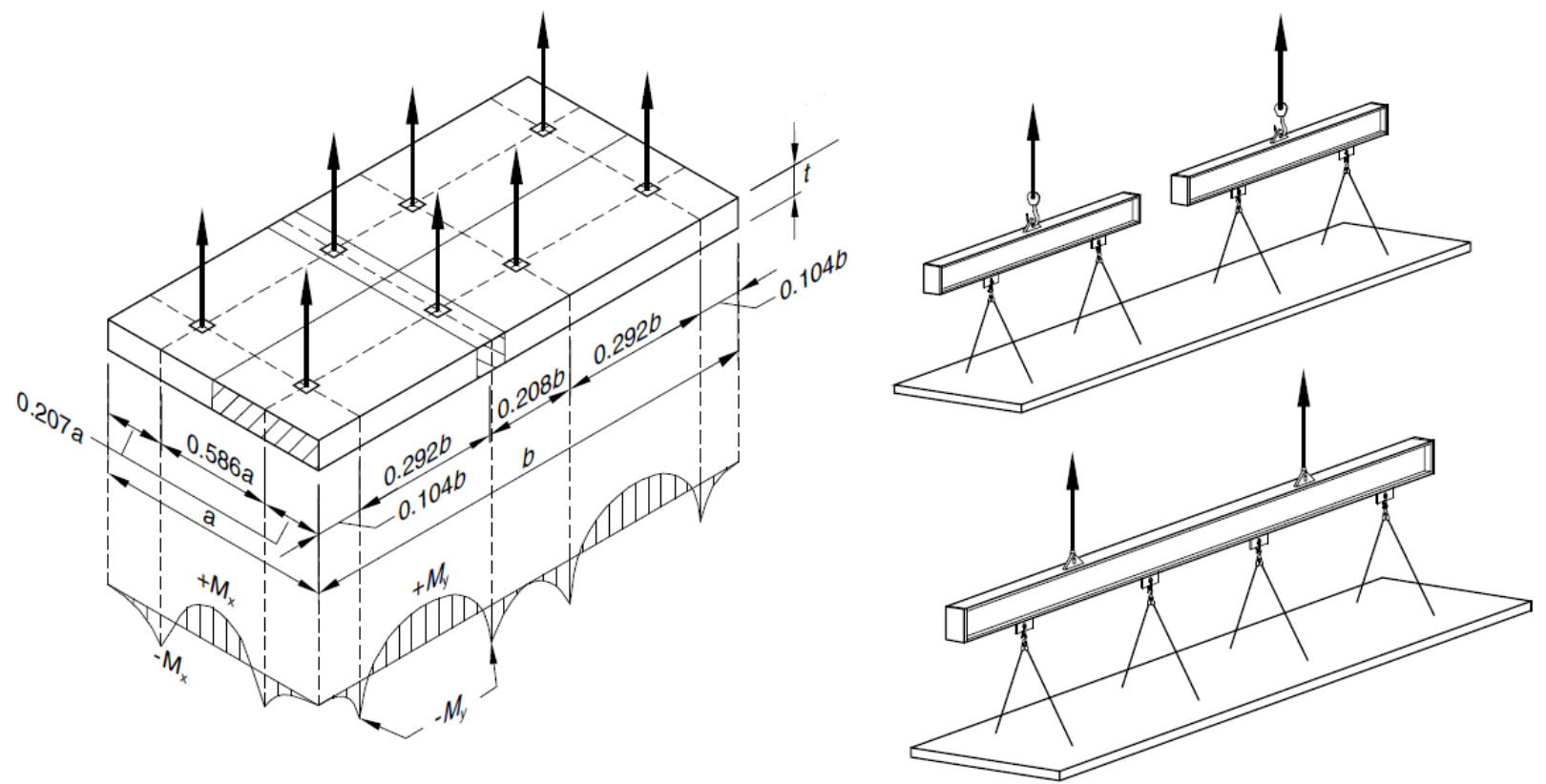

Figura 3.16: Desmoldagem de painéis através de oito pontos na superfície e diagramas de momentos fletores [Adaptado: PCI (2010)]

O PCI (2010) determina que o esforço $M_{x}$ deve ser resistido pela seção de largura igual ao menor valor entre $15 t$ e b/4. Já o esforço $\mathrm{M}_{\mathrm{y}}$ deve ser resistido pela seção com largura a/2. Os esforços solicitantes são dados pelas seguintes equações:

$$
\begin{aligned}
& +\mathrm{M}_{\mathrm{x}}=-\mathrm{M}_{\mathrm{x}}=0,0054 q \mathrm{q}^{2} \mathrm{~b}(\mathrm{kN} . \mathrm{m}) \\
& +\mathrm{M}_{\mathrm{y}}=-\mathrm{M}_{\mathrm{y}}=0,0027 q a b^{2}(\mathrm{kN} . \mathrm{m})
\end{aligned}
$$

\subsubsection{Transporte}

O transporte rodoviário utilizado para conduzir os elementos pré-moldados da fábrica até o local de montagem pode promover ações dinâmicas, comprometendo os elementos.

Essa ação dinâmica é considerada no cálculo do painel multiplicando-se o peso da peça pelo coeficiente mostrado na Tabela 3.1 (El Debs, 2000). 
Também de acordo com El Debs (2000), para efeito de projeto, devem ser consideradas as limitações impostas nas rodovias brasileiras, no que diz respeito aos gabaritos, comprimento e peso dos elementos. Os gabaritos devem ser inseridos em um intervalo de 2,6 $\mathrm{m}$ de largura e 4,4 $\mathrm{m}$ de altura. O comprimento do elemento para transporte pode ser de até $30 \mathrm{~m}$, e dependendo da localidade essa limitação pode cair para $20 \mathrm{~m}$. Quanto ao peso, deve ser limitado pelas cargas por eixo impostas pela "lei da balança", como apresenta a Tabela 3.2.

Tabela 3.2: Valores das máximas cargas por eixo permitidas nas rodovias nacionais [Adaptado: http://www.dnit.gov.br/rodovias/operacoes-rodoviarias/pesagem/qfv-2012abril.pdf, acesso em: 05/11/2012]

\begin{tabular}{|c|c|c|c|c|}
\hline $\begin{array}{c}\text { EIXO ou } \\
\text { CONJUNTOS } \\
\text { DE EIXOS }\end{array}$ & RODAGEM & SUSPENSÃO & $\begin{array}{c}\text { ENTRE-EIXOS } \\
(\mathbf{m})\end{array}$ & $\begin{array}{c}\text { CARGA } \\
(\mathbf{k g})\end{array}$ \\
\hline Isolado & simples & direcional & - & 6.000 \\
\hline Isolado & simples & direcional & - & 6.000 \\
\hline Isolado & dupla & - & - & 10.000 \\
\hline Duplo & simples & direcional & - & 12.000 \\
\hline Duplo & dupla & tandem & $>1,20 \mathrm{ou} \leq 2,40$ & 17.000 \\
\hline Duplo & dupla & não em tandem & $>1,20 \mathrm{ou} \leq 2,40$ & 15.000 \\
\hline Duplo & simples+dupla & especial & $<1,20$ & 9.000 \\
\hline Duplo & simples+dupla & especial & $>1,20 \mathrm{ou} \leq 2,40$ & 13.500 \\
\hline Duplo & Extralarga & pneumática & $>1,20 \mathrm{ou} \leq 2,40$ & 17.000 \\
\hline Triplo & dupla & tandem & $>1,20 \mathrm{ou} \leq 2,40$ & 25.500 \\
\hline Triplo & Extralarga & pneumática & $>1,20 \mathrm{ou} \leq 2,40$ & 25.500 \\
\hline
\end{tabular}

A Figura 3.17 ilustra o transporte de um painel por meio de duas linhas de apoio e o respectivo diagrama de momento fletor. Neste caso, é interessante determinar o momento fletor de maneira que os momentos negativos e positivos possuam igual magnitude.

O momento fletor é determinado pela equação a seguir, levando em consideração as variáveis apresentadas na Figura 3.17:

$$
\mathrm{M}_{1}=-\mathrm{M}_{2}=0,0107 \mathrm{qab}^{2}(\mathrm{kN} . \mathrm{m})
$$

$\mathrm{q}=$ peso do painel por unidade de área $\left(\mathrm{kN} / \mathrm{m}^{2}\right)$;

$\mathrm{a}=$ altura do painel $(\mathrm{m})$;

$\mathrm{b}=$ comprimento do painel (m). 


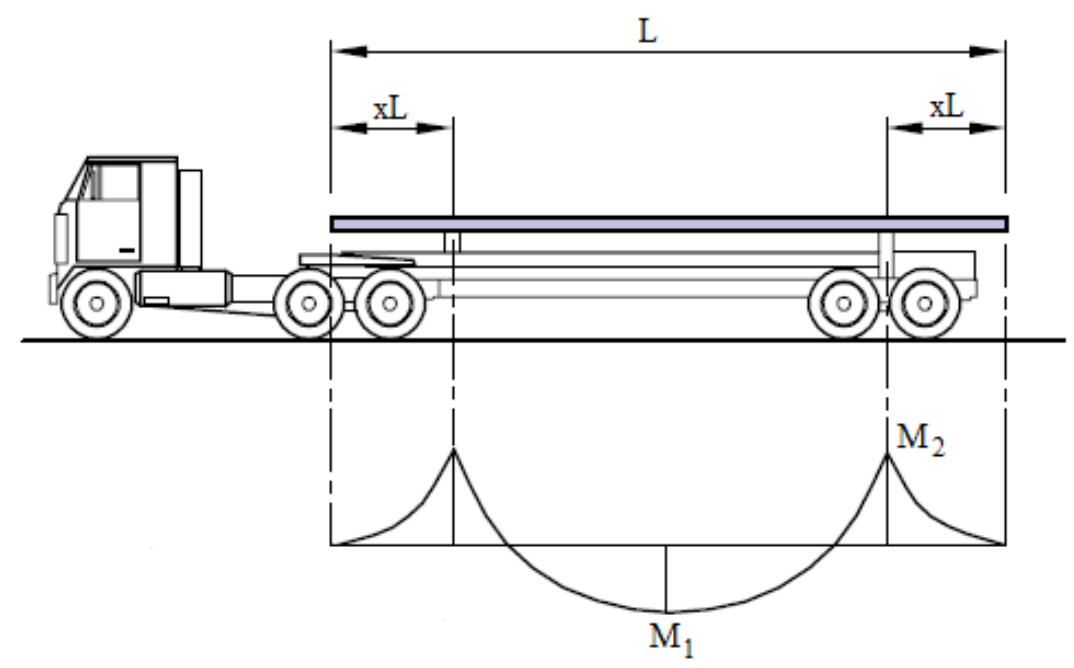

Figura 3.17: Transporte de painel pré-moldado [Adaptado: PCI (2010)]

Para os painéis que são transportados na vertical, com a utilização dos cavaletes, não são provocados esforços adicionais nos painéis, pois eles já se encontram na posição para a qual foram dimensionados.

Na determinação da carga por eixo do transporte, deve-se somar o peso dos painéis ao peso próprio do transporte, e dividir pelo número de eixos.

\subsubsection{Içamento}

No canteiro de obra, os painéis podem ser dispostos na posição vertical e na posição horizontal. Em sua grande maioria, os painéis são encontrados na posição horizontal, por facilidade de estocagem e transporte.

O PCI (2010) apresenta situações de içamento para painéis pré-moldados dispostos na posição horizontal por meio de dois pontos e também de três pontos.

Para a situação em que o içamento for feito por meio de dois pontos (Figura 3.18), utiliza-se as seguintes expressões para igualar os momentos positivos com os negativos:

$$
-\mathrm{M}=+\mathrm{M}=0,044 \mathrm{qL}^{2}(\mathrm{kN} . \mathrm{m} / \mathrm{m})
$$

$\mathrm{q}=$ peso do painel por unidade de área $\left(\mathrm{kN} / \mathrm{m}^{2}\right)$;

$\mathrm{L}=$ comprimento do painel (m). 


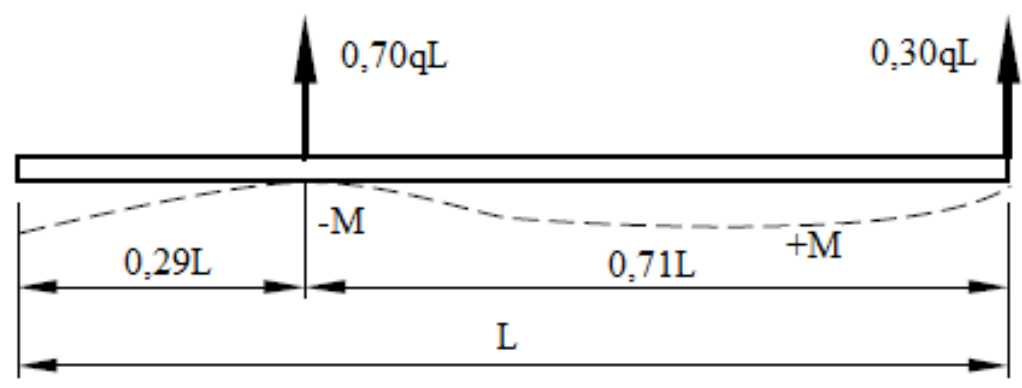

Figura 3.18: Içamento através de dois pontos de rotação [Adaptado: PCI (2010)]

Na situação em que o içamento ocorre por meio de três pontos (Figura 3.19), utilizam-se as equações (3.22) e (3.23) para determinação dos momentos máximos negativos e positivos:

$$
\begin{aligned}
-\mathrm{M}_{\text {máx. }} & =-0,005 \mathrm{qL}^{2}(\mathrm{kN} . \mathrm{m} / \mathrm{m}) \\
+\mathrm{M}_{\text {máx. }} & =0,041 \mathrm{qL}^{2}(\mathrm{kN} . \mathrm{m} / \mathrm{m})
\end{aligned}
$$

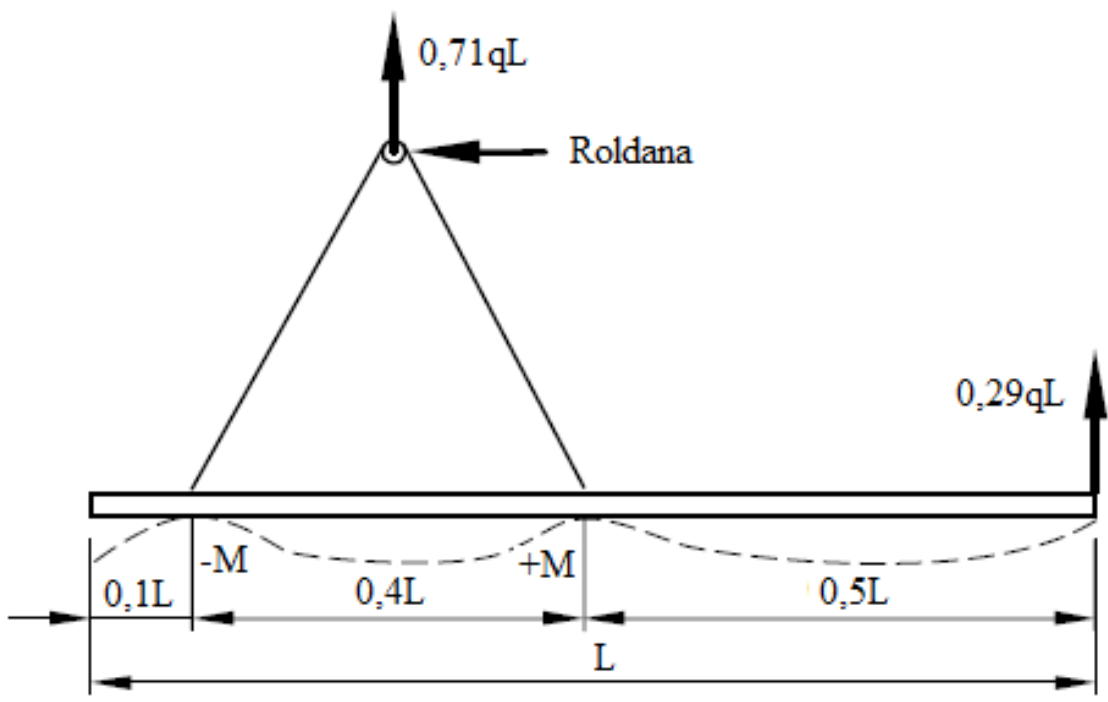

Figura 3.19: Içamento através de três pontos de rotação [Adaptado: PCI (2010)] 


\section{PROJETO DE PAINÉIS PRÉ-MOLDADOS}

O dimensionamento dos painéis pré-moldados é uma etapa que requer atenção na escolha do modelo adotado para representar com acurácia o que irá ocorrer na prática. No projeto de painéis pré-moldados, deve-se ter uma definição prévia das excentricidades envolvidas, para determinar os esforços de segunda ordem que ocorrem nos painéis. Também se devem levar em conta nos projetos de elementos pré-moldados as considerações relativas ao colapso progressivo.

\subsection{MODELO DE ASSOCIAÇÃO DE PÓRTICOS PLANOS}

As equações da resistência dos materiais permitem determinar o deslocamento no topo de uma barra isolada, por meio da rigidez (EI), como mostra a Figura 4.1. Para determinação da linha elástica da barra tem-se:

$$
\mathrm{EI}=\frac{\mathrm{qH}^{4}}{8 \mathrm{a}}
$$

$\mathrm{E}=$ módulo de elasticidade do concreto;

I = momento de inércia da seção;

$\mathrm{q}=$ ação lateral uniformemente distribuída;

$\mathrm{H}=$ altura da barra;

$\mathrm{a}=$ deslocamento do topo.

Para o caso de uma edificação, pode-se realizar uma analogia por meio de um modelo bidimensional formando pórticos planos que representam o edifício nas direções de interesse (Figura 4.2). Dessa forma, é possível determinar o deslocamento no topo do edifício.

Vale ressaltar que a equação 4.1 é apenas ilustrativa. De acordo com o item 14.8.1 da ABNT NBR 6118:2007, permite-se representar elementos como vigas-parede e pilares-parede por elemento linear, desde que a deformação por cisalhamento seja levada em consideração, e seja realizado um ajuste de sua rigidez à flexão, para que se represente o comportamento real.

A montagem do pórtico plano é um processo simples que apresenta resultados satisfatórios para edificações pequenas. Para o caso de painéis pré-moldados, algumas considerações especiais são utilizadas. 


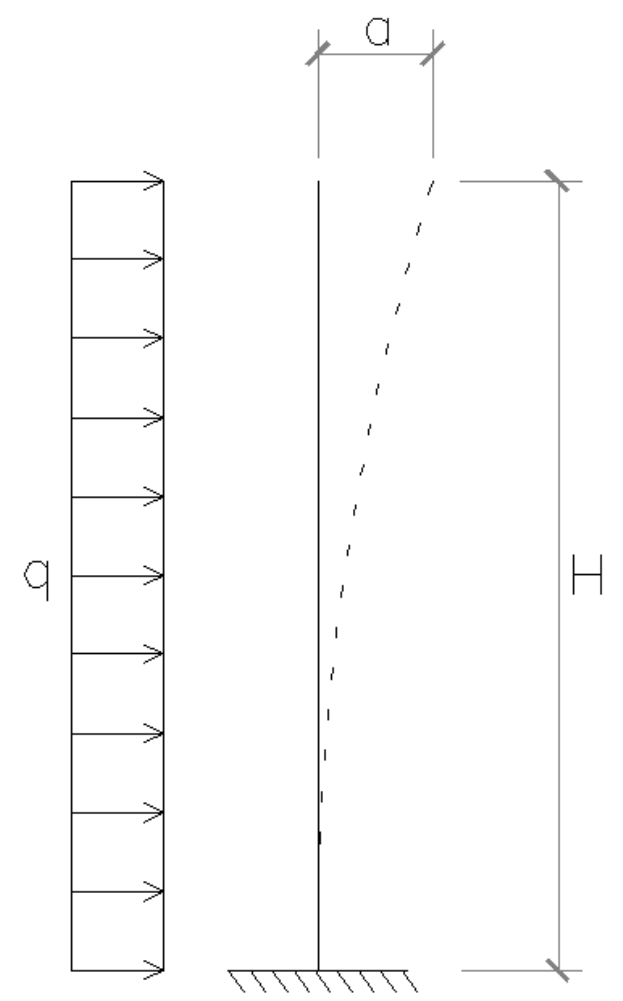

Figura 4.1: Deslocamento do topo de uma barra isolada

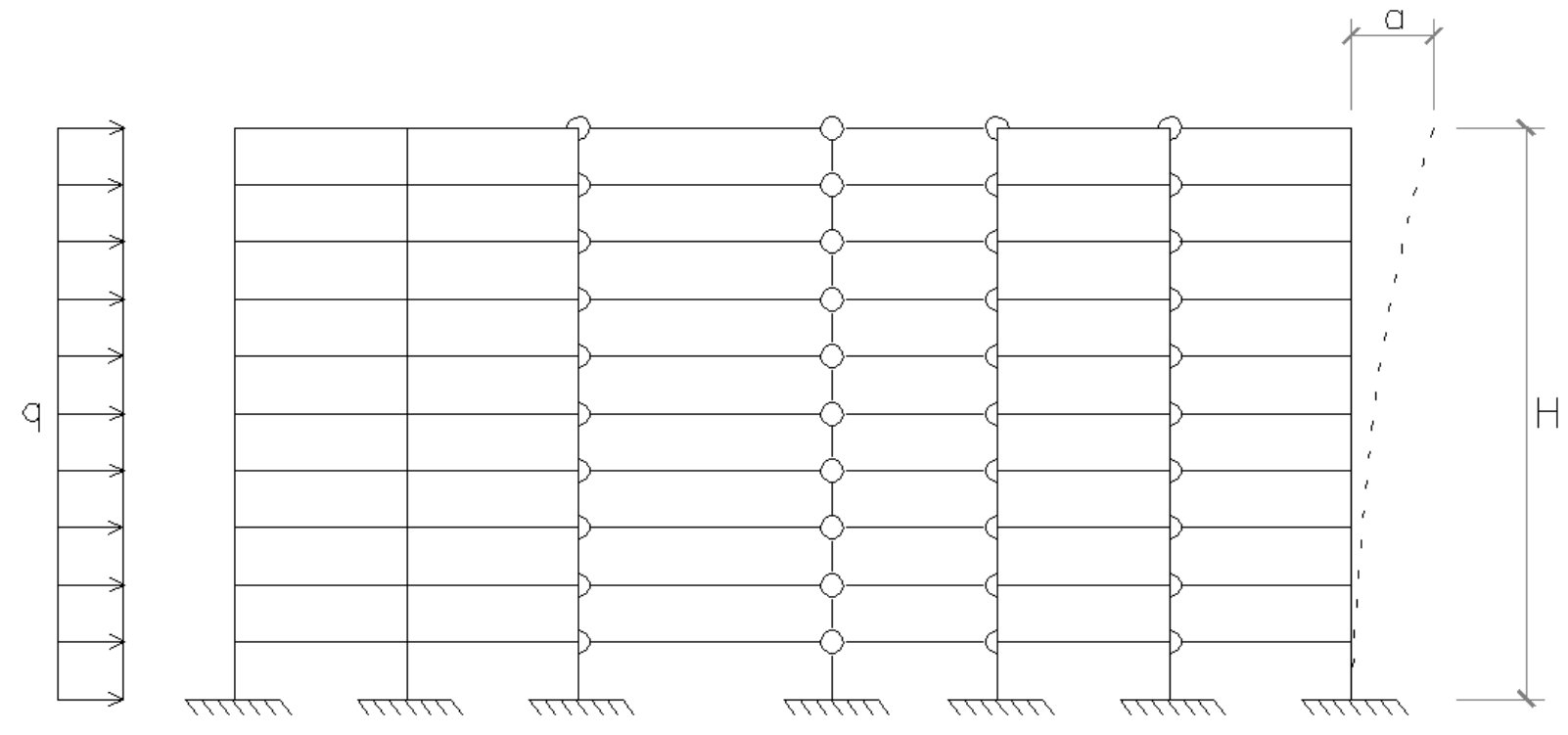

Figura 4.2: Modelo de pórtico bidimensional

Para um painel de fachada que apresente abertura superior a $1 \mathrm{~m}^{2}$, deve-se considerá-lo como um pórtico em que as duas barras verticais flexíveis representam as partes sólidas e a barra horizontal flexível é representada pelo lintel formado pela abertura (Figura 4.3). 


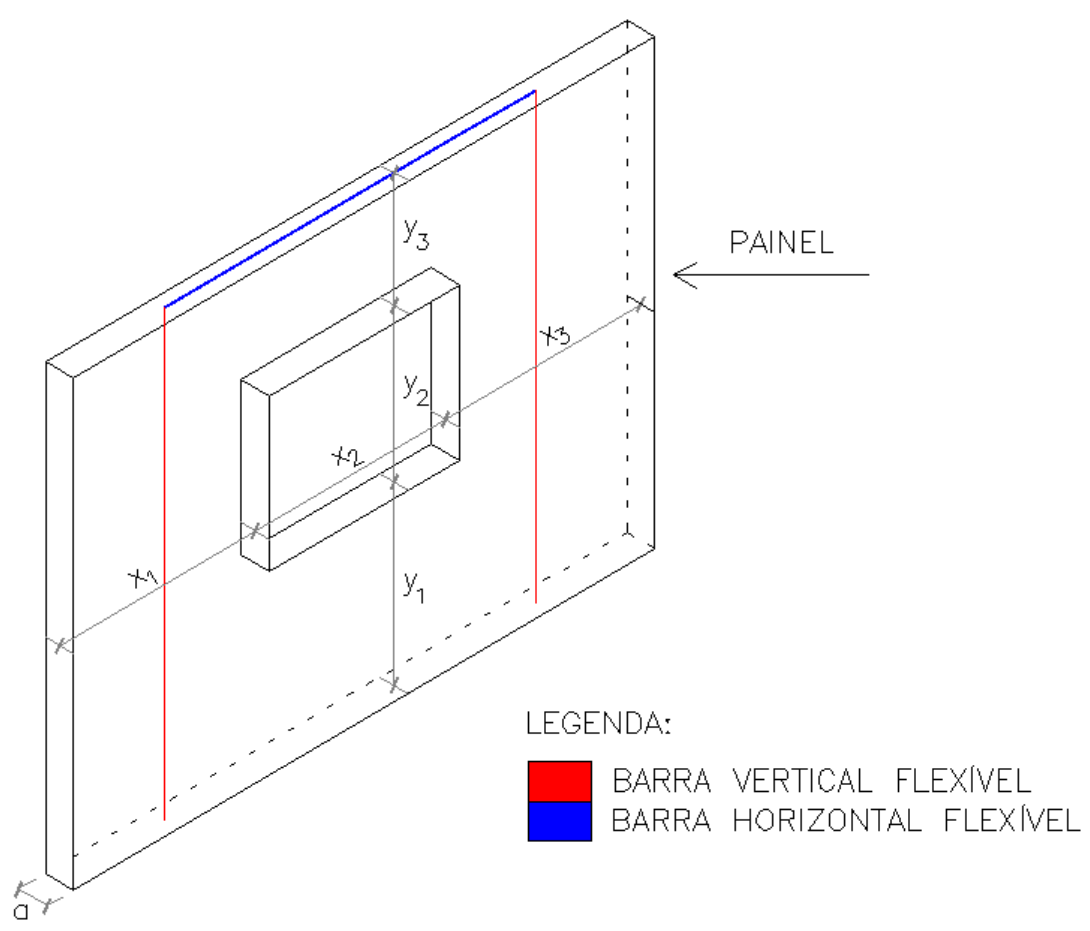

Figura 4.3: Representação do painel com abertura

Sendo assim, a área da seção sólida $\left(\mathrm{A}_{1}\right)$, o momento de inércia $\left(\mathrm{I}_{1}\right)$ e o módulo de resistência $\left(\mathrm{W}_{1}\right)$ da barra vertical flexível são determinados pelas seguintes equações:

$$
\begin{aligned}
\mathrm{A}_{1} & =\mathrm{a} \cdot \mathrm{x}_{1} \\
\mathrm{I}_{1} & =\frac{\mathrm{a} \cdot \mathrm{x}_{1}{ }^{3}}{12} \\
\mathrm{~W}_{1} & =\frac{\mathrm{a} \cdot \mathrm{x}_{1}{ }^{2}}{6}
\end{aligned}
$$

$\mathrm{a}=$ espessura do painel;

$\mathrm{x}_{1}=$ distância da face lateral esquerda do painel até a abertura.

As recomendações da ABNT NBR 6118:2007 são utilizadas para dimensionar a barra horizontal flexível.

Essa Norma comenta que os trechos de elementos lineares pertencentes à região comum ao cruzamento de dois ou mais elementos podem ser considerados como rígidos (nós de dimensões finitas), como se ilustra na Figura 4.4.

Vale ressaltar que $0,3 \mathrm{~h}_{1}$ não deve ultrapassar a metade da seção do elemento em que será considerado o trecho rígido. 
----- Elemento normal

- Trecho rígido

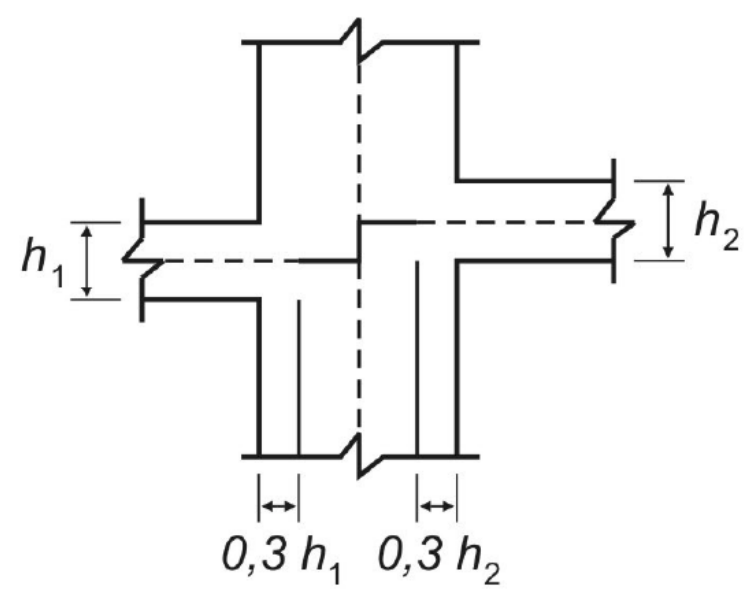

Figura 4.4: Trecho rígido (Fonte: ABNT NBR 6118:2007)

A Norma recomenda também utilizar o menor valor entre as relações apresentadas para as variáveis A e B, na determinação do comprimento da barra horizontal flexível.

Sendo assim, o comprimento do trecho flexível e os valores de A e B são dados por:

$$
\begin{aligned}
\mathrm{L}_{\text {flex. }} & =x_{2}+A+B \\
A & =\left\{\begin{array}{c}
x_{1} / 2 \\
0,3 \cdot y_{3}
\end{array}\right. \\
B & =\left\{\begin{array}{c}
x_{3} / 2 \\
0,3 \cdot y_{3}
\end{array}\right.
\end{aligned}
$$

$\mathrm{y}_{3}=$ distância da abertura até o extremo superior do painel;

$\mathrm{x}_{3}=$ distância do extremo lateral direito do painel até a abertura.

Para determinação da área da seção transversal e do momento de inércia da seção da barra horizontal flexível tem-se que:

$$
\begin{aligned}
& A_{\text {flex. }}=a \cdot\left(y_{1}+y_{3}\right) \\
& I_{\text {flex. }}=a \cdot \frac{\left(y_{1}{ }^{3}+y_{3}{ }^{3}\right)}{12}
\end{aligned}
$$

sendo $y_{1}$ a distância da abertura até o extremo inferior do painel.

Os demais painéis são considerados, no modelo de associação de pórticos, como painéis isolados, sendo representados apenas por uma barra vertical flexível que possui as mesmas características geométricas do painel (Figura 4.5). 


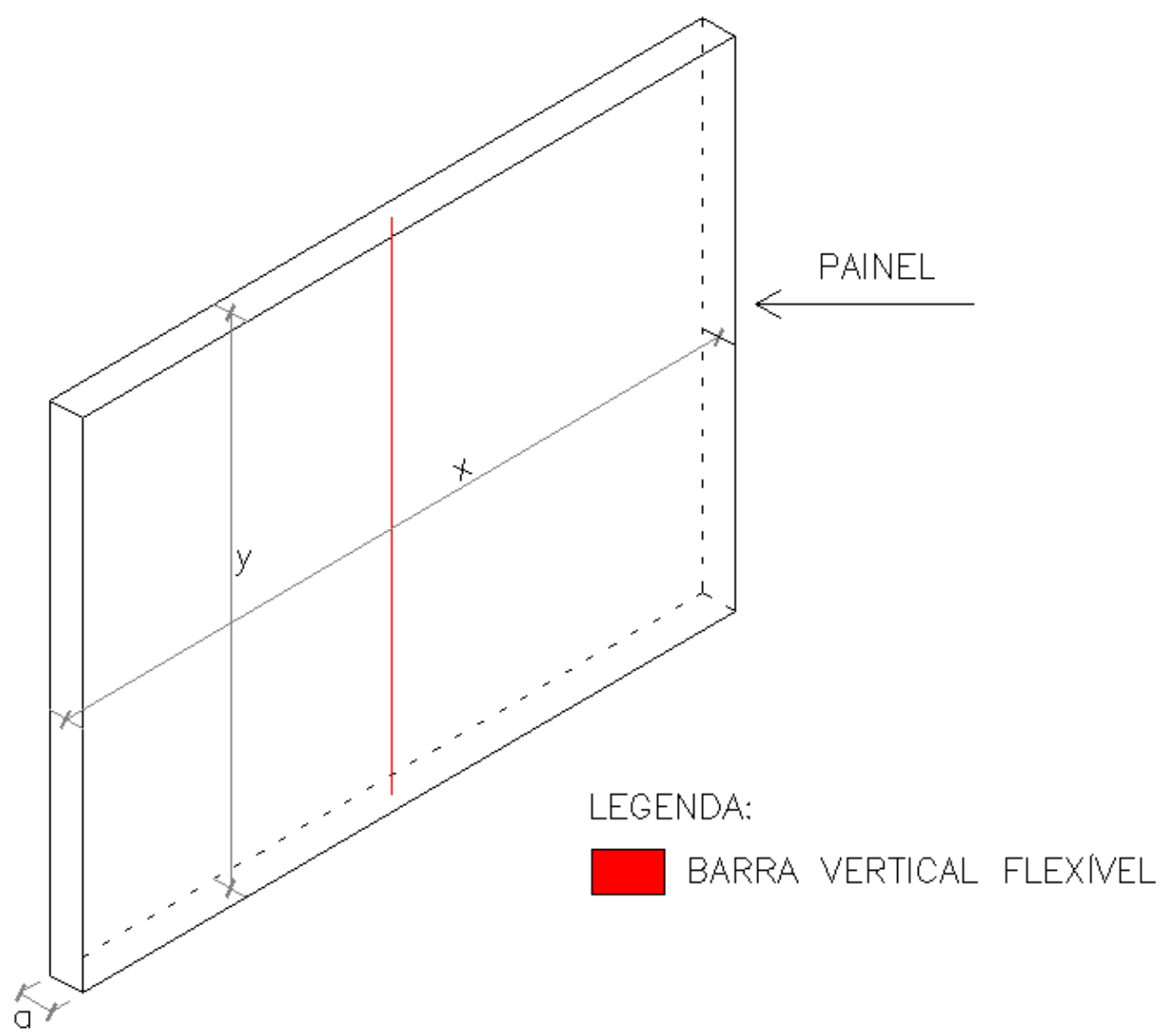

Figura 4.5: Representação do painel isolado

A área da seção sólida (A), o momento de inércia (I) e o módulo de resistência (W) da barra vertical flexível são determinados pelas equações:

$$
\begin{gathered}
A=a \cdot x \\
I=\frac{a \cdot x^{3}}{12} \\
W=\frac{a \cdot x^{2}}{6}
\end{gathered}
$$

$\mathrm{a}=$ espessura do painel;

$\mathrm{x}=$ comprimento do painel isolado.

Para ligar os pórticos formados pelos painéis com aberturas entre eles aos painéis isolados, utiliza-se um elemento que representa a laje. Esse elemento deve transmitir apenas esforços normais, eliminando os momentos fletores. Para isso, o elemento é articulado nas duas extremidades e deve apresentar uma área de seção transversal maior, de modo que não ocorra deformação axial. 


\subsection{EXCENTRICIDADES DE PROJETO}

Em projetos de elementos pré-moldados é de suma importância estabelecer tolerâncias levando-se em conta os desvios de produção, locação, verticalidade da obra, montagem dos elementos e situações especiais de temperatura e vento (ABNT NBR 9062, 2006).

\subsubsection{Excentricidade mínima}

De acordo com as recomendações do PCI (2010) e da ABNT NBR 6118 (2007), a excentricidade mínima de projeto é expressa por:

$$
\mathrm{e}_{\text {mín }}=0,015+0,03 \mathrm{~h}
$$

sendo $\mathrm{h}$ a espessura do painel em metros.

Se a soma das excentricidades de projeto não for superior à excentricidade mínima, deve-se adotar como excentricidade de projeto o valor encontrado na equação (4.13).

\subsubsection{Excentricidade de produção}

Nas recomendações normativas do PCI (2010), a excentricidade de produção é definida por:

$$
\mathrm{e}_{\mathrm{p}}=\frac{\mathrm{L}}{360}
$$

em que L é o comprimento do painel.

A norma limita ainda a excentricidade de produção em 12,7 mm.

\subsubsection{Excentricidade de montagem dos elementos}

A excentricidade mínima de montagem não deve exceder 12,7 mm (PCI, 2010). A tolerância sugerida pela ABNT NBR 9062:2006 para montagem em planta é de $\pm 10 \mathrm{~mm}$ entre apoios consecutivos, não podendo exceder o valor acumulado de $0,1 \%$ do comprimento da estrutura.

\subsubsection{Excentricidade de temperatura}

Segundo o PCI (2010), a diferença de temperatura entre a face interna e a externa do painel provoca um empenamento térmico (Figura 4.6). A magnitude desse empenamento pode ser determinada por: 


$$
\Delta=\alpha \frac{\ell^{2}}{8 h}
$$

$\alpha=$ gradiente térmico ao longo da espessura do painel;

$\ell=$ distância entre os apoios;

$\mathrm{h}=$ espessura do painel.

O gradiente térmico, cuja diferença de temperatura se dá entre a face interna e a externa do painel, é determinado pela equação que segue:

$$
\alpha=\mathrm{C}\left(\mathrm{T}_{1}-\mathrm{T}_{2}\right)
$$

$\mathrm{C}=$ coeficiente de dilatação térmica;

$\mathrm{T}_{1}, \mathrm{~T}_{2}=$ temperatura externa e interna, respectivamente.

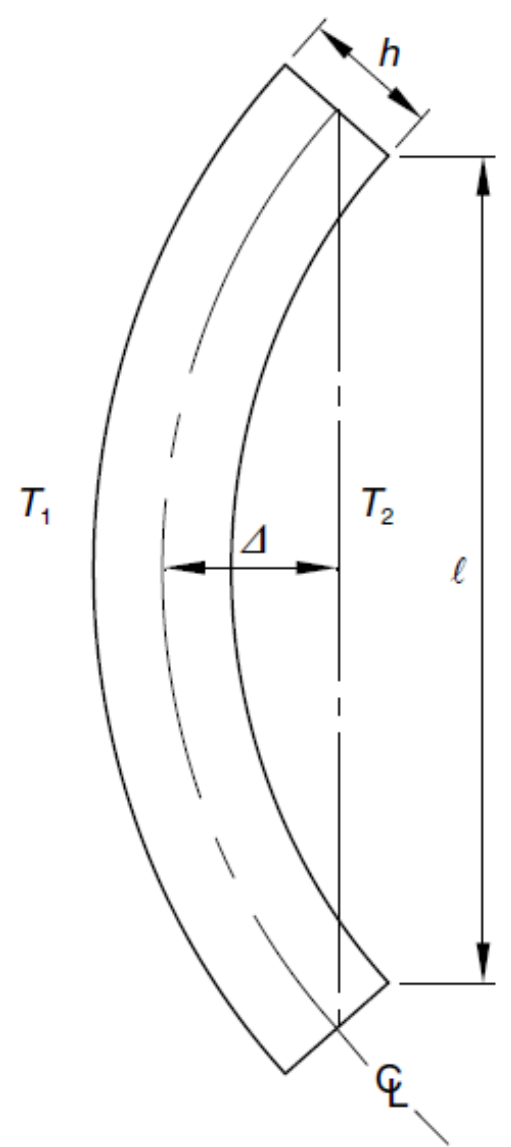

Figura 4.6: Empenamento térmico no painel [Fonte: PCI (2010)]

\subsubsection{Excentricidade devida ao vento}

A excentricidade devida à ação do vento é determinada por analogia com uma viga biapoiada. Sendo assim, tal excentricidade pode ser encontrada pela expressão: 


$$
\mathrm{e}_{\mathrm{w}}=\frac{5 \mathrm{q} \ell^{4}}{384 \mathrm{EI}_{\mathrm{e}}}
$$

$\alpha=$ gradiente térmico ao longo da espessura do painel;

$\ell=$ distância entre os apoios;

$\mathrm{h}=$ espessura do painel.

\subsection{EFEITOS DE SEGUNDA ORDEM (PROCESSO P- $\delta$ )}

Os efeitos de segunda ordem são provenientes das variações geométricas que ocorrem ao longo da peça, como excentricidades devidas a erros de montagem, empenamento térmico e ação do vento.

$\mathrm{O}$ P- $\delta$ é um processo iterativo que leva em consideração, de forma aproximada, a não linearidade geométrica do modelo, caracterizando uma nova configuração de deslocamentos laterais a cada iteração. Dessa forma, ao final do processo é possível obter os esforços de segunda ordem para os momentos fletores e forças axiais.

De acordo com o PCI (2010), são necessárias quatro iterações para a convergência do deslocamento lateral do elemento. Quando isso não ocorre deve-se reavaliar as seções do elemento, sendo este, considerado instável.

Para análise dos efeitos de segunda ordem é importante determinar o índice de esbeltez. Este índice indica se o elemento necessita de considerações dos efeitos de segunda ordem. O PCI (2010) sugere uma equação para determinar esse parâmetro:

$$
\lambda=\frac{\mathrm{k} \cdot \ell_{\mathrm{u}}}{\mathrm{r}}
$$

$\mathrm{k}=$ coeficiente de flambagem;

$\ell_{\mathrm{u}}=$ altura do elemento;

$\mathrm{r}=$ raio de giração.

De acordo com as recomendações normativas do CPCI (2007), o coeficiente de flambagem depende das vinculações do elemento.

Essas vinculações correspondem a três situações: elementos sem restrição lateral, elementos com uma restrição lateral e elementos com restrição lateral em ambos os lados. 
Para o caso em que o elemento não apresenta nenhuma restrição lateral ao longo de seu comprimento (Figura 4.7), o valor do coeficiente de flambagem (k) para todos os valores da relação $\ell_{\mathrm{u}} / \mathrm{b}$ é igual a 1,0 .

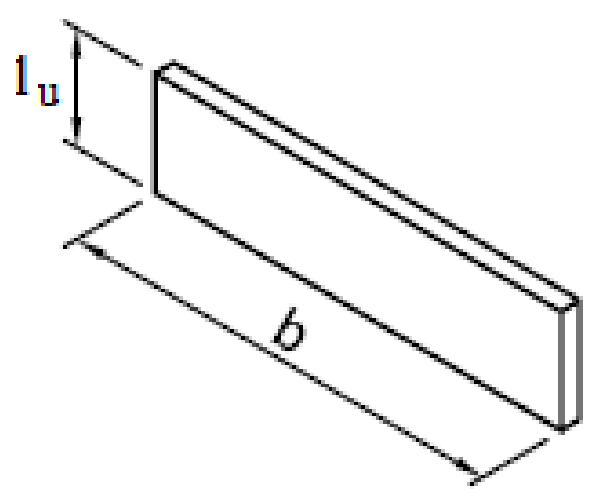

Figura 4.7: Painel sem restrição lateral ao longo do comprimento [Adaptado: CPCI (2007)]

No caso em que o elemento apresenta apenas uma restrição lateral ao longo do seu comprimento (Figura 4.8), o coeficiente de flambagem é determinado por três intervalos de relação $\ell_{\mathrm{u}} / \mathrm{b}$.

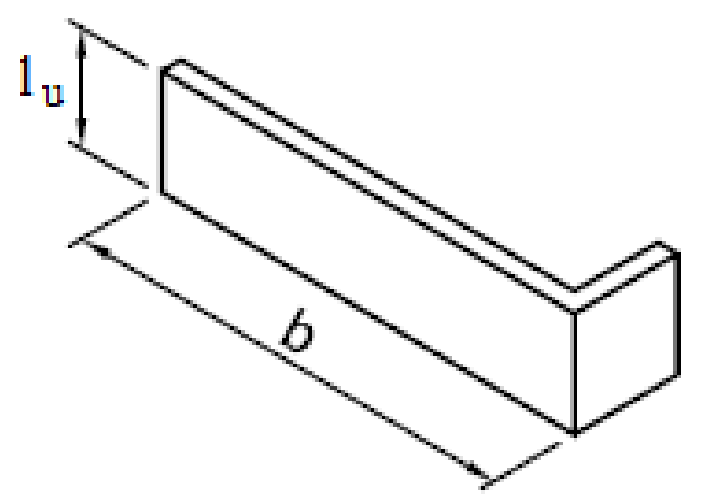

Figura 4.8: Painel com apenas uma restrição lateral ao longo do comprimento [Adaptado: CPCI (2007)]

O CPCI (2007) apresenta as equações das três relações de $\ell_{\mathrm{u}} / \mathrm{b}$, para determinação do coeficiente de flambagem.

$$
\begin{gathered}
\ell_{\mathrm{u}} / \mathrm{b}<1 / 2 \rightarrow k=1,0 \\
1 / 2 \leq \ell_{\mathrm{u}} / \mathrm{b} \leq 2 \rightarrow \mathrm{k}=1,0-0,423\left[\ell_{\mathrm{u}} / \mathrm{b}-1\right] \\
\ell_{\mathrm{u}} / \mathrm{b}>2 \rightarrow k=1,0 / \sqrt{1+\left(\ell_{\mathrm{u}} / \mathrm{b}\right)^{2} / 2}
\end{gathered}
$$


Para o caso em que o elemento apresenta duas restrições laterais ao longo do seu comprimento (Figura 4.9), o coeficiente de flambagem também é determinado por três intervalos de relação $\ell_{\mathrm{u}} / \mathrm{b}$.

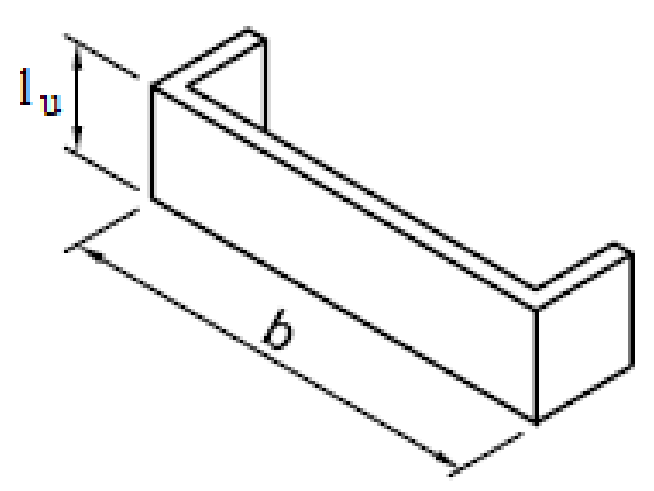

Figura 4.9: Painel com duas restrições laterais ao longo do comprimento [Adaptado: CPCI (2007)]

O CPCI (2007) apresenta as equações das três relações de $\ell_{\mathrm{u}} / \mathrm{b}$, para determinação do coeficiente de flambagem para painel com duas restrições laterais:

$$
\begin{gathered}
\ell_{\mathrm{u}} / \mathrm{b}<1 / 2 \rightarrow \mathrm{k}=1,0 \\
1 / 2 \leq \ell_{\mathrm{u}} / \mathrm{b} \leq 1 \rightarrow \mathrm{k}=1,5-\ell_{\mathrm{u}} / \mathrm{b} \\
\ell_{\mathrm{u}} / \mathrm{b}>1 \rightarrow k=1,0 /\left[1+\left(\ell_{\mathrm{u}} / \mathrm{b}\right)^{2}\right]
\end{gathered}
$$

\subsection{COLAPSO PROGRESSIVO}

Para identificar a propagação de uma ruptura inicial localizada de modo semelhante a uma reação em cadeia utiliza-se o colapso progressivo, que conduz à ruptura parcial ou total de um edifício.

O colapso progressivo é caracterizado, basicamente, pela desproporcionalidade da ruptura final em relação à ruptura inicial. Dessa forma, deve-se prever a integridade da estrutura após a ruptura, de modo a evitar uma progressão desproporcional dos danos (LARANJEIRAS, 2010).

O citado autor comenta que existem diversos atributos que garantem rigidez e robustez a um sistema estrutural, tais como: continuidade, redundância, ductilidade e resistência. A continuidade é caracterizada pela capacidade de redistribuir os esforços após sofrer um dano. 
A redundância é a disponibilidade de várias alternativas para redistribuir os esforços. Já a ductilidade consiste na capacidade de plastificação, ou seja, de suportar grandes deformações antes de romper. E a resistência deve ser suficiente para evitar ameaças ao colapso progressivo.

Laranjeiras (2010) comenta, ainda, que as estruturas de concreto pré-moldado exigem cuidados maiores em relação a esse tipo de colapso, por não permitirem adequada continuidade dos esforços na estrutura. As estruturas moldadas in loco são menos susceptíveis ao colapso progressivo, por apresentarem ligações monolíticas.

Um exemplo clássico de construção com estrutura de elementos pré-moldados que sofreu colapso progressivo é o Edifício Ronan Point, localizado em Londres. Em 1980, ocorreu um vazamento de gás no $18^{\circ}$ pavimento que provocou uma explosão que derrubou uma das paredes externas que sustentava os andares superiores. A perda dessa parede provocou um colapso progressivo de parte do edifício, que desabou até o pavimento térreo (Figura 4.10). A estrutura era composta de ligações articuladas, ou seja, não possuía um caminho alternativo para redistribuição dos esforços em casos de ruptura localizada (LARANJEIRAS, 2010).

El Debs (2000) comenta que a redução do risco de ocorrência do colapso progressivo pode ser realizada por meio de três procedimentos combinados entre si, como: redução do risco da ocorrência de ações excepcionais; projeto da estrutura para suportar as ações excepcionais; e prevenção da propagação de possíveis ruínas localizadas.

Segundo Laranjeiras (2010), existem dois métodos para projetar estruturas de edifícios resistentes ao colapso progressivo: o método indireto e o direto. O primeiro é caracterizado por utilizar uma aproximação simplificada e prescritiva, que promove à estrutura um nível mínimo de conectividade entre os diversos componentes estruturais. As prescrições não exigem análise numérica adicional da estrutura. É necessário, apenas, que o projetista indique providências e detalhes de projeto que aumentem a robustez e a integridade estrutural. Já o método direto apoia-se na análise numérica da estrutura, a fim de identificar a capacidade de resistir aos efeitos de uma ação excepcional. Além disso, o método direto é capaz de reproduzir resultados que tendem gerar estruturas economicamente inviáveis. Portanto, não é considerado um método obrigatório, de acordo com a maioria das normas internacionais. 


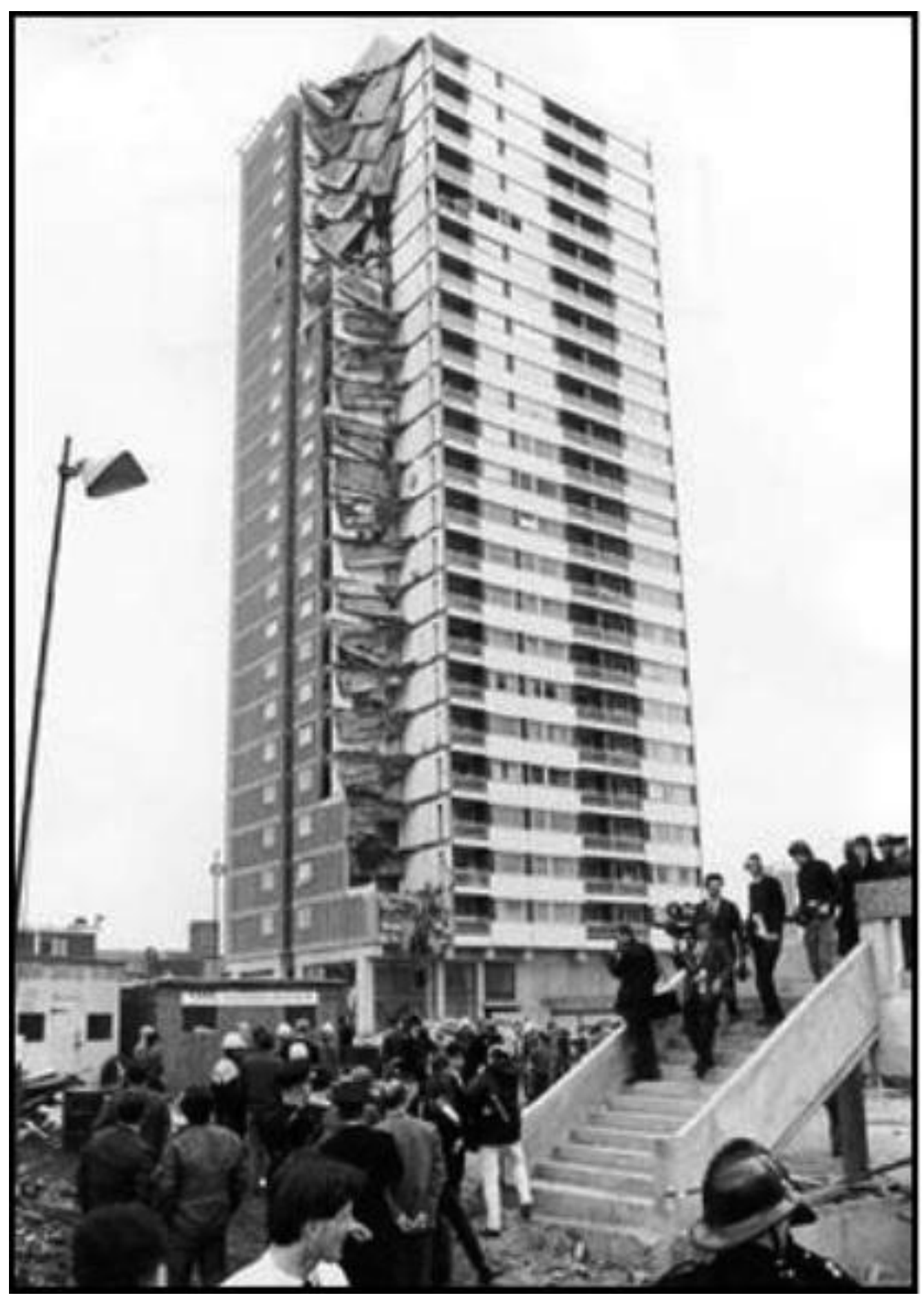

Figura 4.10: Edifício em Ronan Point, Londres [Fonte: Laranjeiras (2010)]

Entre essas normas, a FIB (2008) prescreve algumas recomendações quanto ao colapso progressivo através do método indireto, em que devem ser conhecidos os principais mecanismos de colapso em estruturas de painéis portantes pré-moldados. A Figura 4.11 apresenta alguns dos mecanismos a serem considerados no projeto, como se indica a seguir: 
a) Ação de balanço dos painéis;

b) Ação de viga-parede e de arco dos painéis;

c) Ação de catenária parcial e de membrana de vãos sucessivos das lajes de piso;

d) Suspensão vertical de painéis;

e) Ação diafragma das lajes.

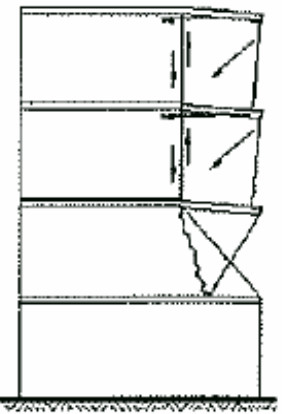

a)

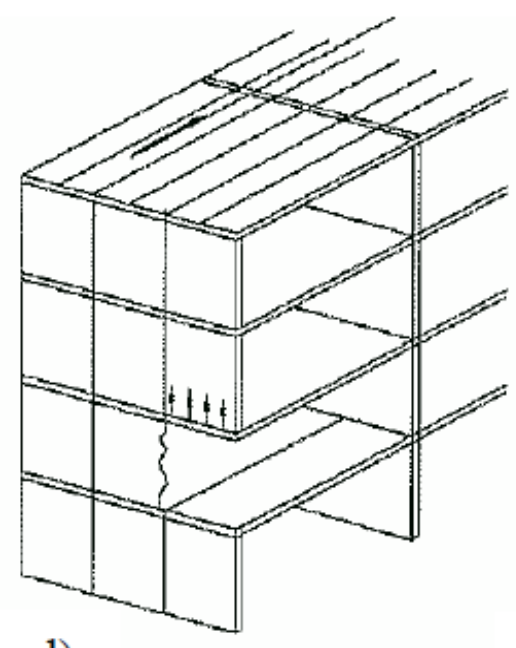

d)

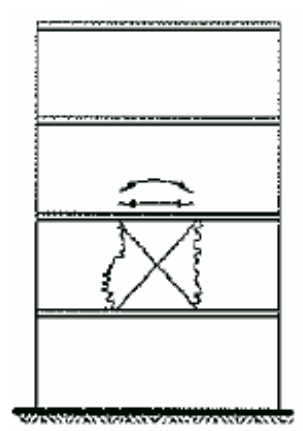

b)

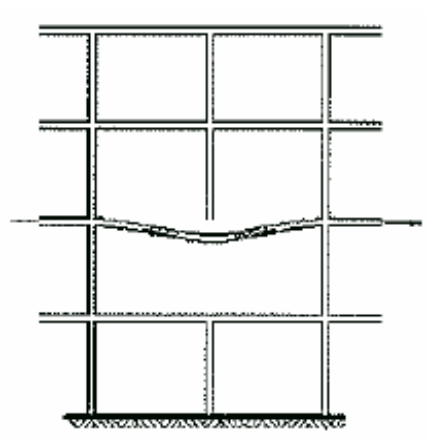

c)

e)

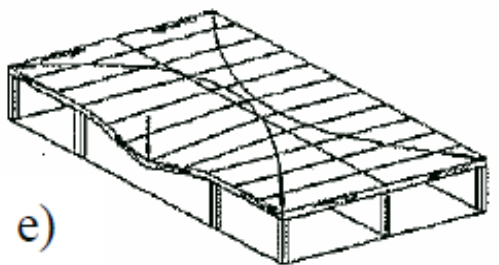

Figura 4.11: Mecanismos de colapso progressivo [Adaptado: FIB (2008)]

\subsubsection{Determinação da energia de deformação das barras de ligação}

De acordo com a FIB (2008), a tensão máxima de aderência para a barra de ancoragem antes de entrar no escoamento, na situação do concreto confinado, pode ser obtida pelo deslizamento máximo dado por $\mathrm{s}_{\mathrm{b} 1}=1,0 \mathrm{~mm}$.

O deslizamento total $\left(s_{\text {end,y }}\right)$ que ocorre na barra pode ser determinado pela relação entre a tensão do aço e o deslizamento da barra, como apresentado na equação (4.21). 
Essa relação é válida ao longo da barra, desde que ela se encontre no regime elástico e o deslizamento seja inferior a $1,0 \mathrm{~mm}$.

$$
S_{\text {end,y }}=0,288\left(\frac{\phi \cdot \sigma_{s}^{2}}{\tau_{b, \text { máx }} \cdot E_{s}}\right)^{0,714}+\frac{\sigma_{s}}{E_{s}} \cdot 2 \phi
$$

$\tau_{\mathrm{b}, \text { máx }}=2,5 \sqrt{f_{c c}}$, para condições de boa aderência;

$\tau_{\mathrm{b} \text {,máx }}=1,25 \sqrt{f_{c c}}$, para todas as situações.

$\mathrm{O}$ valor da resistência do concreto à compressão $\mathrm{f}_{\mathrm{cc}}$ deve ser colocado em MPa.

O primeiro termo da equação (4.21) corresponde ao deslizamento proveniente da ação de ancoragem ao longo do comprimento de transmissão. Nesse termo aparecem os esforços de ligação, denominados de $s_{\text {end,net }}$ (Equação 4.22).

A segunda parcela corresponde ao deslizamento provocado pela falha no concreto na forma de cone, que ocorre próxima à região livre (Figura 4.12).

$$
\mathrm{S}_{\text {end,net }}=0,288\left(\frac{\phi \cdot \sigma_{\mathrm{s}}^{2}}{\tau_{\mathrm{b}, \text { máx }} \cdot \mathrm{E}_{\mathrm{s}}}\right)^{0,714}
$$

Segundo a FIB (2008), o comprimento de transmissão onde aparecem os esforços de ligação é determinado pela equação (4.23).

$$
\ell_{\mathrm{t}, \mathrm{y}}=0,583 \frac{\phi \cdot \sigma_{\mathrm{s}}}{\tau_{\mathrm{b}, \text { máx }} \cdot \mathrm{s}_{\text {end,net }}^{0,4}}+2 \phi
$$

Para a situação em que a barra de ancoragem entra em escoamento, o concreto apresenta uma falha na forma de cone próxima à região livre, podendo sofrer deformações plásticas diretamente.

Na situação em que a ancoragem é suficiente para resistir aos esforços de tração na barra até a sua ruptura, atinge-se o comprimento máximo da barra que ocorre em regime plástico.

Ao longo da zona plástica ocorre um aumento da tensão de escoamento do aço de $\mathrm{f}_{\mathrm{yk}}$ para $\mathrm{f}_{\mathrm{u}}$, como mostra a Figura 4.12. 


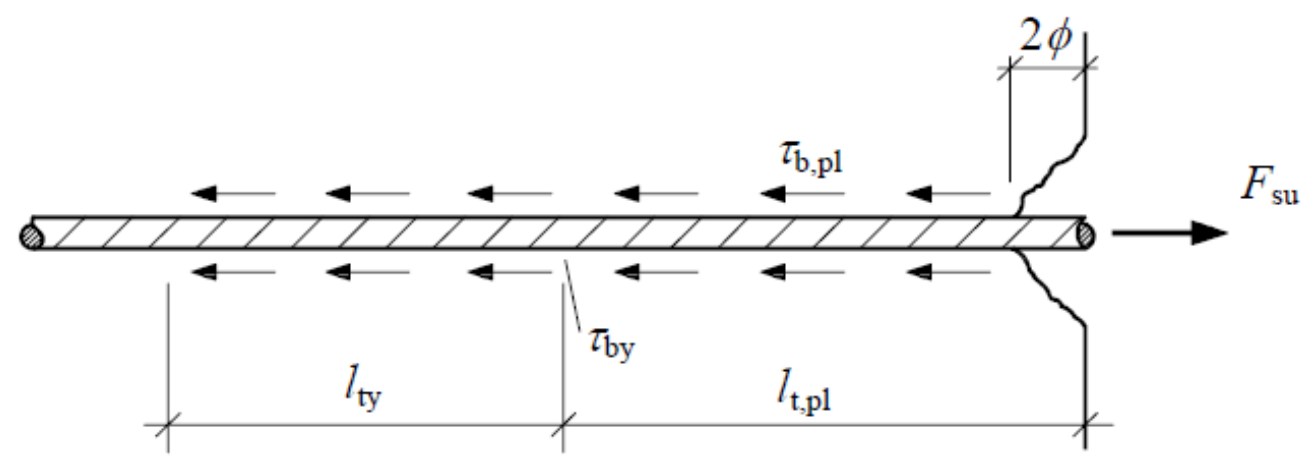

Figura 4.12: Condição de equilíbrio da barra de ancoragem no regime plástico até a ruptura [Fonte: FIB (2008)]

O comprimento máximo $\left(\ell_{\mathrm{t}, \mathrm{pl}}\right)$ em regime plástico pode ser obtido por condições de equilíbrio, como mostra a equação (4.24).

$$
\ell_{\mathrm{t}, \mathrm{pl}}=\frac{\mathrm{F}_{\mathrm{su}}-\mathrm{F}_{\mathrm{sy}}}{\tau_{\mathrm{bm}, \mathrm{pl}} \pi \phi}=\frac{\mathrm{f}_{\mathrm{u}}-\mathrm{f}_{\mathrm{yk}}}{\tau_{\mathrm{bm}, \mathrm{pl}}} \cdot \frac{\phi}{4}
$$

Segundo a FIB (2008), a tensão de aderência média em regime plástico para barras nervuradas de alta ductilidade pode ser determinada pela equação (4.25):

$$
\tau_{\mathrm{bm}, \mathrm{pl}}=0,27 \cdot \tau_{\mathrm{b} \text {,máx }}
$$

Quando conhecido o comprimento máximo em regime plástico, é possível determinar o deslizamento máximo da barra pela expressão (4.26):

$$
\mathrm{s}_{\mathrm{end}, \mathrm{u}}=\ell_{\mathrm{t}, \mathrm{pl}} \cdot \varepsilon_{\mathrm{sm}, \mathrm{pl}}+\mathrm{s}_{\mathrm{end}, \mathrm{y}}
$$

A deformação média do aço $\varepsilon_{\text {sm,pl }}$ em regime plástico pode ser estimada pela equação (4.27).

$$
\varepsilon_{\mathrm{sm}, \mathrm{pl}}=0,5 \cdot \varepsilon_{\mathrm{su}}
$$

$\varepsilon_{\text {su }}$ é a deformação máxima do aço.

O modelo idealizado entre o deslizamento máximo e as forças de tração que são provocados nas barras de ancoragem é apresentado na Figura 4.13, mostrando a responsabilidade da barra de aço antes da ruptura.

Segundo a FIB (2008), a abertura da fissura que ocorre no ponto mais fraco do concreto depende dos deslizamentos máximos das barras de ancoragem em ambos os lados da fissura. Sendo assim, a abertura da fissura no escoamento da barra de aço é determinada por $\mathrm{w}_{\mathrm{y}} \mathrm{e}$ a abertura da fissura para a ruptura da barra de aço é dada por $\mathrm{w}_{\mathrm{u}}$. 


$$
\begin{aligned}
& \mathrm{w}_{\mathrm{y}}=2 \cdot \mathrm{s}_{\text {end, } \mathrm{y}} \\
& \mathrm{w}_{\mathrm{u}}=2 \cdot \mathrm{s}_{\text {end, } \mathrm{u}}
\end{aligned}
$$

A capacidade de energia de deformação das barras de ligação é determinada pela equação (4.30) (FIB, 2008).

$$
\xi_{\mathrm{u}}=\frac{\mathrm{W}_{\mathrm{int}}\left(\mathrm{u}_{\mathrm{u}}\right)}{\mathrm{S}_{\mathrm{máx}} \cdot \mathrm{u}_{\mathrm{u}}}
$$

$\mathrm{W}_{\text {int }}=$ energia de deformação;

$\mathrm{S}_{\text {máx }}=$ resistência máxima;

$\mathrm{u}_{\mathrm{u}}=$ deslocamento máximo.

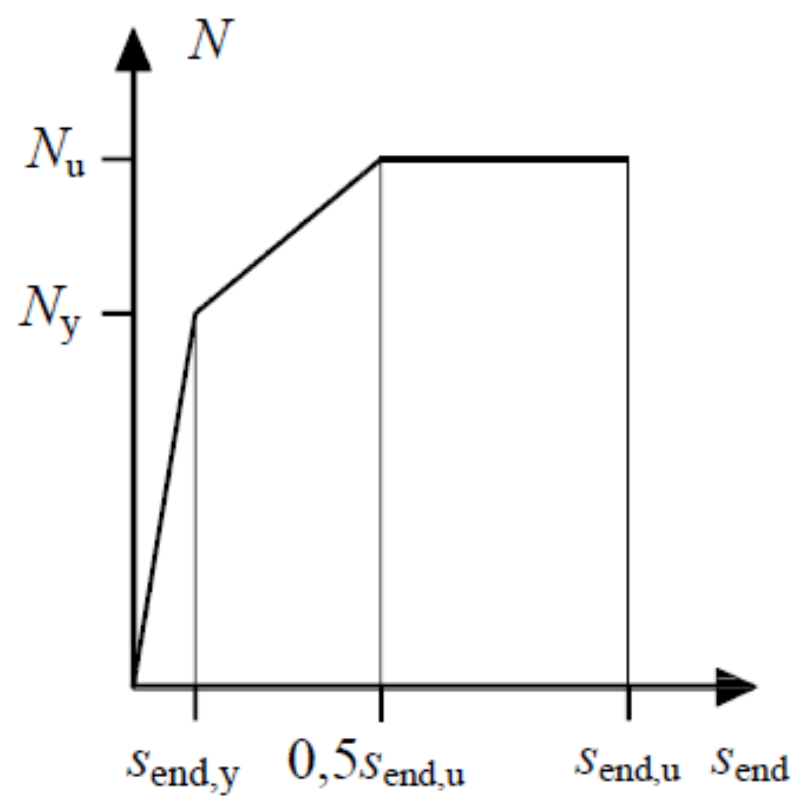

Figura 4.13: Modelo idealizado entre os esforços de tração e final do deslizamento [Fonte: FIB (2008)]

\subsubsection{Mecanismos de rotação - Ação de balanço para painéis}

Considerando o sistema em balanço ilustrado na Figura 4.14, para uma pequena rotação $\phi$, o alongamento da barra de ligação i pode ser expresso aproximadamente por:

$$
\mathrm{w}_{\mathrm{i}} \approx \ell_{\mathrm{i}} \cdot \phi
$$

$\ell_{\mathrm{i}}$ é a distância entre o centro de rotação e a barra de ligação i.

O deslocamento vertical da força resultante $\mathrm{Q}$ do painel é dado por:

$$
\mathrm{a}_{\mathrm{qz}} \approx \ell_{\mathrm{qx}, 0} \cdot \phi
$$

$\ell_{\mathrm{qx}, 0}$ é a distância entre o centro de rotação e a força resultante $\mathrm{Q}$ no sistema indeformado. 


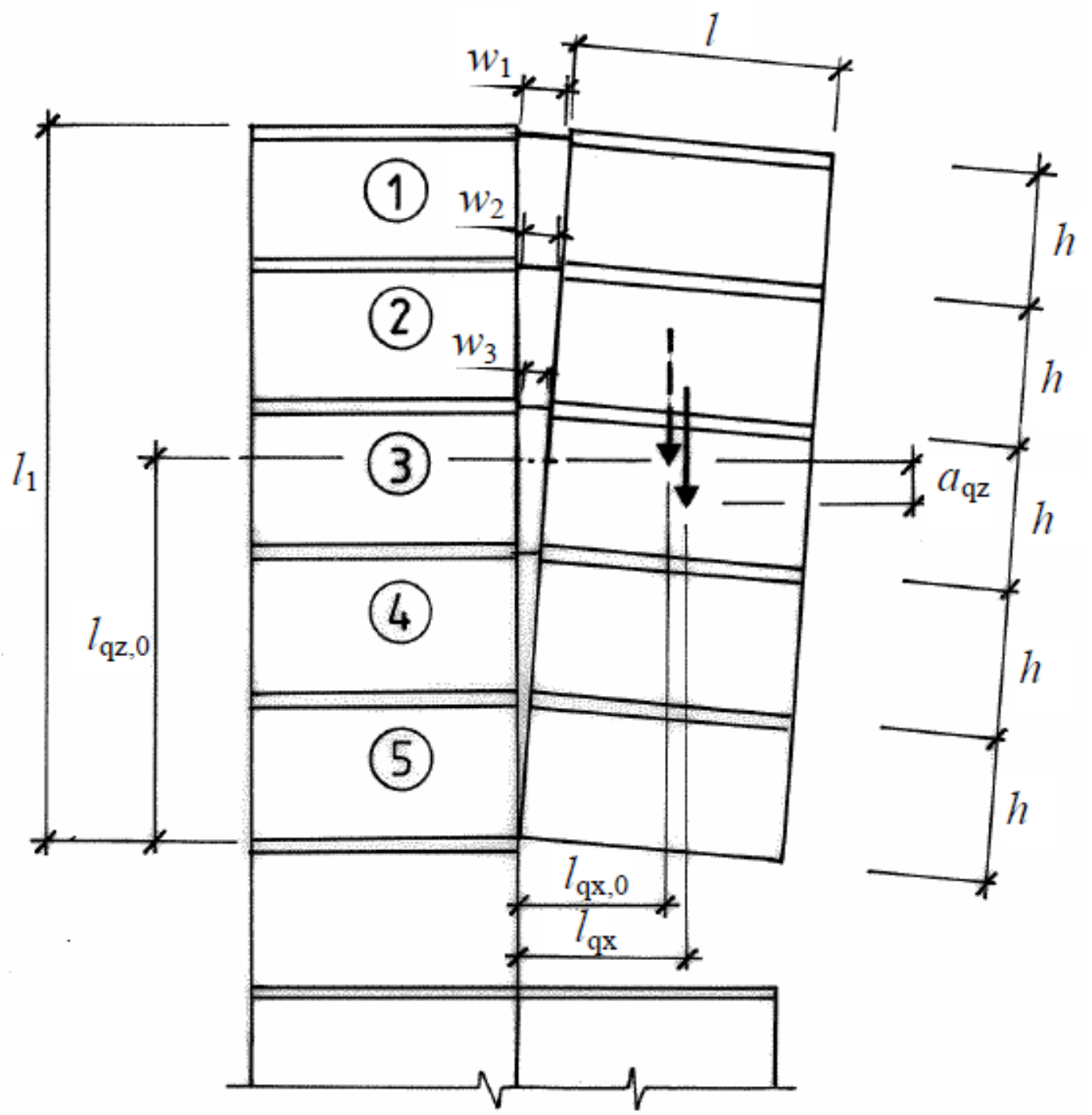

Figura 4.14: Mecanismo de rotação para os painéis em balanço devido a um dano local [Fonte: FIB (2008)]

Utilizando as equações (4.31) e (4.32), é possível realizar uma simples relação geométrica a fim de obter o alongamento de cada barra de ligação.

$$
\mathrm{w}_{\mathrm{i}} \approx \frac{\ell_{\mathrm{i}}}{\ell_{\mathrm{qx}, 0}} \mathrm{a}_{\mathrm{qz}}
$$

Para uma pequena rotação $\phi$ dos painéis pré-moldados em balanço, a condição de equilíbrio estática é dada por:

$$
\mathrm{Q} \cdot \ell_{\mathrm{qx}}=\sum_{\mathrm{i}} \mathrm{N}_{\mathrm{i}}\left(\mathrm{w}_{\mathrm{i}}\right) \cdot \ell_{\mathrm{i}}
$$

$\ell_{\mathrm{qx}}$ é a distância entre o centro de rotação e eixo da força resultante $\mathrm{Q}$ deslocada e $\mathrm{N}_{\mathrm{i}}\left(\mathrm{w}_{\mathrm{i}}\right)$ é o valor do esforço de tração correspondente ao alongamento da barra de ligação $\mathrm{i}$. 
A resistência estática do sistema em balanço expressa a capacidade que esse sistema possui de equilibrar a força resultante do painel (Q) atuando no centro de gravidade da estrutura em balanço.

Uma vez que se desenvolvem forças de tração nas barras de ligação devidas à rotação do sistema, a resistência estática varia de acordo com essa rotação. Sendo assim, a resistência estática pode ser expressa como função do deslocamento vertical da força resultante no painel, dada por:

$$
\mathrm{R}_{\mathrm{stat}}\left(\mathrm{a}_{\mathrm{qz}}\right)=\frac{1}{\ell_{\mathrm{qx}}} \sum_{\mathrm{i}} \mathrm{N}_{\mathrm{i}}\left(\mathrm{w}_{\mathrm{i}}\right) \cdot \ell_{\mathrm{i}}
$$

Para um valor tolerável de deslocamento vertical máximo $\mathrm{a}_{\mathrm{qz}, \max }$ em um sistema em balanço, a resistência dinâmica para o deslocamento vertical máximo $\mathrm{R}_{\mathrm{dyn}}\left(\mathrm{a}_{\mathrm{qz}, \max }\right)$ pode ser determinada pelo equilíbrio de energia, como mostra a equação (4.36).

$$
\mathrm{Q} \cdot \mathrm{a}_{\mathrm{qz}, \text { max }}=\sum_{\mathrm{i}} \xi_{\mathrm{i}}\left(\mathrm{w}_{\mathrm{i}, \text { max }}\right) \mathrm{N}_{\mathrm{i}, \mathrm{u}} \cdot \mathrm{w}_{\mathrm{i}, \text { max }}
$$

A equação (4.37) expressa a força resultante máxima atuante que pode ser suportada no sistema em balanço com a remoção de um painel portante, sendo essa a resistência dinâmica do sistema. Portanto, a resistência dinâmica é função do deslocamento vertical $\mathrm{a}_{\mathrm{qz}, \max }$, que é usado para retardar o movimento.

$$
\mathrm{R}_{\mathrm{dyn}}\left(\mathrm{a}_{\mathrm{qz}, \max }\right)=\sum_{\mathrm{i}} \xi_{\mathrm{i}}\left(\mathrm{w}_{\mathrm{i}, \mathrm{max}}\right) \frac{\ell_{\mathrm{i}}}{\ell_{\mathrm{qx}, 0}} \mathrm{~N}_{\mathrm{i}, \mathrm{u}}
$$

\subsubsection{Mecanismos de rotação - Ação de balanço para lajes}

Indica-se na Figura 4.15 um sistema de lajes pré-moldadas em balanço, depois da remoção do painel de suporte. Supõe-se que as três barras de ligação sejam do mesmo tipo e que apresentem as mesmas características. Para qualquer estado de deformação é considerado que as três barras de ligação apresentem a mesma força de tração, pois as características das relações de carga-deslocamento correspondem ao mesmo alongamento.

Para cada elemento de laje, o peso próprio e as cargas permanentes são representados pela força resultante $\mathrm{Q}$, a qual é considerada atuante no centro de gravidade do elemento. O estado de deformação é definido pelo deslocamento $\mathrm{a}_{\mathrm{qz}}$ das forças atuantes. 


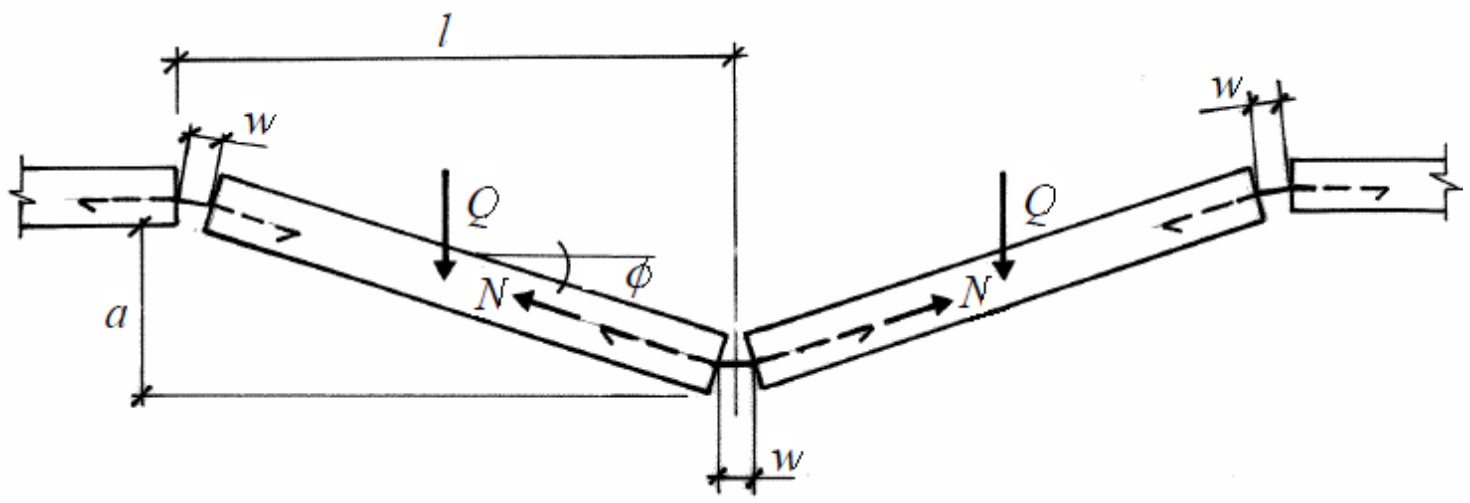

Figura 4.15: Ação de balanço em lajes pré-moldadas depois da remoção do painel de suporte [Fonte: FIB (2008)]

Para cada alongamento w que ocorre nas três barras de ligação no sistema de laje em balanço, o deslocamento $\mathrm{a}_{\mathrm{qz}}$ devido às forças atuantes pode ser determinada pela equação:

$$
\mathrm{a}_{\mathrm{qz}}=\frac{\sqrt{3 \ell \mathrm{w}}}{2}
$$

$\ell$ é o comprimento do painel pré-moldado.

A condição de equilíbrio estático no estado de deformação é dada por:

$$
\mathrm{Q} \cdot \frac{\ell}{2}=\mathrm{N}(\mathrm{w}) \cdot 2 \mathrm{a}_{\mathrm{qz}}
$$

De acordo com a equação (4.38) e a condição de equilíbrio estático, equação (4.39), a resistência estática pode ser expressa por:

$$
\mathrm{R}_{\text {stat }}\left(\mathrm{a}_{\mathrm{qz}}\right)=2 \mathrm{~N}(\mathrm{w}) \sqrt{\frac{3 \mathrm{w}}{\ell}}
$$

Quanto aos mecanismos de rotação, é conveniente introduzir um valor formal para a resistência estática máxima $\left(\mathrm{R}_{\max }\right)$. No entanto, como a resistência depende diretamente do deslocamento, esse valor formal pode ser expresso pelo deslocamento máximo $\mathrm{a}_{\mathrm{qz}, \mathrm{max}}$, sendo esse o valor máximo de flecha.

$$
\mathrm{R}_{\max }\left(\mathrm{a}_{\mathrm{qz}, \max }\right)=2 \mathrm{~N}_{\mathrm{u}} \sqrt{\frac{3 \mathrm{w}_{\text {max }}}{\ell}}
$$


A energia de deformação do deslocamento da laje depende do alongamento das três barras de ligação do sistema. A condição de equilíbrio de energia para o vão duplo é expressa pela equação (4.42):

$$
2 \mathrm{Q} \cdot \mathrm{a}_{\mathrm{qz}, \max }=3 \xi\left(\mathrm{w}_{\max }\right) \mathrm{N}_{\mathrm{u}} \mathrm{w}_{\max }
$$

Sendo assim, a resistência dinâmica é obtida por:

$$
\mathrm{R}_{\mathrm{dyn}}\left(\mathrm{a}_{\mathrm{qz}, \max }\right)=\xi\left(\mathrm{w}_{\max }\right) \mathrm{N}_{\mathrm{u}} \sqrt{\frac{3 \mathrm{w}_{\text {max }}}{\ell}}
$$

A partir das equações (4.41) e (4.43), fica evidente que a resistência dinâmica do sistema de lajes em balanço não depende apenas da capacidade de tração e da ductilidade das barras de ligação, mas também diretamente da sua capacidade de alongamento. 


\section{CÁLCULO DE UM EDIFÍCIO MULTIFAMILIAR}

A planta do edifício escolhido para dimensionamento foi concedida pela empresa PEDREIRA ENGENHARIA LTDA., que atua principalmente no ramo dos pré-moldados. A construção tem como foco principal atender as classes C e D da população, através do PAC (Programa de Aceleração do Crescimento) do governo brasileiro.

O fluxograma apresentado na Figura 5.1 indica as etapas de cálculo do empreendimento analisado neste trabalho.

O dimensionamento do edifício é realizado com carregamentos provenientes das lajes, dos painéis, e também da ação do vento. A partir dos carregamentos atuantes nas lajes é possível realizar o dimensionamento delas, a fim de obter as respectivas reações de apoio para os painéis pré-moldados, assim como os esforços provenientes da ação do vento nos painéis. Após o dimensionamento dos elementos estruturais, analisa-se o colapso progressivo, que é uma prática necessária em edificações pré-moldadas.

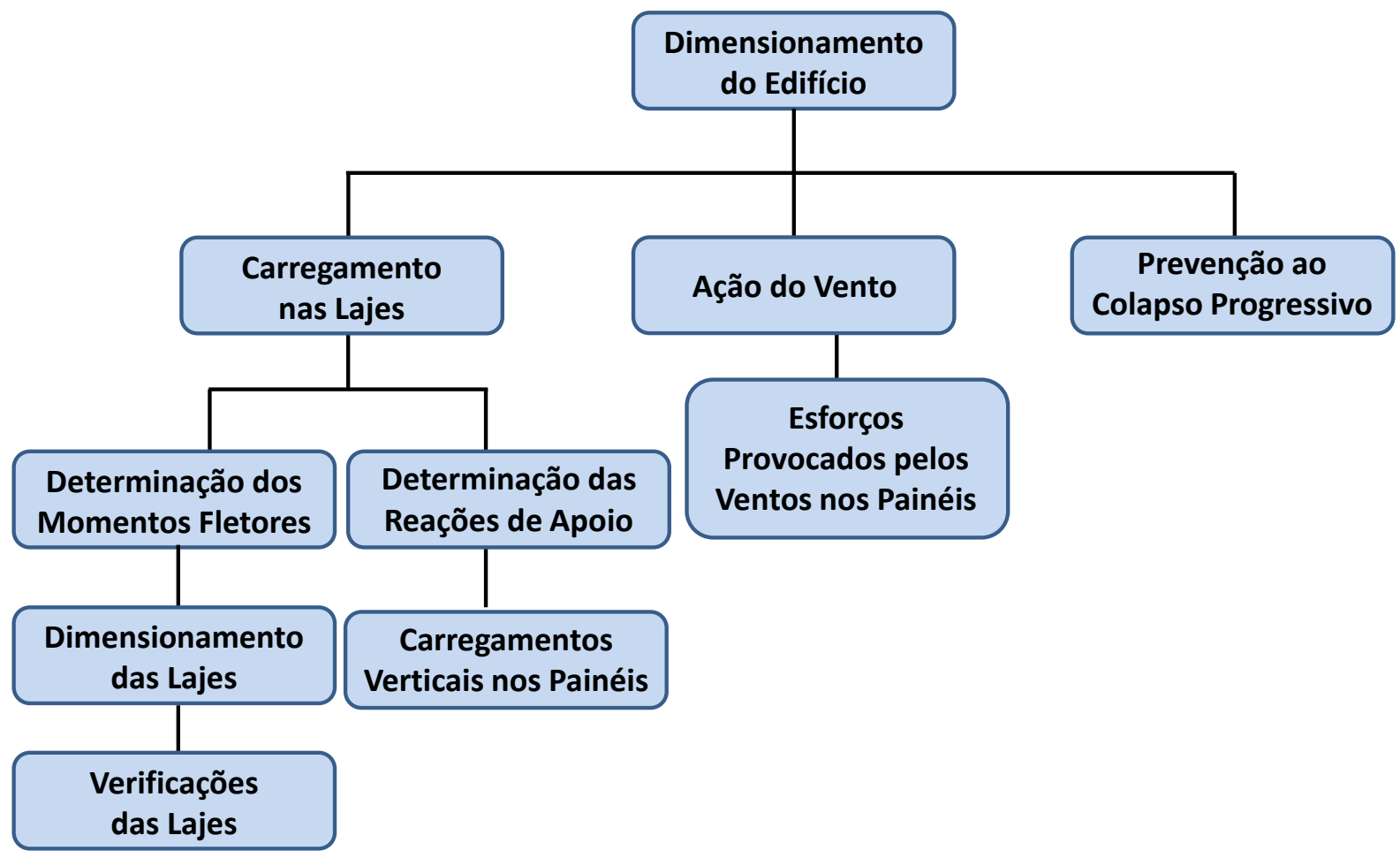

Figura 5.1: Procedimento de cálculo do edifício em estudo 


\subsection{APRESENTAÇÃO DA PLANTA}

O edifício em estudo possui cinco pavimentos com pé-direito de 2,70 m (piso a piso), sendo composto de um pavimento térreo e quatro pavimentos tipo.

As dimensões totais em planta são de $14,45 \mathrm{~m}$ por $14,90 \mathrm{~m}$ e uma altura total de $13,5 \mathrm{~m}$. As características dos cômodos e ambientes comuns do edifício estão apresentadas na Tabela 5.1, com as dimensões por pavimento e as respectivas medidas de cada apartamento.

Tabela 5.1: Dimensões e quantidades de ambientes por pavimento do edifício

\begin{tabular}{|c|c|c|}
\hline Quant. & Ambiente & $\begin{array}{l}\text { Área } \\
\left(\mathbf{m}^{2}\right)\end{array}$ \\
\hline 4 & Apartamento & 34,93 \\
\hline \multirow{5}{*}{ 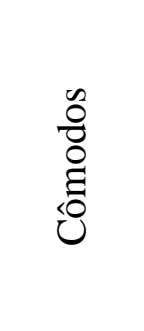 } & Estar/Jantar & 11,65 \\
\hline & $\begin{array}{c}\text { Cozinha/Área de } \\
\text { serviço }\end{array}$ & 5,65 \\
\hline & Banheiro & 2,55 \\
\hline & Dormitório 1 & 8,06 \\
\hline & Dormitório 2 & 7,02 \\
\hline 1 & Hall & 6,14 \\
\hline 1 & Escada & 8,89 \\
\hline \multicolumn{2}{|c|}{ Total $\mathrm{p} /$ pavimento } & 154,75 \\
\hline
\end{tabular}

O pavimento térreo e o tipo são semelhantes, diferindo-se apenas na entrada do edifício e nas entradas da escada de acesso aos outros pavimentos (Figura 5.2). Na Tabela 5.2 são apresentadas as dimensões das esquadrias utilizadas.

Tabela 5.2: Dimensões das esquadrias do edifício

\begin{tabular}{|c|c|c|c|c|}
\hline Esquadrias & Ambiente & $\begin{array}{c}\text { Comprimento } \\
(\mathbf{m})\end{array}$ & $\begin{array}{c}\text { Altura } \\
(\mathbf{m})\end{array}$ & $\begin{array}{c}\text { Peitoril } \\
(\mathbf{m})\end{array}$ \\
\hline Porta & Hall & 1,20 & 2,21 & - \\
\hline Janela & Hall & 1,20 & 1,38 & 1,00 \\
\hline Janela & Dormitório 1 & 1,18 & 1,38 & 1,00 \\
\hline Janela & Dormitório 2 & 1,18 & 1,38 & 1,00 \\
\hline Janela & Estar & 1,38 & 1,38 & 1,00 \\
\hline Janela & Cozinha & 0,98 & 1,38 & 1,00 \\
\hline Janela & Banheiro & 0,58 & 0,58 & 1,60 \\
\hline
\end{tabular}




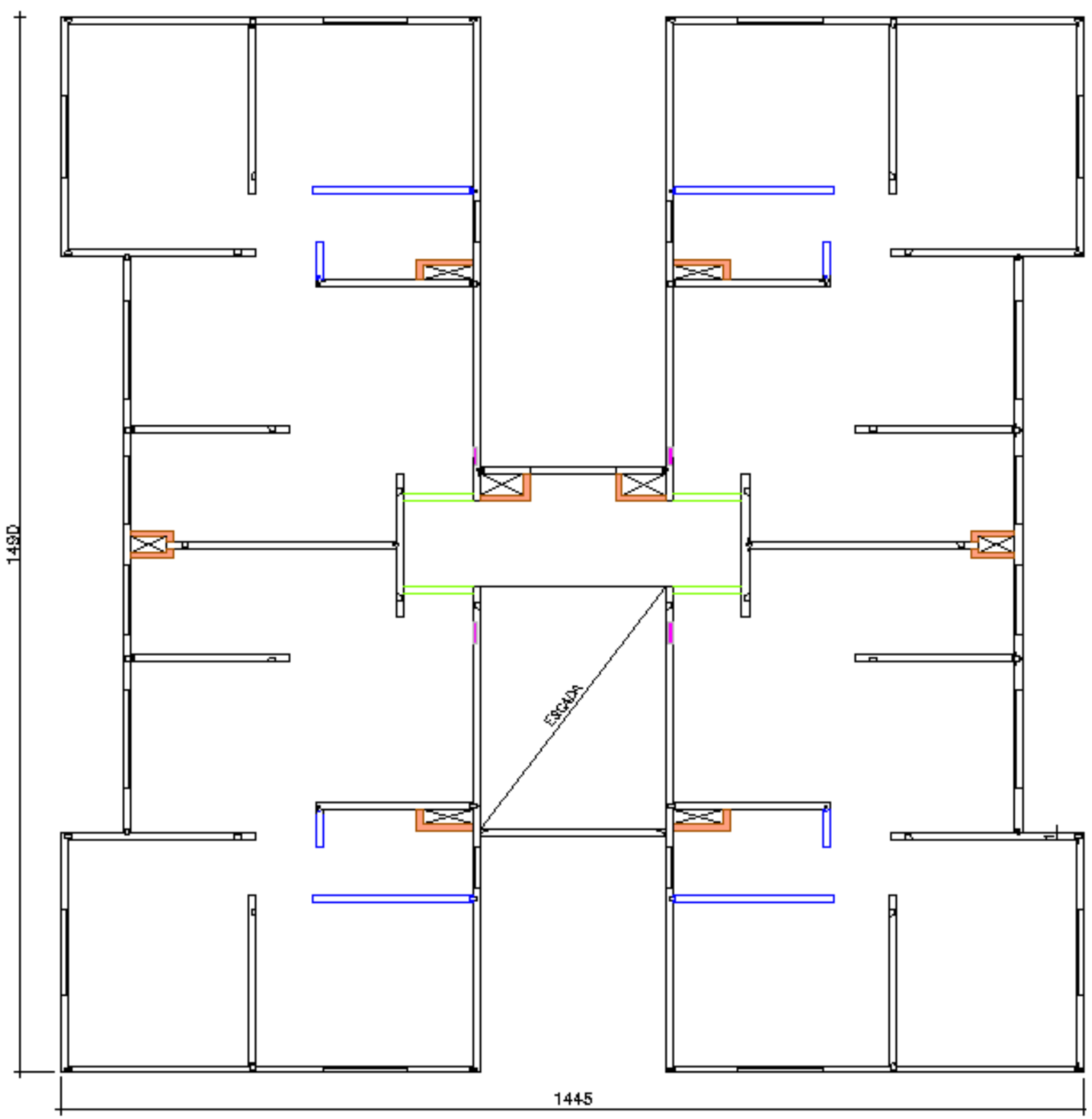

Figura 5.2: Planta baixa do pavimento térreo do edifício, unidades em centímetros

A Figura 5.3 apresenta a ampliação de um apartamento tipo ilustrado na planta baixa da Figura 5.2, visto que os apartamentos apresentam as mesmas dimensões de cômodos.

É possível observar na Figura 5.3 as dimensões dos painéis, esquadrias e as respectivas áreas dos cômodos. 


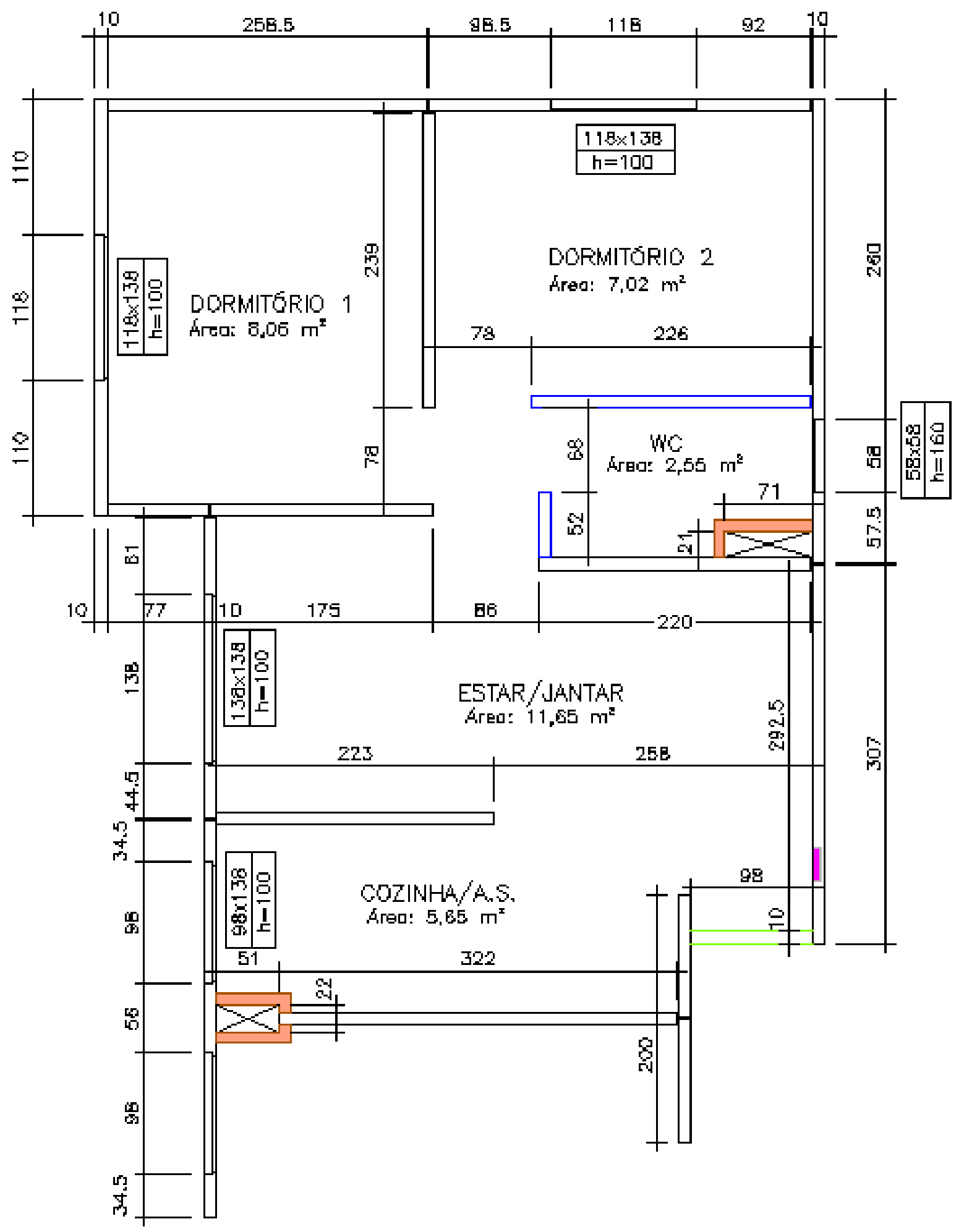

Figura 5.3: Cotas de um apartamento

De acordo com a planta baixa do pavimento térreo do edifício (Figura 5.2), determinam-se as lajes que serão projetadas, numeradas de acordo com a Figura 5.4. 


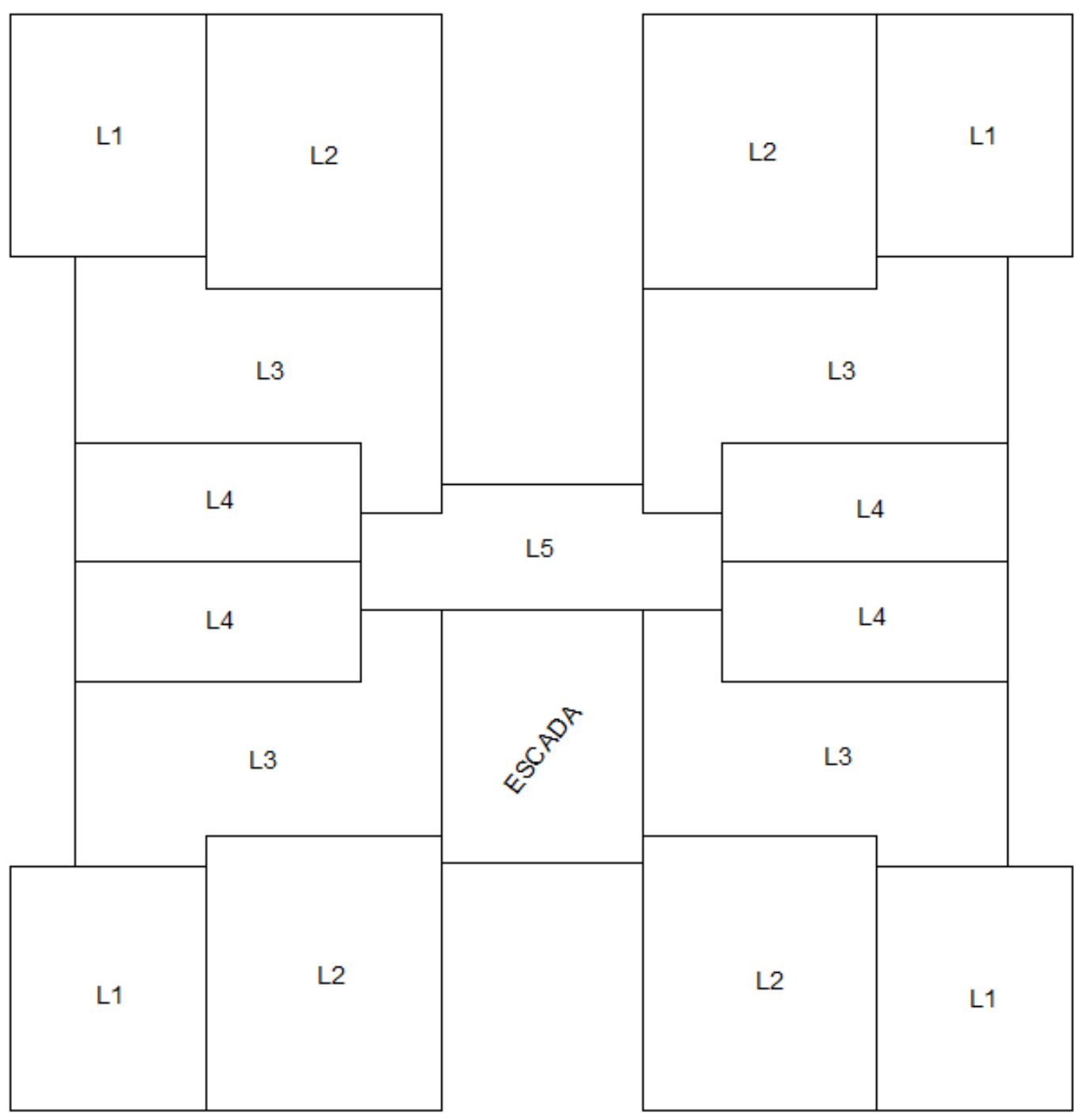

Figura 5.4: Numeração das lajes do edifício em estudo

A nomenclatura dos painéis foi determinada a partir de três classificações. Para os painéis internos adotou-se a abreviação "P”, já para os painéis de fachada, "PF", e para os painéis de divisória, "PD". Os painéis de divisória não têm função estrutural, ou seja, servem apenas para fechamento dos cômodos.

As setas vermelhas mostradas na Figura 5.5 indicam o posicionamento do painel em relação ao operador de montagem desses painéis.

Devido à simetria dos apartamentos, utilizaram-se duas nomenclaturas de indicação, "D” para direita e "E" para esquerda. 


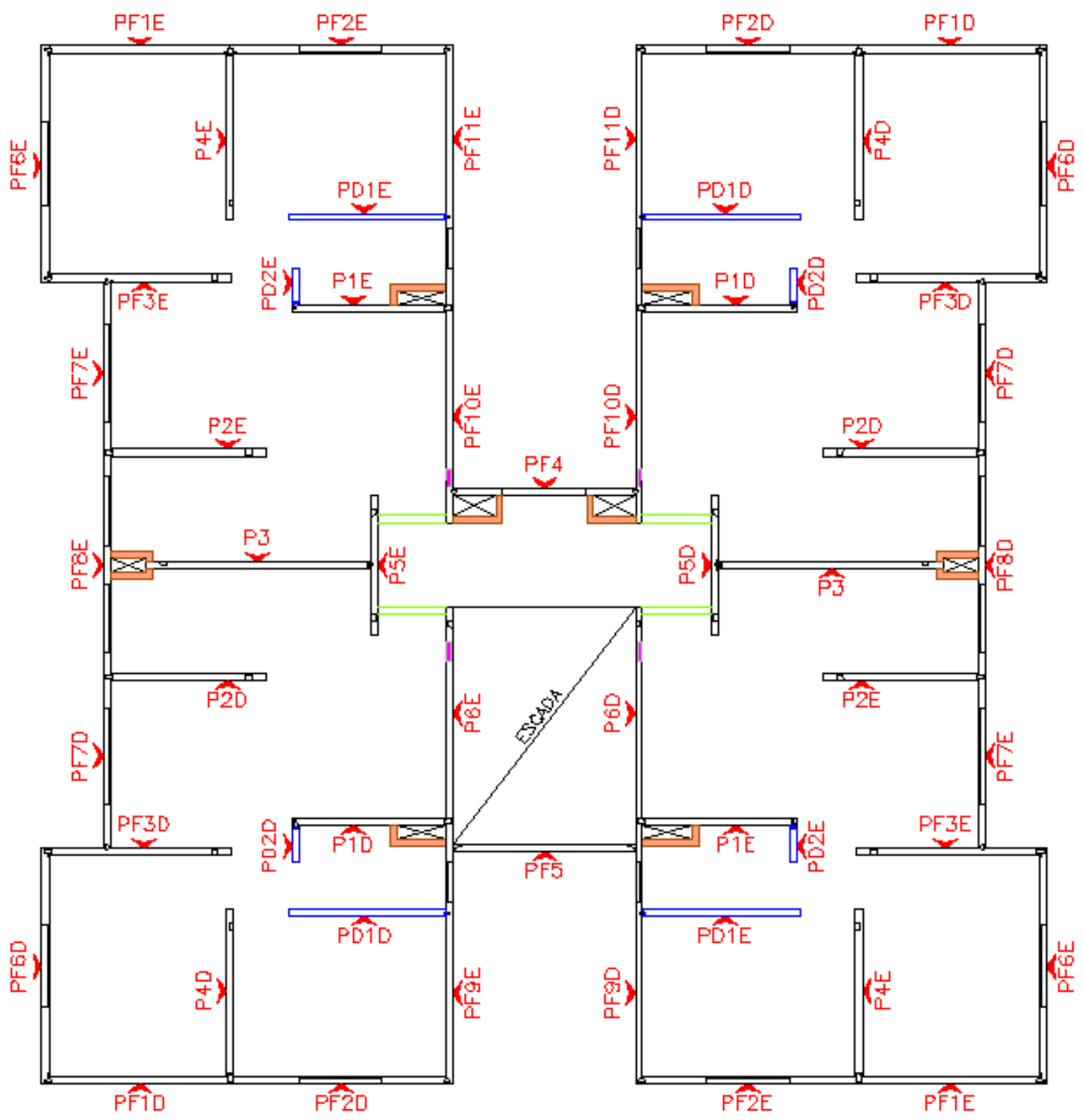

Figura 5.5: Nomenclatura adotada para os painéis pré-moldados

\subsection{CONSIDERAÇÕES DE PROJETO}

Para o dimensionamento do edifício foram utilizadas algumas considerações de projeto para elaboração do modelo:

a) Modelo de pórticos planos;

b) A fundação é rígida, sem ocorrência de deformações;

c) As lajes irão atuar como um diafragma rígido;

d) Continuidade entre os painéis verticais, para garantir a não ocorrência da tração;

e) Vento nas duas direções principais, de $0^{\circ}$ e $90^{\circ}$. 
A estrutura foi composta basicamente de painéis pré-moldados e lajes prontas maciças. Para a escada, foi considerada apenas sua carga sobre os painéis. As ligações foram realizadas de acordo com a necessidade de garantir as condições impostas para o dimensionamento dos elementos.

Seguem as características consideradas para os materiais utilizados.

Para o concreto:

a) Peso específico de $13 \mathrm{kN} / \mathrm{m}^{3}$ para o CLE e $24 \mathrm{kN} / \mathrm{m}^{3}$ para o CAA;

b) Resistência à compressão de 12,5 MPa para o CLE e $60 \mathrm{MPa}$ para o CAA;

c) Módulo de elasticidade de 10 GPa para o CLE e 36,8 GPa para o CAA;

d) Coeficiente de Poisson igual a 0,2 para ambos os concretos;

e) Fator de redução da resistência do concreto de 0,75 para o CLE.

Para o aço:

a) Utilização de telas soldadas para as lajes e para os painéis pré-moldados;

b) Resistência característica de escoamento de $600 \mathrm{MPa}$;

c) Módulo de elasticidade de $210 \mathrm{GPa}$.

\subsection{DIMENSIONAMENTO DAS LAJES}

Os carregamentos das lajes são provenientes de peso próprio (PP), revestimento (Rev), piso e sobrecarga (g). Essas cargas podem diferenciar a depender das características do pavimento. Todas as lajes foram consideras com bordas apoiadas.

A Figura 5.6 apresenta as dimensões e as respectivas áreas de influência para utilização do processo das áreas, como apresentado na ABNT NBR 6118:2007.

Com as características apresentadas na Figura 5.6, é possível elaborar a Tabela 5.3, com os valores das respectivas áreas de influência. 

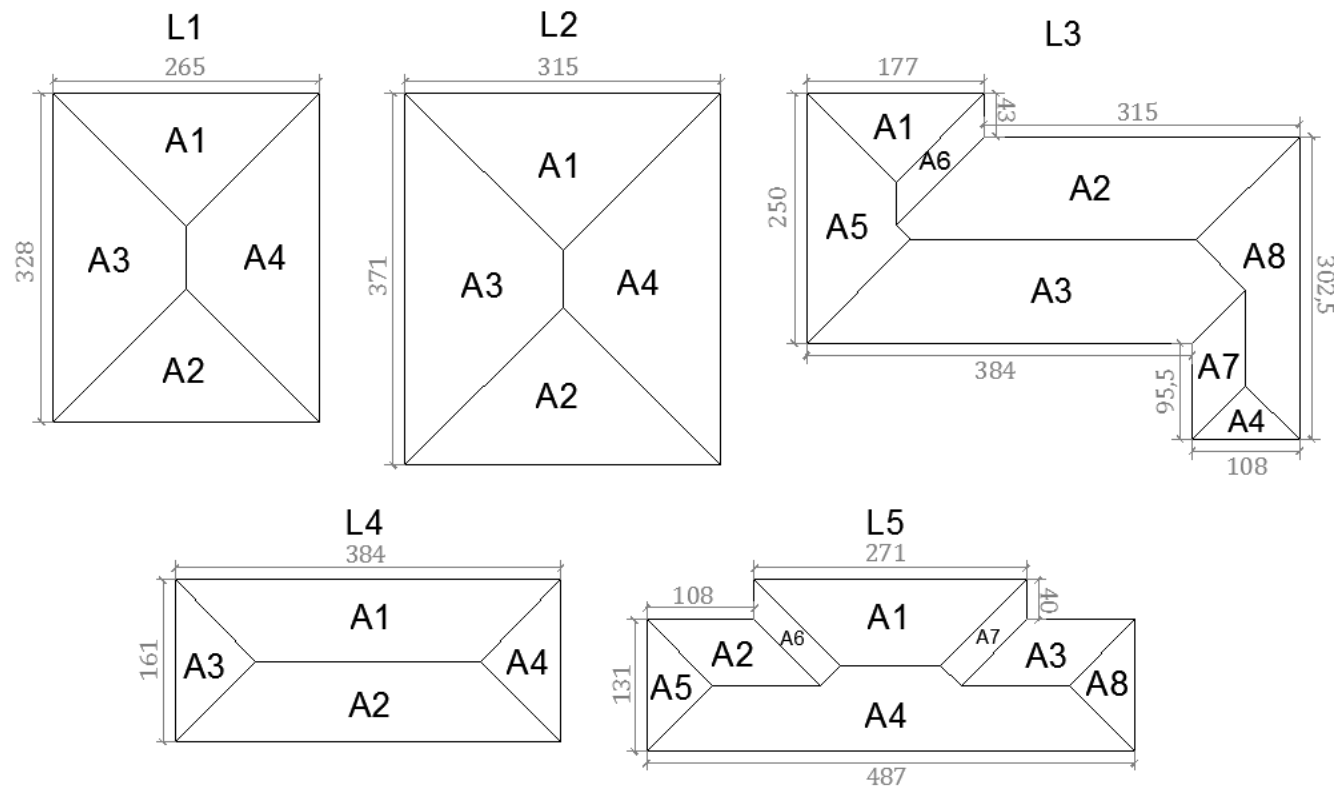

Figura 5.6: Lajes do edifício com suas respectivas dimensões e áreas de e dimensões

Tabela 5.3: Resumo das áreas de influência das lajes do edifício

\begin{tabular}{|c|c|c|c|c|c|c|c|c|c|}
\hline \multirow{2}{*}{ LAJES Áreas de distribuição das cargas $\mathbf{( m}^{\mathbf{2}} \mathbf{4}$} \\
\cline { 2 - 10 } & $\mathbf{A 1}$ & $\mathbf{A 2}$ & $\mathbf{A 3}$ & $\mathbf{A 4}$ & $\mathbf{A 5}$ & $\mathbf{A 6}$ & $\mathbf{A 7}$ & A8 & TOTAL \\
\hline L1 & 1,7556 & 1,7556 & 2,5904 & 2,5904 & - & - & - & - & 8,6920 \\
\hline L2 & 2,4806 & 2,4806 & 3,3626 & 3,3626 & - & - & - & - & 11,6864 \\
\hline L3 & 0,7832 & 3,2324 & 3,7338 & 0,2916 & 1,4522 & 0,3778 & 0,5157 & 1,5869 & 11,9736 \\
\hline L4 & 2,4432 & 2,4432 & 0,6480 & 0,6480 & - & - & - & - & 6,1824 \\
\hline L5 & 1,5860 & 0,7074 & 0,7074 & 3,0008 & 0,4290 & 0,3020 & 0,3020 & 0,4290 & 7,4636 \\
\hline
\end{tabular}

A Tabela 5.4, apresenta os carregamentos nas lajes do pavimento tipo, seguindo as recomendações normativas da ABNT NBR 6120:1980. Foram utilizadas lajes com espessura de $10 \mathrm{~cm}$, respeitando as exigências para a situação da estrutura em incêndio. Vale ressaltar que a laje L2 sofreu um acréscimo de carga devido à presença de painéis de divisória sobre essa laje.

Tabela 5.4: Carregamentos das lajes do pavimento tipo

\begin{tabular}{|c|c|c|c|c|c|c|c|c|c|}
\hline \multirow{2}{*}{ LAJES } & \multirow{2}{*}{$\begin{array}{c}\gamma_{\mathbf{c}} \\
\left(\mathbf{k N} / \mathbf{m}^{3}\right)\end{array}$} & \multirow{2}{*}{$\begin{array}{c}\text { h } \\
(\mathbf{c m})\end{array}$} & \multicolumn{6}{|c|}{ Carregamentos $\left(\mathrm{kN} / \mathrm{m}^{2}\right)$} & \multirow{2}{*}{$\begin{array}{c}\text { Carga } \\
(\mathbf{k N})\end{array}$} \\
\hline & & & PP & Rev & Piso & $\mathbf{q}$ & Outras & TOTAL & \\
\hline L1 & 13 & 10 & 1,30 & 0,50 & 0,50 & 1,50 & - & 3,80 & 33,03 \\
\hline L2 & 13 & 10 & 1,30 & 0,50 & 0,50 & 1,50 & 0,84 & 4,64 & 54,22 \\
\hline L3 & 13 & 10 & 1,30 & 0,50 & 0,50 & 1,50 & - & 3,80 & 45,50 \\
\hline L4 & 13 & 10 & 1,30 & 0,50 & 0,50 & 1,50 & - & 3,80 & 23,49 \\
\hline L5 & 13 & 10 & 1,30 & 0,50 & 0,50 & 1,50 & - & 3,80 & 28,36 \\
\hline
\end{tabular}


Conhecidos os carregamentos, foram obtidas as reações de apoio das lajes (Tabela 5.5) e os respectivos momentos fletores (Tabela 5.6).

Cabe lembrar que em dimensionamentos de elementos pré-moldados a ABNT NBR 6118:2007 permite utilizar um coeficiente de majoração para os esforços igual a 1,30 ( $\left.\gamma_{\mathrm{f}}\right)$. Essa majoração é necessária, a fim de levar em conta a variabilidade no peso próprio da peça.

Tabela 5.5: Reações de apoio das lajes do pavimento tipo

\begin{tabular}{|c|c|c|c|c|c|c|c|c|}
\hline \multirow{2}{*}{ LAJES } & \multicolumn{8}{|c|}{ Reações de apoio das lajes (kN/m) } \\
\cline { 2 - 10 } & A1 & $\mathbf{A 2}$ & $\mathbf{A 3}$ & $\mathbf{A 4}$ & $\mathbf{A 5}$ & $\mathbf{A 6}$ & $\mathbf{A 7}$ & $\mathbf{A 8}$ \\
\hline L1 & 2,52 & 2,52 & 3,00 & 3,00 & - & - & - & - \\
\hline L2 & 3,65 & 3,65 & 4,21 & 4,21 & - & - & - & - \\
\hline L3 & 1,68 & 3,90 & 3,69 & 1,03 & 2,21 & 3,34 & 2,05 & 1,99 \\
\hline L4 & 2,42 & 2,42 & 1,53 & 1,53 & - & - & - & - \\
\hline L5 & 2,22 & 2,49 & 2,49 & 2,34 & 1,24 & 2,87 & 2,87 & 1,24 \\
\hline
\end{tabular}

Tabela 5.6: Momentos de cálculo para as lajes do pavimento tipo

\begin{tabular}{|c|c|c|c|c|c|}
\hline \multirow{2}{*}{ LAJES } & \multirow{2}{*}{$\boldsymbol{\lambda}$} & \multicolumn{4}{|c|}{ Momentos de cálculo $(\mathbf{k N . m} / \mathbf{m})$} \\
\cline { 3 - 6 } & & $\mathbf{m}_{\mathbf{x}, \mathbf{d}}$ & $\mathbf{m}_{\mathbf{x}, \mathbf{d}}^{\prime}$ & $\mathbf{m}_{\mathbf{y}, \mathbf{d}}$ & $\mathbf{m}_{\mathbf{y}, \mathbf{d}}^{\prime}$ \\
\hline L1 & 1,24 & 2,19 & - & 1,53 & - \\
\hline L2 & 1,18 & 3,53 & - & 2,68 & - \\
\hline L3 & 2,02 & 3,84 & - & 0,97 & - \\
\hline L4 & 2,39 & 1,68 & - & 0,43 & - \\
\hline L5 & 2,85 & 1,90 & - & 0,48 & - \\
\hline
\end{tabular}

Em seguida, foram determinadas as áreas mínimas de aço, calculadas e adotadas como mostra a Tabela 5.7. Após determinadas as áreas de aço, foram escolhidas as respectivas telas soldadas (Tabela 5.8). Para as lajes L1 e L2 utilizou-se a tela soldada Q113, por serem armadas em duas direções, e para as lajes L3, L4 e L5 foi utilizada a R159.

Tabela 5.7: Área de aço para as lajes do pavimento tipo

\begin{tabular}{|c|c|c|c|c|c|c|c|}
\hline \multirow{2}{*}{ LAJES } & \multirow{2}{*}{$\boldsymbol{\lambda}$} & \multicolumn{2}{|c|}{$\mathbf{a}_{\mathbf{s}, \mathbf{m} \text { ín. }}\left(\mathbf{c m}^{2} / \mathbf{m}\right)$} & \multicolumn{2}{|c|}{$\mathbf{a}_{\mathbf{s}, \mathbf{c a l c .}}\left(\mathbf{c m}^{2} / \mathbf{m}\right)$} & \multicolumn{2}{|c|}{$\mathbf{a}_{\mathbf{s}}\left(\mathbf{c m}^{2} / \mathbf{m}\right)$} \\
\cline { 3 - 8 } & & $\mathbf{a}_{\mathbf{s}, \mathbf{x}}$ & $\mathbf{a}_{\mathbf{s}, \mathbf{y}}$ & $\mathbf{a}_{\mathbf{s}, \mathbf{x}}$ & $\mathbf{a}_{\mathbf{s} \mathbf{y}}$ & $\mathbf{a}_{\mathbf{s}, \mathbf{x}}$ & $\mathbf{a}_{\mathbf{s , \mathbf { y }}}$ \\
\hline L1 & 1,24 & 1,00 & 1,00 & 0,56 & 0,41 & 1,00 & 1,00 \\
\hline L2 & 1,18 & 1,00 & 1,00 & 0,92 & 0,73 & 1,00 & 1,00 \\
\hline L3 & 2,02 & 1,50 & 0,90 & 1,02 & 0,26 & 1,50 & 0,90 \\
\hline L4 & 2,39 & 1,50 & 0,90 & 0,43 & 0,11 & 1,50 & 0,90 \\
\hline L5 & 2,85 & 1,50 & 0,90 & 0,49 & 0,13 & 1,50 & 0,90 \\
\hline
\end{tabular}


Tabela 5.8: Telas soldadas utilizadas nas lajes do pavimento tipo

\begin{tabular}{|c|c|c|c|c|c|}
\hline \multirow{2}{*}{ LAJES } & \multicolumn{2}{|c|}{$\mathbf{a}_{\mathbf{s}}\left(\mathbf{c m}^{2} \mathbf{m}\right)$} & \multirow{2}{*}{ Tela } & \multicolumn{2}{c|}{$\mathbf{a}_{\mathbf{s}, \text { tela }}\left(\mathbf{c m}^{2} / \mathbf{m}\right)$} \\
\cline { 2 - 3 } \cline { 5 - 6 } & $\mathbf{a}_{\mathbf{s , \mathbf { x }}}$ & $\mathbf{a}_{\mathbf{s}, \mathbf{y}}$ & & $\mathbf{a}_{\mathbf{s}, \mathbf{x}}$ & $\mathbf{a}_{\mathbf{s}, \mathbf{y}}$ \\
\hline L1 & 1,00 & 1,00 & Q113 & 1,13 & 1,13 \\
\hline L2 & 1,00 & 1,00 & Q113 & 1,13 & 1,13 \\
\hline L3 & 1,50 & 0,90 & R159 & 1,59 & 1,06 \\
\hline L4 & 1,50 & 0,90 & R159 & 1,59 & 1,06 \\
\hline L5 & 1,50 & 0,90 & R159 & 1,59 & 1,06 \\
\hline
\end{tabular}

Por fim, as lajes passaram pelo processo de verificação de flecha e abertura de fissura (ELS) e resistência ao cisalhamento, no ELU (Tabela 5.9).

Pelo fato do concreto apresentar baixo peso específico, as cargas sofrem uma diminuição acentuada, o que é evidenciado pelas folgas nas verificações indicadas nessa tabela.

Tabela 5.9: Verificações das lajes do pavimento tipo

\begin{tabular}{|c|c|c|c|c|c|c|}
\hline \multirow{2}{*}{ LAJES } & \multicolumn{2}{|c|}{ Flecha $(\mathbf{m m})$} & \multicolumn{2}{c|}{$\begin{array}{c}\text { Abertura de fissuras } \\
(\mathbf{m m})\end{array}$} & \multicolumn{2}{c|}{$\begin{array}{c}\text { Cisalhamento } \\
(\mathbf{k N} / \mathbf{m})\end{array}$} \\
\cline { 2 - 7 } & Total & Limite & Total & Limite & $\mathbf{V}_{\text {sd }}$ & $\mathbf{V}_{\mathbf{R d 1}}$ \\
\hline L1 & 2,42 & 10,60 & 0,08 & 0,30 & 4,10 & 21,67 \\
\hline L2 & 5,84 & 12,60 & 0,22 & 0,30 & 5,78 & 21,67 \\
\hline L3 & 3,87 & 9,74 & 0,15 & 0,30 & 6,32 & 21,51 \\
\hline L4 & 0,74 & 6,44 & 0,03 & 0,30 & 4,18 & 21,51 \\
\hline L5 & 0,94 & 6,84 & 0,04 & 0,30 & 4,44 & 21,51 \\
\hline
\end{tabular}

\subsection{FORÇAS VERTICAIS NOS PAINÉIS}

As forças verticais ocorrem por conta das reações de apoio das lajes e pelo peso próprio dos painéis. A Figura 5.7 mostra as considerações adotadas para a distribuição dos carregamentos das lajes nos respectivos painéis.

Nessa figura, os comprimentos dos painéis foram modificados para coincidirem com os comprimentos das lajes. As diferenças de carregamento distribuído nos painéis são devidas à adição das reações das lajes, e a carga concentrada decorre da criação de eixo imaginário para transferir as cargas da laje L3 até o painel PF3. 
PF1 (HORIZONTAL)

10

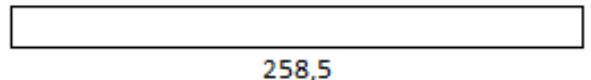

258,5

PF2 (HORIZONTAL)

10

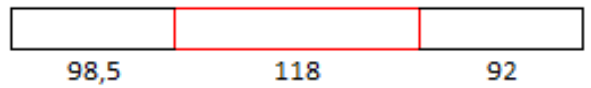

PF3 (HORIZONTAL)

10

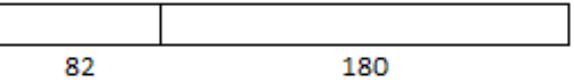

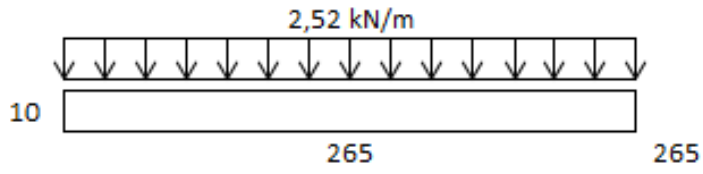

10

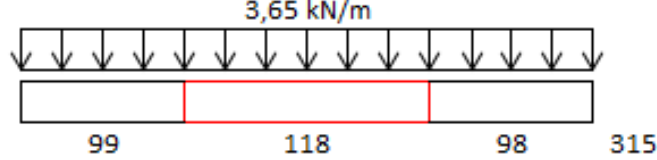

10

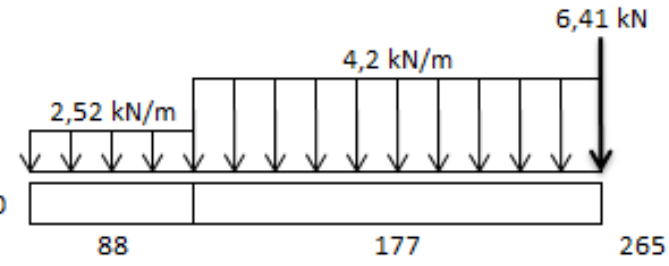

Figura 5.7: Representação das reações de apoio das lajes nos respectivos painéis

Sendo assim, na Tabela 5.10 apresentam-se os valores das forças verticais nos painéis para cada pavimento. As parcelas das reações das lajes foram divididas, referentes às cargas permanentes (peso próprio, revestimento e piso) e às cargas acidentais.

Tabela 5.10: Carregamentos verticais nos painéis

\begin{tabular}{|c|c|c|c|c|c|c|c|c|c|}
\hline Painel & $\begin{array}{c}\text { Quant. } \\
\mathbf{p} / \mathbf{p a v} .\end{array}$ & $\begin{array}{c}\text { Comp. } \\
\text { do painel } \\
(\mathbf{c m})\end{array}$ & $\begin{array}{c}\text { Espessura } \\
(\mathbf{c m})\end{array}$ & $\begin{array}{c}\text { Altura } \\
\mathbf{( c m})\end{array}$ & $\begin{array}{c}\text { Carga } \\
\mathbf{d e ~ l a j e} \\
\mathbf{( k N )}\end{array}$ & $\begin{array}{c}\text { Carga } \\
\mathbf{d e ~ P P} \\
\mathbf{( k N )}\end{array}$ & $\begin{array}{c}\text { Carga } \\
\text { Perm. } \\
(\mathbf{k N})\end{array}$ & $\begin{array}{c}\text { Carga } \\
\text { Acid. } \\
(\mathbf{k N})\end{array}$ & $\begin{array}{c}\text { Carga no } \\
\mathbf{p a i n e l} \\
(\mathbf{k N})\end{array}$ \\
\hline PF1 & 4 & 258,5 & 10 & 270 & 6,67 & 9,07 & 13,11 & 2,63 & 15,74 \\
\hline PF2 & 4 & 308,5 & 10 & 270 & 11,51 & 10,83 & 17,79 & 4,54 & 22,34 \\
\hline PF3 & 4 & 262,0 & 10 & 270 & 16,06 & 9,20 & 18,92 & 6,34 & 25,26 \\
\hline PF4 & 1 & 259,0 & 10 & 270 & 6,03 & 9,09 & 12,74 & 2,38 & 15,12 \\
\hline PF5 & 1 & 259,0 & 10 & 270 & 17,25 & 9,09 & 19,53 & 6,81 & 26,34 \\
\hline PF6 & 4 & 338,0 & 10 & 270 & 9,84 & 11,86 & 17,82 & 3,89 & 21,71 \\
\hline PF7 & 4 & 243,5 & 10 & 270 & 5,52 & 8,55 & 11,89 & 2,18 & 14,07 \\
\hline PF8 & 2 & 321,0 & 10 & 270 & 4,92 & 11,27 & 14,25 & 1,94 & 16,19 \\
\hline PF9 & 2 & 375,5 & 10 & 270 & 15,60 & 13,18 & 22,62 & 6,16 & 28,78 \\
\hline PF10 & 2 & 307,0 & 10 & 270 & 9,08 & 10,78 & 16,27 & 3,58 & 19,85 \\
\hline PF11 & 2 & 375,5 & 10 & 270 & 15,60 & 13,18 & 22,62 & 6,16 & 28,78 \\
\hline P1 & 4 & 220,0 & 10 & 270 & 23,79 & 7,72 & 22,12 & 9,39 & 31,52 \\
\hline P2 & 4 & 223,0 & 10 & 270 & 23,47 & 7,83 & 22,03 & 9,27 & 31,30 \\
\hline P3 & 2 & 322,0 & 10 & 270 & 18,57 & 11,30 & 22,54 & 7,33 & 29,87 \\
\hline P4 & 4 & 239,0 & 10 & 270 & 20,47 & 8,39 & 20,78 & 8,08 & 28,86 \\
\hline P5 & 2 & 200,0 & 10 & 270 & 12,80 & 7,02 & 14,77 & 5,05 & 19,82 \\
\hline P6 & 2 & 307,0 & 10 & 270 & 20,91 & 10,78 & 23,43 & 8,25 & 31,69 \\
\hline
\end{tabular}


Em seguida, foram determinadas as cargas por pavimento até o nível de fundação, como mostra a Tabela 5.11. Foram divididos em painéis individuais por pavimento tipo e térreo, considerando a carga individual de cada painel na fundação. Na coluna intitulada Fundação Total a carga foi obtida multiplicando-se a carga de cada painel na fundação pelo número de repetição nos pavimentos, indicado na Tabela 5.10.

Tabela 5.11: Carregamentos verticais até a fundação

\begin{tabular}{|c|c|c|c|c|}
\hline PAINEL & Tipo $(\mathbf{k N})$ & Térreo $(\mathbf{k N})$ & Fundação $(\mathbf{k N})$ & Fundação total $(\mathbf{k N})$ \\
\hline PF1 & 62,98 & 15,74 & 78,72 & 314,89 \\
\hline PF2 & 89,35 & 22,34 & 111,69 & 446,77 \\
\hline PF3 & 101,03 & 25,26 & 126,29 & 505,17 \\
\hline PF4 & 60,47 & 15,12 & 75,59 & 75,59 \\
\hline PF5 & 105,36 & 26,34 & 131,70 & 131,70 \\
\hline PF6 & 86,83 & 21,71 & 108,54 & 434,15 \\
\hline PF7 & 56,26 & 14,07 & 70,33 & 281,30 \\
\hline PF8 & 64,77 & 16,19 & 80,96 & 161,92 \\
\hline PF9 & 115,13 & 28,78 & 143,91 & 287,83 \\
\hline PF10 & 79,41 & 19,85 & 99,26 & 198,52 \\
\hline PF11 & 115,13 & 28,78 & 143,91 & 287,83 \\
\hline P1 & 126,06 & 31,52 & 157,58 & 630,30 \\
\hline P2 & 125,20 & 31,30 & 156,50 & 626,00 \\
\hline P3 & 119,48 & 29,87 & 149,35 & 298,71 \\
\hline P4 & 115,42 & 28,86 & 144,28 & 577,11 \\
\hline P5 & 79,30 & 19,82 & 99,12 & 198,24 \\
\hline P6 & 126,75 & 31,69 & 158,43 & 316,86 \\
\hline & \multicolumn{3}{|r|}{ TOTAL } & 5772,88 \\
\hline
\end{tabular}

\subsection{AÇÃO DO VENTO}

Para o cálculo da ação do vento foram realizadas algumas considerações, como a determinação da velocidade básica do vento e dos fatores $S_{1}, S_{2}$ e $S_{3}$, conforme as recomendações da ABNT NBR 6123:1988. A seguir têm-se os valores adotados:

a) A velocidade básica do vento $\left(\mathrm{V}_{\mathrm{o}}\right)$ adotada foi de $40 \mathrm{~m} / \mathrm{s}$, sendo abrangente para quase a totalidade do território brasileiro;

b) $\mathrm{O}$ fator topográfico $\left(\mathrm{S}_{1}\right)$ adotado foi de 1,0, para terreno plano ou fracamente acidentado; 
c) A categoria adotada para determinação do fator $S_{2}$ foi a IV (Terrenos cobertos por obstáculos numerosos e pouco espaçados, em zona florestal, industrial ou urbanizados) e a classe A (Todas as unidades de vedação, seus elementos de fixação e peças individuais de estruturas sem vedação. Toda edificação na qual a maior dimensão horizontal ou vertical não exceda $20 \mathrm{~m}$ ).

d) $\mathrm{O}$ fator estatístico $\mathrm{S}_{3}$ adotado foi 1,0, que caracteriza edificações para hotéis e residências, além de edificações para comércio e indústria com alto fator de ocupação.

A força de arrasto foi definida a partir do método da área de influência de atuação das forças em intervalos de cotas do edifício, como mostra a Figura 5.8. É possível observar que entre as cotas $12,15 \mathrm{~m}$ e 13,50 $\mathrm{m}$ a área de influência é definida pela metade das demais áreas. Para o intervalo de cotas entre $0 \mathrm{~m}$ e 1,35 m, a ação do vento não apresenta influência suficiente para ser considerada em projeto, pois está próxima ao nível do terreno.

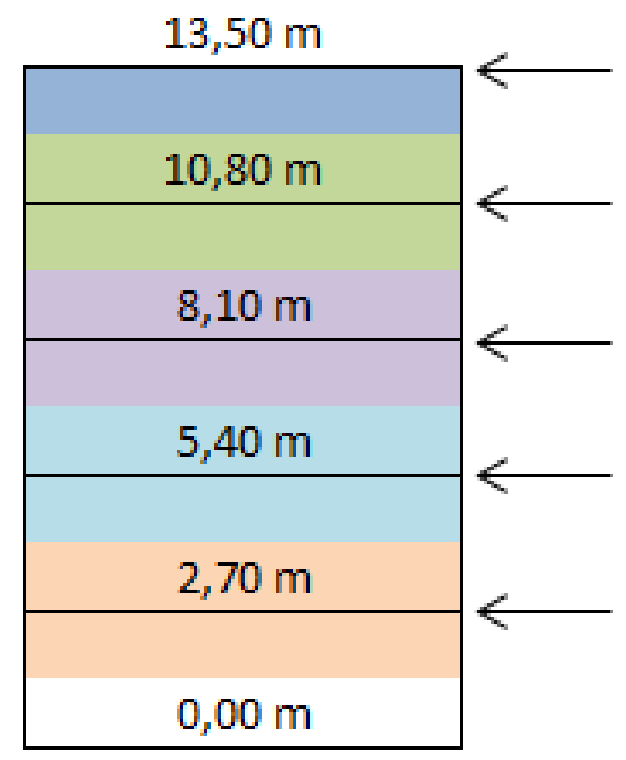

Figura 5.8: Área de influência para determinação das forças do vento

A Tabela 5.12 apresenta os valores utilizados para obtenção da força de arrasto. Esses valores foram obtidos a partir das tabelas propostas pela norma ABNT NBR 6123:1988, na qual são utilizados para determinação do fator $S_{2}$ os valores dos parâmetros b, $F_{r}$ e p. Foram calculados os valores da área de influência $\left(\mathrm{A}_{\mathrm{e}}\right)$, nas direções principais correspondentes a $0^{\circ}$ e $90^{\circ}$, denominados de direção " $\mathrm{X}$ " e "Y" respectivamente, bem como os respectivos coeficientes de $\operatorname{arrasto}\left(\mathrm{C}_{\mathrm{a}}\right)$. 
Tabela 5.12: Valores utilizados para obtenção da força de arrasto

\begin{tabular}{|c|c|}
\hline Item & Valores \\
\hline $\mathrm{V}_{0}(\mathrm{~m} / \mathrm{s})$ & 40 \\
\hline $\mathrm{S}_{1}$ & 1,0 \\
\hline $\mathrm{S}_{3}$ & 1,0 \\
\hline Categoria & $\mathrm{IV}$ \\
\hline Classe & $\mathrm{A}$ \\
\hline $\mathrm{b}$ & 0,86 \\
\hline $\mathrm{F}_{\mathrm{r}}$ & 1,00 \\
\hline $\mathrm{p}$ & 0,12 \\
\hline $\mathrm{A}_{\mathrm{e}}($ direção "X") / pavimento & 40,23 \\
\hline $\mathrm{A}_{\mathrm{e}}($ direção $\mathrm{Y}$ ") / pavimento & 39,02 \\
\hline Turbulência & Baixa \\
\hline $\mathrm{C}_{\mathrm{a}}$ (direção "X") & 1,14 \\
\hline $\mathrm{C}_{\mathrm{a}}$ (direção "Y") & 1,10 \\
\hline
\end{tabular}

Como mostra a Tabela 5.13, foram calculados os valores para as forças de arrasto nas direções "X" e "Y", para as cotas apresentadas na Figura 5.8.

Tabela 5.13: Forças de arrasto para direção X e Y

\begin{tabular}{|c|c|c|c|c|c|c|}
\hline Pavim. & $\mathbf{z}(\mathbf{m})$ & $\mathbf{S}_{\mathbf{2}}$ & $\mathbf{V}_{\mathbf{k}}(\mathbf{m} / \mathbf{s})$ & $\begin{array}{c}\mathbf{q} \\
\left(\mathbf{k N} / \mathbf{m}^{\mathbf{2}}\right)\end{array}$ & $\mathbf{F}_{\mathbf{x}}(\mathbf{k N})$ & $\mathbf{F}_{\mathbf{y}}(\mathbf{k N})$ \\
\hline $5^{\mathbf{o}}$ & 13,50 & 0,89 & 35,66 & 0,78 & 17,88 & 16,73 \\
\hline $4^{\mathbf{o}}$ & 10,80 & 0,87 & 34,72 & 0,74 & 33,89 & 31,71 \\
\hline $3^{\mathbf{o}}$ & 8,10 & 0,84 & 33,54 & 0,69 & 31,63 & 29,60 \\
\hline $2^{{ }^{\circ}}$ & 5,40 & 0,80 & 31,95 & 0,63 & 28,70 & 26,85 \\
\hline $1^{{ }^{\circ}}$ & 2,70 & 0,73 & 29,40 & 0,53 & 24,30 & 22,74 \\
\hline
\end{tabular}

\subsection{ESFORÇOS NOS PAINÉIS}

Os esforços que atuam nos painéis foram determinados pela metodologia proposta, a partir do modelo de associação de pórticos, apresentado no capítulo 4.

Para melhor compreensão foram adotadas as siglas s1, s2 e s3, para as partes sólidas 1, 2 e 3, respectivamente, assim como, a1 e a2, para as aberturas 1 e 2 (Figura 5.9). Os painéis isolados apresentam apenas uma parte sólida, enquanto que os painéis com aberturas são constituídos de pelo menos duas partes sólidas e uma abertura. 


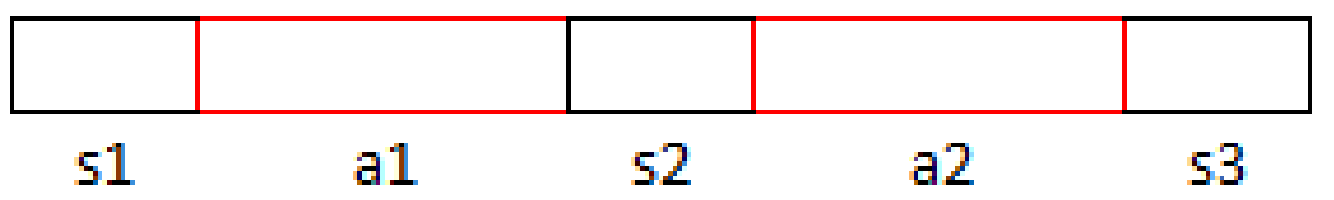

Figura 5.9: Exemplo das partes sólidas e abertas no painel

As características dos painéis estão apresentadas na Tabela 5.14, sendo os painéis PF1, PF3, PF5, PF9, PF10, PF11, P1, P2, P3, P4, P5 e P6 constituídos apenas de partes sólidas, e os painéis PF2, PF4, PF6, PF7 e PF8, de partes sólidas mais aberturas.

Tabela 5.14: Características dos painéis do edifício

\begin{tabular}{|c|c|c|c|c|c|c|c|}
\hline \multirow{2}{*}{ Painel } & \multirow{2}{*}{ Direção } & \multirow{2}{*}{\begin{tabular}{c} 
Espessura \\
\cline { 5 - 8 }
\end{tabular}} & & \multicolumn{6}{|c|}{ Comprimento (cm) } \\
\cline { 5 - 8 } & & $\mathbf{s 1}$ & $\mathbf{a 1}$ & $\mathbf{s 2}$ & $\mathbf{a 2}$ & $\mathbf{s 3}$ \\
\hline PF1 & $\mathrm{X}$ & 10 & 258,5 & - & - & - & - \\
\hline PF2 & $\mathrm{X}$ & 10 & 98,5 & 118,0 & 92,0 & & \\
\hline PF3 & $\mathrm{X}$ & 10 & 262,0 & - & - & - & - \\
\hline PF4 & $\mathrm{X}$ & 10 & 69,5 & 120,0 & 69,5 & & \\
\hline PF5 & $\mathrm{X}$ & 10 & 259,0 & - & - & - & - \\
\hline PF6 & $\mathrm{Y}$ & 10 & 110,0 & 118,0 & 110,0 & - & - \\
\hline PF7 & $\mathrm{Y}$ & 10 & 61,0 & 138,0 & 44,5 & - & - \\
\hline PF8 & $\mathrm{Y}$ & 10 & 34,5 & 98,0 & 56,0 & 98,0 & 34,5 \\
\hline PF9 & $\mathrm{Y}$ & 10 & 375,5 & - & - & - & - \\
\hline PF10 & $\mathrm{Y}$ & 10 & 307,0 & - & - & - & - \\
\hline PF11 & $\mathrm{Y}$ & 10 & 375,5 & - & - & - & - \\
\hline P1 & $\mathrm{X}$ & 10 & 220,0 & - & - & - & - \\
\hline P2 & $\mathrm{X}$ & 10 & 223,0 & - & - & - & - \\
\hline P3 & $\mathrm{X}$ & 10 & 322,0 & - & - & - & - \\
\hline P4 & $\mathrm{Y}$ & 10 & 239,0 & - & - & - & - \\
\hline P5 & $\mathrm{Y}$ & 10 & 200,0 & - & - & - & - \\
\hline P6 & $\mathrm{Y}$ & 10 & 307,0 & - & - & - & - \\
\hline
\end{tabular}

Em seguida, foram determinadas as áreas das seções transversais, momentos de inércia e módulos de rigidez dos painéis pré-moldados, com auxílio das equações (4.2) até (4.12).

A Tabela 5.15 apresenta esses valores, e a Tabela 5.16 mostra as áreas e momentos de inércia totais, de acordo com a quantidade de repetição do painel no pavimento. 
Tabela 5.15: Características geométricas dos painéis

\begin{tabular}{|c|c|c|c|c|c|c|c|c|c|}
\hline \multirow{2}{*}{ Painel } & \multicolumn{3}{|c|}{ Áreas $\left(\mathbf{m}^{2}\right)$} & \multicolumn{3}{c|}{ Momentos de Inércia $\left(\mathbf{m}^{\mathbf{4}}\right)$} & \multicolumn{2}{c|}{ Módulos de rigidez $\left(\mathbf{m}^{3}\right)$} \\
\cline { 2 - 10 } & s1 & $\mathbf{s 2}$ & $\mathbf{s 3}$ & $\mathbf{s 1}$ & $\mathbf{s 2}$ & $\mathbf{s 3}$ & $\mathbf{s 1}$ & $\mathbf{s 2}$ & $\mathbf{s 3}$ \\
\hline PF1 & 0,259 & - & - & 0,14395 & - & - & 0,1114 & - & - \\
\hline PF2 & 0,099 & 0,092 & - & 0,00796 & 0,00649 & - & 0,0162 & 0,0141 & - \\
\hline PF3 & 0,262 & - & - & 0,14987 & - & - & 0,1144 & - & - \\
\hline PF4 & 0,070 & 0,070 & - & 0,00280 & 0,00280 & - & 0,0081 & 0,0081 & - \\
\hline PF5 & 0,259 & - & - & 0,14478 & - & - & 0,1118 & - & - \\
\hline PF6 & 0,110 & 0,110 & - & 0,01109 & 0,01109 & - & 0,0202 & 0,0202 & - \\
\hline PF7 & 0,061 & 0,045 & - & 0,00189 & 0,00073 & - & 0,0062 & 0,0033 & - \\
\hline PF8 & 0,035 & 0,056 & 0,035 & 0,00034 & 0,00146 & 0,00034 & 0,0020 & 0,0052 & 0,0020 \\
\hline PF9 & 0,376 & - & - & 0,44121 & - & - & 0,2350 & - & - \\
\hline PF10 & 0,307 & - & - & 0,24112 & - & - & 0,1571 & - & - \\
\hline PF11 & 0,376 & - & - & 0,44121 & - & - & 0,2350 & - & - \\
\hline P1 & 0,220 & - & - & 0,08873 & - & - & 0,0807 & - & - \\
\hline P2 & 0,223 & - & - & 0,09241 & - & - & 0,0829 & - & - \\
\hline P3 & 0,322 & - & - & 0,27822 & - & - & 0,1728 & - & - \\
\hline P4 & 0,239 & - & - & 0,11377 & - & - & 0,0952 & - & - \\
\hline P5 & 0,200 & - & - & 0,06667 & - & - & 0,0667 & - & - \\
\hline P6 & 0,307 & - & - & 0,24112 & - & - & 0,1571 & - & - \\
\hline
\end{tabular}

Tabela 5.16: Área e Momento de inércia total das seções sólidas

\begin{tabular}{|c|c|c|c|c|c|c|c|}
\hline \multirow{2}{*}{ Painel } & \multirow{2}{*}{ Quant. } & \multicolumn{3}{|c|}{ Áreas Totais $\left(\mathbf{m}^{\mathbf{2}}\right)$} & \multicolumn{3}{c|}{ Mom. de Inércia Totais $\left(\mathbf{m}^{\mathbf{4}}\right)$} \\
\cline { 3 - 8 } & & $\mathbf{s 1}$ & $\mathbf{s 2}$ & $\mathbf{s 3}$ & $\mathbf{s 1}$ & $\mathbf{s 2}$ & $\mathbf{s 3}$ \\
\hline PF1 & 4 & 1,034 & - & - & 0,57579 & - & - \\
\hline PF2 & 4 & 0,394 & 0,368 & - & 0,03186 & 0,02596 & - \\
\hline PF3 & 4 & 1,048 & - & - & 0,59949 & - & - \\
\hline PF4 & 1 & 0,070 & 0,070 & - & 0,00280 & 0,00280 & - \\
\hline PF5 & 1 & 0,259 & - & - & 0,14478 & - & - \\
\hline PF6 & 4 & 0,440 & 0,440 & - & 0,04437 & 0,04437 & - \\
\hline PF7 & 4 & 0,244 & 0,178 & - & 0,00757 & 0,00294 & - \\
\hline PF8 & 2 & 0,069 & 0,112 & 0,069 & 0,00068 & 0,00293 & 0,00068 \\
\hline PF9 & 2 & 0,751 & - & - & 0,88243 & - & - \\
\hline PF10 & 2 & 0,614 & - & - & 0,48224 & - & - \\
\hline PF11 & 2 & 0,751 & - & - & 0,88243 & - & - \\
\hline P1 & 4 & 0,880 & - & - & 0,35493 & - & - \\
\hline P2 & 4 & 0,892 & - & - & 0,36965 & - & - \\
\hline P3 & 2 & 0,644 & - & - & 0,55644 & - & - \\
\hline P4 & 4 & 0,956 & - & - & 0,45506 & - & - \\
\hline P5 & 2 & 0,400 & - & - & 0,13333 & - & - \\
\hline P6 & 2 & 0,614 & - & - & 0,48224 & - & - \\
\hline
\end{tabular}


As Tabela 5.17 e 5.18 apresentam as características geométricas, a área e o momento de inércia total dos lintéis que irão constituir os pórticos.

Dessa forma, foi possível determinar as características necessárias para a obtenção dos esforços nos painéis.

Tabela 5.17: Características geométricas dos lintéis

\begin{tabular}{|c|c|c|c|c|c|c|c|}
\hline Painel & Abertura & $\begin{array}{c}\text { Espessura } \\
(\mathbf{c m})\end{array}$ & $\begin{array}{c}\text { Peitoril } \\
(\mathbf{c m})\end{array}$ & $\begin{array}{c}\text { Alt. } \\
\text { Janela } \\
(\mathbf{c m})\end{array}$ & $\begin{array}{c}\text { Comp. } \\
\text { Flex. }(\mathbf{c m})\end{array}$ & Área $\left(\mathbf{m}^{\mathbf{2})}\right.$ & $\begin{array}{c}\text { Mom. de } \\
\text { Inércia } \\
\left(\mathbf{m}^{4}\right)\end{array}$ \\
\hline PF2 & a1 & 10 & 100 & 138 & 137,2 & 0,132 & 0,01917 \\
\hline PF4 & a1 & 10 & 100 & 138 & 139,2 & 0,132 & 0,01917 \\
\hline PF6 & a1 & 10 & 100 & 138 & 137,2 & 0,132 & 0,01917 \\
\hline PF7 & a1 & 10 & 100 & 138 & 157,2 & 0,132 & 0,01917 \\
\hline PF8 & a1 & 10 & 100 & 138 & 117,2 & 0,132 & 0,01917 \\
\hline PF8 & a2 & 10 & 100 & 138 & 117,2 & 0,132 & 0,01917 \\
\hline
\end{tabular}

Tabela 5.18: Área e momento de inércia total dos lintéis

\begin{tabular}{|c|c|c|c|}
\hline Painel & Quant. & $\begin{array}{c}\text { Área } \\
\text { Total }\left(\mathbf{m}^{\mathbf{2}}\right)\end{array}$ & $\begin{array}{c}\text { Mom. de } \\
\text { Inércia } \\
\text { Total }\left(\mathbf{m}^{\mathbf{4}}\right)\end{array}$ \\
\hline PF2 & 4 & 0,528 & 0,07667 \\
\hline PF4 & 1 & 0,132 & 0,01917 \\
\hline PF6 & 4 & 0,528 & 0,07667 \\
\hline PF7 & 4 & 0,528 & 0,07667 \\
\hline PF8 & 2 & 0,264 & 0,03833 \\
\hline PF8 & 2 & 0,264 & 0,03833 \\
\hline
\end{tabular}

Após a determinação das características dos painéis, foi possível gerar um modelo de pórtico plano, como apresentado no capítulo 4.

O software comercial utilizado para gerar esse modelo foi o SAP2000.

A Figura 5.10 e a Figura 5.11 apresentam os pórticos planos nas direções x e y, com as respectivas forças do vento. 


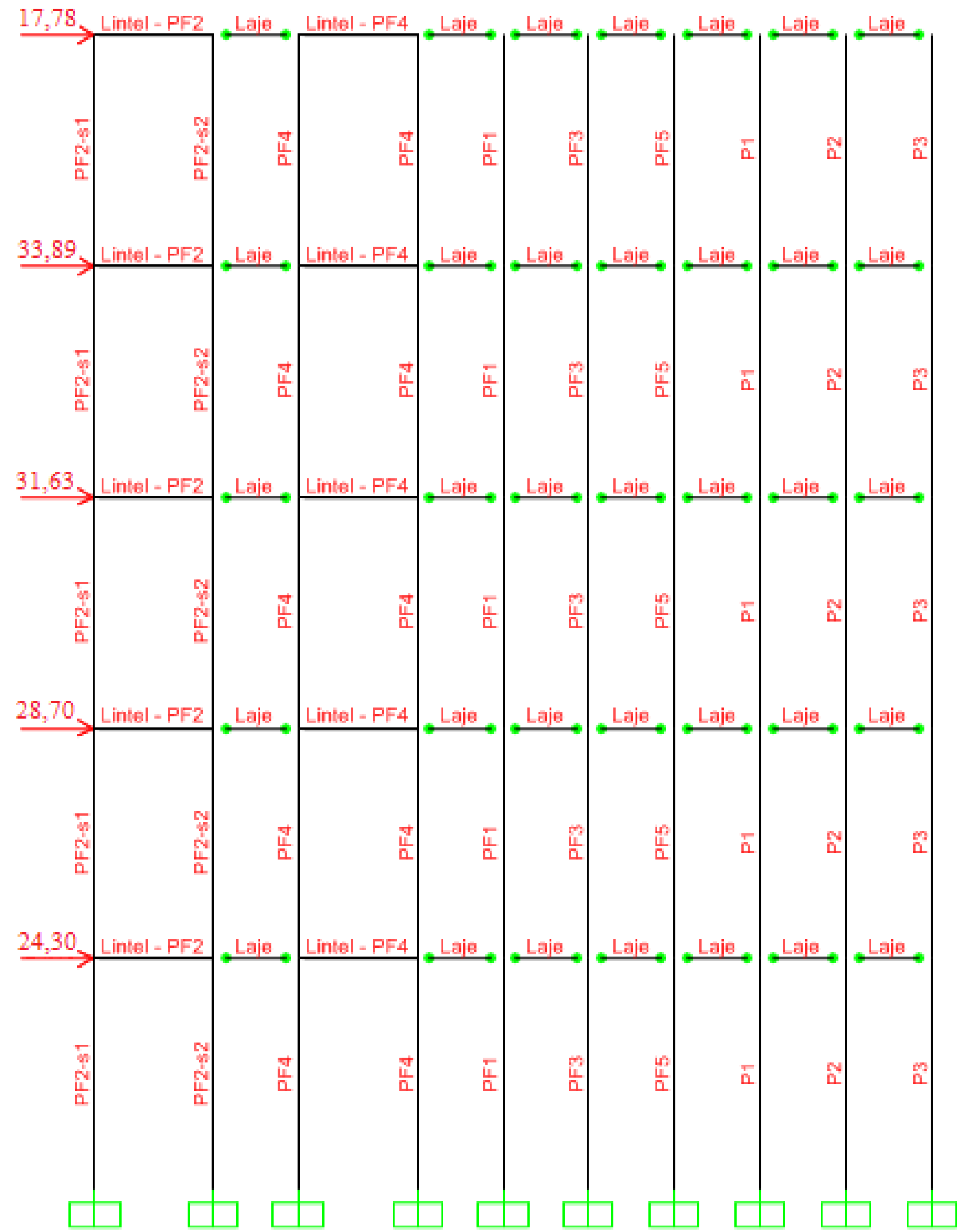

Figura 5.10: Modelo de pórtico plano na direção x 


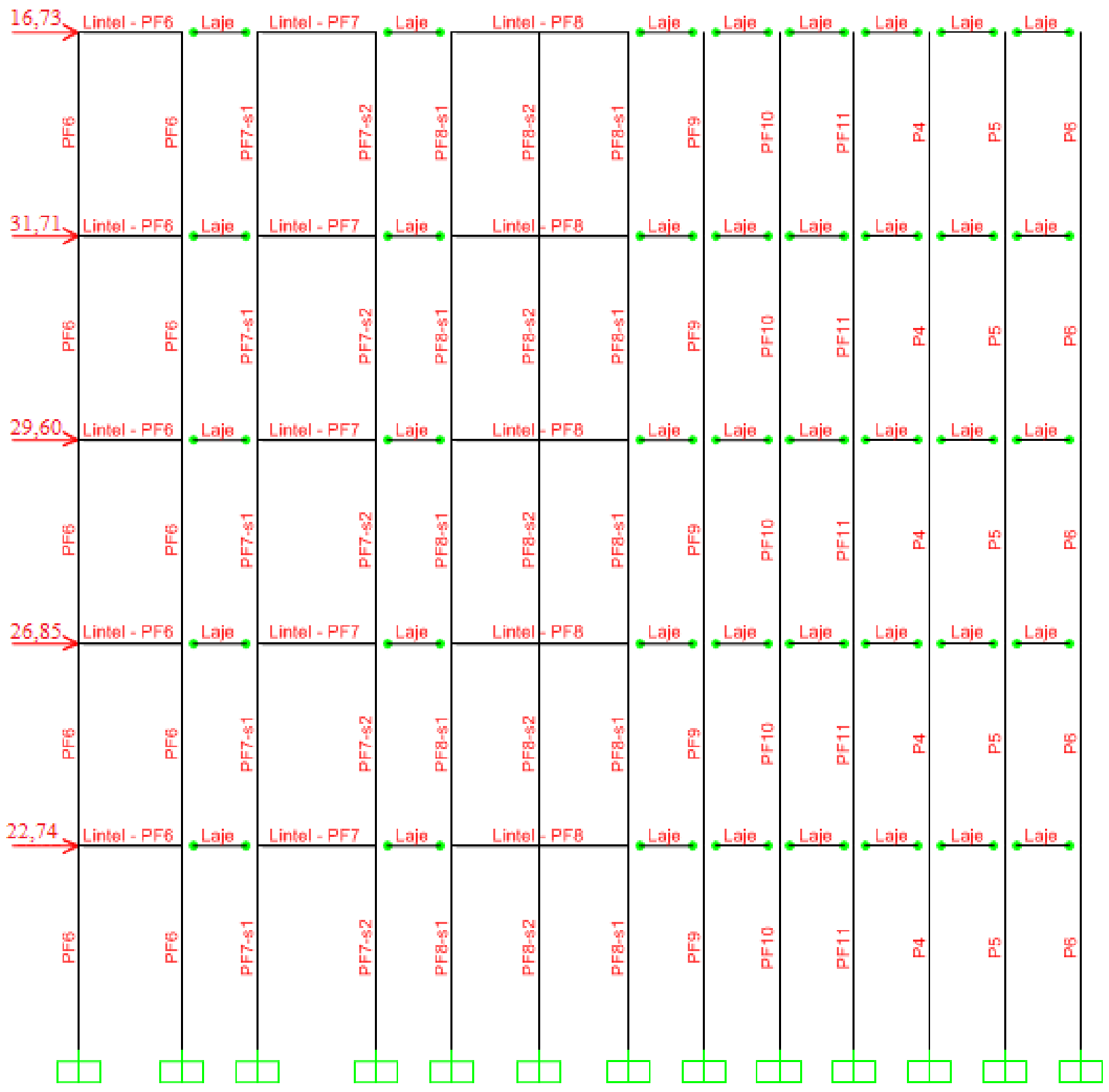

Figura 5.11: Modelo de pórtico plano na direção y

A partir do modelo de pórtico plano, determinaram-se os deslocamentos no topo do edifício para as direções x e y, como mostram as Figura 5.12 e Figura 5.13.

O deslocamento do topo na direção $\mathrm{x}$ foi de $1,80 \mathrm{~mm}$, enquanto que na direção y foi de $1,27 \mathrm{~mm}$. 


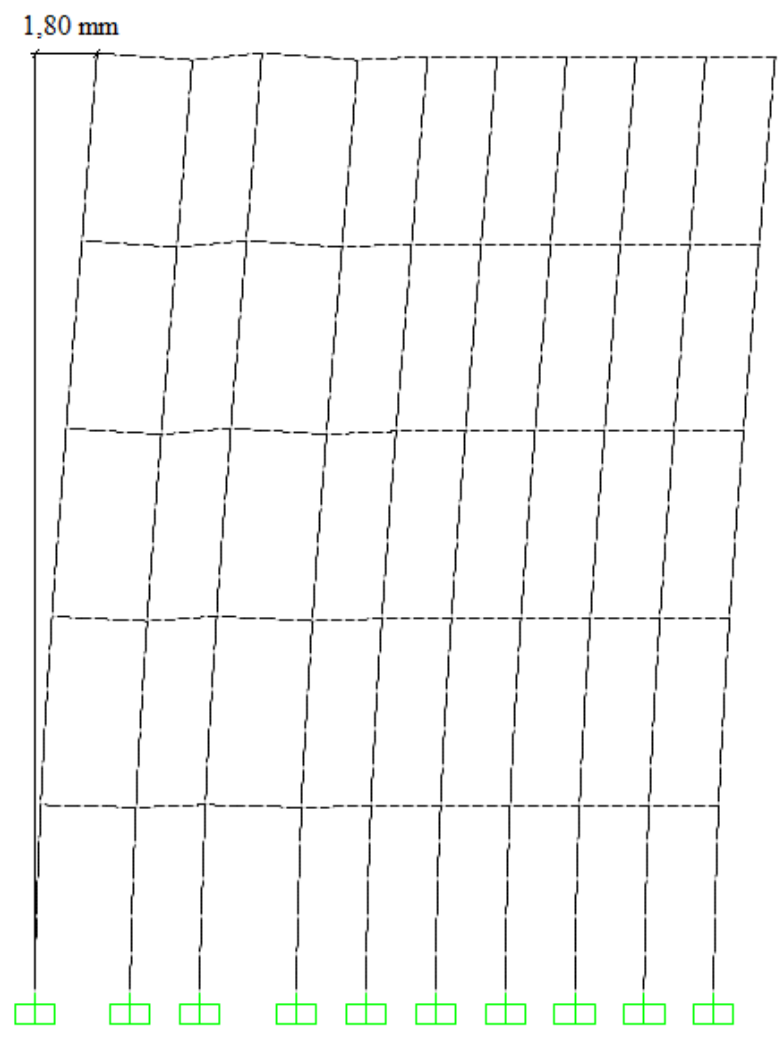

Figura 5.12: Deslocamento no topo na direção x

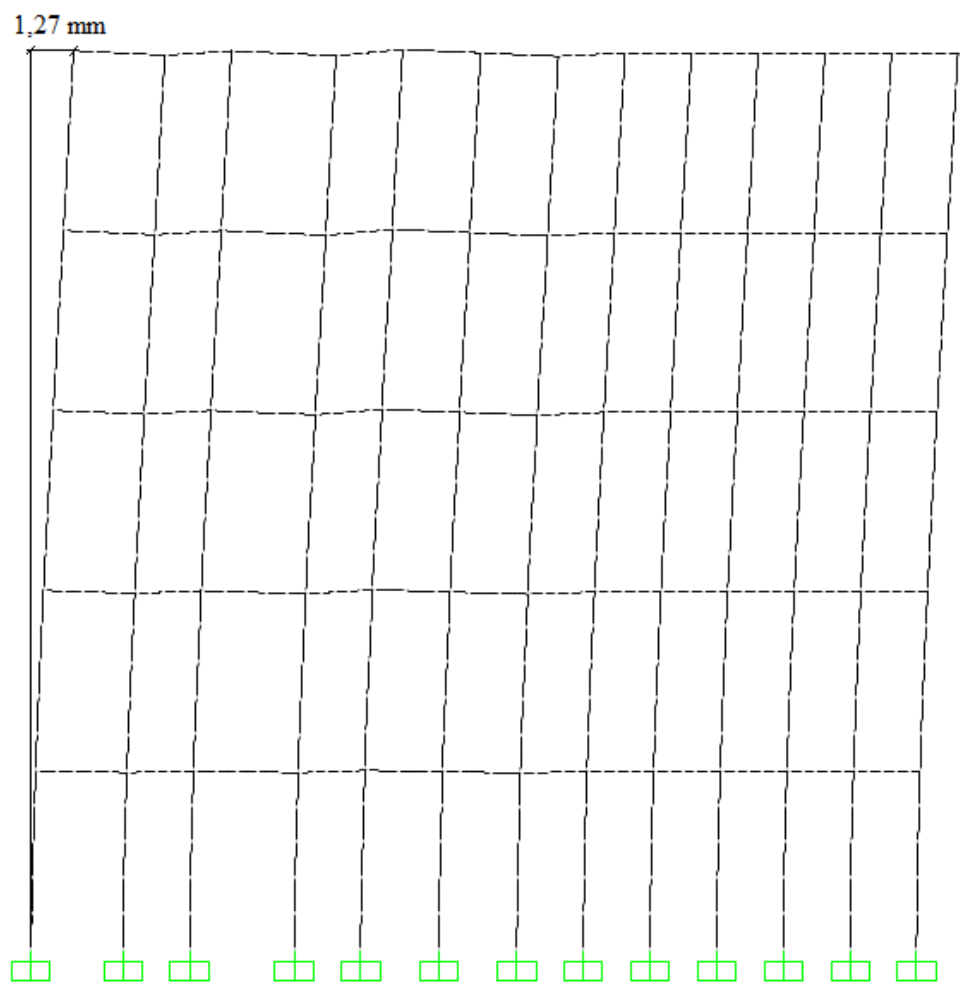

Figura 5.13: Deslocamento no topo na direção y 
Foram determinados, também, os esforços normais nos painéis para as direções x e y provocados pela ação do vento. Nas Figura 5.14 e Figura 5.15 são apresentados os esforços normais nas direções x e y, respectivamente.

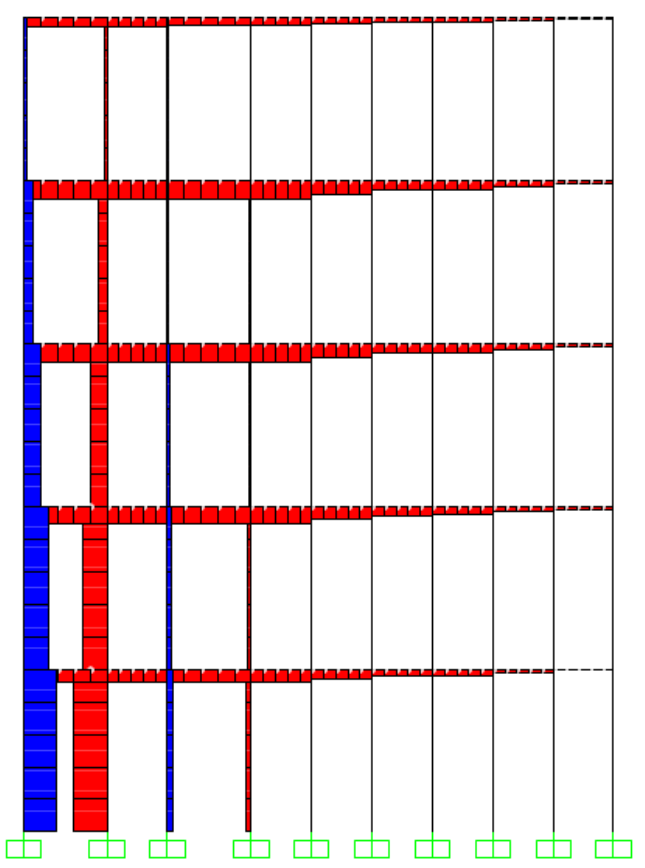

Figura 5.14: Esforços normais nos painéis, provocados pelo vento da direção $\mathrm{x}$

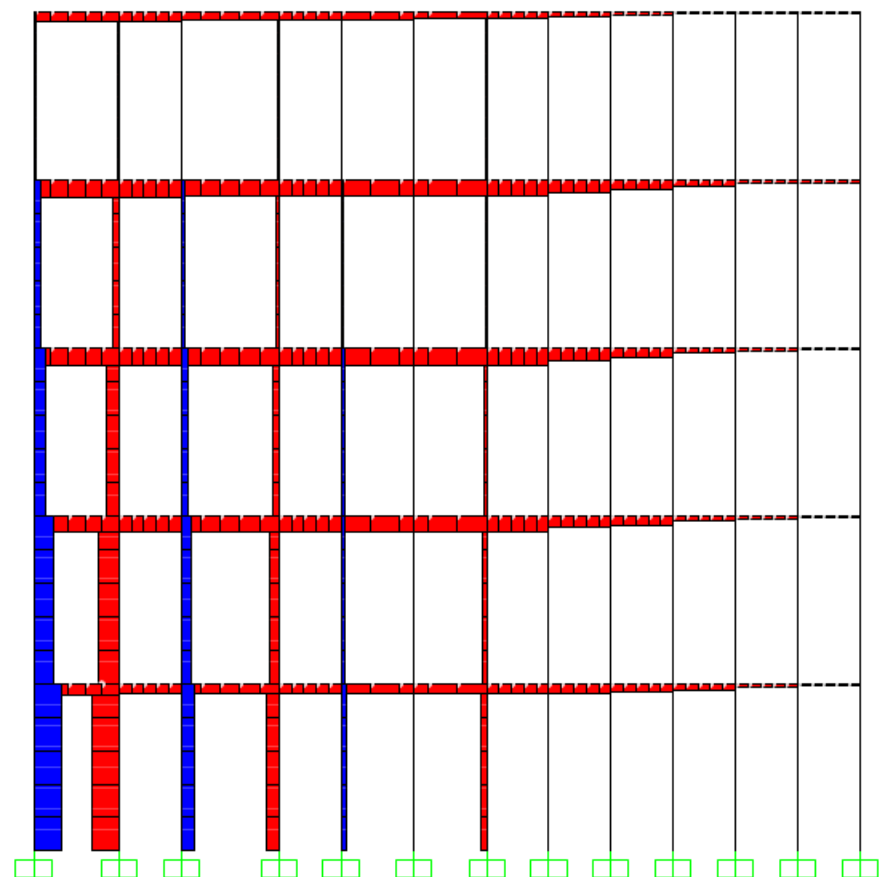

Figura 5.15: Esforços normais nos painéis, provocados pelo vento da direção y 
As Figura 5.16 e 5.17 mostram os momentos fletores nos painéis pré-moldados, provocados pela ação do vento nas direções x e y.

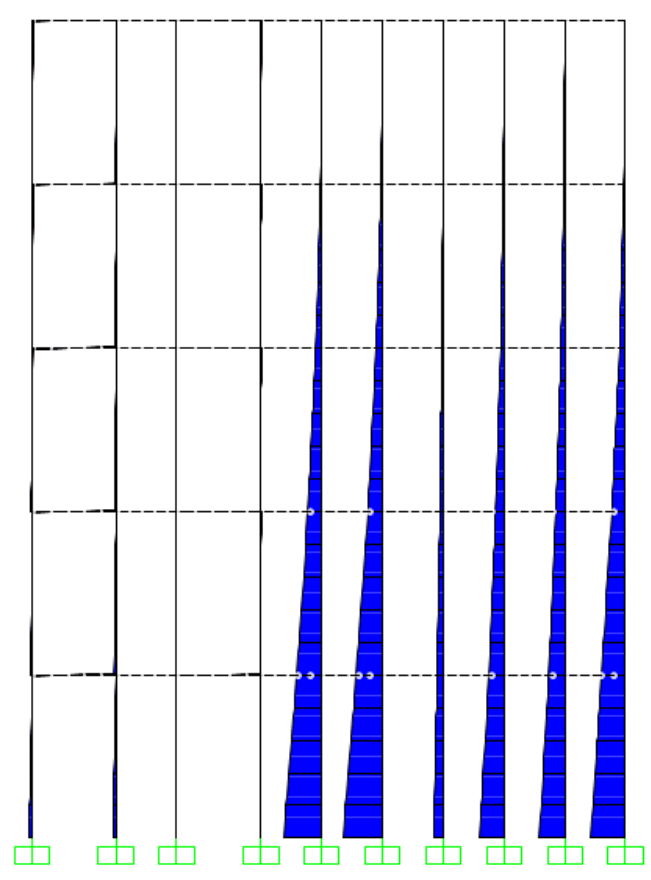

Figura 5.16: Momentos fletores nos painéis, provocados pelo vento na direção x

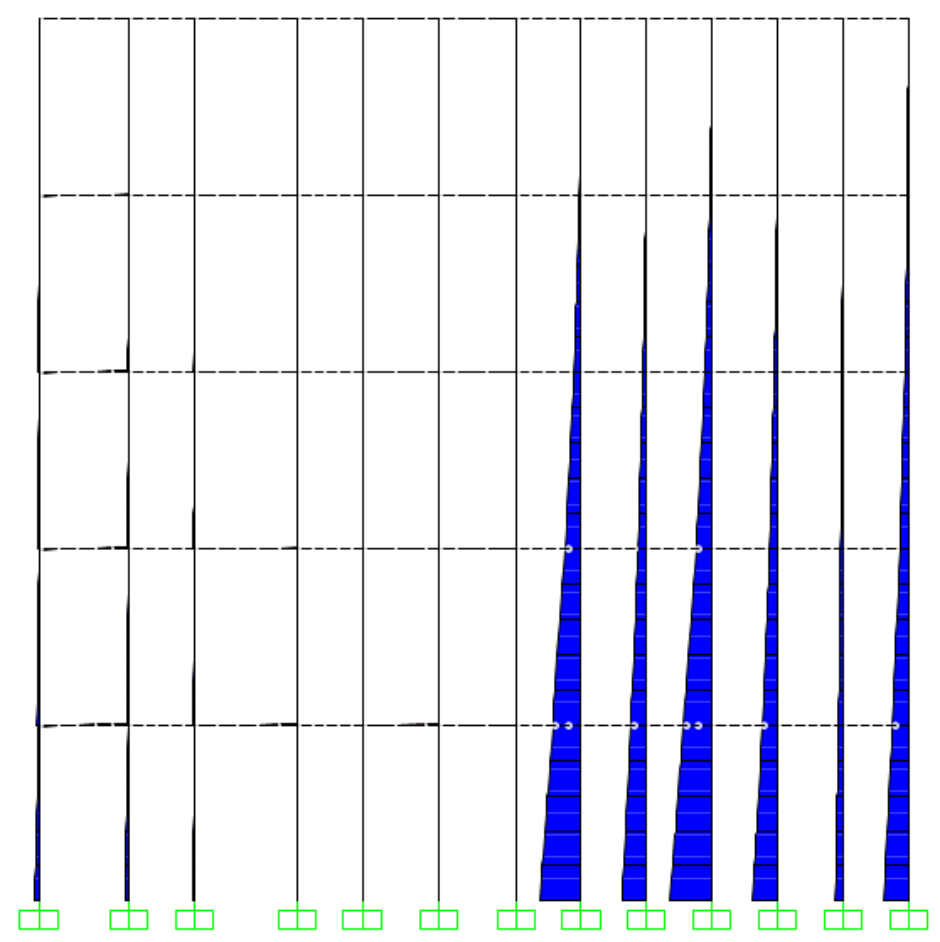

Figura 5.17: Momentos fletores nos painéis, provocados pelo vento na direção y 
Não foram apresentados os valores dos esforços normais e dos momentos fletores provocados pela ação do vento, devido à escala utilizada para apresentação.

Portanto, foi elaborada uma tabela a fim de mostrar esses valores para cada pavimento do edifício (Tabela 5.19).

Tabela 5.19: Esforços normais e momentos fletores, provocados pela ação do vento

\begin{tabular}{|c|c|c|c|c|c|c|c|c|c|c|c|c|}
\hline \multirow[b]{2}{*}{ Painel } & \multirow[b]{2}{*}{ Sólido } & \multirow[b]{2}{*}{ Quant. } & \multicolumn{2}{|c|}{$5^{\circ}$ Pavimento } & \multicolumn{2}{|c|}{$4^{\circ}$ Pavimento } & \multicolumn{2}{|c|}{$3^{\circ}$ Pavimento } & \multicolumn{2}{|c|}{$2^{\circ}$ Pavimento } & \multicolumn{2}{|c|}{$1^{\circ}$ Pavimento } \\
\hline & & & $\begin{array}{c}\mathbf{N}_{\mathbf{k}} \\
(\mathbf{k N})\end{array}$ & $\begin{array}{c}\mathbf{M}_{\mathbf{k}} \\
(\mathbf{k N} \cdot \mathbf{m})\end{array}$ & $\begin{array}{c}\mathbf{N}_{\mathbf{k}} \\
(\mathbf{k N})\end{array}$ & $\begin{array}{c}\mathbf{M}_{\mathbf{k}} \\
(\mathbf{k N} \cdot \mathbf{m})\end{array}$ & $\begin{array}{c}\mathbf{N}_{\mathbf{k}} \\
(\mathrm{kN})\end{array}$ & $\begin{array}{c}\mathbf{M}_{\mathbf{k}} \\
(\mathrm{kN} \cdot \mathrm{m})\end{array}$ & $\begin{array}{c}\mathbf{N}_{\mathbf{k}} \\
(\mathbf{k N})\end{array}$ & $\begin{array}{c}\mathbf{M}_{\mathbf{k}} \\
(\mathrm{kN} \cdot \mathrm{m})\end{array}$ & $\begin{array}{c}\mathbf{N}_{\mathbf{k}} \\
(\mathbf{k N})\end{array}$ & $\begin{array}{c}\mathbf{M}_{\mathbf{k}} \\
(\mathbf{k N} \cdot \mathbf{m})\end{array}$ \\
\hline PF1 & s1 & 4 & 0,00 & 7,69 & 0,00 & 33,46 & 0,00 & 77,43 & 0,00 & 138,73 & 0,00 & 212,34 \\
\hline PF2 & s1 & 4 & 4,61 & 1,89 & 13,87 & 5,95 & 26,69 & 8,80 & 40,83 & 10,91 & 54,80 & 19,54 \\
\hline PF2 & s2 & 4 & $-4,61$ & 2,30 & $-13,87$ & 5,49 & $-26,69$ & 7,96 & $-40,83$ & 9,94 & $-54,80$ & 15,65 \\
\hline PF3 & s1 & 4 & 0,00 & 8,12 & 0,00 & 34,95 & 0,00 & 80,72 & 0,00 & 144,47 & 0,00 & 220,27 \\
\hline PF4 & s1 & 1 & 0,90 & 0,48 & 2,71 & 0,92 & 5,05 & 1,25 & 7,65 & 1,47 & 9,99 & 1,88 \\
\hline PF4 & s2 & 1 & $-0,90$ & 0,66 & $-2,71$ & 0,90 & $-5,05$ & 1,26 & $-7,65$ & 1,51 & $-9,99$ & 1,54 \\
\hline PF5 & s1 & 1 & 0,00 & 1,94 & 0,00 & 8,42 & 0,00 & 19,47 & 0,00 & 34,89 & 0,00 & 53,37 \\
\hline P1 & s1 & 4 & 0,00 & 4,06 & 0,00 & 19,95 & 0,00 & 47,08 & 0,00 & 85,01 & 0,00 & 136,49 \\
\hline $\mathrm{P} 2$ & s1 & 4 & 0,00 & 4,29 & 0,00 & 20,82 & 0,00 & 49,08 & 0,00 & 88,60 & 0,00 & 141,68 \\
\hline $\mathrm{P} 3$ & $\mathrm{~s} 1$ & - & 0,00 & 9,27 & 0,00 & 34,38 & 0,00 & 76,55 & 00 & 133,69 & 0,00 & 192,31 \\
\hline PF6 & s1 & 4 & 3,34 & 0,63 & 10,24 & 4,64 & 20,49 & 7,32 & 32,32 & 9,72 & 44,74 & 20,85 \\
\hline PF6 & s2 & 4 & $-3,34$ & 1,01 & $-10,24$ & 4,62 & $-20,49$ & 7,34 & $-32,32$ & 10,03 & $-44,74$ & 19,85 \\
\hline PF7 & s1 & 4 & 1,77 & 1,43 & 5,64 & 2,41 & 10,62 & 3,09 & 16,09 & 3,55 & 21,14 & 4,31 \\
\hline PF7 & s2 & 4 & $-1,77$ & 1,10 & $-5,64$ & 1,61 & $-10,62$ & 1,97 & $-16,09$ & 2,16 & $-21,14$ & 1,88 \\
\hline PF8 & s1 & 2 & 0,92 & 0,38 & 2,86 & 0,52 & 5,14 & 0,60 & 7,52 & 0,62 & 9,50 & 0,48 \\
\hline PF8 & s2 & 2 & 0,02 & 1,32 & 0,04 & 1,67 & 0,04 & 1,97 & 0,02 & 2,04 & $-0,05$ & 1,67 \\
\hline PF8 & s3 & 2 & $-0,93$ & 0,44 & $-2,90$ & 0,52 & $-5,18$ & 0,60 & $-7,54$ & 0,59 & $-9,45$ & 0,40 \\
\hline PF9 & s1 & 2 & 0,00 & 9,41 & 0,00 & 36,49 & 0,00 & 83,15 & 0,00 & 147,09 & 0,00 & 214,07 \\
\hline PF10 & s1 & 2 & 0,00 & 3,81 & 0,00 & 18,38 & 0,00 & 44,21 & 0,00 & 81,04 & 0,00 & 125,89 \\
\hline PF11 & s1 & 2 & 0,00 & 9,41 & 0,00 & 36,49 & 0,00 & 83,15 & 0,00 & 147,09 & 0,00 & 214,07 \\
\hline P4 & s1 & 4 & 0,00 & 2,38 & 0,00 & 16,04 & 0,00 & 40,46 & 0,00 & 75,77 & 0,00 & 128,69 \\
\hline P5 & s1 & 2 & 0,00 & 0,50 & 0,00 & 4,52 & 0,00 & 11,68 & 0,00 & 21,82 & 0,00 & 39,61 \\
\hline P6 & s1 & 2 & 0,00 & 3,81 & 0,00 & 18,38 & 0,00 & 44,21 & 0,00 & 81,04 & 0,00 & 125,89 \\
\hline
\end{tabular}

\subsection{PREVENÇÃO AO COLAPSO PROGRESSIVO}

O colapso progressivo é um fenômeno que pode ser evitado por meio da inserção de barras de aço ao modelo, a fim de redistribuir os esforços na situação em que algum elemento portante seja retirado do edifício. 


\subsubsection{Determinação da energia de deformação da barra de ligação}

A energia de deformação para a barra de ligação com diâmetro de $10 \mathrm{~mm}$ foi determinada com as seguintes considerações: comprimento de ancoragem maior e concreto confinado com $\mathrm{f}_{\mathrm{ck}}=12,5 \mathrm{MPa}$, em boas condições de ancoragem. Sendo assim, as características do aço foram:

$$
\mathrm{f}_{\mathrm{yk}}=500 \mathrm{MPa} \quad\left(\mathrm{f}_{\mathrm{u}} / \mathrm{f}_{\mathrm{yk}}\right)=1,08 \quad \mathrm{E}_{\mathrm{s}}=210 \mathrm{GPa} \quad \varepsilon_{\text {suk }}=50 \cdot 10^{-3}
$$

Força no escoamento: $\mathrm{N}_{\mathrm{y}}=\mathrm{f}_{\mathrm{yk}} \cdot \mathrm{A}_{\mathrm{s}}=39 \mathrm{kN}$

Força na ruptura: $\mathrm{N}_{\mathrm{u}}=1,08 \cdot \mathrm{N}_{\mathrm{y}}=42 \mathrm{kN}$

Em seguida foi calculado o valor do deslizamento final $\left(s_{\text {end,y }}\right)$, a partir da equação (4.21).

$$
\begin{gathered}
\mathrm{f}_{\mathrm{cm}}=\mathrm{f}_{\mathrm{ck}}+8 \mathrm{MPa}=20,5 \mathrm{MPa} \\
\tau_{\mathrm{b}, \text { máx }}=2,5 \sqrt{20,5}=11,3 \mathrm{MPa} \\
\mathrm{s}_{\text {end,y }}=0,288\left(\frac{10 \cdot\left(500 \cdot 10^{6}\right)^{2}}{11,3 \cdot 10^{6} \cdot 210 \cdot 10^{9}}\right)^{0,714}+\frac{500 \cdot 10^{6}}{210 \cdot 10^{9}} \cdot 2 \cdot 10 \\
\mathrm{~s}_{\text {end,y }}=0,299+0,047=0,346 \mathrm{~mm}
\end{gathered}
$$

em que $\mathrm{s}_{\mathrm{y}, \text { net }}=0,299 \mathrm{~mm}<1,0 \mathrm{~mm}$, sendo satisfeita a verificação.

Sendo assim, tem-se que o comprimento de transmissão de esforços é dado pela equação (4.23):

$$
l_{t, y}=0,583 \frac{10 \cdot 500 \cdot 10^{6}}{11,3 \cdot 10^{6} \cdot 0,299^{0,4}}+2 \cdot 10=438 \mathrm{~mm}
$$

O alongamento máximo da barra no regime plástico [equação (4.24) e o deslizamento final da barra foram obtidos pela equação (4.26)].

$$
\begin{gathered}
\mathrm{l}_{\mathrm{t}, \mathrm{pl}}=\frac{1,08 \cdot 500 \cdot 10^{6}-500 \cdot 10^{6}}{0,27 \cdot 11,3 \cdot 10^{6}} \cdot \frac{10}{4}=32,7 \mathrm{~mm} \\
\mathrm{~s}_{\text {end,u }}=32,7 \cdot\left(0,5 \cdot 50 \cdot 10^{-3}\right)+0,346=1,16 \mathrm{~mm}
\end{gathered}
$$


Os valores das aberturas de fissura foram determinados pelas equações (4.28) e (4.29):

$$
\begin{gathered}
\mathrm{w}_{\mathrm{y}}=2 \cdot 0,346=0,692 \mathrm{~mm} \\
\mathrm{w}_{\mathrm{u}}=2 \cdot 1,16=2,328 \mathrm{~mm}
\end{gathered}
$$

Assim, a energia de deformação da barra de ligação com diâmetro de $10 \mathrm{~mm}$ foi obtida pela equação (4.30):

$$
\begin{gathered}
\xi_{(w u)}=\frac{\frac{1}{2} \cdot 39 \cdot 0,692+\frac{39+42}{2}(1,164-0,692)+42 \cdot(2,328-1,164)}{42 \cdot 2,328}=0,833 \\
\xi_{(0,5 w u)}=\frac{\frac{1}{2} \cdot 39 \cdot 0,692+\frac{39+42}{2}(1,164-0,692)}{42 \cdot 1,164}=0,666
\end{gathered}
$$

Da mesma forma, foram determinadas as forças no escoamento $\left(\mathrm{N}_{\mathrm{y}}\right)$, as forças na ruptura $\left(\mathrm{N}_{\mathrm{u}}\right)$, as aberturas de fissura (w) e as energias de deformação das barras $(\xi)$ com diâmetros de $8 \mathrm{~mm}, 10 \mathrm{~mm}, 12,5 \mathrm{~mm}, 16 \mathrm{~mm}$ e $20 \mathrm{~mm}$, indicadas na Tabela 5.20.

Tabela 5.20: Resumo dos dados para as respectivas bitolas

\begin{tabular}{|c|c|c|c|c|c|c|}
\hline $\begin{array}{c}\text { Bitola } \\
(\mathbf{m m})\end{array}$ & $\mathbf{N}_{\mathbf{y}} \mathbf{( k \mathbf { N } )}$ & $\mathbf{N}_{\mathbf{u}}(\mathbf{k N )}$ & $\mathbf{w}_{\mathbf{y}}(\mathbf{m m})$ & $\mathbf{w}_{\mathbf{u}}(\mathbf{m m})$ & $\boldsymbol{\xi}_{(\mathbf{w u})}$ & $\boldsymbol{\xi}_{(\mathbf{0}, \mathbf{5 w u})}$ \\
\hline 8 & 25 & 27 & 0,585 & 1,894 & 0,827 & 0,654 \\
\hline 10 & 39 & 42 & 0,692 & 2,328 & 0,833 & 0,666 \\
\hline 12,5 & 61 & 66 & 0,819 & 2,864 & 0,838 & 0,677 \\
\hline 16 & 101 & 109 & 0,988 & 3,605 & 0,845 & 0,689 \\
\hline 20 & 157 & 170 & 1,170 & 4,442 & 0,850 & 0,700 \\
\hline
\end{tabular}

\subsubsection{Exemplo de um painel isolado amarrado por um ponto}

A seguir, apresenta-se um exemplo de explosão do painel PF11D ocorrido no $1^{\circ}$ pavimento, assumindo os mecanismos de rotação para um sistema de painéis em balanço (Figura 5.18). A ligação horizontal foi realizada por uma barra de $8 \mathrm{~mm}$ de diâmetro, ancorada em concreto confinado de $12,5 \mathrm{MPa}$ de resistência à compressão, em boas condições de ancoragem. $\mathrm{O}$ peso próprio do painel é de $13,18 \mathrm{kN}$ e a carga proveniente da laje corresponde a 15,60 kN. 

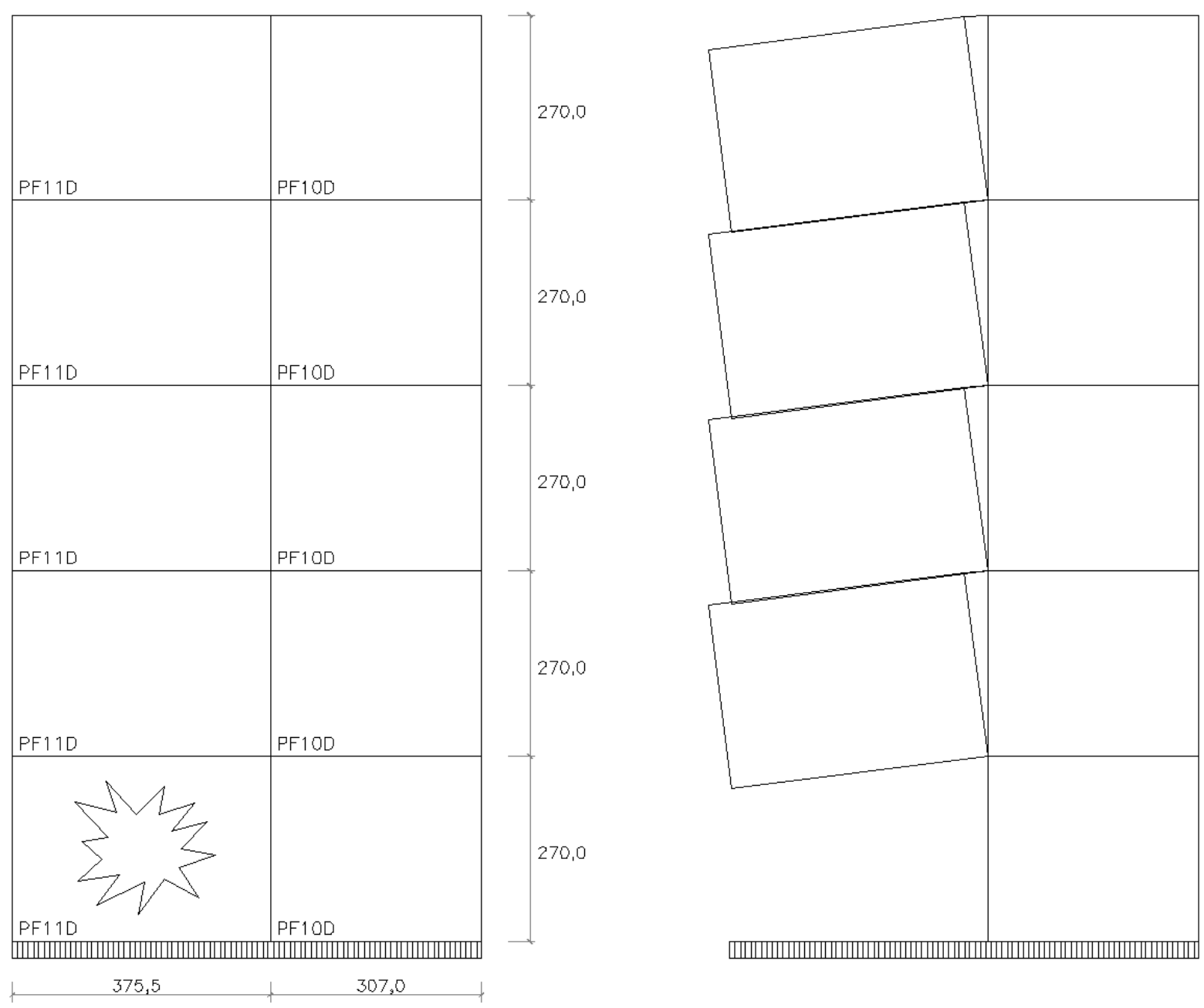

Figura 5.18: Análise da alternativa de suporte de carga nos painéis pré-moldados:

a) Dano localizado; b) Mecanismo de colapso de separação dos painéis em balanço

Após definição dos carregamentos tem-se, então, G no valor de $13,18 \mathrm{kN}$ (peso próprio do painel) e q igual a 15,60 kN (carga da laje), como mostra a Figura 5.19. Em seguida, são determinados os respectivos valores para $\mathrm{l}_{\mathrm{qx}, 0}$ e $\mathrm{l}_{\mathrm{qz}, 0}$.

$$
\begin{gathered}
\mathrm{Q}=\mathrm{G}+\mathrm{q}=28,78 \mathrm{kN} \\
\mathrm{l}_{\mathrm{qx}, 0}=1,88 \mathrm{~m} \\
\mathrm{l}_{\mathrm{qz}, 0}=\frac{13,02 \cdot 1,35+15,17 \cdot 2,70}{28,19}=2,08 \mathrm{~m}
\end{gathered}
$$




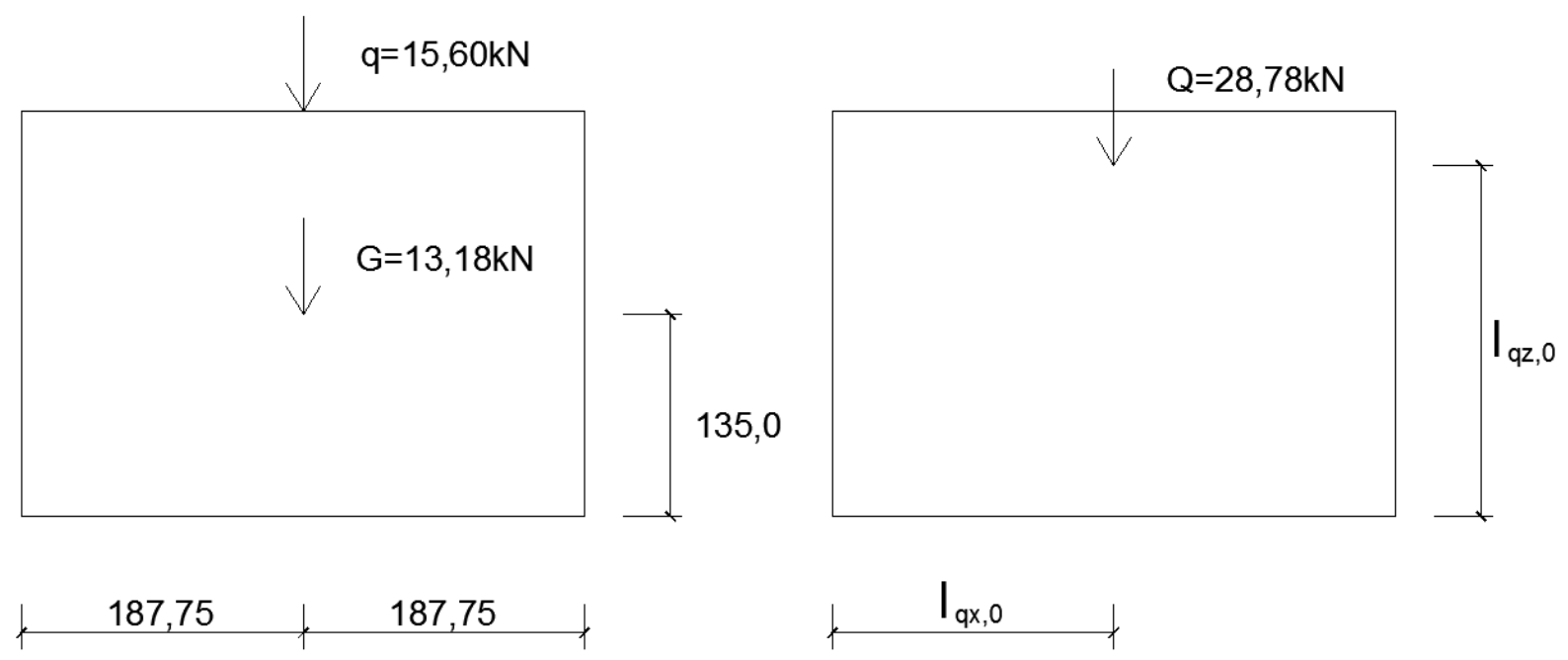

Figura 5.19: Força resultante Q e sua localização em painel isolado

De acordo com os cálculos realizados no item 5.7.1, uma barra de $8 \mathrm{~mm}$ de diâmetro apresenta o valor de $\mathrm{N}_{\mathrm{y}}=25 \mathrm{kN}$ e $\mathrm{N}_{\mathrm{u}}=27 \mathrm{kN}$. O valor característico da abertura de fissura é de $\mathrm{w}_{\mathrm{y}}=0,585 \mathrm{~mm}$ e $\mathrm{w}_{\mathrm{u}}=1,894 \mathrm{~mm}$. A energia de deformação para a abertura de fissura máxima foi de $\xi_{(\mathrm{wu})}=0,827$ e $\xi_{(0,5 \mathrm{wu})}=0,654$ para metade da abertura de fissura máxima.

A rotação máxima do painel em balanço é determinada a partir da capacidade de deformação das barras de ancoragem. Sendo assim, a abertura de fissura máxima do concreto é $\mathrm{w}_{\max }=$ $\mathrm{w}_{\mathrm{u}}=1,894 \mathrm{~mm}$. A rotação correspondente é mostrada na Figura 5.20 e o deslocamento vertical máximo é calculado por:

$$
\mathrm{a}_{\mathrm{qz}, \max }=\frac{\mathrm{l}_{\mathrm{qx}, 0}}{\mathrm{~h}} \mathrm{w}_{\mathrm{u}}=1,32 \mathrm{~mm}
$$

Sendo assim, a resistência dinâmica do sistema em balanço pode ser obtida pela equação (4.37), e a resistência estática pela equação (4.35).

$$
\begin{gathered}
\mathrm{R}_{\text {dyn }}\left(\mathrm{a}_{\mathrm{qz}, \mathrm{max}}\right)=\frac{\mathrm{w}_{\text {max }}}{\mathrm{a}_{\mathrm{qz}, \max }} \xi\left(\mathrm{w}_{\max }\right) \mathrm{N}_{\mathrm{u}}=32,28 \mathrm{kN}>Q=28,78 k N \\
\mathrm{R}_{\mathrm{stat}}\left(\mathrm{a}_{\mathrm{qz}}\right)=\frac{\mathrm{h}}{\mathrm{l}_{\mathrm{qx}, 0}+\mathrm{l}_{\mathrm{qz}, 0} \frac{\mathrm{w}}{\mathrm{h}}} \cdot \mathrm{N}(\mathrm{w})=39,00 \mathrm{kN}>Q=28,78 k N
\end{gathered}
$$


Como as resistências dinâmica e estática apresentaram valores maiores que a força resultante atuante no painel, tem-se então, que uma barra de $8 \mathrm{~mm}$ é suficiente para resistir à ação de balanço, para o painel em análise.

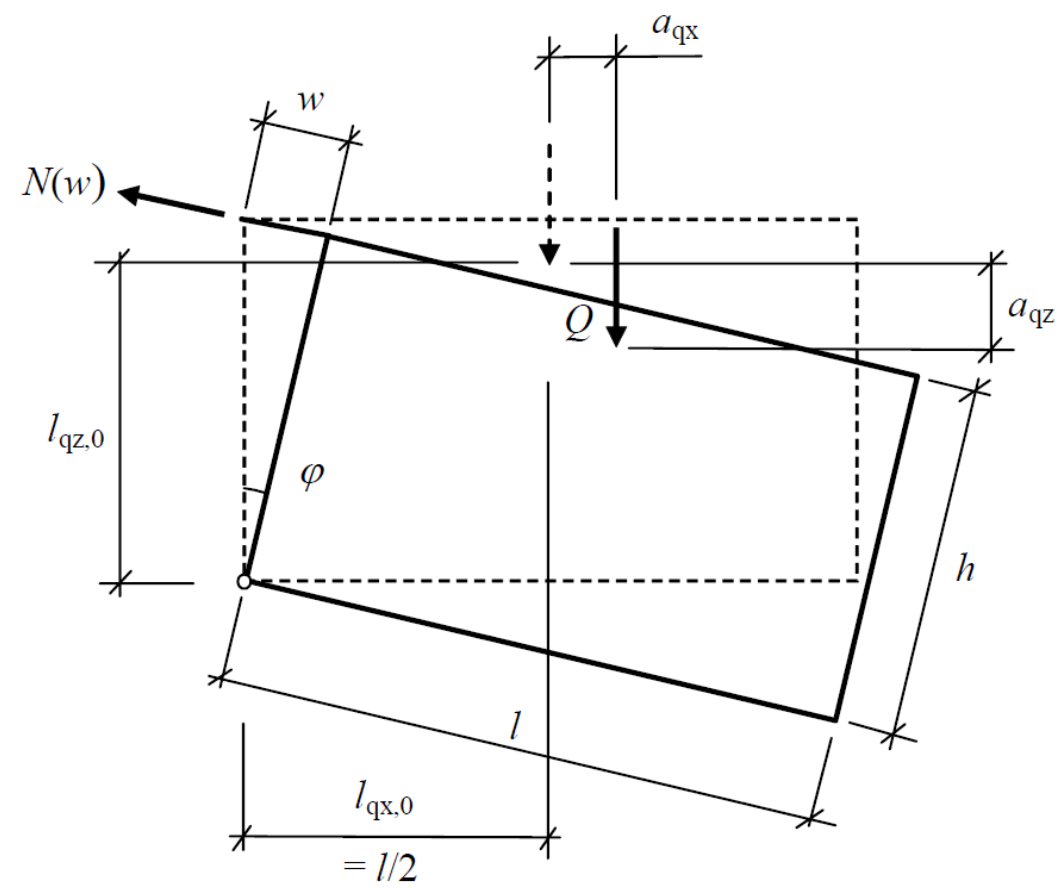

Figura 5.20: Rotação de um painel isolado [Fonte: FIB (2008)]

\subsubsection{Exemplo de uma laje}

O exemplo a seguir simulou a destruição total dos painéis que suportavam a laje L4 do $1^{\circ}$ pavimento, admitindo um mecanismo de rotação para um sistema de lajes em balanço, como mostra a Figura 5.18. A ligação horizontal foi realizada por duas barras de aço com $20 \mathrm{~mm}$ de diâmetro, ancoradas em um concreto confinado de 12,5 $\mathrm{MPa}$ de resistência à compressão, em boas condições de ancoragem. Foram considerados como carregamentos: o peso próprio da laje, revestimento e piso, além do peso próprio do painel P3 sobre a laje, o que totaliza uma carga de $25,52 \mathrm{kN}$.

Usando os mesmos mecanismos de cálculo do item 5.7.1 tem-se, então, duas barras de $20 \mathrm{~mm}$ de diâmetro, com $\mathrm{N}_{\mathrm{y}}=314 \mathrm{kN}$ e $\mathrm{N}_{\mathrm{u}}=339 \mathrm{kN}$. O valor característico da abertura de fissura é de $\mathrm{w}_{\mathrm{y}}=1,214 \mathrm{~mm}$ e $\mathrm{w}_{\mathrm{u}}=4,486 \mathrm{~mm}$. A energia de deformação para a abertura de fissura máxima foi de $\xi_{(w u)}=0,846$, e $\xi_{(0,5 w u)}=0,692$ para metade da abertura de fissura máxima. 
A rotação máxima do painel em balanço foi determinada pela capacidade de deformação das barras de ancoragem. Para o concreto tem-se que a abertura máxima é de:

$\mathrm{w}_{\max }=\mathrm{w}_{\mathrm{u}}=4,486 \mathrm{~mm}$.
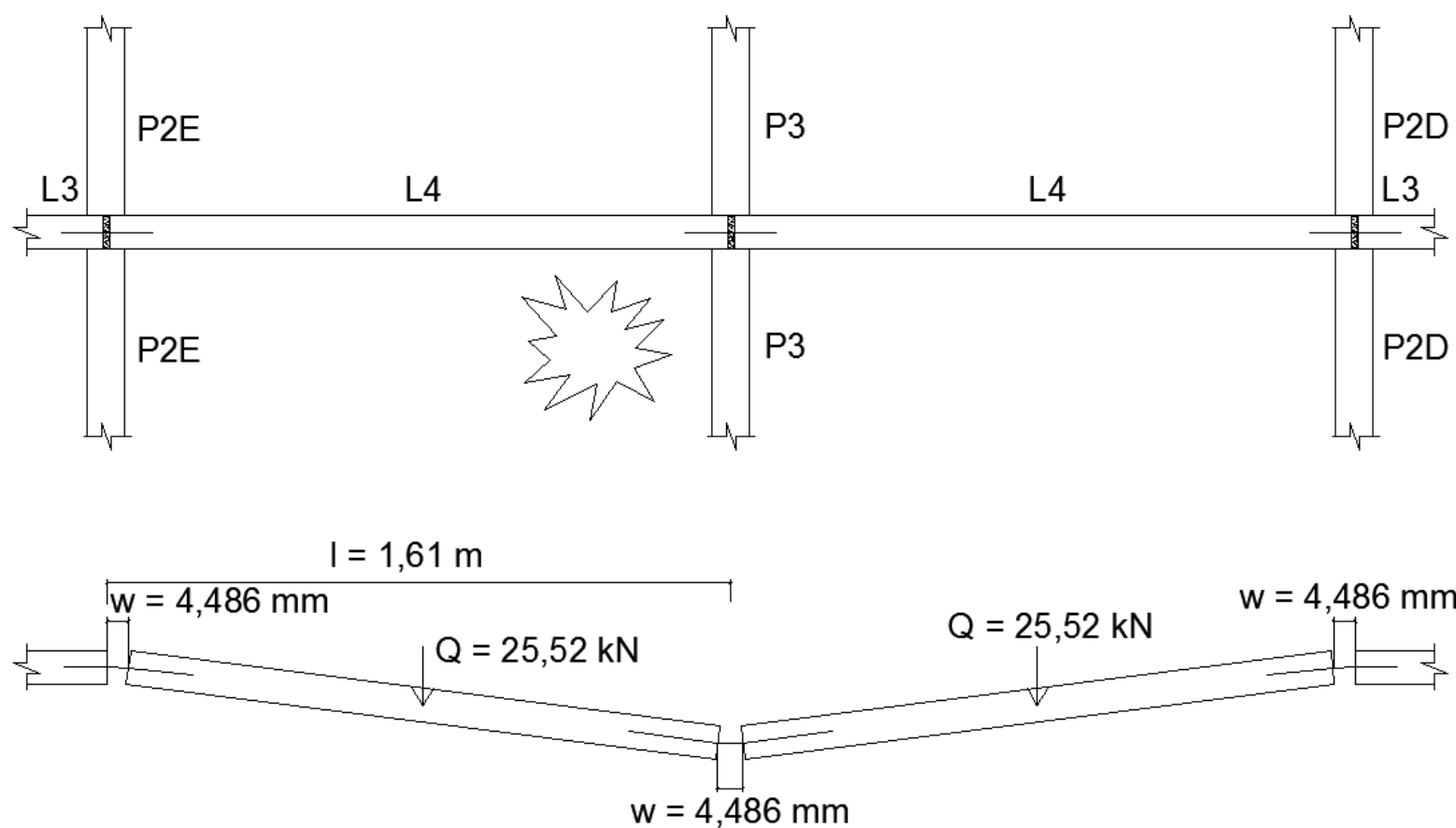

Figura 5.21: Situação de laje em balanço, com a retirada do painel de apoio

O deslocamento vertical máximo é obtido pela equação (4.38):

$$
\mathrm{a}_{\max }=2 \cdot \mathrm{a}_{\mathrm{qz}, \max }=2 \cdot \frac{\sqrt{3 \cdot 1,61 \cdot 0,00449}}{2}=0,147 \mathrm{~m}
$$

A resistência estática máxima pode ser determinada pela equação (4.40), enquanto que a resistência dinâmica máxima, pela equação (4.43).

$$
\begin{gathered}
\mathrm{R}_{\text {stat }}\left(\mathrm{a}_{\mathrm{qz}, \text { max }}\right)=2 \cdot \mathrm{N}\left(\mathrm{w}_{\text {max }}\right) \sqrt{\frac{3 \mathrm{w}}{\mathrm{l}}}=62,04 \mathrm{kN}>Q=25,52 \mathrm{kN} \\
\mathrm{R}_{\text {dyn }}\left(\mathrm{a}_{\mathrm{qz}, \text { max }}\right)=\frac{1}{2} \xi\left(\mathrm{w}_{\text {max }}\right) \mathrm{R}_{\text {stat }}=26,25 \mathrm{kN}>Q=25,52 \mathrm{kN}
\end{gathered}
$$


Como as resistências dinâmica e estática foram maiores do que a força atuante no painel, as duas barras de $20 \mathrm{~mm}$ foram satisfatórias para resistir à ação de balanço na laje pré-moldada em análise. 


\section{EXEMPLO DE DIMENSIONAMENTO DO PAINEL PF11D}

Este capítulo apresenta o dimensionamento do painel PF11D, bem como as análises dos esforços pelo processo $\mathrm{P}-\delta$, o cálculo da armadura, o detalhamento do painel e as verificações nas fases transitórias.

\subsection{CARACTERÍSTICAS DO PAINEL}

As dimensões de projeto do painel PF11D são apresentadas na Figura 6.1. O comprimento do painel é de $375,5 \mathrm{~cm}$, com altura de $260 \mathrm{~cm}$ e espessura de $10 \mathrm{~cm}$. O painel possui também uma janela de $58 \mathrm{~cm}$ x $58 \mathrm{~cm}$ e peitoril de $159 \mathrm{~cm}$. Foi considerada uma resistência a compressão de $12,5 \mathrm{MPa}$ aos 28 dias $\left(\mathrm{f}_{\mathrm{ck} 28}\right)$, e após as 8 horas uma resistência à compressão de $6,0 \mathrm{MPa}\left(\mathrm{f}_{\mathrm{ck} 8 \mathrm{~h}}\right)$. O peso específico do concreto ultraleve adotado foi de $13,0 \mathrm{kN} / \mathrm{m}^{3}$, com um módulo de elasticidade de $10 \mathrm{GPa}$.

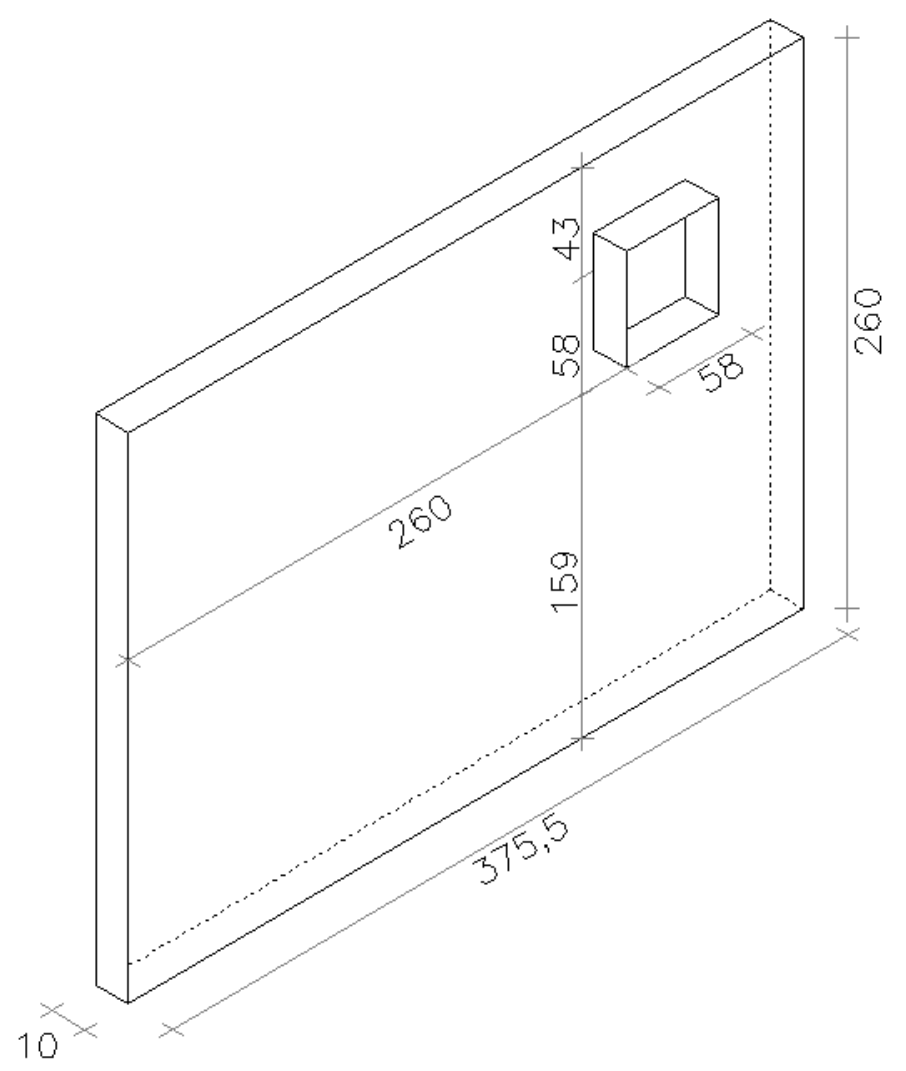

Figura 6.1: Dimensões do painel PF11D em centímetros 
Segundo as recomendações do ACI-318 (2011), para concretos leves deve-se considerar um fator de redução das propriedades mecânicas $(\lambda)$. Esse fator de redução varia de 0,75 até 1,0, sendo o valor de 0,75 utilizado para qualquer concreto leve, e o valor de 1,0 , para concreto com peso específico normal. Neste trabalho adotou-se para $\lambda$ o valor de 0,75 .

Para determinação dos esforços na peça e cálculo da armadura, foi considerado o painel como uma peça totalmente sólida, em que suas características são:

$$
\begin{array}{ccc}
\mathrm{A}=0,3755 \mathrm{~m}^{2} & \mathrm{I}_{\mathrm{x}}=0,4412 \mathrm{~m}^{4} & \mathrm{I}_{\mathrm{y}}=0,0003 \mathrm{~m}^{4} \\
\mathrm{~W}_{\mathrm{x}}=0,2350 \mathrm{~m}^{3} & \mathrm{~W}_{\mathrm{y}}=0,0062 \mathrm{~m}^{3} &
\end{array}
$$

Para a verificação na fase transitória, considerou-se o painel com abertura de janela. As características referentes à seção sólida são:

$$
\begin{array}{lll}
\mathrm{A}_{\mathrm{x}, \text { sól. }}=2600 \mathrm{~cm}^{2} & \mathrm{I}_{\mathrm{x} \text {,sól. }}=21667 \mathrm{~cm}^{4} & \mathrm{~W}_{\mathrm{x}, \text { sól. }}=6258 \mathrm{~cm}^{3} \\
\mathrm{~A}_{\mathrm{y}, \text { sól. }}=3755 \mathrm{~cm}^{2} & \mathrm{I}_{\mathrm{y} \text {,sól. }}=31292 \mathrm{~cm}^{4} & \mathrm{~W}_{\mathrm{y}, \text { sól. }}=4333 \mathrm{~cm}^{3}
\end{array}
$$

Na seção com abertura tem-se:

$$
\begin{array}{lll}
\mathrm{A}_{\mathrm{x}, \text { abe. }}=2020 \mathrm{~cm}^{2} & \mathrm{I}_{\mathrm{x}, \text { abe. }}=16833 \mathrm{~cm}^{4} & \mathrm{~W}_{\mathrm{x}, \text { abe. }}=5292 \mathrm{~cm}^{3} \\
\mathrm{~A}_{\mathrm{y}, \text { abe. }}=3175 \mathrm{~cm}^{2} & \mathrm{I}_{\mathrm{y}, \text { abe. }}=26458 \mathrm{~cm}^{4} & \mathrm{~W}_{\mathrm{y}, \text { abe. }}=3367 \mathrm{~cm}^{3}
\end{array}
$$

Vale ressaltar que as características mecânicas do painel para determinação de esforços e cálculo da armadura são diferentes das características para verificação. Isso ocorre devido à posição do painel, em que as análises dos esforços e da armadura são realizadas na posição vertical, enquanto que as verificações na fase transitória são realizadas com o painel na posição horizontal. Da mesma forma, para facilitar o cálculo, algumas características se encontram em metros e outras em centímetros. 


\subsection{PROCESSO P- $\delta$}

Os esforços determinados por meio do processo P- $\delta$ necessitam definir os esforços solicitantes, bem como as excentricidades de projeto.

\subsubsection{Esforços solicitantes no painel}

Os esforços solicitantes do painel, ao longo do edifício, apresentados na Tabela 6.1, estão divididos de acordo com o tipo de ação (carga permanente, carga acidental e ação do vento). Como o painel PF11D não está associado a nenhum outro, o vento não produz forças normais.

Tabela 6.1: Esforços solicitantes no painel PF11D ao longo do edifício

\begin{tabular}{|c|c|c|c|c|}
\hline \multirow{3}{*}{ Pavimento } & \multicolumn{4}{|c|}{ Esforços } \\
\cline { 2 - 5 } & Permanente & Acidental & \multicolumn{2}{|c|}{ Vento na direção y } \\
\cline { 2 - 5 } & $\mathbf{N}_{\mathbf{g}}(\mathbf{k N})$ & $\mathbf{N}_{\mathbf{q} 1}(\mathbf{k N})$ & $\mathbf{N}_{\mathbf{q} 2}(\mathbf{k N})$ & $\mathbf{M}_{\mathbf{q 2}}(\mathbf{k N . m})$ \\
\hline $5^{\mathbf{0}}$ & 22,62 & 6,16 & 0,00 & 4,71 \\
\hline $4^{\mathbf{o}}$ & 45,25 & 12,32 & 0,00 & 18,25 \\
\hline $3^{\mathbf{o}}$ & 67,87 & 18,48 & 0,00 & 41,58 \\
\hline $2^{\mathbf{o}}$ & 90,49 & 24,64 & 0,00 & 73,55 \\
\hline $1^{\mathbf{o}}$ & 113,12 & 30,79 & 0,00 & 107,04 \\
\hline
\end{tabular}

Para atender a segurança do painel para solicitações normais no estado limite último, a ABNT NBR 16055:2012 recomenda a expressão 6.1:

$$
\begin{aligned}
& \mathrm{N}_{\mathrm{d}, \text { resist }} \geq \frac{3 \cdot \mathrm{N}_{\mathrm{d} \text {,máx }}+\mathrm{N}_{\mathrm{d} \text {,mín }}}{4} \\
\mathrm{~N}_{\mathrm{d} \text {,máx }}= & \text { maior valor da força normal por unidade de comprimento, para o } \\
& \text { carregamento considerado, no trecho escolhido; } \\
\mathrm{N}_{\mathrm{d} \text {,mín }}= & \text { menor valor da força normal por unidade de comprimento, para o } \\
& \text { carregamento considerado, no trecho escolhido. }
\end{aligned}
$$

Segundo as recomendações da ABNT NBR 16055:2012, os valores de $\mathrm{N}_{\mathrm{d} \text {,máx }}$ e $\mathrm{N}_{\mathrm{d} \text {,mín }}$ devem corresponder aos esforços extremos do trecho considerado, mantendo variação linear desses valores, ao longo de toda extensão dos trechos, como mostra a Figura 6.2. 


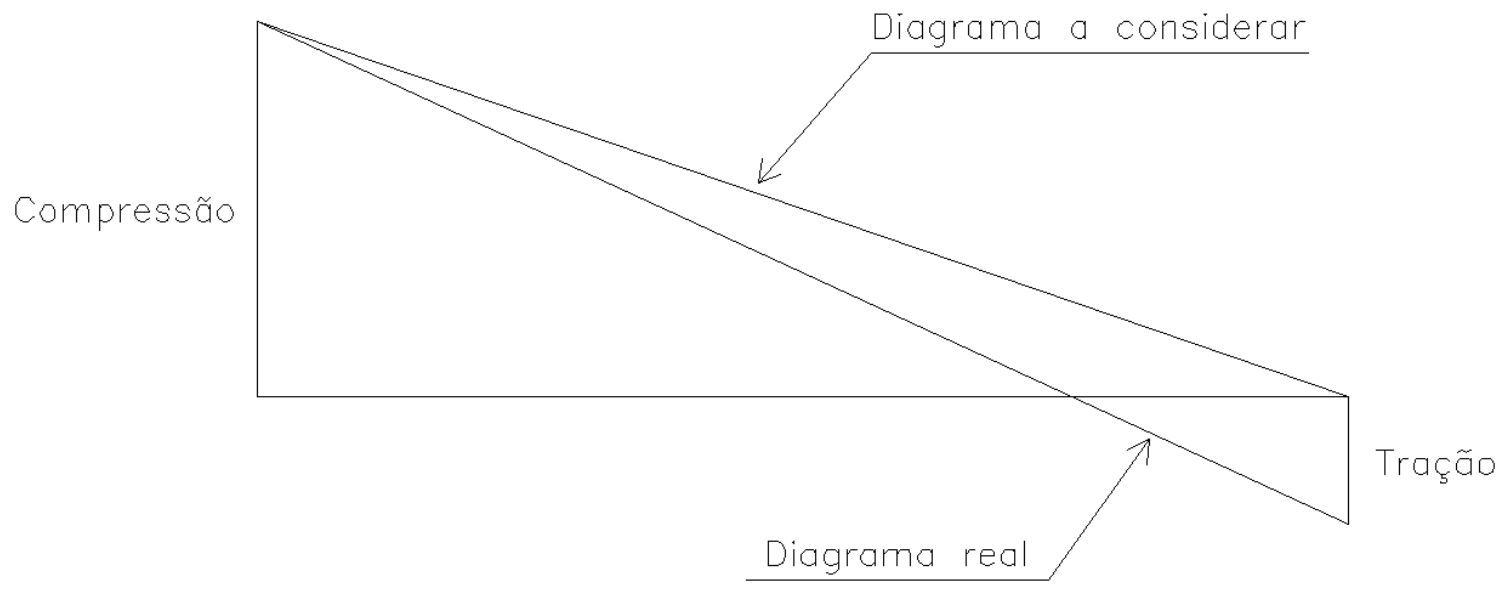

Figura 6.2: Diagrama de esforços de compressão (Adaptado: ABNT NBR 16055:2012)

A partir das combinações de ações apresentadas na ABNT NBR 6118:2007, considerou-se na primeira combinação a carga acidental como ação variável principal e o vento como ação variável secundária [equação (6.2)], e na segunda combinação, o vento como principal e a acidental como secundária [equação (6.3)].

$$
\begin{aligned}
& \mathrm{N}_{\mathrm{d}}=\gamma_{\mathrm{g}} \mathrm{N}_{\mathrm{g}}+\gamma_{\mathrm{q}} \mathrm{N}_{\mathrm{q} 1}+\gamma_{\mathrm{q}} \psi_{0} \mathrm{~N}_{\mathrm{q} 2} \\
& \mathrm{~N}_{\mathrm{d}}=\gamma_{\mathrm{g}} \mathrm{N}_{\mathrm{g}}+\gamma_{\mathrm{q}} \mathrm{N}_{\mathrm{q} 2}+\gamma_{\mathrm{q}} \Psi_{0} \mathrm{~N}_{\mathrm{q} 1}
\end{aligned}
$$

Nessas equações, $\gamma_{\mathrm{g}}, \gamma_{\mathrm{q}}$ e $\psi_{0}$ são os coeficientes de ponderação das ações, no estado limite último.

Os cálculos dos esforços normais para a combinação 1 [(equação (6.2)] e a combinação 2 [equação (6.3)] estão mostrados na Tabela 6.2.

\begin{tabular}{|c|c|c|c|c|c|c|c|c|c|c|c|c|c|}
\hline \multirow[b]{2}{*}{ Comb. } & \multicolumn{2}{|c|}{ Permanentes } & \multicolumn{3}{|c|}{ Acidental } & \multicolumn{4}{|c|}{ Vento na direção $X$} & \multirow[b]{2}{*}{$\begin{array}{l}\mathbf{N}_{\mathrm{d}, \text { máx }} \\
(\mathrm{kN} / \mathbf{m})\end{array}$} & \multirow[b]{2}{*}{$\begin{array}{c}\mathbf{N}_{\mathrm{d}, \mathbf{m} ́ \mathbf{n}} \\
(\mathbf{k N} / \mathbf{m})\end{array}$} & \multirow[b]{2}{*}{$\begin{array}{c}\mathbf{N}_{\mathbf{d}} \\
(\mathbf{k N} / \mathbf{m})\end{array}$} & \multirow[b]{2}{*}{$\begin{array}{c}\mathbf{N}_{\mathbf{d}} \\
(\mathbf{k N})\end{array}$} \\
\hline & $\begin{array}{c}\mathbf{N}_{\mathbf{g}} \\
(\mathbf{k N} / \mathbf{m})\end{array}$ & $\gamma_{\mathrm{g}}$ & $\begin{array}{c}\mathbf{N}_{\mathrm{q} 1} \\
(\mathrm{kN} / \mathrm{m})\end{array}$ & $\gamma_{q}$ & $\Psi_{0}$ & $\begin{array}{l}\mathbf{N}_{\mathrm{q} 2, \mathbf{m}} \mathbf{x} \\
(\mathrm{kN} / \mathrm{m})\end{array}$ & $\begin{array}{l}\mathbf{N}_{\mathbf{q} 2, \mathbf{m} ́ n} \\
(\mathbf{k N} / \mathbf{m})\end{array}$ & $\gamma_{\mathrm{q}}$ & $\Psi_{0}$ & & & & \\
\hline 1 & 30,12 & 1,3 & 8,20 & 1,4 & 1,0 & 45,55 & $-45,55$ & 1,4 & 0,6 & 88,90 & 12,38 & 69,77 & 262,00 \\
\hline 2 & 30,12 & 1,3 & 8,20 & 1,4 & 0,5 & 45,55 & $-45,55$ & 1,4 & 1,0 & 108,67 & $-18,86$ & 81,50 & 306,04 \\
\hline
\end{tabular}

Tabela 6.2: Cálculo dos esforços normais para as combinações 1 e 2

A Tabela 6.2 mostra que o maior valor de $\mathrm{N}_{\mathrm{d}}$ encontrado foi na combinação 2, com um esforço normal de $306,04 \mathrm{kN}$. 


\subsubsection{Excentricidade de projeto}

Como apresentado no capítulo 4.2, é necessário considerar as excentricidades de projeto nos elementos pré-moldados, como se apresenta a seguir.

a) Excentricidade mínima

Utilizando a equação (4.13), tem-se que:

$$
\mathrm{e}_{\text {mín }}=0,015+0,03 \mathrm{~h}=0,015+0,03 \cdot 0,10=0,018 \mathrm{~m}=18,0 \mathrm{~mm}
$$

b) Tolerância de montagem

De acordo com o PCI (2010), a excentricidade de montagem deve ser:

$$
\mathrm{e}_{\mathrm{m}}=12,7 \mathrm{~mm}
$$

c) Tolerância de produção

Utilizando a equação (4.14), resulta:

$$
\mathrm{e}_{\mathrm{p}}=\frac{\mathrm{L}}{360}=\frac{2600}{360}=7,2 \mathrm{~mm} \therefore 7,2<12,7
$$

d) Diferença térmica

Tem-se na equação (4.16) a determinação do gradiente térmico, que define o valor do coeficiente de dilatação térmica (concreto) e a temperatura externa e interna:

$$
\alpha=\mathrm{C}\left(\mathrm{T}_{1}-\mathrm{T}_{2}\right)=10^{-5}(30-15)=0,00015
$$

Logo, para a determinação do empenamento térmico, utiliza-se a equação (4.15):

$$
\Delta_{\mathrm{T}}=\alpha \frac{\mathrm{l}^{2}}{8 \mathrm{~h}}=15 \cdot 10^{-5} \cdot \frac{2600^{2}}{8 \cdot 100}=1,3 \mathrm{~mm}
$$

\subsubsection{Esforços através do Processo P- $\delta$}

O processo P- $\delta$ considera a não linearidade geométrica. De acordo com o PCI (2010), a não linearidade física é considerada pelo fator de redução da resistência do concreto $\left(\phi_{\mathrm{k}}\right)$ para elementos pré-moldados (maior controle tecnológico) no valor de 0,85, que leva em consideração os coeficientes de fissuração e o efeito de fluência no concreto.

Para determinação do coeficiente $\beta_{\mathrm{d}}$ tem-se,

$$
\beta_{d}=\frac{\gamma_{g} N_{k}}{N_{d}}=\frac{1,30 \cdot 113,12}{306,04}=0,48
$$


A rigidez efetiva da seção é determinada por:

$$
\mathrm{EI}_{\mathrm{e}}=\frac{\phi_{\mathrm{k}} \mathrm{E}_{\mathrm{c}} \mathrm{I}_{\mathrm{g}}}{1+\beta_{\mathrm{d}}}=\frac{0,85 \cdot 10 \cdot 10^{6} \cdot 3,1 \cdot 10^{-4}}{1+0,48}=1796,5 \mathrm{kN} \cdot \mathrm{m}^{2}
$$

Para a rigidez efetiva da seção com a consideração do vento tem-se que $\beta_{d}=0$, logo:

$$
\mathrm{EI}_{\mathrm{e}, \mathrm{w}}=\frac{\phi_{\mathrm{k}} \mathrm{E}_{\mathrm{c}} \mathrm{I}_{\mathrm{g}}}{1}=\frac{0,85 \cdot 10 \cdot 10^{6} \cdot 3,1 \cdot 10^{-4}}{1}=2659,8 \mathrm{kN} \cdot \mathrm{m}^{2}
$$

Uma recomendação apresentada no PCI (2010) é a verificação do carregamento de cálculo com a carga crítica de Euler:

$$
\mathrm{P}_{\mathrm{c}}=\frac{\pi^{2} \mathrm{EI}_{\mathrm{e}}}{\mathrm{l}^{2}}=\frac{\pi^{2} \cdot 1796,5}{2,60^{2}}=834,91 \mathrm{kN} \quad \therefore 306,04<834,91
$$

O procedimento de cálculo deve determinar o coeficiente de flambagem do painel PF11D. Dessa forma, o painel não apresenta nenhuma restrição lateral nos extremos, sendo que o valor do coeficiente de flambagem (k) é igual a 1,0. Para determinação do comprimento de flambagem tem-se:

$$
\mathrm{l}_{\mathrm{fla}}=\mathrm{k} \cdot \mathrm{l}=1,0 \cdot 2,6=2,60 \mathrm{~m}
$$

A flecha inicial devida à tolerância de montagem é determinada pela equação:

$$
\Delta_{\mathrm{i}}=\frac{\mathrm{N}_{\mathrm{d}} \mathrm{e}_{\mathrm{m}} \mathrm{l}_{\mathrm{fla}}^{2}}{16 \mathrm{EI}_{\mathrm{e}}}=\frac{306,04 \cdot 12,7 \cdot 2,6^{2}}{16 \cdot 1796,5}=0,91 \mathrm{~mm}
$$

A flecha provocada pela ação do vento é dada por:

$$
\Delta_{\mathrm{w}}=\frac{5 \mathrm{ql}_{\mathrm{fla}}^{4}}{384 \mathrm{EI}_{\mathrm{e}, \mathrm{w}}}=\frac{5 \cdot(0,53 \cdot 14,90) \cdot 2,6^{4}}{384 \cdot 2659,8}=1,77 \mathrm{~mm}
$$

Logo, a excentricidade inicial no meio da altura do painel é definida como:

$$
\mathrm{e}_{\mathrm{i}}=\mathrm{e}_{\mathrm{p}}+\Delta_{\mathrm{T}}+\Delta_{\mathrm{i}}+\Delta_{\mathrm{w}}=7,2+1,3+0,91+1,77=11,17 \mathrm{~mm}
$$


O processo P- $\delta$ é iniciado, então, após a determinação da excentricidade inicial considerando a não linearidade geométrica por meio de um processo iterativo que calcula a flecha na seção, do modo indicado a seguir.

Primeira iteração:

$$
\Delta_{1}=\frac{\mathrm{N}_{\mathrm{d}} \mathrm{l}_{\mathrm{fla}}^{2}}{8 \mathrm{EI} \mathrm{I}_{\mathrm{e}}} \cdot \mathrm{e}_{1}=\frac{306,04 \cdot 2,6^{2}}{8 \cdot 1796,5} \cdot 11,17=1,61 \mathrm{~mm}
$$

Segunda iteração:

$$
\begin{gathered}
\mathrm{e}_{2}=\mathrm{e}_{1}+\Delta_{1}=11,17+1,61=12,78 \mathrm{~mm} \\
\Delta_{2}=\frac{\mathrm{N}_{\mathrm{d}} \mathrm{l}_{\text {fla }}^{2}}{8 \mathrm{EI}} \cdot \mathrm{e}_{2}=\frac{306,04 \cdot 2,6^{2}}{8 \cdot 1796,5} \cdot 12,78=1,84 \mathrm{~mm}
\end{gathered}
$$

Terceira iteração:

$$
\begin{gathered}
\mathrm{e}_{3}=\mathrm{e}_{1}+\Delta_{2}=11,17+1,84=13,01 \mathrm{~mm} \\
\Delta_{3}=\frac{\mathrm{N}_{\mathrm{d}} \mathrm{l}_{\mathrm{fla}}^{2}}{8 \mathrm{EI}} \cdot \mathrm{e}_{3}=\frac{306,04 \cdot 2,6^{2}}{8 \cdot 1796,5} \cdot 13,01=1,87 \mathrm{~mm}
\end{gathered}
$$

Quarta iteração:

$$
\begin{gathered}
\mathrm{e}_{4}=\mathrm{e}_{1}+\Delta_{3}=11,17+1,87=13,04 \mathrm{~mm} \\
\Delta_{4}=\frac{\mathrm{N}_{\mathrm{d}} \mathrm{l}_{\text {fla }}^{2}}{8 \mathrm{EI}} \cdot \mathrm{e}_{4}=\frac{306,04 \cdot 2,6^{2}}{8 \cdot 1796,5} \cdot 13,04=1,88 \mathrm{~mm}
\end{gathered}
$$

Quinta iteração:

$$
\begin{gathered}
\mathrm{e}_{5}=\mathrm{e}_{1}+\Delta_{4}=11,17+1,87=13,04 \mathrm{~mm} \\
\Delta_{5}=\frac{\mathrm{N}_{\mathrm{d}} \mathrm{l}_{\text {fla }}^{2}}{8 \mathrm{EI}} \cdot \mathrm{e}_{5}=\frac{306,04 \cdot 2,6^{2}}{8 \cdot 1796,5} \cdot 13,04=1,88 \mathrm{~mm}
\end{gathered}
$$

Nota-se a convergência da flecha na quarta iteração, com o valor de 13,04 mm. Sendo assim, o momento total de cálculo é determinado por: 


$$
\begin{gathered}
M_{d}=M_{1 \underline{a} \text { Ordem }}+M_{2^{\underline{a}} \text { Ordem }}=\frac{N_{d} \cdot e_{m}}{2}+N_{d} \cdot e_{4}=\frac{306,04 \cdot 0,0127}{2}+306,04 \cdot 0,01304= \\
=5,94 \mathrm{kN} . \mathrm{m}
\end{gathered}
$$

Logo após determinar o momento fletor de cálculo, verifica-se a fissuração do elemento a partir da comparação da tensão de tração com o módulo de ruptura, dado pela equação (3.11). Para o concreto em estudo, deve-se utilizar um coeficiente de redução da resistência de 0,75.

$$
\mathrm{f}_{\mathrm{r}}=0,083 \cdot 7,5 \lambda \sqrt{\mathrm{f}^{\prime}{ }_{\mathrm{c}}}=0,623 \cdot 0,75 \sqrt{12,5}=1,65 \mathrm{MPa}
$$

A tensão de tração solicitante é dada por:

$$
\sigma_{\mathrm{td}}=\frac{\mathrm{M}_{\mathrm{d}}}{\mathrm{W}_{\mathrm{y}}}-\frac{\mathrm{N}_{\mathrm{d}}}{\mathrm{A}}=\frac{5,94}{0,0062}-\frac{306,04}{0,3775}=0,56 \mathrm{MPa}
$$

Como a tração solicitante na seção do elemento é menor que o módulo de ruptura do concreto, a peça não apresenta fissura.

\subsection{CÁlCULO DA ARMADURA}

É recomendado verificar a armadura mínima do painel pré-moldado, mesmo que ele não apresente fissuras. A armadura mínima é determinada pelas recomendações do ACI 318-08, que preconiza uma área bruta de $0,1 \%$ para armadura mínima vertical e horizontal, resultando:

$$
A_{s, \text { mín }}=\frac{0,1}{100} \cdot \frac{A}{l}=0,001 \cdot \frac{0,3775 \cdot 10^{4}}{3,755}=1,00 \frac{\mathrm{cm}^{2}}{\mathrm{~m}}
$$

De acordo com o PCI (2010), em painéis pré-moldados que apresentem espessura inferior a $15 \mathrm{~cm}$, deve-se utilizar apenas uma camada de armadura, sendo esta posicionada no centro do painel. Dessa forma, optou-se pela escolha da tela soldada Q113, que possui $1,13 \mathrm{~cm}^{2} / \mathrm{m}$ nas duas direções.

Para validar se a armadura mínima é suficiente para a segurança do painel, foi utilizado o software livre Normal, produzido por um grupo de pesquisadores da Universidade Federal do Paraná (UFPR). A Figura 6.3 apresenta o diagrama de interação entre o esforço cortante de cálculo $\left(\mathrm{N}_{\mathrm{d}}\right)$ e momento fletor de cálculo $\left(\mathrm{M}_{\mathrm{d}}\right)$. O ponto em azul indica que a armadura utilizada está dentro da curva de interação. 


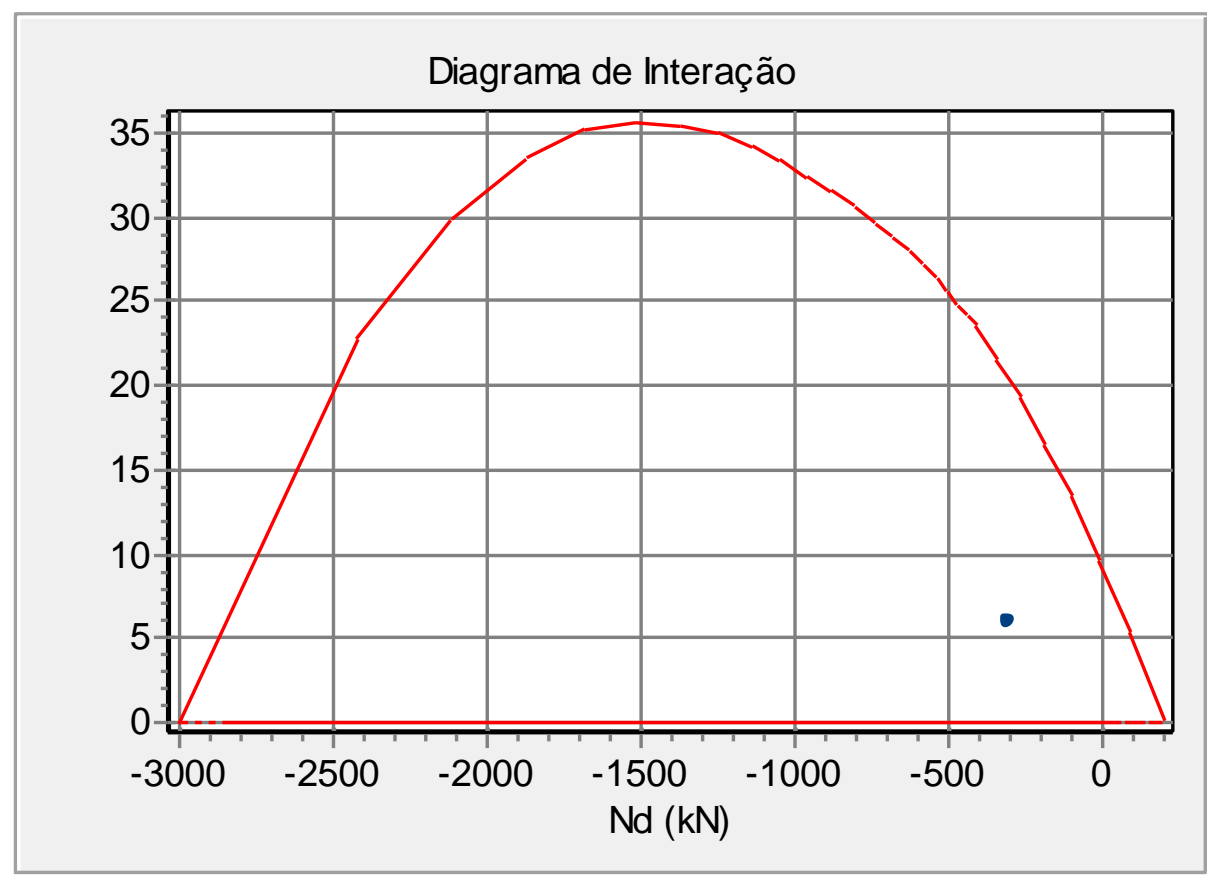

Figura 6.3: Diagrama de interação $N_{d} \times M_{d}$

O ACI-318 (2011) comenta que a armadura horizontal em painéis pré-moldados é inferior às calculadas para as paredes moldadas no local, pois a retração ocorre nas primeiras idades. Nos pré-moldados, os elementos se encontram na fase de estocagem, ou seja, com baixíssimas restrições laterais.

\subsection{DIMENSIONAMENTO DAS JUNTAS}

Nesta etapa do trabalho foram dimensionadas as juntas vertical e horizontal do painel PF11D. Utilizando as prescrições normativas apresentadas no texto, para a junta vertical foi adotado silicone, enquanto que para a junta horizontal, argamassa.

\subsubsection{Junta vertical - silicone}

Como apresentado no capítulo 3, a junta vertical de silicone não possui finalidade estrutural, apenas características que garantem a estanqueidade dos painéis. Nesse caso, deve-se, primeiramente, determinar a largura mínima da junta vertical pela equação (3.1), como foi determinado no item 6.2.2. A montagem apresentou excentricidade de $12,7 \mathrm{~mm}$, com um empenamento térmico de 1,3 mm. Considerou-se, um selante com fator de acomodação igual a $50 \%$. 
Portanto, de acordo com a equação (3.1), a largura mínima da junta vertical resulta:

$$
J=\frac{100 A}{X}+B+C=\frac{100 \cdot 1,3}{50}+12,7+0=15,2 \mathrm{~mm}
$$

De acordo com as recomendações do PCI (2007), as juntas devem apresentar largura mínima de $19 \mathrm{~mm}$, e as juntas de canto, de $30 \mathrm{~mm}$, sendo essas recomendações para painéis sem travamento da laje. Como o painel em estudo apresenta restrição lateral devida à laje, pode-se considerar a largura mínima da junta vertical como sendo o valor calculado, 15,2 mm.

Sendo assim, padronizou-se para todas as juntas externas e internas uma largura de $15 \mathrm{~mm}$. A profundidade utilizada do selante foi de $10 \mathrm{~mm}$, conforme recomendações do PCI (2007), sendo aplicado de forma côncava (Figura 6.4).

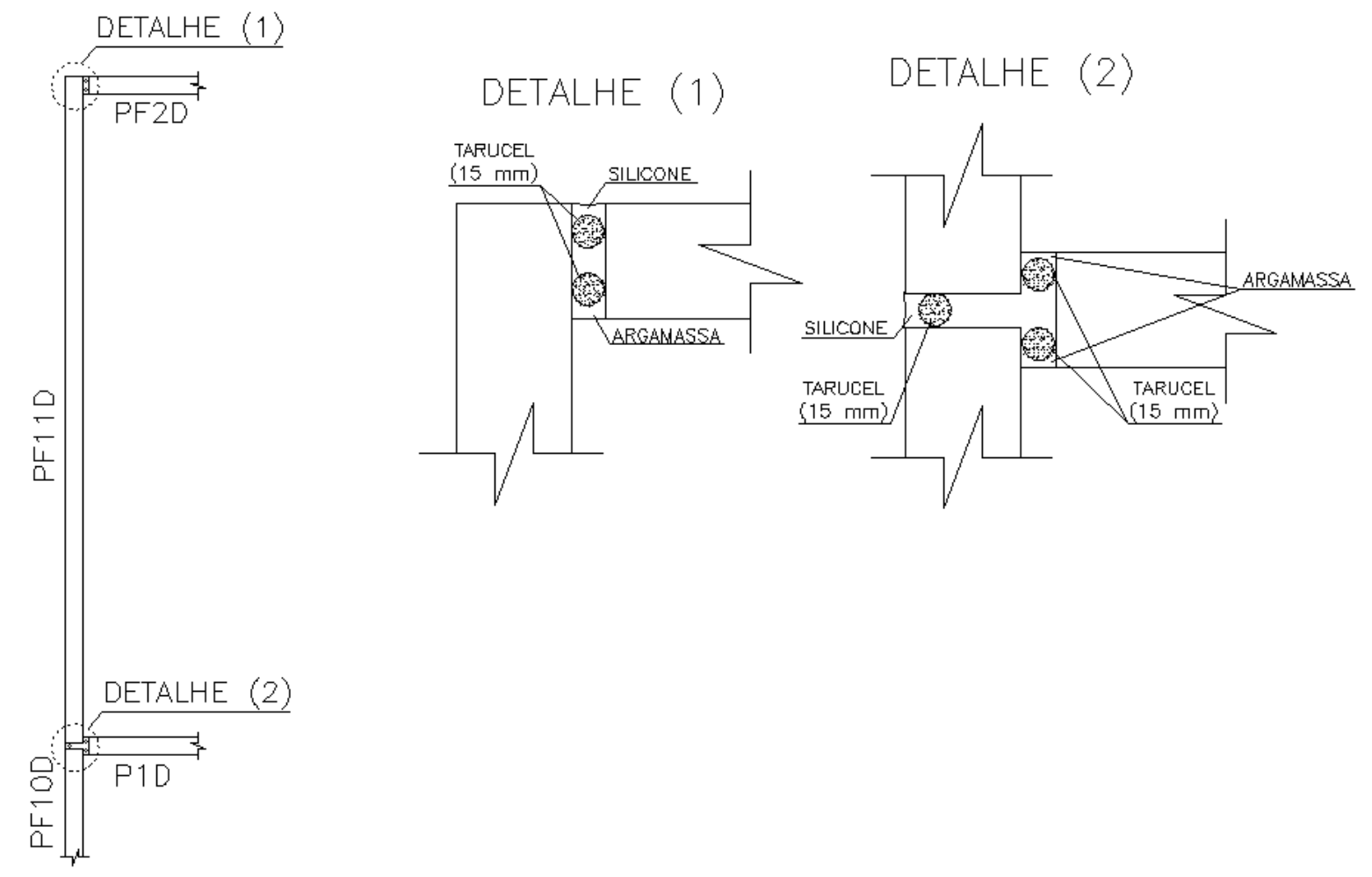

Figura 6.4: Detalhe da ligação da junta vertical com silicone

\subsubsection{Junta horizontal - compressão}

O esforço de compressão obtido no painel PF11D, apresentado neste capítulo, foi igual a $\mathrm{N}_{\mathrm{d}}=81,50 \mathrm{kN} / \mathrm{m}$. 
Para a determinação dos parâmetros $A_{1}$ e $A_{2}$, são necessários os valores da espessura do painel e a tolerância de montagem, sendo $100 \mathrm{~mm}$ a espessura e $12,7 \mathrm{~mm}$ a tolerância de montagem. Resulta:

$$
A_{1}=A_{2}=100-12,7=87,3 \mathrm{~mm}
$$

Para o prosseguimento do dimensionamento da junta horizontal à compressão, foram necessárias algumas características da argamassa, como: espessura $\left(\mathrm{t}_{\mathrm{a}}\right)$, resistência característica à compressão $\left(\mathrm{f}_{\mathrm{ck}, \mathrm{a}}\right)$ e resistência de cálculo à compressão $\left(\mathrm{f}_{\mathrm{cd}, \mathrm{a}}\right)$. Para o coeficiente de minoração da resistência da argamassa $\left(\gamma_{c, a}\right)$ foi adotado o valor 1,4.

$$
\mathrm{t}_{\mathrm{a}}=10 \mathrm{~mm} \quad \mathrm{f}_{\mathrm{ck}, \mathrm{a}}=10 \mathrm{MPa} \quad \mathrm{f}_{\mathrm{cd}, \mathrm{a}}=\frac{\mathrm{f}_{\mathrm{ck}, \mathrm{a}}}{\gamma_{\mathrm{c}, \mathrm{a}}}=7,1 \mathrm{MPa}
$$

Em seguida, determinou-se a relação entre a altura da junta (t) e a largura de apoio do painel $\left(\mathrm{a}_{1}\right)$, conforme foi indicado na Figura 3.10.

$$
\begin{gathered}
\mathrm{t}=2 \cdot \mathrm{t}_{\mathrm{a}}+\mathrm{h}_{\text {laje }}=2 \cdot 10+100=120 \mathrm{~mm} \\
\mathrm{a}_{1}=100-12,7=87,3 \mathrm{~mm} \\
\mathrm{t} / \mathrm{a}_{1}=1,37
\end{gathered}
$$

Obtido o valor da relação entre a altura da junta e a largura do painel, determinou-se o valor de $\beta_{0}$, apresentado na equação (3.5).

$$
\beta_{0}=\frac{f_{\text {cd,mortar }}}{f_{\text {cd,wall }}}=0,74
$$

O $\beta$ foi determinado pelo diagrama apresentado na Figura 3.11, no valor de 0,74.

O valor de cálculo da força normal resistente de compressão da junta foi obtido pela equação (3.3). Sendo assim, tem-se:

$$
\begin{gathered}
\mathrm{f}_{\text {cd,joint }}=\beta \cdot \mathrm{f}_{\text {cd,wall }}=7,1 \mathrm{MPa} \\
\mathrm{f}_{\mathrm{cd}^{*}}=\mathrm{f}_{\text {cd,joint }} \cdot\left(\mathrm{A}_{2} / \mathrm{A}_{1}\right)^{1 / 2}=7,1 \mathrm{MPa} \\
\mathrm{N}_{\mathrm{Rd} \text {,joint }}=\mathrm{f}_{\mathrm{cd}^{*}} \cdot \mathrm{A}_{\text {joint }}=621,17 \mathrm{kN} / \mathrm{m}>\mathrm{N}_{\mathrm{d}}=81,50 \mathrm{kN} / \mathrm{m}
\end{gathered}
$$


Em seguida, é realizada a verificação da necessidade ou não de armadura, de acordo com a recomendação do Eurocode 2, apresentada no item 3.3.

$$
\mathrm{N}_{\mathrm{d}} \leq 0,5 \mathrm{~h} \cdot \mathrm{f}_{\mathrm{cd}} \therefore 81,50 \mathrm{kN} / \mathrm{m} \leq 480,77 \mathrm{kN} / \mathrm{m}
$$

Dessa forma, é possível notar que não há necessidade de armadura para a junta horizontal, visto que a resistência da própria argamassa já é suficiente (Figura 6.5).

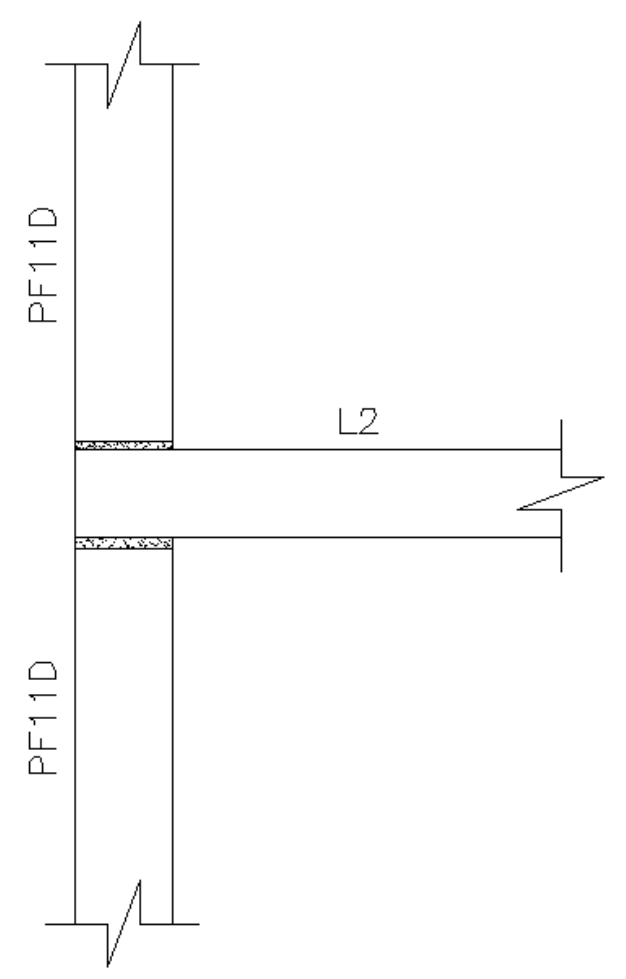

Figura 6.5: Detalhe da ligação horizontal por compressão

\subsection{VERIFICAÇÃO DO PAINEL NA FASE TRANSITÓRIA}

Na fase transitória, os painéis são submetidos a diferentes tipos de esforços, quando estão localizados na posição final. Sendo assim, esses esforços devem ser determinados a fim de garantir a integridade do elemento pré-moldado nas fases de desmoldagem, transporte e montagem do painel.

A partir das características do painel apresentadas neste capítulo, determinou-se o carregamento devido ao peso próprio, sendo:

$$
\mathrm{q}=\rho \cdot \mathrm{h}=13 \cdot 0,10=1,30 \mathrm{kN} / \mathrm{m}^{2}
$$


Para maior viabilidade econômica, foram estabelecidos quatro pontos no painel para a fase transitória de desmoldagem (Figura 6.6), sendo dois pontos superiores, para a fase de montagem (D1 e D4).

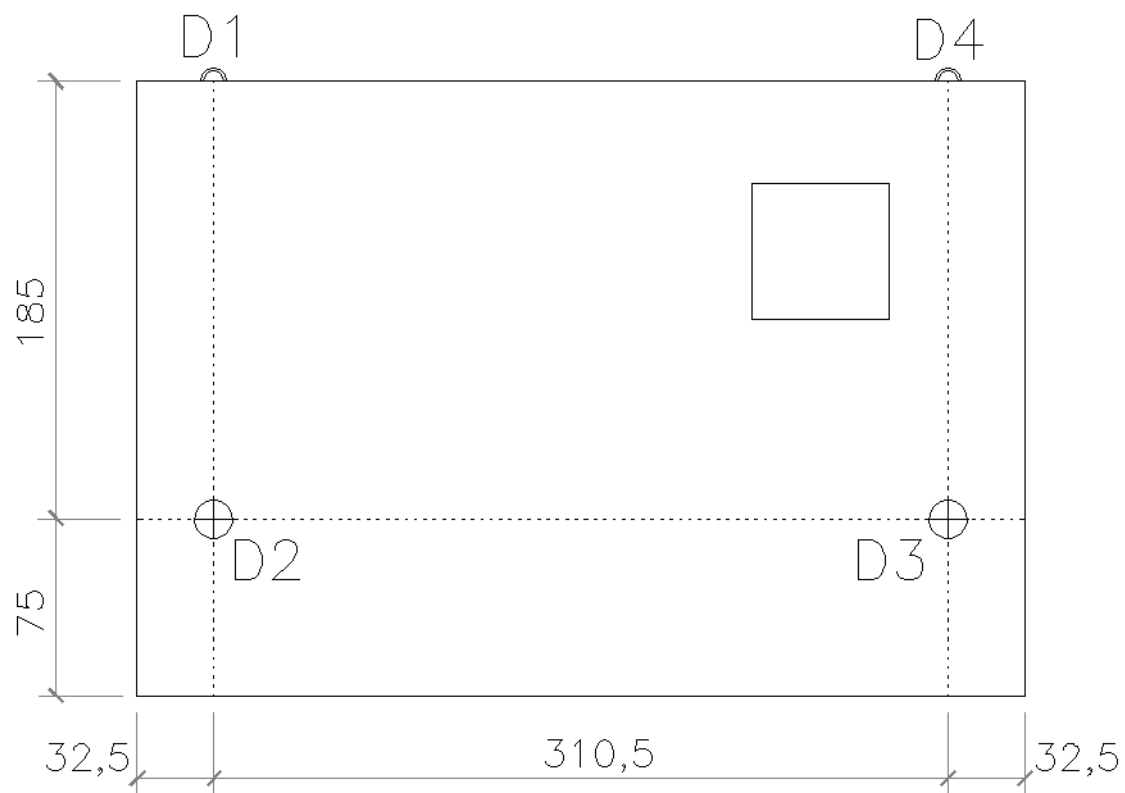

Figura 6.6: Posições dos dispositivos auxiliares para fase transitória, unidades em centímetros

A região circular nos pontos de içamento, como mostrado na Figura 6.6, representa o espraiamento de $45^{\circ}$ das forças atuantes no painel, de modo que se pode desprezar o valor encontrado no pico dos esforços, utilizando o valor no limite de $18 \mathrm{~cm}$ (Figura 6.7).

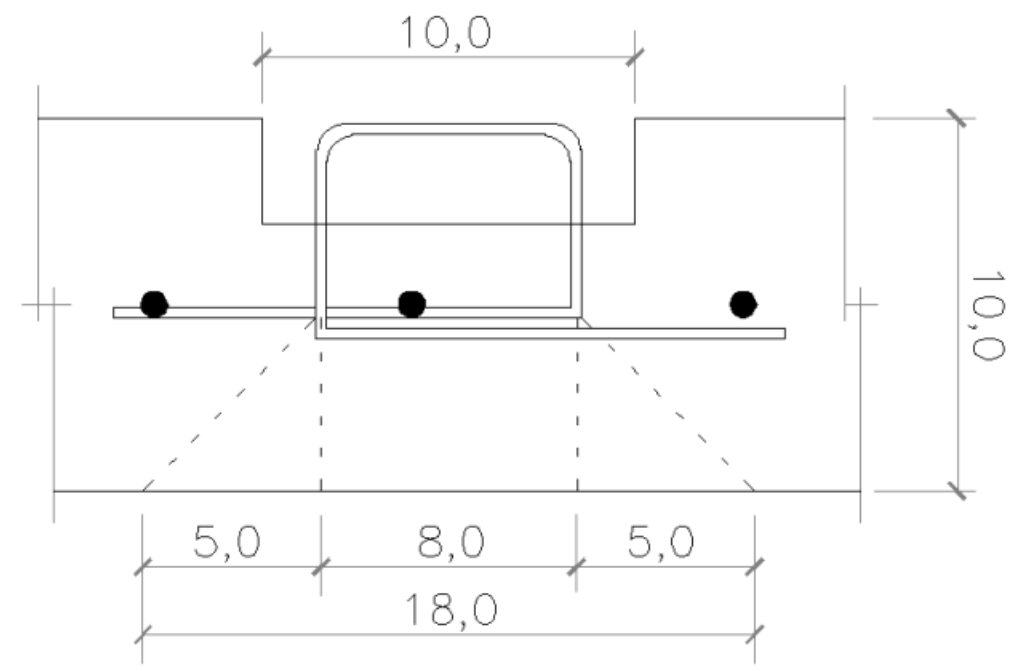

Figura 6.7: Espraiamento das forças à $45^{\circ}$, na fase transitória do painel, unidades em centímetros 


\subsubsection{Fase transitória - Desmoldagem do painel}

Na fase transitória para a desmoldagem do painel, deve-se calcular o módulo de ruptura do concreto, dado pela equação (3.11), com a resistência à compressão após oito horas $\left(\mathrm{f}_{\mathrm{ck} 8 \mathrm{~h}}\right)$ :

$$
\mathrm{f}_{\mathrm{r}, \mathrm{des} .}=0,415 \cdot \lambda \sqrt{\mathrm{f}^{\prime}{ }_{\mathrm{c}}}=0,415 \cdot 0,75 \cdot \sqrt{6,0}=0,76 \mathrm{MPa}
$$

Os esforços solicitantes foram determinados no software SAP2000. A Figura 6.8 apresenta o momento fletor M11, e a Figura 6.9 mostra o momento fletor M22, na fase transitória.

A Tabela 6.3 mostra, de forma resumida, os momentos fletores encontrados nos dispositivos auxiliares. Nota-se o maior momento encontrado no dispositivo auxiliar D2, com valor absoluto de $107,2 \mathrm{kN} . \mathrm{cm} / \mathrm{m}$.

Tabela 6.3: Resumo dos momentos fletores M11 e M22 nos dispositivos auxiliares

\begin{tabular}{|c|c|c|}
\hline $\begin{array}{c}\text { Dispositivo } \\
\text { auxiliar }\end{array}$ & $\begin{array}{c}\text { M11 } \\
\text { (kN.cm/m) }\end{array}$ & $\begin{array}{c}\mathbf{M 2 2} \\
\text { (kN.cm/m) }\end{array}$ \\
\hline D1 & $-61,0$ & $-11,4$ \\
\hline D2 & $-64,4$ & $-107,2$ \\
\hline D3 & $-58,7$ & $-105,9$ \\
\hline D4 & $-53,7$ & $-10,4$ \\
\hline
\end{tabular}

Entre os dispositivos auxiliares D2 e D3 e os dispositivos D1 e D4, foram encontrados momentos fletores M11 de 145,4 kN.cm/m e 140,6 kN.cm/m, respectivamente. Já para os momentos fletores M22 encontrados entre os dispositivos D1 e D2 e D3 e D4, foram de $51,3 \mathrm{kN} . \mathrm{cm} / \mathrm{m}$ e $50,3 \mathrm{kN} . \mathrm{cm} / \mathrm{m}$, respectivamente. Logo, verifica-se que o maior momento fletor encontrado nessa fase transitória foi de $145,4 \mathrm{kN} . \mathrm{cm} / \mathrm{m}$, sendo este o valor utilizado para verificação.

De acordo com o PCI (2010), utilizou-se o coeficiente de segurança apresentado na Tabela 3.1, no valor de 1,4, para majorar o valor absoluto máximo, apresentado na Tabela 6.3.

$$
\mathrm{M}_{\text {máx,des. }}{ }^{+}=1,4 \cdot 145,4=203,6 \mathrm{kN} . \mathrm{cm}
$$

Em seguida, foi determinada a tensão provocada pelo momento fletor:

$$
\mathrm{f}_{\mathrm{t}, \text { des. }}=\frac{\mathrm{M}_{\text {máx,des. }}{ }^{+}}{\mathrm{W}_{\mathrm{y}, \text { sól. }}}=0,047 \frac{\mathrm{kN}}{\mathrm{cm}^{2}}=0,47 \mathrm{MPa}
$$



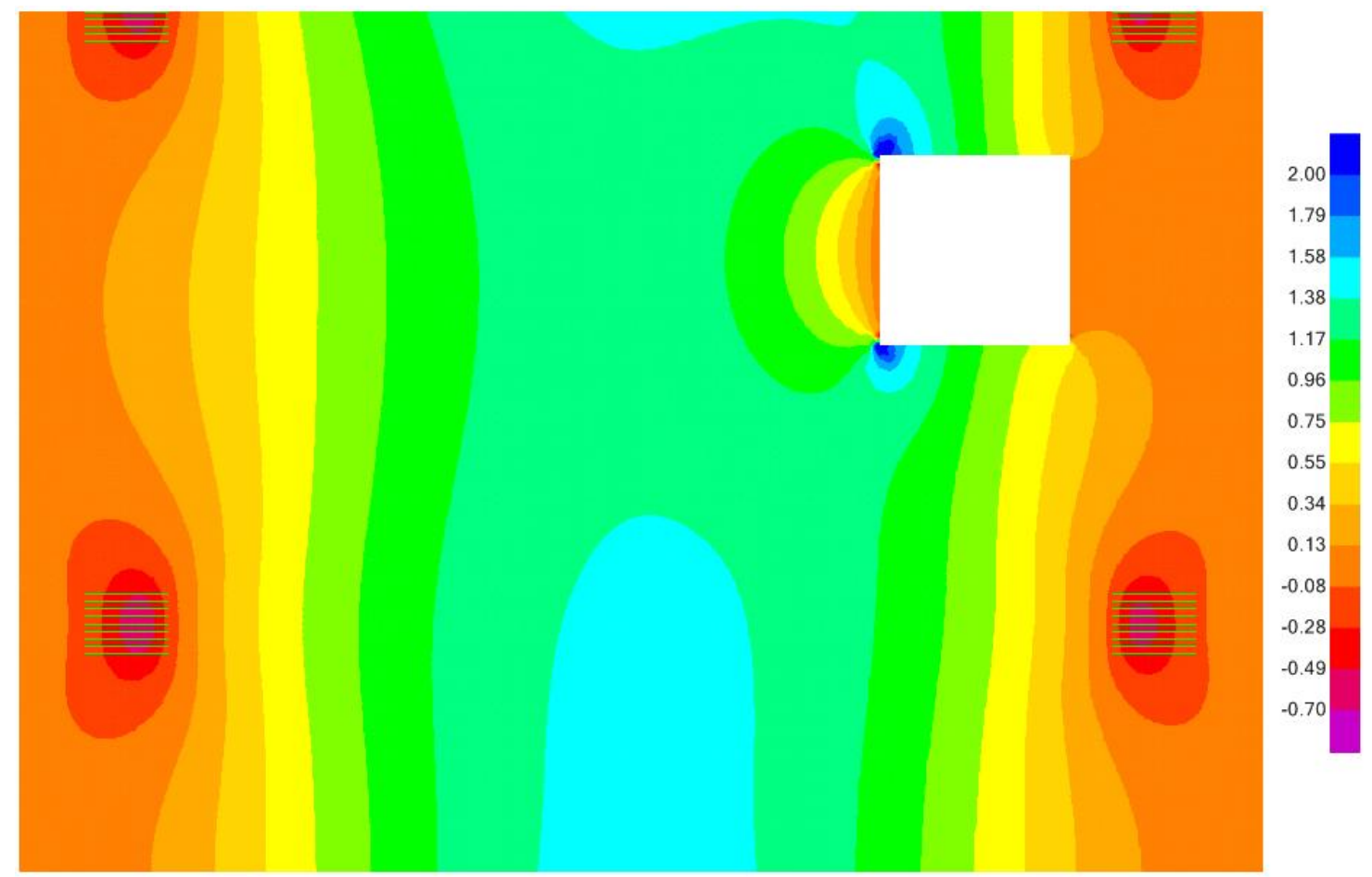

Figura 6.8: Momentos fletores M11 na desmoldagem, em kN.m/m
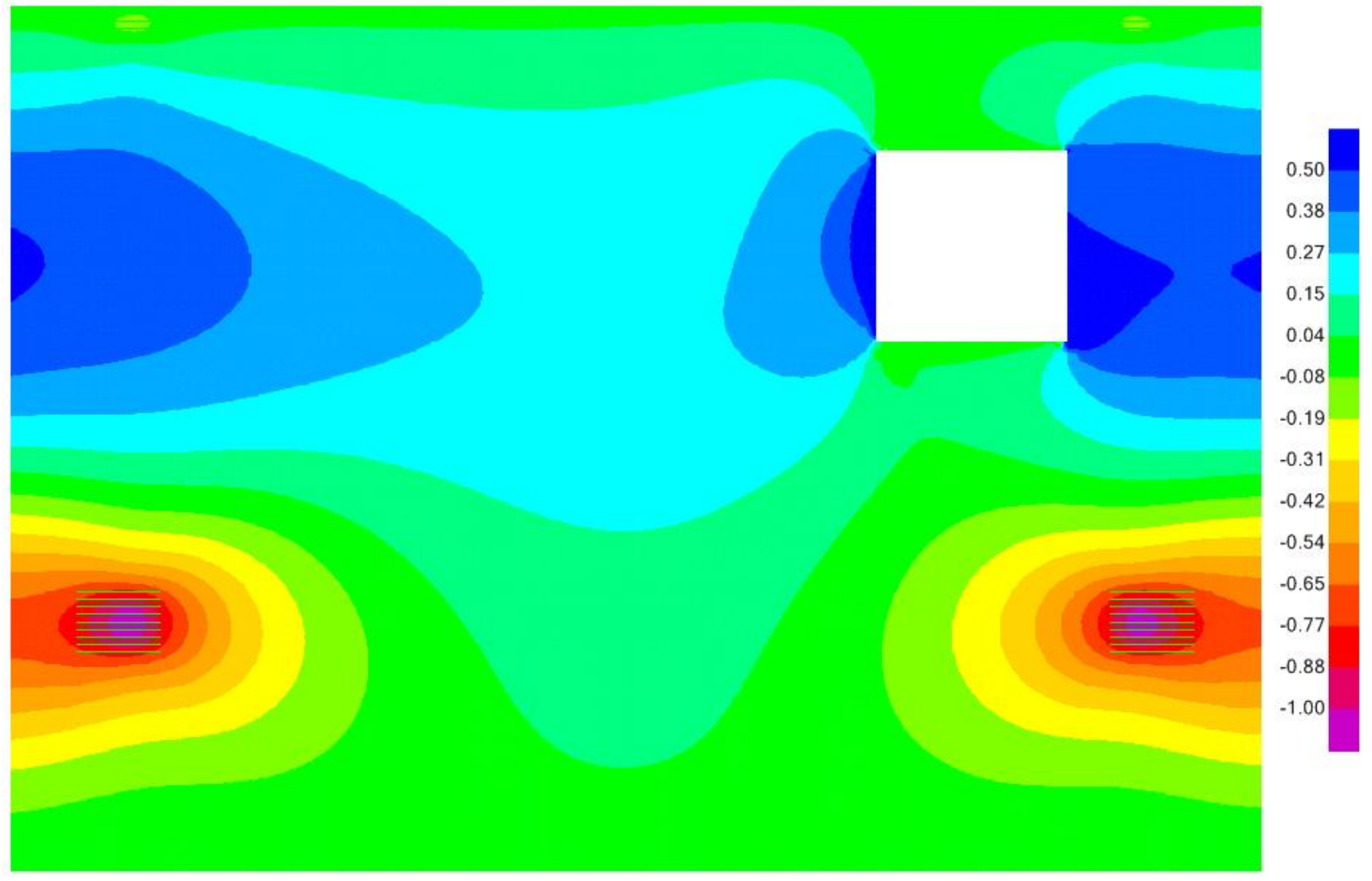

Figura 6.9: Momentos fletores M22 na desmoldagem, em kN.m/m 
A verificação da seção do painel foi calculada utilizando-se a maior tensão provocada no painel, comparando-a com o módulo de ruptura do concreto, resultando:

$$
\mathrm{f}_{\mathrm{t}, \text { des. }} \leq \mathrm{f}_{\mathrm{r} \text {,des. }} \therefore 0,47 \mathrm{MPa}<0,76 M P a
$$

Sendo assim, a seção de Concreto Leve Estrutural com esferas de EPS resiste para a situação de içamento por quatro pontos.

\subsubsection{Fase transitória - Transporte do painel}

$\mathrm{Na}$ fase transitória para o transporte do painel, calcula-se, inicialmente, o módulo de ruptura do concreto, dado pela equação (3.11), com a resistência à compressão aos 28 dias $\left(\mathrm{f}_{\mathrm{ck} 28}\right)$ :

$$
\mathrm{f}_{\mathrm{r}, \text { trans. }}=0,415 \cdot \lambda \sqrt{\mathrm{f}^{\prime}{ }_{\mathrm{c}}}=0,415 \cdot 0,75 \cdot \sqrt{12,5}=1,10 \mathrm{MPa}
$$

Os esforços solicitantes foram determinados no software comercial SAP2000. A Figura 6.10 mostra o momento fletor M11 na fase transitória de transporte do painel. Considerou-se uma linha de apoio com espessura de $10 \mathrm{~cm}$ para esse transporte. O momento fletor máximo absoluto resultante foi de $54,4 \mathrm{kN} . \mathrm{cm} / \mathrm{m}$.

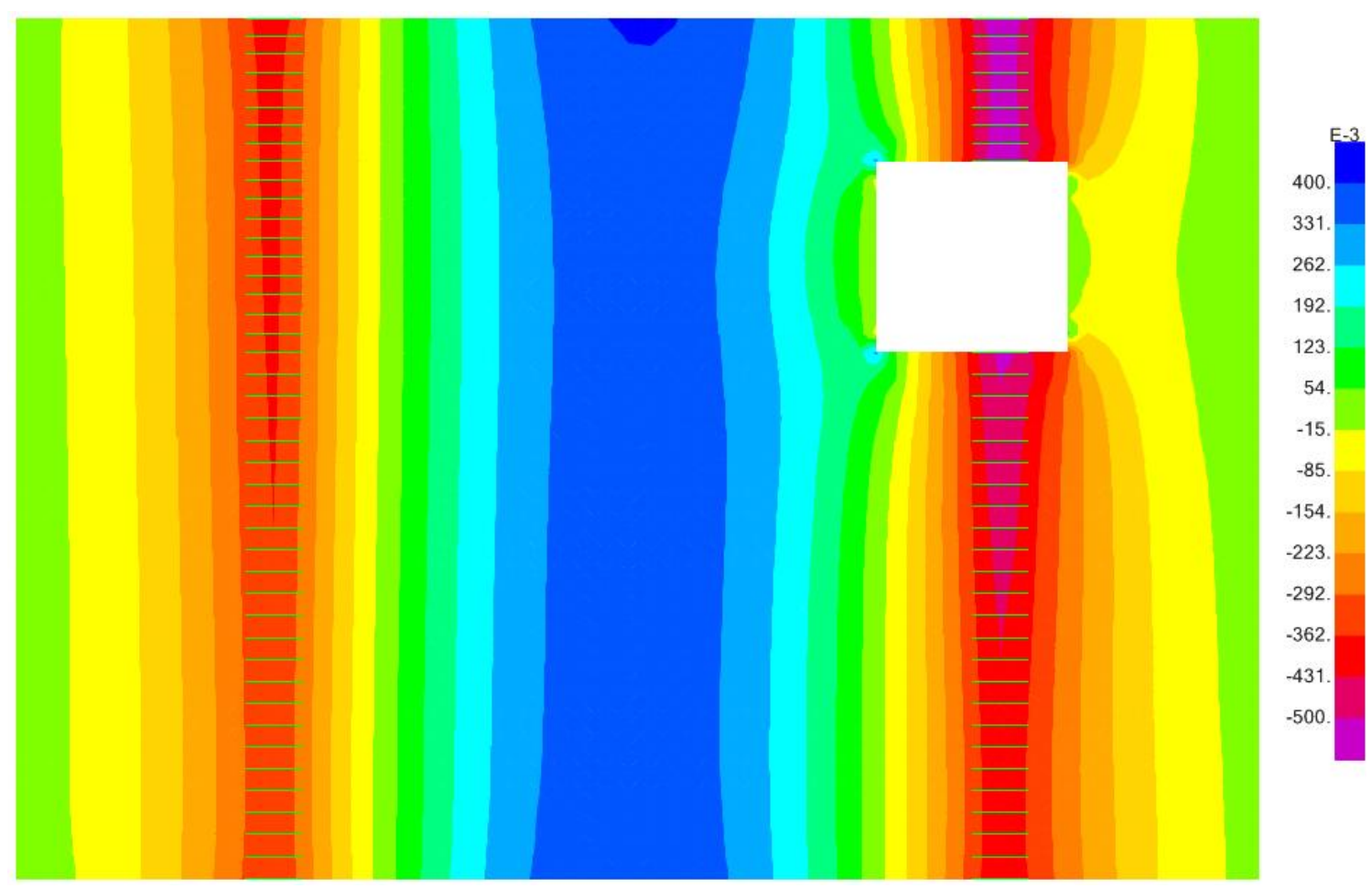

Figura 6.10: Diagrama de momento fletor do transporte do painel, em kN. cm 
De acordo com as recomendações do PCI (2010), utilizou-se o coeficiente de segurança apresentado na Tabela 3.1, no valor de 1,5, para majorar os valores máximos apresentados no diagrama da Figura 6.10. Sendo assim:

$$
\mathrm{M}_{\text {máx,trans.- }} .^{-}=1,5 \cdot 54,5=81,8 \mathrm{kN} . \mathrm{cm}
$$

Em seguida foi determinada a tensão provocada pelos momentos fletores:

$$
\mathrm{f}_{\mathrm{t}, \text { trans. }^{-}}=\frac{\mathrm{M}_{\text {máx,trans. }}{ }^{-}}{\mathrm{W}_{\mathrm{y}, \text { aber. }}}=0,024 \frac{\mathrm{kN}}{\mathrm{cm}^{2}}=0,24 \mathrm{MPa}
$$

Para a verificação da seção do painel, utiliza-se a maior tensão e compara-se com o módulo de ruptura do concreto, obtendo-se:

$$
\mathrm{f}_{\mathrm{t}, \text { trans. }}{ }^{-} \leq \mathrm{f}_{\mathrm{r}, \text { trans. }} \therefore 0,24 \mathrm{MPa}<1,10 \mathrm{MPa}
$$

Sendo assim, a seção de Concreto Leve Estrutural com esferas de EPS resiste para a situação de transporte com duas linhas de apoio.

\subsubsection{Fase transitória - Montagem do painel}

$\mathrm{Na}$ fase transitória de montagem do painel determina-se, também, o módulo de ruptura do concreto pela equação $(3.11)$, com resistência à compressão aos 28 dias $\left(\mathrm{f}_{\mathrm{ck} 28}\right)$ :

$$
\mathrm{f}_{\mathrm{r} \text {,mont. }}=0,415 \cdot \lambda \sqrt{\mathrm{f}^{\prime}{ }_{\mathrm{c}}}=0,415 \cdot 0,75 \cdot \sqrt{12,5}=1,10 \mathrm{MPa}
$$

Os esforços solicitantes foram determinados no software comercial SAP2000. Os momentos fletores M11 foram calculados em duas situações, sendo a primeira com inclinação de $30^{\circ}$ na retirada (Figura 6.11), e a segunda com inclinação de $60^{\circ}$ (Figura 6.12).

Dessa forma, analisando a evolução do painel, da posição horizontal (0 grau) até atingir a posição vertical (90 graus), nota-se que os maiores esforços ocorrem na posição horizontal. Como visto, o maior momento fletor foi de $145,4 \mathrm{kN} . \mathrm{cm} / \mathrm{m}$. De acordo com as recomendações do PCI (2010), foi utilizado o coeficiente de segurança apresentado na Tabela 3.1, no valor de 1,2.

$$
\mathrm{M}_{\text {máx,mont. }}{ }^{+}=1,2 \cdot 145,4=174,5 \mathrm{kN} . \mathrm{cm} / \mathrm{m}
$$



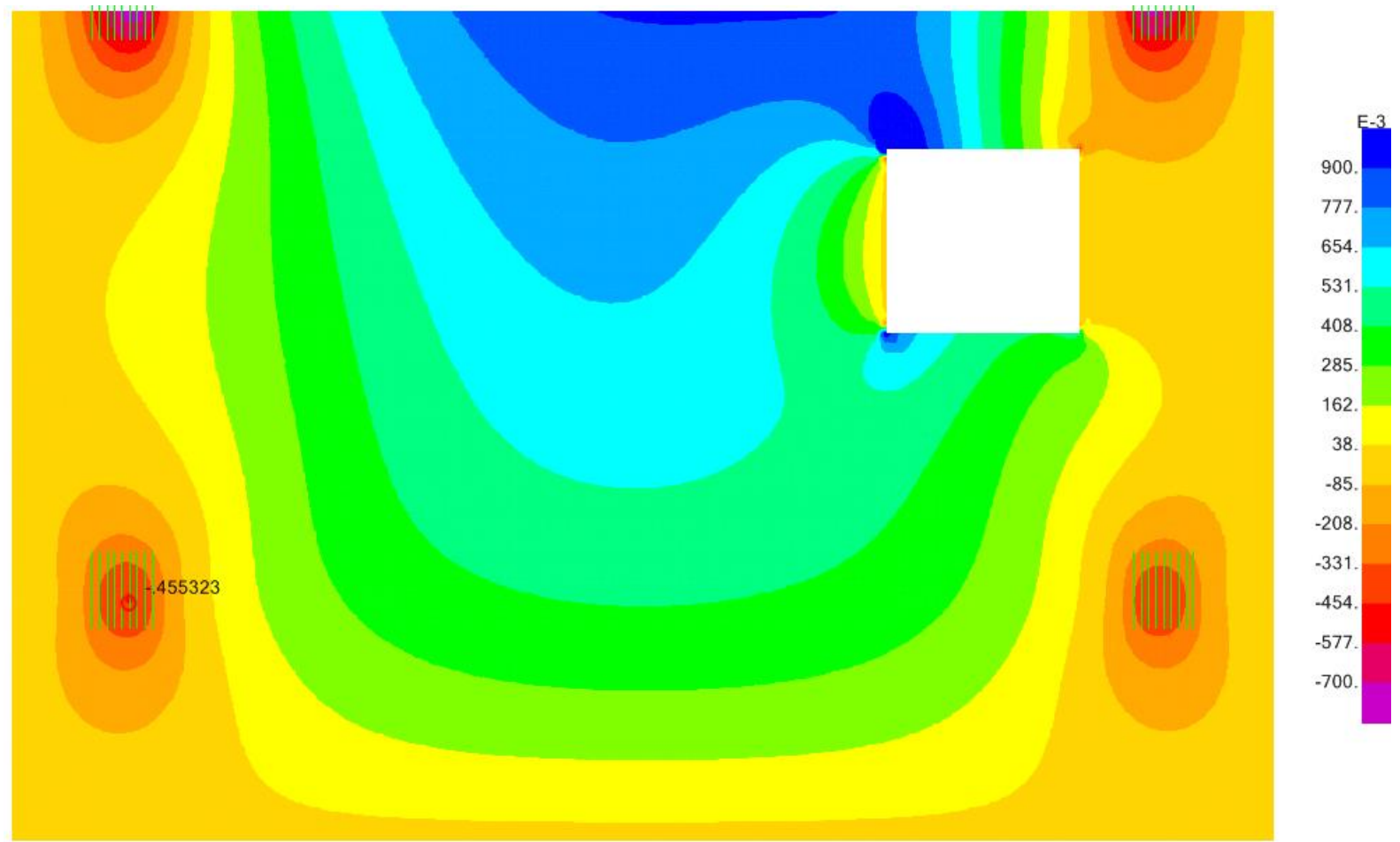

Figura 6.11: Momentos fletores M11 na montagem, com inclinação de $30^{\circ}$, em kN.m/m

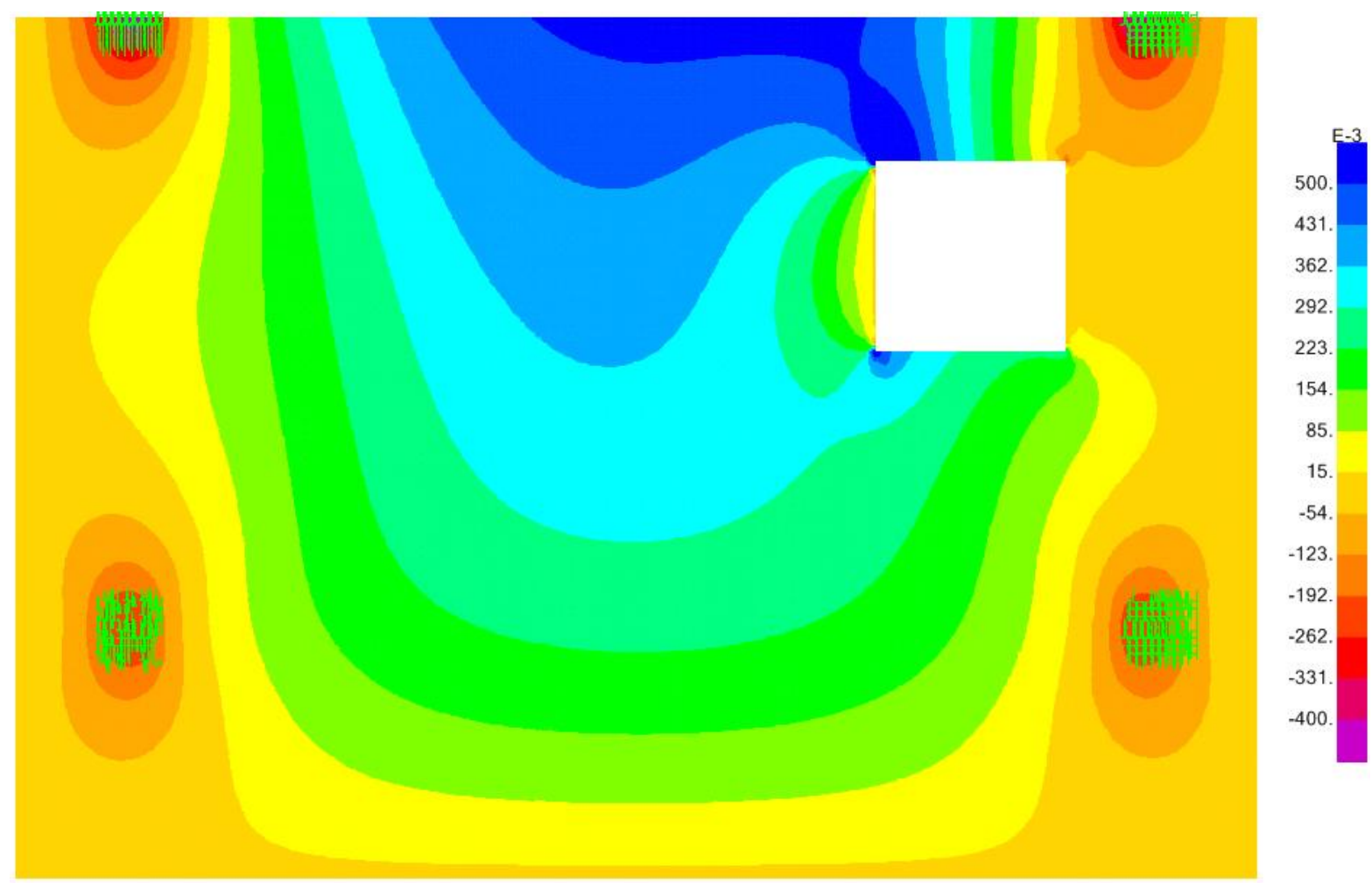

Figura 6.12: Momentos fletores M11 na montagem, com inclinação de $60^{\circ}$, em kN.m/m 
Em seguida, foi determinada a tensão provocada pelos momentos fletores:

$$
\mathrm{f}_{\mathrm{t}, \text { mont }}{ }^{+}=\frac{\mathrm{M}_{\text {máx,mont. }}{ }^{+}}{\mathrm{W}_{\mathrm{y}, \text { sól. }}}=0,040 \frac{\mathrm{kN}}{\mathrm{cm}^{2}}=0,40 \mathrm{MPa}
$$

Para a verificação da seção do painel, utiliza-se a maior tensão provocada e compara-se com o módulo de ruptura do concreto, encontrando-se:

$$
\mathrm{f}_{\mathrm{t}, \mathrm{aber}} \text { - } \mathrm{f}_{\mathrm{r}, \text { mont. }} \therefore 0,40 \mathrm{MPa}<1,10 \mathrm{MPa}
$$

Sendo assim, a seção de CLE resiste para a situação de içamento por quatro pontos.

\subsection{CÁLCULO DAS ALÇAS DE IÇAMENTO}

Como apresentado no item 6.4, são necessários quatro içadores para o painel PF11. Essas alças para içamento serão dimensionadas com a utilização de dispositivo auxiliar do tipo laço, por questão de viabilização econômica.

O peso total do painel, descontando o vazio pela existência da janela, é de $12,25 \mathrm{kN}$. Na Figura 6.13 são apresentadas as forças necessárias para içamento em cada um dos dois içadores, sendo elas de $6,13 \mathrm{kN}$.

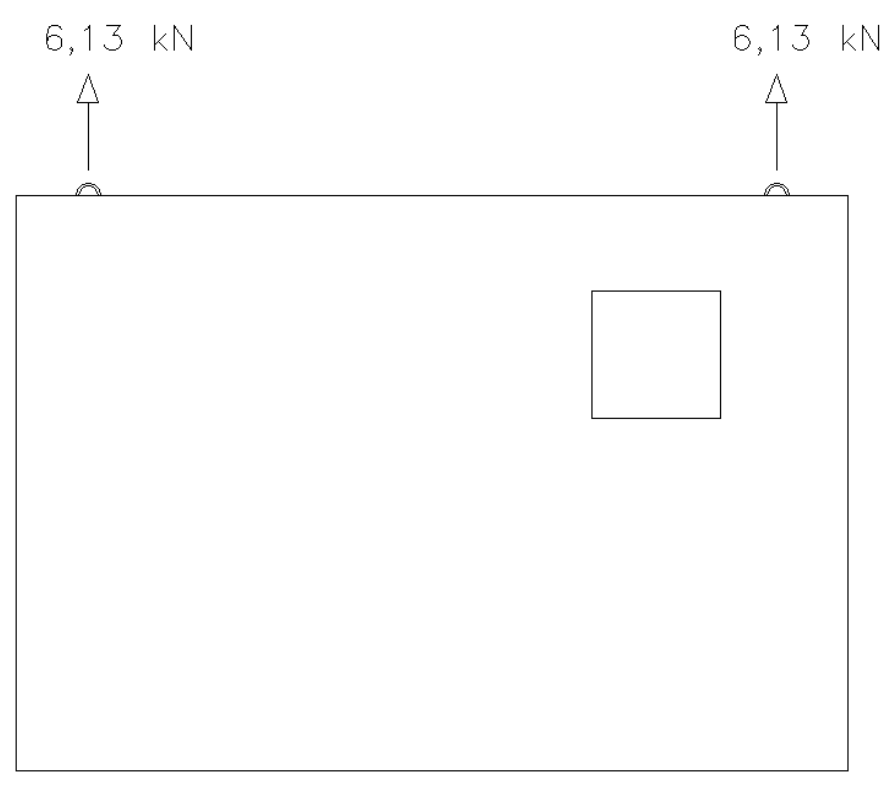

Figura 6.13: Forças nas alças de içamento 
Definidas as forças em cada alça, apresenta-se na Figura 6.14 a força resultante em cada perna, resultando no valor de $3,06 \mathrm{kN}\left(\mathrm{F}_{\mathrm{k}}\right)$.

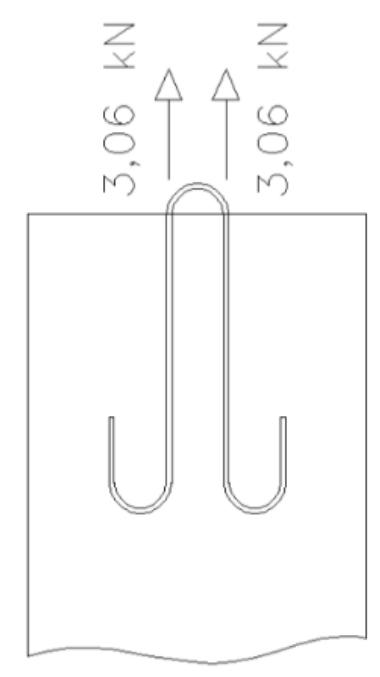

Figura 6.14: Força nas pernas da alça de içamento

De acordo com a ABNT NBR 9062:2006, nas situações de projeto de dispositivos de levantamento, para saque da fôrma, manuseio e montagem, deve-se utilizar um coeficiente de segurança $\left(\beta_{\mathrm{a}}\right)$ igual a 4 . Assim, a força de cálculo de cada perna é dada por:

$$
\mathrm{F}_{\mathrm{d}}=\beta_{\mathrm{a}} \cdot \mathrm{F}_{\mathrm{k}}=4 \cdot 3,06=12,25 \mathrm{kN}
$$

Para desmoldagem, foi adotada resistência do concreto à compressão $\left(\mathrm{f}_{\mathrm{ck} 8 \mathrm{~h}}\right)$ de 6,0 MPa. Para calcular o $f_{c k, i n f}$, utilizou-se a equação proposta pela ABNT NBR 6118:2007:

$$
\mathrm{f}_{\mathrm{ctk}, \text { inf }}=0,7 \cdot 0,3 \cdot \mathrm{f}_{\mathrm{ck} 8 \mathrm{~h}}{ }^{2 / 3}=0,69 \mathrm{MPa}
$$

Optou-se pela utilização de barras de aço CA-25, com resistência característica ao escoamento de $250 \mathrm{MPa}\left(\mathrm{f}_{\mathrm{yk}}\right)$. Segundo a ABNT NBR 9062:2006, podem ser utilizadas somente bitolas de $10 \mathrm{~mm}$ a $16 \mathrm{~mm}$.

De acordo com a ABNT NBR 6118:2007, a resistência de aderência de cálculo $\left(\mathrm{f}_{\mathrm{bd}}\right)$ entre a armadura e o concreto na ancoragem é obtida multiplicando-se o valor de cálculo da resistência do concreto à tração $f_{c t d}$ (igual a $f_{c t k, i n f} / \gamma_{c}$ ) pelos coeficientes $\eta_{1}, \eta_{2}$ e $\eta_{3}$. Foi utilizado $\eta_{1}=1,0$ (para barras lisas), $\eta_{2}=0,7$ (para situação de má aderência) e $\eta_{3}=1,0$ (para bitolas inferiores a $32 \mathrm{~mm}$ ). Para concreto pré-moldado, que possui um melhor controle tecnológico, pode-se utilizar $\gamma_{\mathrm{c}}=1,30$ e $\gamma_{\mathrm{s}}=1,10$. $\mathrm{O}$ valor de $\mathrm{f}_{\mathrm{bd}}$ resulta: 


$$
\mathrm{f}_{\mathrm{bd}}=\eta_{1} \eta_{2} \eta_{3} \mathrm{f}_{\mathrm{ctd}}=1,0 \cdot 0,7 \cdot 1,0 \cdot \frac{0,69}{1,30}=0,37 \mathrm{MPa}
$$

Para a determinação do comprimento de ancoragem básico $\left(l_{b}\right)$, utilizam-se as recomendações da ABNT NBR 6118:2007. Admitindo-se sejam suficientes alças com barras de diâmetro $\phi=10 \mathrm{~mm}=1,0 \mathrm{~cm}$, obtém-se:

$$
\mathrm{l}_{\mathrm{b}}=\frac{\phi}{4} \cdot \frac{\mathrm{f}_{\mathrm{yd}}}{\mathrm{f}_{\mathrm{bd}}}=\frac{1,0}{4} \cdot \frac{\frac{250}{1,10}}{0,37}=152,2 \mathrm{~cm}
$$

O comprimento de ancoragem necessário $\left(l_{\mathrm{b}, \text { nec }}\right)$ foi determinado com o valor de $\alpha_{1}=0,7$ (para barras tracionadas com gancho, com cobrimento no plano normal ao do gancho $\geq 3 \phi$ ), resultando:

$$
\mathrm{l}_{\mathrm{b}, \text { nec }}=\alpha_{1} \mathrm{l}_{\mathrm{b}} \frac{\mathrm{A}_{\mathrm{s}, \mathrm{calc}}}{\mathrm{A}_{\mathrm{s}, \mathrm{ef}}}=0,7 \cdot 152,2 \cdot \frac{\frac{12,25}{25}}{\pi \frac{(1,0)^{2}}{4}}=66,5 \mathrm{~cm}
$$

O valor do comprimento de ancoragem necessário deve ser maior que os estabelecidos para comprimento de ancoragem mínimo, sendo esse comprimento o maior valor entre:

$$
\mathrm{l}_{\mathrm{b}, \min }=\left\{\begin{array}{c}
0,3 \cdot \mathrm{l}_{\mathrm{b}} \\
10 \phi \\
100 \mathrm{~mm}
\end{array}=\left\{\begin{array}{l}
46 \mathrm{~cm} \\
10 \mathrm{~cm} \\
10 \mathrm{~cm}
\end{array}\right.\right.
$$

Como o valor do $\mathrm{l}_{\mathrm{b} \text {,min }}$ é menor que o calculado para o $\mathrm{l}_{\mathrm{b}, \mathrm{nec}}$, o comprimento de ancoragem necessário é igual a $66,5 \mathrm{~cm}$.

De acordo com El Debs (2000), devido à elevada curvatura da barra da alça, deve ser feita uma verificação da necessidade de redução da resistência da barra, o que equivale à determinação de um diâmetro mínimo dado por:

$$
\phi \geq 4,5 \sqrt{\mathrm{F}_{\mathrm{k}}}=4,5 \sqrt{3,06}=7,87 \therefore 10>7,87
$$

Logo, o diâmetro de $10 \mathrm{~mm}$ atende as verificações propostas por El Debs (2000). 


\subsection{DETALHAMENTO DO PAINEL}

Foram calculados todos os elementos que compõem o painel PF11D e foram realizadas as verificações para a fase transitória. Sendo assim, apresenta-se o detalhamento da peça.

A Figura 6.15 apresenta o detalhe da elevação do painel e a respectiva disposição em planta. Já a Figura 6.16 mostra a armação do painel PF11D.

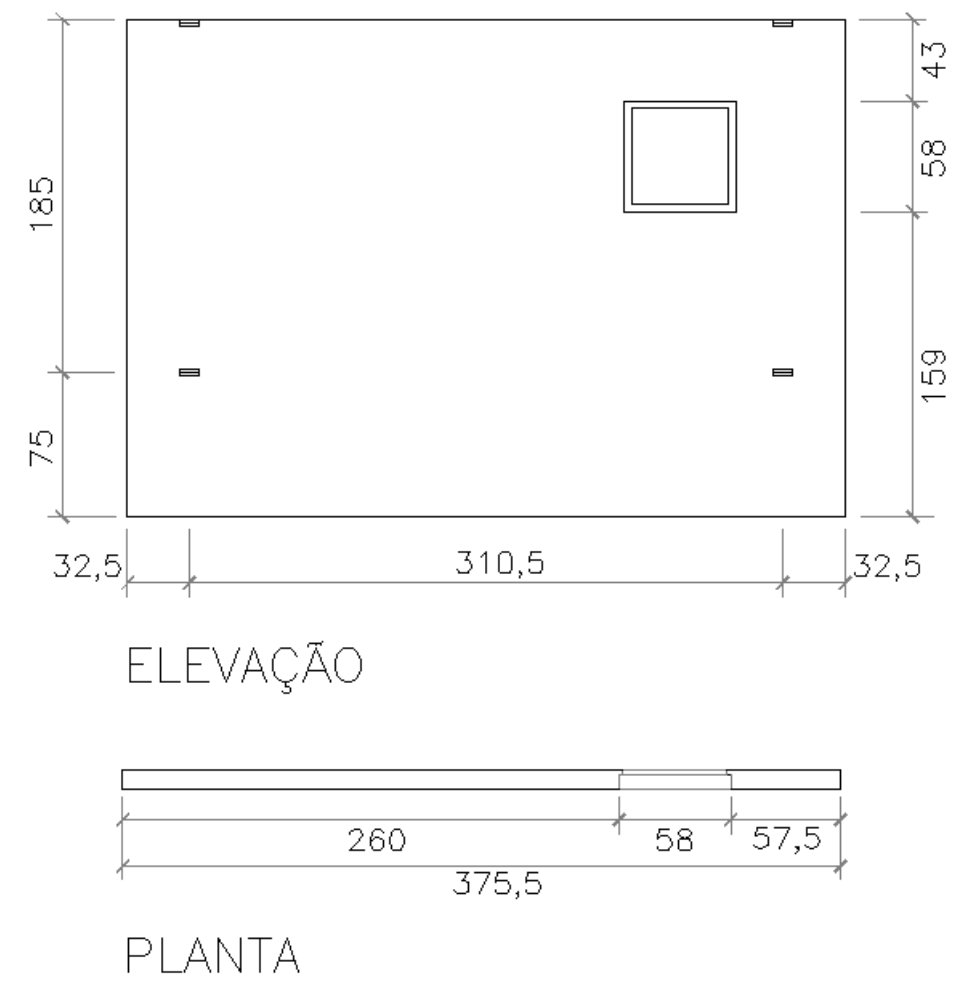

Figura 6.15: Detalhamento do painel - Elevação e planta

Conforme foi apresentado no capítulo 6.3, adotou-se a tela Q113 no centro do painel PF11D, em que essa tela soldada apresenta uma massa específica de $1,80 \mathrm{~kg} / \mathrm{m}^{2}$. Devido as dimensões do painel, foi determinado um cobrimento de $2,5 \mathrm{~cm}$ para armadura, resultando $370,5 \mathrm{~cm}$ na horizontal e $255 \mathrm{~cm}$ na vertical para a tela soldada.

As alças de içamento D1 e D4 (Figura 6.6) foram calculadas no capítulo 6.6, em que foi obtido um comprimento de ancoragem necessário igual a $66,5 \mathrm{~cm}$ e uma barra de aço CA-25 com bitola de $10 \mathrm{~mm}$. Sendo assim, foi deixado uma folga de $10 \mathrm{~cm}$ para içamento da peça, $55 \mathrm{~cm}$ para dentro do concreto e uma dobra com $17 \mathrm{~cm}$, totalizando uma ancoragem de $72 \mathrm{~cm}$. Essa alça deve ser amarrada na tela soldada central. 
As alças de içamento D2 e D3 (Figura 6.6) utilizadas na desmoldagem do painel, foram calculadas utilizando o procedimento apresentado no capítulo 6.6, em que necessitou de um comprimento de ancoragem necessário igual a $45 \mathrm{~cm}$ para uma barra de aço CA-25 com bitola de $10 \mathrm{~mm}$. Assim como as alças de içamento D1 e D4, as alças D2 e D3 devem ser amarradas na tela soldada central.

De acordo com a ABNT NBR 16055:2012, para uma abertura de dimensão horizontal $\mathrm{a}_{\mathrm{h}} \mathrm{e}$ vertical $\mathrm{a}_{\mathrm{v}}$, deve ser considerada uma região de influência de $0,5 \mathrm{a}_{\mathrm{h}}$ de cada lado, horizontalmente, e de $0,75 \mathrm{a}_{\mathrm{v}}$ de cada lado, verticalmente, respeitando uma armadura mínima de $0,5 \mathrm{~cm}^{2}$ em cada face. Adotou-se uma barra de $8 \mathrm{~mm}$ em cada face $\left(0,5 \mathrm{~cm}^{2}\right)$.
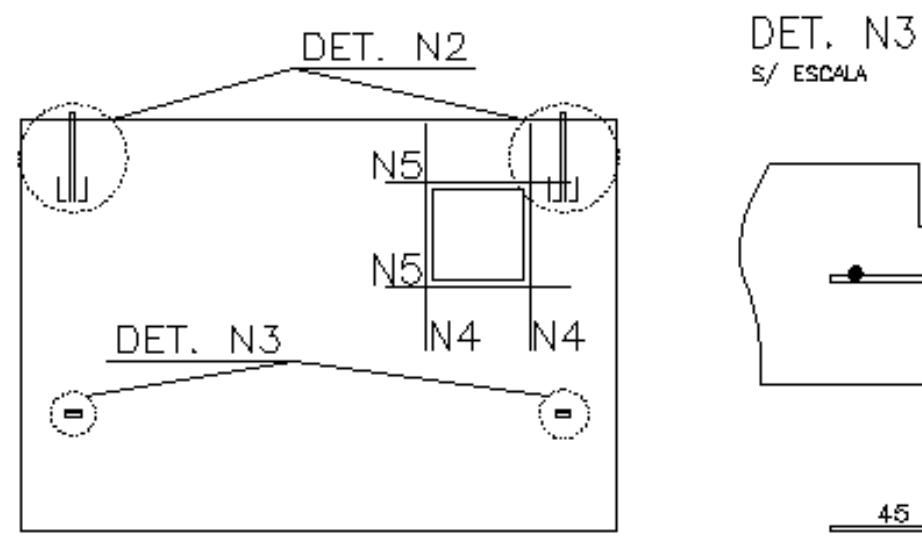

$$
\text { S) ESCALA }
$$
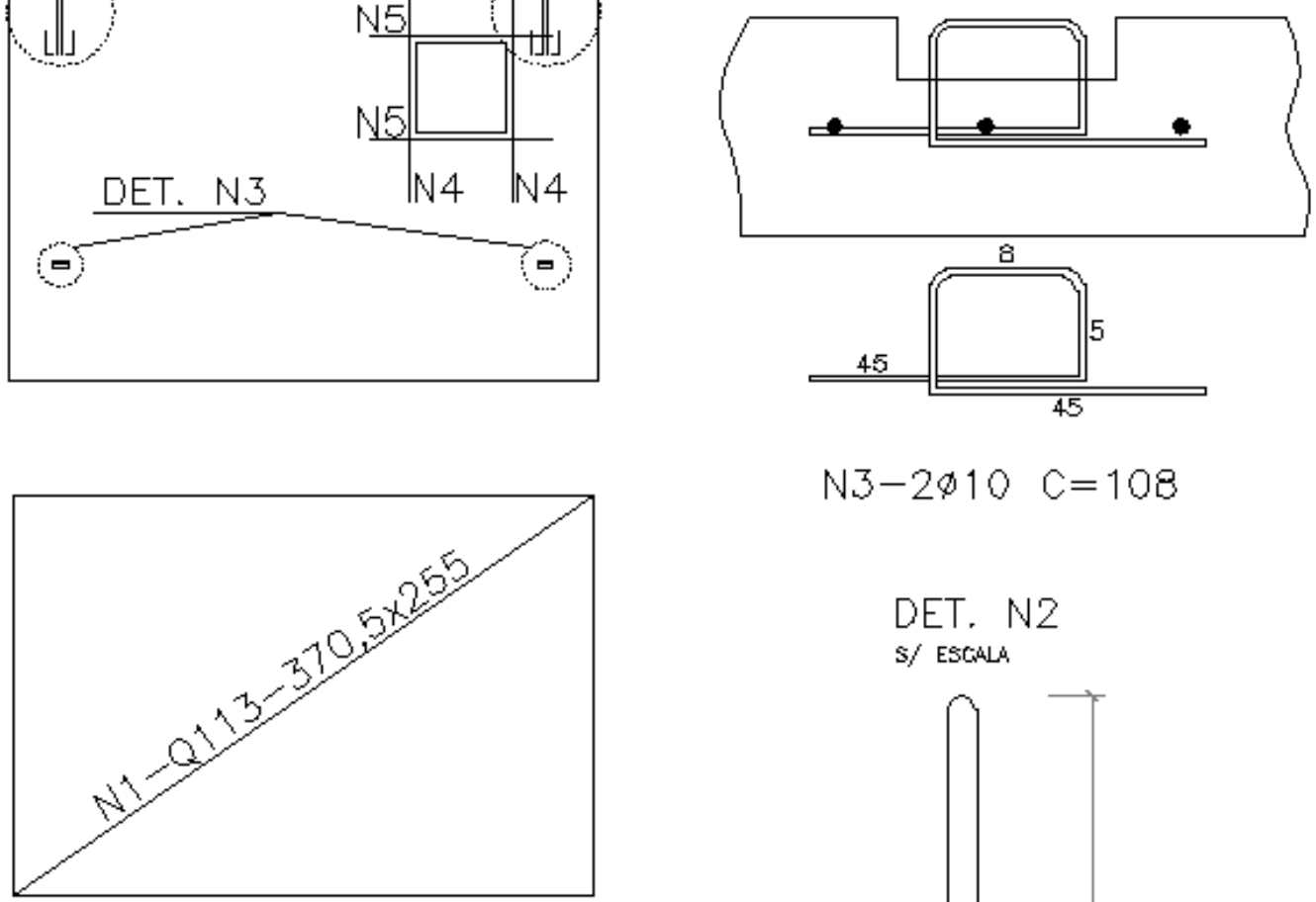

$$
N 3-2 \phi 10 \quad C=108
$$

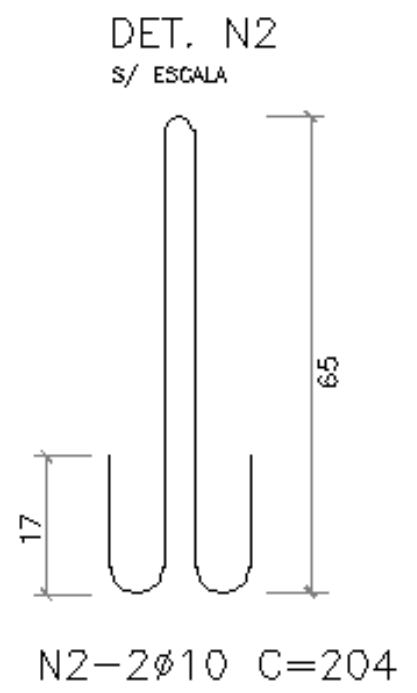

Figura 6.16: Detalhamento do painel - Armação 
Na Tabela 6.4, apresenta-se um resumo da quantidade de aço utilizado para confecção do painel PF11D. O consumo de concreto foi de $1,01 \mathrm{~m}^{3}$.

Tabela 6.4: Resumo da quantidade de aço no painel

\begin{tabular}{|c|c|c|}
\hline Posição & Bitola $(\mathbf{m m})$ & Peso $(\mathbf{k g})$ \\
\hline N1 & 3,8 & 17,01 \\
\hline N2 & 10 & 2,52 \\
\hline N3 & 10 & 1,33 \\
\hline N4 & 8 & 1,12 \\
\hline N5 & 8 & 0,92 \\
\hline \multicolumn{2}{|c|}{ TOTAL $(\mathrm{kg})$} & 22,89 \\
\hline
\end{tabular}




\section{ANÁLISE DOS RESULTADOS}

A partir dos resultados obtidos nos capítulos anteriores, foi possível realizar verificações quanto a ação do vento, colapso progressivo, custos envolvidos na obra e verificações nas fases transitórias.

\subsection{VERIFICAÇÕES PARA A AÇÃO DO VENTO}

Como apresentado no capítulo 5, foram obtidos os esforços verticais nos painéis provenientes de peso próprio, cargas da laje e ação do vento com velocidade de $40 \mathrm{~m} / \mathrm{s}$, bem como os esforços de momentos fletores. Para analisar as tensões provocadas pelos painéis, foram utilizadas combinações de ações recomendadas pela ABNT NBR 6118:2007.

$$
\begin{gathered}
\mathrm{N}_{\mathrm{d}}=\gamma_{\mathrm{g}} \mathrm{N}_{\mathrm{g}}+\gamma_{\mathrm{q} 1} \mathrm{~N}_{\mathrm{q} 1}+\gamma_{\mathrm{q} 2} \psi_{0} \mathrm{~N}_{\mathrm{q} 2} \\
\mathrm{M}_{\mathrm{d}}=\gamma_{\mathrm{g}} \mathrm{M}_{\mathrm{g}}+\gamma_{\mathrm{q} 1} \mathrm{M}_{\mathrm{q} 1}+\gamma_{\mathrm{q} 2} \psi_{0} \mathrm{M}_{\mathrm{q} 2} \\
\sigma_{\text {máx }}=\frac{\mathrm{N}_{\mathrm{d}}}{\mathrm{A}}+\frac{\mathrm{M}_{\mathrm{d}}}{\mathrm{W}} \\
\sigma_{\text {mín }}=\frac{\mathrm{N}_{\mathrm{d}}}{\mathrm{A}}-\frac{\mathrm{M}_{\mathrm{d}}}{\mathrm{W}}
\end{gathered}
$$

$\gamma_{\mathrm{g}}=1,0$, para as cargas permanentes;

$\gamma_{\mathrm{q} 1}=1,0$, para o vento como ação variável principal;

$\gamma_{\mathrm{q} 2}=0$, para a carga acidental como ação variável secundária;

$\psi_{0}=0,5$, para consideração da carga acidental como ação variável secundária.

Nas combinações de ações, existem situações em que os carregamentos podem atuar de forma favorável ou desfavorável. No caso da ação do vento, em que se deseja verificar a existência de esforços de tração nos painéis, o peso próprio atua de forma favorável. Portanto deve ser atribuído a ele o coeficiente de ponderação igual a 1,0. 
Na Tabela 7.1 são apresentadas as tensões provocadas nas bases dos painéis em cada pavimento, para a verificação da ocorrência de tração, sendo avaliadas as tensões máximas ( $\left.\sigma_{\text {máx }}\right)$ e mínimas $\left(\sigma_{\text {mín }}\right)$.

De acordo com os resultados apresentados na Tabela 7.1, verificam-se esforços de tração nas bases de alguns painéis, sendo o esforço máximo de $-223,06 \mathrm{kN} / \mathrm{m}^{2}$, que corresponde a aproximadamente $-0,22 \mathrm{MPa}$.

Tabela 7.1: Tensões nas bases dos painéis pré-moldados para o CLE ( $\mathrm{v}=40 \mathrm{~m} / \mathrm{s})$

\begin{tabular}{|c|c|c|c|c|c|c|c|c|c|c|c|}
\hline \multirow[t]{2}{*}{ Painel } & \multirow[t]{2}{*}{ ólido } & \multicolumn{2}{|c|}{$\begin{array}{c}5^{\circ} \text { Pavimento } \\
\left(\mathrm{kN} / \mathrm{m}^{2}\right)\end{array}$} & \multicolumn{2}{|c|}{$\begin{array}{c}4^{\circ} \text { Pavimento } \\
\left(\mathrm{kN} / \mathrm{m}^{2}\right)\end{array}$} & \multicolumn{2}{|c|}{$\begin{array}{c}3^{\circ} \text { Pavimento } \\
\left(\mathrm{kN} / \mathrm{m}^{2}\right)\end{array}$} & \multicolumn{2}{|c|}{$\begin{array}{c}2^{\circ} \text { Pavimento } \\
\left(\mathrm{kN} / \mathrm{m}^{2}\right)\end{array}$} & \multicolumn{2}{|c|}{$\begin{array}{c}1^{\circ} \text { Pavimento } \\
\left(\mathrm{kN} / \mathrm{m}^{2}\right)\end{array}$} \\
\hline & & $\sigma_{\text {máx }}$ & $\sigma_{\mathrm{m}}$ & $\sigma_{\text {máx }}$ & $\sigma_{\text {mín }}$ & $\sigma_{\text {máx }}$ & $\sigma_{\text {mín }}$ & $\sigma_{\text {máx }}$ & $\sigma_{\text {mín }}$ & $\sigma_{\text {máx }}$ & $\sigma_{\text {mín }}$ \\
\hline PF1 & s1 & 67,99 & 15 & 6,55 & 33 & 5,96 & $-21,64$ & 514,30 &, 53 & 730,26 & \\
\hline PF2 & & 7,83 & 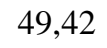 &, 41 & 9 & 9,34 & & 6,40 & & 14,70 & \\
\hline $\mathrm{P}$ & & 0 & & 8 & & 66 & &, 00 & & 92 & \\
\hline PF3 & 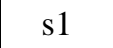 & 89,95 & (2) & 220,79 & on & 393,00 & 2 & 604,53 & & 842,36 & 29 \\
\hline PF4 & & 8,26 & & 258,64 & & 357,64 & &, 74 & & 547,97 & \\
\hline PF4 & s2 &, 22 & ( & 34,70 & U, & 503,69 & 191,56 & 664,39 & $20,0 J$ & 793,59 & 410,47 \\
\hline PF5 & & 5 & - & 2 & - & 41 & & 68 & & 39 & \\
\hline $\mathrm{P} 1$ & s1 &, 15 & 87 & 262,93 & 39,30 & 447,58 & &, 71 & & 925,80 & 79 \\
\hline $\mathrm{P} 2$ & s1 & , & 00 & 260,43 & 34,80 & 444,47 & & ,49 & & 21,39 & 70 \\
\hline P3 & & 6,83 & 43 & 239,48 & 40,53 & 431,49 & 17 & 666,84 & 81 & 906,46 & -20 \\
\hline PF6 & & 20 & & 196,24 & 1,23 & 287,22 & &, 13 & & 61,80 & \\
\hline PF6 & & 101,07 & 7 & 242,58 & - & 59 & & 66 & 1 & 81 & 3 \\
\hline PF7 & s1 & 147,72 & 32,66 & 268,98 & 74,53 & 373,49 & & 466,99 & & 574,39 & 70 \\
\hline PF7 & & 0 & 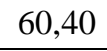 & 1 & 00 & 609,60 & 07 & ,97 & 35 & 29,21 &, 88 \\
\hline PF8 & s1 & 0,27 & 2 & 76 & 94,01 & 489,89 & 66 & 20 & 03 & 3 & 43 \\
\hline PF8 & & 211,40 & $-42,08$ & 329,13 & 9,31 & 442,86 & & 534,19 & & 584,00 & 02 \\
\hline PF8 & s3 & 52 & 4 & 4 & 18 & 36 & 6 & 1 & 51 & 92 & 72 \\
\hline PF9 & 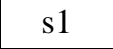 & 80,27 & 40,23 & 198,14 & 42,86 & 357,67 & 3,83 & 553,96 & $-71,97$ & 756,72 & $-154,22$ \\
\hline PF10 & & 5,13 & 40,85 & 164,48 & 47,49 & 299,71 & 25 & 469,94 & & 665,68 & $-135,74$ \\
\hline PF11 & 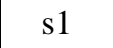 & 80,27 & 40,23 & 198,14 & 42,86 & 357,67 & 3,83 & 553,96 & $-71,97$ & 756,72 & $-154,22$ \\
\hline $\mathrm{P} 4$ & s1 & 93,19 & 80,67 & 215,99 & 131,73 & 367,05 & 154,54 & 546,69 & 148,76 & 772,59 & 96,73 \\
\hline P5 & 51 & 63 & 71 & 62 & 113,77 & 309,17 & ,92 & 459,05 & 13 & 666,34 & 72,15 \\
\hline P6 & $\mathrm{s}$ & 88,47 & 64,19 & 211,15 & 94,16 & 369,71 & 88,25 & 563,27 & 47,34 & 782,34 & $-19,08$ \\
\hline
\end{tabular}

Para assentamento de blocos de concreto, a ABNT NBR 15961-1 sugere utilizar para a resistência à tração da argamassa com cimento, cal e areia o valor 0,25 $\mathrm{MPa}$, para uma argamassa com resistência à compressão superior a 7,0 MPa,. 
Por analogia supõe-se que a argamassa utilizada nos blocos de concreto será igual para o assentamento dos painéis pré-moldados. Nesta situação as verificações irão considerar os esforços provenientes da ação do vento. Sendo assim, não há necessidade de adicionar armaduras para combater os esforços de tração que ocorrem na base dos painéis analisados.

Considerando os painéis pré-moldados e as lajes maciças de CAA, com peso específico de $24 \mathrm{kN} / \mathrm{m}^{3}$, foi possível obter resistência ao vento de $45 \mathrm{~m} / \mathrm{s}$ com a mesma argamassa de assentamento utilizada para o CLE. Neste caso, a tensão máxima obtida foi de $-0,16 \mathrm{MPa}$, ou seja, menor do que a obtida para o CLE. Logo, como era esperado, fica evidente a influência positiva do peso próprio para a consideração do vento em edificações (Tabela 7.2).

Tabela 7.2: Tensões nas bases dos painéis pré-moldados para o CAA (v = $45 \mathrm{~m} / \mathrm{s})$

\begin{tabular}{|c|c|c|c|c|c|c|c|c|c|c|c|}
\hline \multirow[t]{2}{*}{ Painel } & \multirow[t]{2}{*}{ Sólido } & \multicolumn{2}{|c|}{$\begin{array}{c}5^{\circ} \text { Pavimento } \\
\left(\mathrm{kN} / \mathrm{m}^{2}\right)\end{array}$} & \multicolumn{2}{|c|}{$\begin{array}{l}4^{\circ} \text { Pavimento } \\
\left(\mathrm{kN} / \mathrm{m}^{2}\right)\end{array}$} & \multicolumn{2}{|c|}{$\begin{array}{c}3^{\circ} \text { Pavimento } \\
\left(\mathrm{kN} / \mathrm{m}^{2}\right)\end{array}$} & \multicolumn{2}{|c|}{$\begin{array}{c}2^{\circ} \text { Pavimento } \\
\left(\mathrm{kN} / \mathrm{m}^{2}\right)\end{array}$} & \multicolumn{2}{|c|}{$\begin{array}{c}1^{\circ} \text { Pavimento } \\
\left(\mathrm{kN} / \mathrm{m}^{2}\right)\end{array}$} \\
\hline & & $\sigma_{\text {máx }}$ & $\sigma_{\text {mín }}$ & $\sigma_{\text {máx }}$ & $\sigma_{\operatorname{mín}}$ & $\sigma_{\text {máx }}$ & $\sigma_{\text {mín }}$ & $\sigma_{\text {máx }}$ & $\sigma_{\text {mín }}$ & $\sigma_{\text {máx }}$ & $\sigma_{\text {mín }}$ \\
\hline PF1 & s1 & 109,74 & 66,04 & 270,82 & 80,74 & 483,60 & 43,74 & 745,64 & $-42,51$ & 1042,64 & $-163,73$ \\
\hline PF2 & s1 & 173,76 & 99,87 & 375,07 & 142,34 & 541,38 & 196,98 & 688,87 & 261,88 & 964,48 & 199,76 \\
\hline PF2 & $\mathrm{s} 2$ & 229,73 & 126,67 & 495,58 & 249,18 & 757,23 & 400,33 & 1012,74 & 566,79 & 1351,24 & 649,07 \\
\hline PF3 & s1 & 141,59 & 96,70 & 334,93 & 141,65 & 580,63 & 134,24 & 876,08 & 77,08 & 1204,82 & $-13,36$ \\
\hline PF4 & s1 & 218,52 & 67,80 & 414,43 & 124,98 & 583,27 & 190,00 & 729,47 & 268,11 & 911,25 & 320,17 \\
\hline PF4 & $\mathrm{s} 2$ & 279,21 & 72,63 & 510,67 & 226,22 & 768,08 & 373,10 & 1015,00 & 540,01 & 1222,07 & 737,24 \\
\hline PF5 & s1 & 132,95 & 89,08 & 317,30 & 126,76 & 553,44 & 112,64 & 838,91 & 49,20 & 1159,10 & $-48,97$ \\
\hline P1 & s1 & 175,59 & 143,74 & 397,54 & 241,11 & 663,62 & 294,36 & 972,06 & 305,25 & 1333,61 & 263,03 \\
\hline $\mathrm{P} 2$ & s1 & 175,33 & 142,63 & 397,44 & 238 & 664,27 & 285 & 974,11 & 72 & 1335,68 & 254 \\
\hline P3 & s1 & 150,33 & 82,46 & 358,66 & 106,93 & 629,45 & 68,92 & 955,09 & $-23,92$ & 1286,13 & $-122,17$ \\
\hline PF6 & s1 & 139,81 & 120,16 & 322,50 & 176,93 & 474,71 & 244,95 & 617,97 & 312,82 & 896,34 & 242,17 \\
\hline PF6 & $\mathrm{s} 2$ & 164,97 & 133,42 & 381,15 & 236,14 & 592,88 & 362,53 & 808,74 & 493,91 & 1138,10 & 515,19 \\
\hline PF7 & s1 & 233,43 & 87,84 & 433,42 & 187,31 & 612,18 & 296,50 & 776,99 & 414,50 & 959,42 & 519,37 \\
\hline PF7 & $\mathrm{s} 2$ & 350,49 & 140,19 & 659,79 & 351,47 & 962,72 & 584,89 & 1252,19 & 838,81 & 1494,68 & 1133,55 \\
\hline PF8 & s1 & 348,09 & 105,33 & 599,04 & 270,28 & 827,98 & 444,71 & 1033,12 & 639,30 & 1196,00 & 891,05 \\
\hline PF8 & $\mathrm{s} 2$ & 310,25 & $-10,54$ & 501,97 & 97,20 & 688,61 & 210,83 & 846,91 & 352,98 & 952,66 & 548,95 \\
\hline PF8 & s3 & 400,42 & 120,96 & 705,56 & 375,14 & 1015,89 & 635,32 & 1300,81 & 924,28 & 1519,17 & 1262,82 \\
\hline PF9 & s1 & 125,81 & 75,13 & 299,19 & 102,67 & 525,31 & 77,49 & 797,96 & 5,77 & 1078,78 & $-74,12$ \\
\hline PF10 & s1 & 106,61 & 75,89 & 256,53 & 108,47 & 451,86 & 95,65 & 691,49 & 38,52 & 963,40 & $-50,89$ \\
\hline PF11 & s1 & 125,81 & 75,13 & 299,19 & 102,67 & 525,31 & 77,49 & 797,96 & 5,77 & 1078,78 & $-74,12$ \\
\hline $\mathrm{P} 4$ & s1 & 147,52 & 131,68 & 332,53 & 225,89 & 553,29 & 284,33 & 810,22 & 306,60 & 1125,71 & 270,33 \\
\hline P5 & s1 & 126,87 & 117,29 & 287,10 & 201,22 & 477,14 & 255,34 & 695,45 & 281,19 & 986,41 & 234,39 \\
\hline P6 & s1 & 135,46 & 104,74 & 314,23 & 166,17 & 538,41 & 182,19 & 806,88 & 153,92 & 1107,65 & 93,36 \\
\hline
\end{tabular}


Para a situação do vento de $45 \mathrm{~m} / \mathrm{s}$ atuando em uma estrutura confeccionada com CLE, é necessário utilizar uma argamassa mais resistente à tração, ou então utilizar uma ligação vertical entre os painéis e a fundação.

O valor da tensão máxima de tração para o vento de $45 \mathrm{~m} / \mathrm{s}$, obtido na ligação entre o painel e a fundação, foi de $-0,35 \mathrm{MPa}$, como mostra a Tabela 7.3. Dessa forma, verifica-se que o esforço de tração provocado pelo vento pode ser evitado facilmente com uma argamassa mais resistente à tração ou uma ligação vertical.

Vale ressaltar, ainda, que esta combinação seria utilizada apenas para a fase em que as cargas acidentais foram desprezadas, com atuação de vento apresentando um coeficiente igual a 1,0.

Tabela 7.3: Tensões nas bases dos painéis pré-moldados para o CLE $(\mathrm{v}=45 \mathrm{~m} / \mathrm{s})$

\begin{tabular}{|c|c|c|c|c|c|c|c|c|c|c|c|}
\hline \multirow{2}{*}{ Painel } & \multirow{2}{*}{ Sólido } & \multicolumn{2}{|c|}{$\begin{array}{c}5^{\circ} \text { Pavimento } \\
\left(\mathrm{kN} / \mathrm{m}^{2}\right)\end{array}$} & \multicolumn{2}{|c|}{$\begin{array}{c}4^{\circ} \text { Pavimento } \\
\left(\mathrm{kN} / \mathrm{m}^{2}\right)\end{array}$} & \multicolumn{2}{|c|}{$\begin{array}{c}3^{\circ} \text { Pavimento } \\
\left(\mathrm{kN} / \mathrm{m}^{2}\right)\end{array}$} & \multicolumn{2}{|c|}{$\begin{array}{c}2^{\circ} \text { Pavimento } \\
\left(\mathrm{kN} / \mathrm{m}^{2}\right)\end{array}$} & \multicolumn{2}{|c|}{$\begin{array}{c}1^{\circ} \begin{array}{c}\text { Pavimento } \\
\left(\mathrm{kN} / \mathrm{m}^{2}\right)\end{array} \\
\end{array}$} \\
\hline & & $\sigma_{\text {máx }}$ & $\sigma_{\text {mín }}$ & $\sigma_{\text {máx }}$ & $\sigma_{\text {mín }}$ & $\sigma_{\text {máx }}$ & $\sigma_{\text {mín }}$ & $\sigma_{\text {máx }}$ & $\sigma_{\text {mín }}$ & $\sigma_{\text {máx }}$ & $\sigma_{\text {mín }}$ \\
\hline PF1 & s1 & 72,57 & 37 & 196,48 & 40 & 372,09 & $-67,77$ & 596,96 & 0 & 56,79 & -3 \\
\hline PF2 & 政 & 2,46 & 58 & 52,47 & 19,74 & 357,48 & $\mathrm{~J}$, & 443,68 & & 557,99 & \\
\hline PF2 & 52 & 10 & & 64,33 & 92 & 60,34 & & 750,22 & & 923,10 & \\
\hline PF3 & & 65 & 9,76 & 55 & 77 & 39,82 & & 32 & & 70, & \\
\hline PF4 & s1 & 0,62 & $-0,09$ & 278,64 & 0,81 & 79,59 & \begin{tabular}{|l|}
-13 \\
\end{tabular} & 457,90 & & 571,79 & \\
\hline PF4 & $\mathrm{s} 2$ & 1,32 & 4,73 & |374,89 & 90,44 & 564,41 & 169,42 & 743,44 & 20 & 82,61 & \begin{tabular}{|l}
397,79 \\
\end{tabular} \\
\hline PF5 & & & & 6,09 & & T0,0J & & 00 & & & \\
\hline P1 & &, 49 & 84,63 & 279,34 & 90 & 86,31 & 117 & 735,65 & & 38,0 & \\
\hline P2 & s1 1 & 5,16 & 82,46 & 277,10 & 18,14 & 483,76 & 109,09 & 733,43 & 57,04 & 1034,83 & $-46,74$ \\
\hline P3 & DI & 3,94 & 36,00 & 265,87 & 14,14 & 490,27 & $-\pi 0, \angle 0$ & 769,51 & $-209,49$ & 1054,17 & $-354,14$ \\
\hline PF6 & & & & 34 & 9,76 & 298,97 & & 383,64 & & & \\
\hline PF6 & $\mathrm{s}_{2}^{2}$ & 6,38 & 74,84 & 263,98 & 118,98 & 417,14 & 186,78 & 574,41 & & 345,19 & 222,28 \\
\hline PF7 & s1 & 1,06 & 15,47 & 288,67 & 42,56 & 395,06 & 79,38 & 487,50 & 01 & 597,56 & 157,51 \\
\hline $\mathrm{F} 7$ & & 20 & 40,98 & 1,38 & 153,06 & 5,10 & 2 & 855,36 & & 998,63 & 637,52 \\
\hline PF8 & & 21 & & 387,26 & & 10,32 & 127 & 609,57 & & ,57 & \\
\hline PF8 & s2 & 245,02 & $-75,78$ & 371,50 & $-33,27$ & 492,91 & 13 & 585,97 & 92,05 & 26,49 & 22 \\
\hline PF8 & $\mathrm{S}$ & 294,54 & 08 & 493,79 & 163,36 & 698,23 & 317,66 & 877,26 & 50 & 989,73 & 733,39 \\
\hline PF9 & 31 & 99 & 1 & 218,76 & 24 & 94,66 & $-43,16$ & \begin{tabular}{|l}
637,09 \\
\end{tabular} & 09 & 77,70 & $-275,20$ \\
\hline PF10 & s1 & & & 1 & & 337,09 & & 8,46 & & 11 & 年 \\
\hline PF11 & $\mathrm{s}$ & 85,59 & 34,91 & 218,76 & 22,24 & 404,66 & $-43,16$ & 637,09 & $-155,09$ & 877,70 & $-275,20$ \\
\hline P4 & $\mathrm{s}$ & 94,85 & 79,01 & 227,18 & 120,54 & 395,27 & 126,32 & 599,54 & 5,92 & 862,35 & 6,97 \\
\hline P5 & s1 & 78,64 & 69,06 & 190,63 & 104,76 & 332,44 & 110,65 & 502,52 & 26 & 45,25 & $-6,77$ \\
\hline P6 & s1 & 91,69 & 60,96 & 226,68 & 78,62 & 407,09 & 50,87 & 631,79 & $-21,18$ & 888,78 & $-125,51$ \\
\hline
\end{tabular}


Para a situação em que a edificação encontra-se ocupada, se for possível estimar que $30 \%$ das cargas acidentais têm características de carga permanente (móveis, equipamentos, utensílios etc.), o esforço máximo de tração poderia ser reduzido para -0,32 $\mathrm{MPa}$, para um vento com velocidade de $45 \mathrm{~m} / \mathrm{s}$.

\subsection{DESLOCAMENTO NO TOPO DO EDIFÍCIO}

No capítulo 5 deste trabalho foi calculado o deslocamento no topo da edificação, resultando $1,80 \mathrm{~mm}$ na direção x e 1,27 mm na direção y, lembrando que se trata de uma edificação de cinco pavimentos com altura de $2,70 \mathrm{~m}$ de piso a piso, totalizando $13,5 \mathrm{~m}$.

De acordo com a tabela 13.2 da ABNT NBR 6118:2007, o movimento lateral do edifício para as paredes é definido por:

$$
\mathrm{M}_{\text {lat. }}=\frac{\mathrm{H}}{1700}=\frac{13500 \mathrm{~mm}}{1700}=7,94 \mathrm{~mm}
$$

Sendo assim, o movimento lateral limite da edificação é bem menor que o deslocamento encontrado no topo da edificação.

\subsection{COLAPSO PROGRESSIVO}

Para o painel executado com CLE, as resistências dinâmica e estática foram suficientes para suportar a ação de balanço dos painéis, com apenas uma barra de $8 \mathrm{~mm}$. Para a análise do colapso progressivo em painéis confeccionados com CAA, a barra de $10 \mathrm{~mm}$ apresentou resultado satisfatório, no que diz respeito à resistência à ação de balanço.

No exemplo apresentado para o colapso progressivo em laje pré-moldada confeccionada com CLE, foram necessárias duas barras de $20 \mathrm{~mm}$, atingindo as resistências suficientes dinâmicas e estáticas. Para o caso do CAA, foram necessárias quatro barras de $20 \mathrm{~mm}$ de diâmetro, para resistir à ação de balanço nas lajes.

Notou-se, também, que a massa específica do concreto tem influência direta na análise do colapso progressivo. Esse fato é comprovado pelo CLE, que possui uma massa específica de aproximadamente $54 \%$ da relativa ao concreto comum, reduzindo de forma significativa o consumo de aço na laje em estudo. 


\subsection{VERIFICAÇÃO NA FASE TRANSITÓRIA}

Como apresentado no item 6.5, o painel PF11D foi analisado na situação de desmoldagem por meio de alças em quatro pontos, com transporte na posição horizontal e içamento da peça até a posição final.

Para a confecção de painéis pré-moldados, é interessante que a produção seja realizada na vertical, mesmo que a produção em mesas horizontais apresente custos mais baixos. Com a moldagem na vertical, o painel já se encontra na posição de montagem, e, além disso, o armazenamento também deve ser feito na vertical, pois o dimensionamento prevê que o painel permaneça nessa posição.

Logo, a produção na vertical acarreta em economia nos dispositivos para içamento, pois são necessários somente dois pontos para desmoldagem e montagem do painel.

Em relação ao transporte, o painel na posição horizontal excede as dimensões máximas permitidas pelo DNIT (Departamento Nacional de Infraestrutura de Transportes), que é de 2,60 m de largura.

\subsection{CUSTOS ENVOLVIDOS NA EDIFICAÇÃO}

De acordo com as indicações de Tisaka (2006), a ausência de conhecimento adequado na elaboração do orçamento compromete o valor final previsto para a obra, com a inserção de preços elevados. Valores fora da realidade do mercado impossibilitam a contratação da obra, assim como a fixação de um preço insuficiente para cobrir os custos incidentes. Dessa forma, o risco de ocorrência de prejuízos é maior, podendo até levar à paralisação das atividades da empresa. Sendo assim, fica clara a importância da correta contabilização dos custos envolvidos em cada sistema construtivo existente na construção civil, cabendo ao proprietário avaliar a viabilidade de cada processo.

Para um levantamento preciso dos custos da obra, é necessário um estudo mais elaborado de todos os fatores que podem influenciar, de forma direta ou indireta. Por conta disso, foram levantados apenas alguns fatores que influenciam no custo direto da edificação. Estudos globais mais refinados devem ser feitos, levando em conta as características de cada empresa. 
Um dos materiais que está envolvido diretamente com o custo da obra é o concreto. Portanto, a maior relevância para o levantamento desse item é determinar o volume de concreto total utilizado. Para o caso desta pesquisa, o volume de concreto nos painéis foi de $179,60 \mathrm{~m}^{3}$, e nas lajes, de $80,80 \mathrm{~m}^{3}$, totalizando $260,40 \mathrm{~m}^{3}$ por edificação. A espessura média de concreto por pavimento é de $32,23 \mathrm{~cm}$, valor aceitável para esse sistema construtivo.

De acordo com o Engenheiro Milton José Kerbauy, que inventou e patenteou o CLE (Concreto Ultraleve $^{\circledR}$ ), o custo desse concreto pode atingir até $30 \%$ a mais do que concreto comum, porém, seu custo é semelhante ao do CAA. De acordo com os valores apresentados no Apêndice, o custo direto para confecção dos elementos estruturais na obra varia de $25 \%$ a $29 \%$ do custo total do empreendimento para o CAA. Já para o CLE, esse foi praticamente igual, variando de $26 \%$ a $30 \%$ do custo total.

Em contrapartida, a vantagem da utilização do CLE está do peso das peças, em torno de 54\% do relativo ao concreto comum (46\% mais leve). Esse fato influencia nos custos com o transporte dos elementos, que envolvem de $5 \%$ a $9 \%$ do custo da obra. Com a utilização do CLE, esse custo pode ser reduzido de $2 \%$ a $6 \%$.

Outros fatores que devem ser detalhados para melhor precisão no levantamento dos custos envolvidos, quando comparado o CLE com o CAA, são:

a) As cargas transmitidas à fundação são menores com a utilização do CLE, devido ao baixo peso específico. Portanto, o material é adequado para locais que apresentam solos com baixa capacidade de carga;

b) Os custos com os equipamentos de desmoldagem e içamento dos elementos prémoldados são diretamente ligados à manutenção das máquinas. Quanto mais leve o elemento a ser manuseado, menor é o custo com manutenção;

c) O CLE permite confeccionar elementos mais robustos que o concreto comum, apresentando pesos iguais, o que torna o sistema mais rápido e mais produtivo, reduzindo as ligações entre os painéis e os custos com aluguel de equipamentos;

d) Elementos mais leves propiciam manuseio com facilidade e rapidez, aumentando significativamente a velocidade da obra, além de diminuir os riscos de acidentes envolvendo os operários; 
e) O baixo peso específico do CLE permite a não utilização de baterias verticais para a confecção, pois os esforços que atuam nas fases transitórias são baixos, e eles podem ser resistidos por esse tipo de concreto leve. Dessa forma, há redução nos custos iniciais da obra. 


\section{CONSIDERAÇÕES FINAIS}

Este trabalho buscou analisar a utilização do Concreto Leve Estrutural com EPS (CLE) em peças pré-moldadas para aplicação em sistemas construtivos com lajes maciças e paredes portantes, a fim de comparar o desempenho do material com o Concreto Autoadensável (CAA). Como objetivo, mostrou-se o dimensionamento de acordo com as normas nacionais e internacionais, detalhes de projeto, apresentação do sistema estrutural com painéis prémoldados e lajes prontas maciças, bem como os custos com materiais e transporte.

Na fase de análise de projeto, foi utilizado o software comercial SAP2000 para obtenção dos esforços atuantes na estrutura, por meio de um modelo de pórtico plano, que teve desempenho satisfatório no caso estudado. A partir desse modelo foram obtidos os momentos fletores e esforços normais atuantes na estrutura devidos à ação do vento, sendo consideradas articuladas todas as ligações entre painéis. Vale ressaltar que essa análise poderia ser realizada de forma semelhante com o software livre FTOOL, porém, esse software não permite considerar a deformação por cisalhamento, que apresenta influência significativa nos resultados obtidos, principalmente para edificações altas.

O sistema construtivo de painéis pré-moldados apresentou elevada rigidez, mesmo para as ligações articuladas, que foram utilizadas para representação das juntas siliconadas no modelo. A aplicação desse tipo de junta é relativamente simples, e o custo do material é baixo, sendo ideal para edificações de pequena altura.

Os deslocamentos no topo do edifício foram relativamente pequenos quando comparados aos valores limites da ABNT NBR 6118:2007. Para edificações altas, recomenda-se utilizar ligações que apresentem rigidez, de maneira que permitam a transferência de forças cortantes entre os painéis. Essas juntas de cisalhamento aumentam de forma significativa os custos da obra, pois aumentam o consumo de aço e os gastos com mão de obra especializada.

Para edificações altas é necessária a utilização de um modelo mais refinado para obtenção dos esforços. O modelo de pórtico tridimensional apresentado no trabalho do Nascimento Neto (1999) é capaz de atender esse grau de refinamento desejado. No trabalho de Tomo (2013), utiliza-se o modelo de pórtico tridimensional para edifícios de 13 pavimentos, em que foram utilizadas ligações que garantem a transferência dos esforços de cisalhamento entre os painéis. 
A fase de análise do colapso progressivo contemplou o estudo de duas situações. O primeiro caso estudado abordou um painel com apenas um ponto de amarração; o segundo caso considerou uma laje em situação de balanço.

Na primeira situação, para o CLE foi adotada uma barra de $10 \mathrm{~mm}$, enquanto que para o concreto autoadensável foi de $12,5 \mathrm{~mm}$, as quais foram suficientes para resistir aos esforços provocados.

Já na situação de lajes em balanço, foram necessárias duas barras de $20 \mathrm{~mm}$ para o CLE e quatro barras de $20 \mathrm{~mm}$ para o CAA.

Essa redução significativa de aço para o CLE pode ser explicada pelo fato desse concreto apresentar massa específica de aproximadamente 54\% da relativa ao concreto autoadensável, acarretando em uma redução significativa nos custos globais, principalmente em obras de larga escala de repetições.

$\mathrm{Na}$ fase de projeto, inicialmente determinaram-se os carregamentos provenientes das lajes. Em seguida, as lajes foram dimensionadas e verificadas, para então determinar as reações de apoio. Por fim, calculou-se a armadura necessária para os painéis pré-moldados, sendo foi adotada armadura mínima, pelo fato do painel não apresentar fissuras.

Após a fase de dimensionamento, as peças foram detalhadas a partir do software AUTOCAD, apresentando-se detalhes típicos de painéis pré-moldados, como juntas verticais e horizontais e armação do painel.

$\mathrm{Na}$ análise do vento para uma velocidade básica de $40 \mathrm{~m} / \mathrm{s}$, o sistema estrutural confeccionado com CLE apresentou tensão de tração na base de alguns painéis, porém com intensidade que pode ser absorvida pela argamassa de assentamento usada na base desses painéis prémoldados.

Já para vento com uma velocidade básica de $45 \mathrm{~m} / \mathrm{s}$, essa argamassa não apresentou resistência suficiente para as tensões de tração entre alguns painéis e a fundação. Neste caso, foi necessário inserir armaduras verticais para resistir os esforços de tração, ou melhorar a argamassa de assentamento. 
Para a construção com CAA, a argamassa de assentamento apresentou resistência suficiente para as tensões de tração provocadas pelo vento, com velocidade básica de $45 \mathrm{~m} / \mathrm{s}$. Isto se deve ao fato do peso próprio da estrutura atuar de modo favorável nessa verificação.

Com relação aos custos envolvidos neste sistema produtivo, ficou evidente a necessidade de considerar todos os fatores que influenciam de forma direta e indireta para elaboração de um orçamento detalhado.

A título de uma análise genérica, foram levantados apenas os custos relativos a produção e transporte dos painéis pré-moldados, bem como das lajes prontas maciças. Verificou-se que o CLE tem custo de produção ligeiramente mais elevado, porém, apresenta vantagens no que diz respeito ao baixo peso específico, que influencia de forma direta em fundações para solos com baixa capacidade portante, além de reduzir custos com manutenção de equipamentos, aumentar a produtividade e a agilidade, entre outros benefícios.

Sendo assim, ao final da contabilização total dos custos, o Concreto Leve Estrutural com EPS pode ser considerado viável economicamente, quando aplicado em obras residenciais com produção em grande escala de repetição.

\subsection{CONCLUSÕES}

Este trabalho mostrou a viabilidade de construção de um edifício residencial de cinco pavimentos, atendendo às normas e regulamentações vigentes, sob a ação de vento à velocidade básica de $40 \mathrm{~m} / \mathrm{s}$, sendo ela superior à máxima especificada para quase todo o território brasileiro.

Para o caso estudado e para as regiões em que velocidade básica for de $45 \mathrm{~m} / \mathrm{s}$, devem-se utilizar algumas das recomendações sugeridas neste trabalho, como o uso de armadura para resistir tração na base de alguns painéis ou de argamassa com maior resistência à tração.

Vale ressaltar que o trabalho apresenta um caráter exploratório, e para validação de todos os resultados obtidos para o dimensionamento de painéis e de lajes pré-moldadas devem ser realizados os ensaios para garantir que o CLE possua as mesmas características do concreto convencional. Caso isso não ocorra, algumas adaptações podem ser necessárias. 
De um modo geral, o CLE é um material de inovação ao mercado da construção civil, que permite a confecção de diversas peças estruturais, dentre elas os painéis pré-moldados, as lajes prontas maciças e as pré-lajes, por exemplo. É possível também confeccionar peças não estruturais, como painéis de fachada, bancos de concreto, entre diversas outras aplicações.

Além da viabilidade técnica do uso do CLE em edificações, a estimativa de custos indicada no Apêndice, para o obra analisada, mostra que o material também é vantajoso no aspecto econômico, o que poderá ser comprovado por análises mais rigorosas dos custos de outros empreendimentos.

\subsection{TRABALHOS FUTUROS}

Como sugestões para trabalhos futuros, destacam-se os seguintes itens:

a) Maior conhecimento sobre o material em estudo, para validação das hipóteses adotadas;

b) Interação solo-estrutura em edifícios com painéis pré-moldados;

c) Software para estudo do colapso progressivo, em que fosse possível a "retirada" de painéis e a análise posterior do comportamento global da estrutura;

d) Software para automatizar os cálculos de dimensionamento e detalhamento de painéis pré-moldados, utilizando o modelo de pórticos planos;

e) Dimensionamento de edifícios mais altos, com o emprego de CLE;

f) Análise dos custos envolvidos nas fundações, com a utilização do sistema de painéis portantes, com o uso de CLE e de concreto de peso normal;

g) Estudos em que sejam detalhados, de forma rigorosa, os diversos custos envolvidos na construção de edifícios semelhantes ao que foi analisado, levando em conta inclusive outros materiais e outros sistemas construtivos. Esses estudos poderão dar mais evidência à aplicabilidade do material e do sistema construtivo considerados neste trabalho. 


\section{REFERÊNCIAS}

AMERICAN CONCRETE INSTITUTE (2011). ACI-318: Building code requirements for structural concrete. Farmington Hills.

ASSOCIAÇÃO BRASILEIRA DE NORMAS TÉCNICAS (1995). NBR NM 35: Agregados leves para concreto estrutural - Especificações. Rio de Janeiro.

. (2007). NBR 6118: Projeto de estruturas de concreto - Procedimento. Rio de Janeiro.

. (1980). NBR 6120: Cargas para o cálculo de estruturas de edificações. Rio de Janeiro.

. (1988). NBR 6123: Forças devidas ao vento em edificações. Rio de Janeiro.

. (2003). NBR 8681: Ações e segurança nas estruturas - Procedimento. Rio de Janeiro.

(2006). NBR 9062: Projeto e execução de estruturas de concreto pré-moldado. Rio de Janeiro.

(2005). NBR 12721: Avaliação de custos de construção para incorporação imobiliária e outras disposições para condomínios edilícios. Rio de Janeiro.

(2011). NBR 15961-1: Alvenaria estrutural - Blocos de concreto - Parte 1:

Projeto. Rio de Janeiro.

(2012). NBR 16055: Parede de concreto moldada no local para a construção de edificações - Requisitos e procedimentos. Rio de Janeiro.

BLJUGER. F (1988). Design of precast concrete structures. Chichester. Ellis Horwood/New York. John Wiley.

BRUMATTI. D. O. (2008). Uso de pré-moldados - estudo e viabilidade. 54p. Monografia (Especialidade) - Universidade Federal de Minas Gerais. Vitória. 
CATOIA. T. (2012). Concreto ultraleve ${ }^{\circledR}$ estrutural com pérolas de EPS: caracterização do material e estudo de sua aplicação em lajes unidirecionais. Tese (Doutorado) - Escola de Engenharia de São Carlos. Universidade de São Paulo. São Carlos.

CAVAlCANTI. F. S.; CARAM. R. M.; PINHEIRO. L. M. (2012). Concreto Ultraleve ${ }^{\circledR}$ em Sistemas de Vedação Pré-moldados: Sustentabilidade e conforto térmico. IBRACON. No 54. (ISSN 2175-8182).

COLETÂNEA DE ATIVOS (2008-2009). Parede de concreto. Disponível em: http://www.abesc.org.br/assets/files/coletania-aditivos-08.09.pdf. Acesso em: 05/11/2012.

CONCRETO \& CONSTRUÇÕES (2009). Concreto: Material construtivo mais consumido no mundo. IBRACON. Ano XXXVII No 53. (ISSN 1809-7197).

CANADIAN PRESTRESSED CONCRETE INSTITUTE. CPCI (2007). Design Manual. 4.ed. Ottawa. 2007.

EL DEBS. M. K. (2000). Concreto pré-moldado: fundamentos e aplicações. São Carlos: Edusp.

ENV-EC2 (1992). "Eurocode 2: Design of concrete structures - part 1: General rules and rule for buildings". British Standards Institution. London. England.

FÉDÉRATION INTERNATIONALE DU BÉTON. FIB (2008). Structural connections for precast concrete buildings. Lausanne. Switzerland.

GHOSH. S. K (1995). Observations on the performance of structures in the Kobe earthquake of January 17. PCI Journal. Chicago. USA.

HOFF. G. C. (1991). High strength lightweight concrete for Artic applications. ACI Symposium on Performance of Structural Lightweight Concrete. Dallas. USA.

IBTS (2012). Tabelas de telas soldadas. Disponível em:

http://www.ibts.org.br/telas_tab_estrutura.asp. Acesso em: 17/10/2012.

KERBAUY. M. J. (2011). Concreto estrutural ultraleve com desmoldagem rápida destinado à fabricação de placas, painéis e lajes. Patente depositada no Instituto Nacional de Propriedade Industrial (INPI). (PI-1004268-7) 
KERBAUY. M. J. (2011). Concreflex®: a evolução da construção. Folder comercial do Concreto Ultraleve®. Divulgado no segundo semestre de 2011.

KIANOUSH. M. R.; ELMORSI. M.; SCANLON. A. (1996). Response of large panel precast wall systems: analysis and design. PCI Journal. Chicago. USA.

LARANJEIRAS. A. C. R (2010). Colapso progressivo dos edifícios - Breve introdução.

MELO. C. E. E. (2007). Manual Munte de projetos pré-fabricados de concreto. 2.ed. São Paulo: Pini.

MEHTA. P. K.; MONTEIRO. P. J. M. (1994). Concreto: estrutura, propriedades, materiais. São Paulo: Pini.

NASCIMENTO NETO. J. A. (1999). Investigação das solicitações de cisalhamento em edifícios de alvenaria estrutural submetidos a ações horizontais. Dissertação (Mestrado) Escola de Engenharia de São Carlos. Universidade de São Paulo. São Carlos.

OLIVEIRA. L. A. (2002). Tecnologia de painéis pré-fabricados arquitetônicos de concreto para emprego em fachadas de edifícios. Dissertação (Mestrado) - Escola Politécnica. Universidade de São Paulo. São Paulo.

PERESWIET-SOLTAN. S. (1980). Edilizia residenziale prefabbricata: sistemi, particolari, calcoli. Milão. I.T.E.C.

PINHEIRO. L. M.; MUZARDO. C. D.; SANTOS. S. P. (2010). Fundamentos do Concreto e Projeto de Edifícios. Lajes maciças. Cap.11. 29p. Disponível em:

www.set.eesc.usp.br/mdidatico/concreto.

PINHEIRO. L. M. et al. (2010). Fundamentos do Concreto e Projeto de Edifícios. Projeto de lajes maciças. Cap.12. 30p. Disponível em: www.set.eesc.usp.br/mdidatico/concreto.

PRECAST AND PRESTRESSED CONCRETE (2007). PCI Architectural precast concrete. 3.ed. Chicago, USA. 
ROSSIGNOLO. J. A.; AGNESINI. M. V. C. (2005). Concreto Estrutural Leve. In: ISAIA. G. C. (ed.). Concreto: ensino, pesquisa e realizações. São Paulo: IBRACON. Cap.43. 2v. p.1333-1362.

SBRIGHI NETO. C. (2005). Agregados para concreto. In: ISAIA. G. C. (Ed.). Concreto: ensino, pesquisa e realizações. São Paulo: IBRACON. Cap.11. 2v.. p.323-343.

SINDUSCONSP (2013). Boletim Econômico: Fevereiro/2013. Disponível em:

http://www.sindusconsp.com.br/downloads/estprod/economia/2013/Fevereiro_13.pdf. Acessado em 30/03/2013.

TISAKA, MAÇAHICO. (2006). Orçamento na construção civil: consultoria, projeto e execução. São Paulo: Pini.

TOMO. F. C. (2013). Critérios para projeto de estruturas de paredes portantes préfabricadas de concreto armado. Dissertação (Mestrado) - Escola de Engenharia de São Carlos. Universidade de São Paulo. São Carlos.

YAGUI. T. (1978). Análise de estruturas de edifícios constituídas de núcleo de concreto armado e pilares ou pendurais de aço (carregamento crítico de instabilidade). Tese (Livre-docência) - Universidade Estadual de Campinas. Campinas. 


\section{APÊNDICE: LEVANTAMENTO DOS CUSTOS}

Para o levantamento de custos do CLE e do CAA, foram determinados os índices referentes a volume. A Tabela AP.1 apresenta os volumes unitários de cada painel, bem como o volume total de concreto utilizado nos painéis do edifício, sendo esse volume total de $179,70 \mathrm{~m}^{3}$.

Tabela AP.1: Volume de concreto dos painéis pré-moldados

\begin{tabular}{|c|c|c|c|c|c|c|c|}
\hline Painel & $\begin{array}{c}\text { Comprimento } \\
\text { (cm) }\end{array}$ & $\begin{array}{c}\text { Espessura } \\
(\mathrm{cm})\end{array}$ & $\begin{array}{c}\text { Altura } \\
(\mathbf{c m})\end{array}$ & $\begin{array}{c}\text { Volume } \\
\text { unitário } \\
\left(\mathbf{m}^{\mathbf{3}}\right)\end{array}$ & $\begin{array}{c}\text { Quantidade } \\
\text { p/ pav. }\end{array}$ & $\begin{array}{l}\text { Volume p/ } \\
\text { pav. }\left(\mathbf{m}^{3}\right)\end{array}$ & $\begin{array}{l}\text { Volume p/ } \\
\text { edif. }\left(\mathbf{m}^{3}\right)\end{array}$ \\
\hline PF1 & 258,5 & 10 & 270 & 0,70 & 4 & 2,79 & 13,96 \\
\hline PF2 & 308,5 & 10 & 270 & 0,83 & 4 & 3,33 & 16,66 \\
\hline PF3 & 262,0 & 10 & 270 & 0,71 & 4 & 2,83 & 14,15 \\
\hline PF4 & 259,0 & 10 & 270 & 0,70 & 1 & 0,70 & 3,50 \\
\hline PF5 & 259,0 & 10 & 270 & 0,70 & 1 & 0,70 & 3,50 \\
\hline PF6 & 338,0 & 10 & 270 & 0,91 & 4 & 3,65 & 18,25 \\
\hline PF7 & 243,5 & 10 & 270 & 0,66 & 4 & 2,63 & 13,15 \\
\hline PF8 & 321,0 & 10 & 270 & 0,87 & 2 & 1,73 & 8,67 \\
\hline PF9 & 375,5 & 10 & 270 & 1,01 & 2 & 2,03 & 10,14 \\
\hline PF10 & 307,0 & 10 & 270 & 0,83 & 2 & 1,66 & 8,29 \\
\hline PF11 & 375,5 & 10 & 270 & 1,01 & 2 & 2,03 & 10,14 \\
\hline $\mathrm{P} 1$ & 220,0 & 10 & 270 & 0,59 & 4 & 2,38 & 11,88 \\
\hline $\mathrm{P} 2$ & 223,0 & 10 & 270 & 0,60 & 4 & 2,41 & 12,04 \\
\hline $\mathrm{P} 3$ & 322,0 & 10 & 270 & 0,87 & 2 & 1,74 & 8,69 \\
\hline $\mathrm{P} 4$ & 239,0 & 10 & 270 & 0,65 & 4 & 2,58 & 12,91 \\
\hline P5 & 200,0 & 10 & 270 & 0,54 & 2 & 1,08 & 5,40 \\
\hline P6 & 307,0 & 10 & 270 & 0,83 & 2 & 1,66 & 8,29 \\
\hline
\end{tabular}

Para a determinação do volume total de concreto utilizado nas lajes, foi realizado um cálculo semelhante ao da determinação dos volumes dos pa. A Tabela AP.2 apresenta os valores de volume unitário de cada laje. De acordo com a repetição delas em cada pavimento, foi determinado o volume total de concreto das lajes, sendo este de $80,80 \mathrm{~m}^{3}$.

Determinado o volume de concreto nos painéis e nas lajes, tem-se o volume total de concreto do edifício: $260,40 \mathrm{~m}^{3}$.

Na Tabela AP.3, foi determinado o custo total para o CLE e o CAA. O custo do CLE $\left(\mathrm{R} \$ 398,58 / \mathrm{m}^{3}\right)$ foi fornecido pelo Eng ${ }^{\mathrm{o}}$. Milton Kerbauy, relativo à dosagem utilizada. Para o CAA de $50 \mathrm{MPa}$, adotou-se um valor médio de mercado $\left(\mathrm{R} \$ 306,65 / \mathrm{m}^{3}\right)$. 
Na produção dos concretos, o custo com mão de obra é da ordem de $\mathrm{R} \$ 50,00 / \mathrm{m}^{3}$ para o CLE e de $\mathrm{R} \$ 75,00 / \mathrm{m}^{3}$ para o CAA.

Para lançamento do concreto e içamento das peças, os custos com mão de obra podem ser considerados iguais para o CLE e o CAA, com valor estimado de $\mathrm{R} \$ 30,00 / \mathrm{m}^{3}$.

Com relação aos custos com instalações e manutenção dos equipamentos, o CLE tem um custo aproximado de $\mathrm{R} \$ 120,00 / \mathrm{m}^{3}$, enquanto que o CAA apresenta um custo da ordem de $\mathrm{R} \$ 180,00 / \mathrm{m}^{3}$.

Sendo assim, para produção dos elementos estruturais pré-moldados, o CLE apresenta um custo total de $\mathrm{R} \$ 598,58 / \mathrm{m}^{3}$, e o CAA, $\mathrm{R} \$ 591,65 / \mathrm{m}^{3}$.

Tabela AP.2: Volume de concreto das lajes prontas maciças

\begin{tabular}{|c|c|c|c|c|c|c|}
\hline Laje & $\begin{array}{l}\text { Área } \\
\left(\mathbf{m}^{2}\right)\end{array}$ & $\begin{array}{l}\text { Espessura } \\
\quad(\mathrm{cm})\end{array}$ & $\begin{array}{c}\text { Volume } \\
\text { unitário } \\
\left(\mathbf{m}^{3}\right)\end{array}$ & $\begin{array}{c}\text { Quantidade } \\
\text { p/ pav. }\end{array}$ & $\begin{array}{l}\text { Volume p/ } \\
\text { pav. }\left(\mathbf{m}^{3}\right)\end{array}$ & $\begin{array}{l}\text { Volume } \mathbf{p} / \\
\text { edifício }\left(\mathbf{m}^{3}\right)\end{array}$ \\
\hline L1 & 8,69 & 10 & 0,87 & 4 & 3,48 & 17,38 \\
\hline L2 & 11,69 & 10 & 1,17 & 4 & 4,67 & 23,37 \\
\hline L3 & 11,97 & 10 & 1,20 & 4 & 4,79 & 23,95 \\
\hline L4 & 6,18 & 10 & 0,62 & 4 & 2,47 & 12,36 \\
\hline L5 & 7,46 & 10 & 0,75 & 1 & 0,75 & 3,73 \\
\hline
\end{tabular}

Tabela AP.3: Custo de produção dos elementos para CLE e CAA

\begin{tabular}{|c|c|c|c|c|}
\hline Concreto & $\begin{array}{c}\text { Peso específico } \\
\left(\mathbf{k g} / \mathbf{m}^{\mathbf{3}}\right)\end{array}$ & $\begin{array}{c}\text { Custo } \\
\left(\mathbf{R} \mathbf{\$} / \mathbf{m}^{\mathbf{3}}\right)\end{array}$ & $\begin{array}{c}\text { Quantidade } \\
\left(\mathbf{m}^{\mathbf{3}}\right)\end{array}$ & Custo total (R\$) \\
\hline CLE & 1300 & 598,58 & 260,40 & $155.872,99$ \\
\hline CAA & 2400 & 591,65 & 260,40 & $154.068,38$ \\
\hline
\end{tabular}

Segundo a Tabela AP.4, o peso total para os painéis foi de $233.485,2 \mathrm{~kg}$ para o CLE e de $431.049,6 \mathrm{~kg}$ para o CAA.

Observando-se a Tabela AP.5, verifica-se que o peso total das lajes foi de 105.040,8 kg para o CLE e de $193.921,4 \mathrm{~kg}$ para o CAA.

A fim de avaliar o custo envolvido com transporte dos elementos pré-moldados foi estabelecido que a fábrica de pré-moldado atendesse num raio de $200 \mathrm{~km}$ de distância da obra. De acordo com os dados fornecidos por empresas locais, o custo médio para um caminhão que suporta 28 toneladas é de $\mathrm{R} \$ 8,64 / \mathrm{km}$. Sendo assim, o custo do caminhão foi calculado em $\mathrm{R} \$ 1.728,00$ por viagem. 
Tabela AP.4: Peso dos painéis pré-moldados

\begin{tabular}{|c|c|c|c|c|c|}
\hline \multirow{2}{*}{ Painel } & \multicolumn{2}{|c|}{ Peso unitário (kg) } & \multirow{2}{*}{$\begin{array}{c}\text { Quant. máx. } \\
\text { p/ edifício }\end{array}$} & \multicolumn{2}{|c|}{ Peso Total (kg) } \\
\cline { 6 - 6 } & CLE & CAA & CLE & CAA \\
\hline PF1 & 907,3 & 1675,1 & 20 & 18146,7 & 33501,6 \\
\hline PF2 & 1082,8 & 1999,1 & 20 & 21656,7 & 39981,6 \\
\hline PF3 & 919,6 & 1697,8 & 20 & 18392,4 & 33955,2 \\
\hline PF4 & 909,1 & 1678,3 & 5 & 4545,5 & 8391,6 \\
\hline PF5 & 909,1 & 1678,3 & 5 & 4545,5 & 8391,6 \\
\hline PF6 & 1186,4 & 2190,2 & 20 & 23727,6 & 43804,8 \\
\hline PF7 & 854,7 & 1577,9 & 20 & 17093,7 & 31557,6 \\
\hline PF8 & 1126,7 & 2080,1 & 10 & 11267,1 & 20800,8 \\
\hline PF9 & 1318,0 & 2433,2 & 10 & 13180,1 & 24332,4 \\
\hline PF10 & 1077,6 & 1989,4 & 10 & 10775,7 & 19893,6 \\
\hline PF11 & 1318,0 & 2433,2 & 10 & 13180,1 & 24332,4 \\
\hline P1 & 772,2 & 1425,6 & 20 & 15444,0 & 28512,0 \\
\hline P2 & 782,7 & 1445,0 & 20 & 15654,6 & 28900,8 \\
\hline P3 & 1130,2 & 2086,6 & 10 & 11302,2 & 20865,6 \\
\hline P4 & 838,9 & 1548,7 & 20 & 16777,8 & 30974,4 \\
\hline P5 & 702,0 & 1296,0 & 10 & 7020,0 & 12960,0 \\
\hline P6 & 1077,6 & 1989,4 & 10 & 10775,7 & 19893,6 \\
\hline
\end{tabular}

Tabela AP.5: Peso das lajes prontas

\begin{tabular}{|c|c|c|c|c|c|}
\hline \multirow{2}{*}{ Laje } & \multicolumn{2}{|c|}{ Peso unitário (kg) } & \multirow{2}{*}{$\begin{array}{c}\text { Quant. máx. } \\
\text { p/ edifício }\end{array}$} & \multicolumn{2}{c|}{ Peso Total (kg) } \\
\cline { 2 - 3 } & Ultraleve & Comum & CLE & CAA \\
\hline L1 & 1130,0 & 2086,1 & 20 & 22599,2 & 41721,6 \\
\hline L2 & 1519,2 & 2804,7 & 20 & 30384,6 & 56094,7 \\
\hline L3 & 1556,6 & 2873,7 & 20 & 31131,4 & 57473,3 \\
\hline L4 & 803,7 & 1483,8 & 20 & 16074,2 & 29675,5 \\
\hline L5 & 970,3 & 1791,3 & 5 & 4851,3 & 8956,3 \\
\hline
\end{tabular}

Na Tabela AP.6, encontra-se a quantidade de viagens necessárias para transportar todos os elementos pré-moldados, sendo que o limite estabelecido foi a carga máxima suportada pelo caminhão.

Tabela AP.6: Custo de transporte para CLE e CAA

\begin{tabular}{|c|c|c|c|c|c|c|}
\hline Concreto & $\begin{array}{c}\text { Peso total a } \\
\text { transportar } \\
\text { (kg) }\end{array}$ & $\begin{array}{c}\text { Limite de } \\
\text { carga (kg) }\end{array}$ & $\begin{array}{c}\text { Perda com } \\
\text { vazios (\%) }\end{array}$ & $\begin{array}{c}\text { Quantidade } \\
\text { de viagens }\end{array}$ & $\begin{array}{c}\text { Custo por } \\
\text { viagem (R\$) }\end{array}$ & $\begin{array}{c}\text { Custo total } \\
(\mathbf{R} \mathbf{\text { ) }})\end{array}$ \\
\hline CLE & 338526,0 & 28000 & 5 & 13 & $1.728,00$ & $22.464,00$ \\
\hline CAA & 624971,0 & 28000 & 5 & 24 & $1.728,00$ & $41.472,00$ \\
\hline
\end{tabular}

De acordo os dados fornecidos pelo Sindicato da Construção Civil do Estado de São Paulo (SINDUSCONSP, 2013), o custo para construção de um prédio composto por um pavimento térreo e quatro pavimentos tipos, no Projeto de Interesse Social (PIS) de padrão baixo, foi de $\mathrm{R} \$ 697,78 / \mathrm{m}^{2}$ para o mês de Fevereiro/2013. 
Convém ressaltar que o SINDUSCON não especifica o sistema construtivo. Portanto, o custo indicado por ele serve, apenas, com uma referência.

O edifício em estudo apresenta uma área de $161,60 \mathrm{~m}^{2}$ por pavimento e uma área total de $808,00 \mathrm{~m}^{2}$. De acordo com esses dados, o custo global de referência resulta:

$$
\text { Custo }_{\text {global }}=697,78 \cdot 808,00=\mathrm{R} \$ 563,806,24
$$

De acordo com a Tabela AP.7, o custo total dos painéis e das lajes com produção dos elementos estruturais e transporte, em relação ao custo total da obra, resulta $31,6 \%$ para o CLE e $34,7 \%$ para o CAA.

Com esses resultados, fica evidente que o CLE é mais vantajoso economicamente, para esta obra específica.

Tabela AP.7: Relação dos custos de produção e transporte com o custo global

\begin{tabular}{|c|c|c|c|c|c|}
\hline Concreto & $\begin{array}{c}\text { Custo com } \\
\text { produção (R\$) }\end{array}$ & $\begin{array}{c}\text { Custo com } \\
\text { transp. (R\$) }\end{array}$ & $\begin{array}{c}\text { Custo total } \\
\text { (R\$) }\end{array}$ & $\begin{array}{c}\text { Custo global } \\
\text { (R\$) }\end{array}$ & Relação \\
\hline CLE & $155.872,99$ & $22.464,00$ & $178.336,99$ & $563.806,24$ & $31,6 \%$ \\
\hline CAA & $154.068,38$ & $41.472,00$ & $195.540,38$ & $563.806,24$ & $34,7 \%$ \\
\hline
\end{tabular}

